$$
\begin{aligned}
& \text { ME I O A M B I E N T E } \\
& \text { SUSTE N T A B I L I D A D E } \\
& \text { \& } \\
& \text { T E C N O L O G I A } \\
& \text { Recursos Hídricos }
\end{aligned}
$$

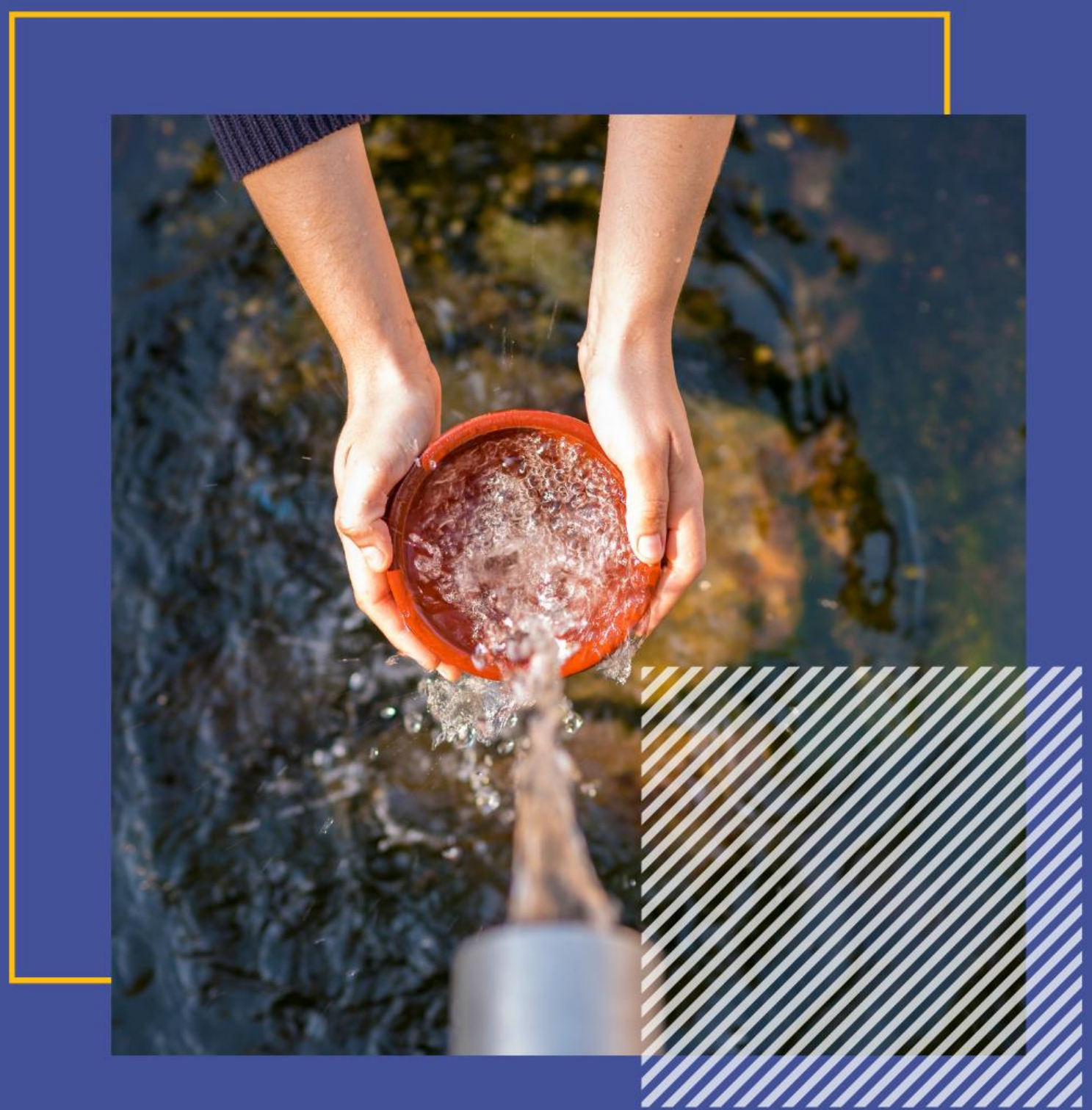

(Organizador)

José Henrique Porto Silveira
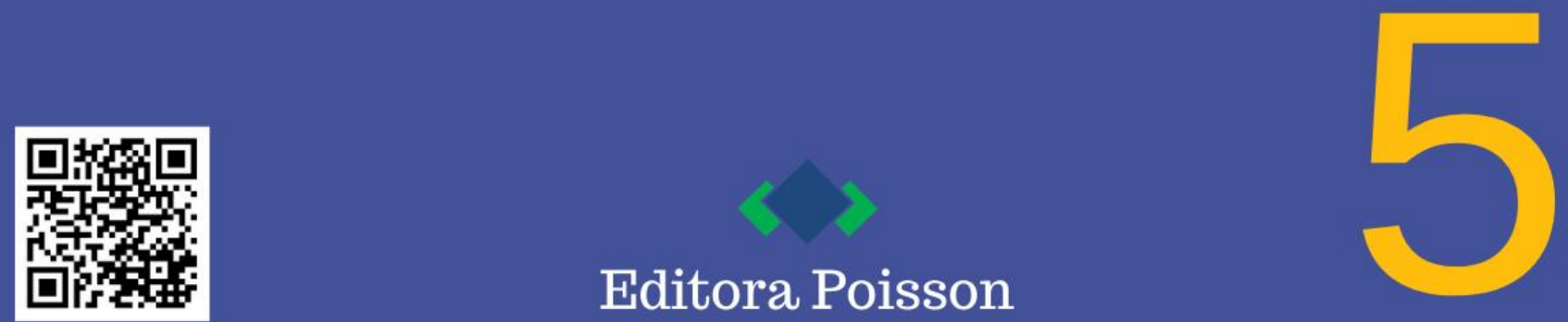
José Henrique Porto Silveira

\title{
Meio Ambiente, Sustentabilidade e Tecnologia Volume 5 Recursos Hídricos
}

\author{
1’- Edição
}

Belo Horizonte

Poisson

2021 
Editor Chefe: Dr. Darly Fernando Andrade

\section{Conselho Editorial}

Dr. Antônio Artur de Souza - Universidade Federal de Minas Gerais Ms. Davilson Eduardo Andrade

Dra. Elizângela de Jesus Oliveira - Universidade Federal do Amazonas

Msc. Fabiane dos Santos

Dr. José Eduardo Ferreira Lopes - Universidade Federal de Uberlândia

Dr. Otaviano Francisco Neves - Pontifícia Universidade Católica de Minas Gerais

Dr. Luiz Cláudio de Lima - Universidade FUMEC

Dr. Nelson Ferreira Filho - Faculdades Kennedy

Ms. Valdiney Alves de Oliveira - Universidade Federal de Uberlândia

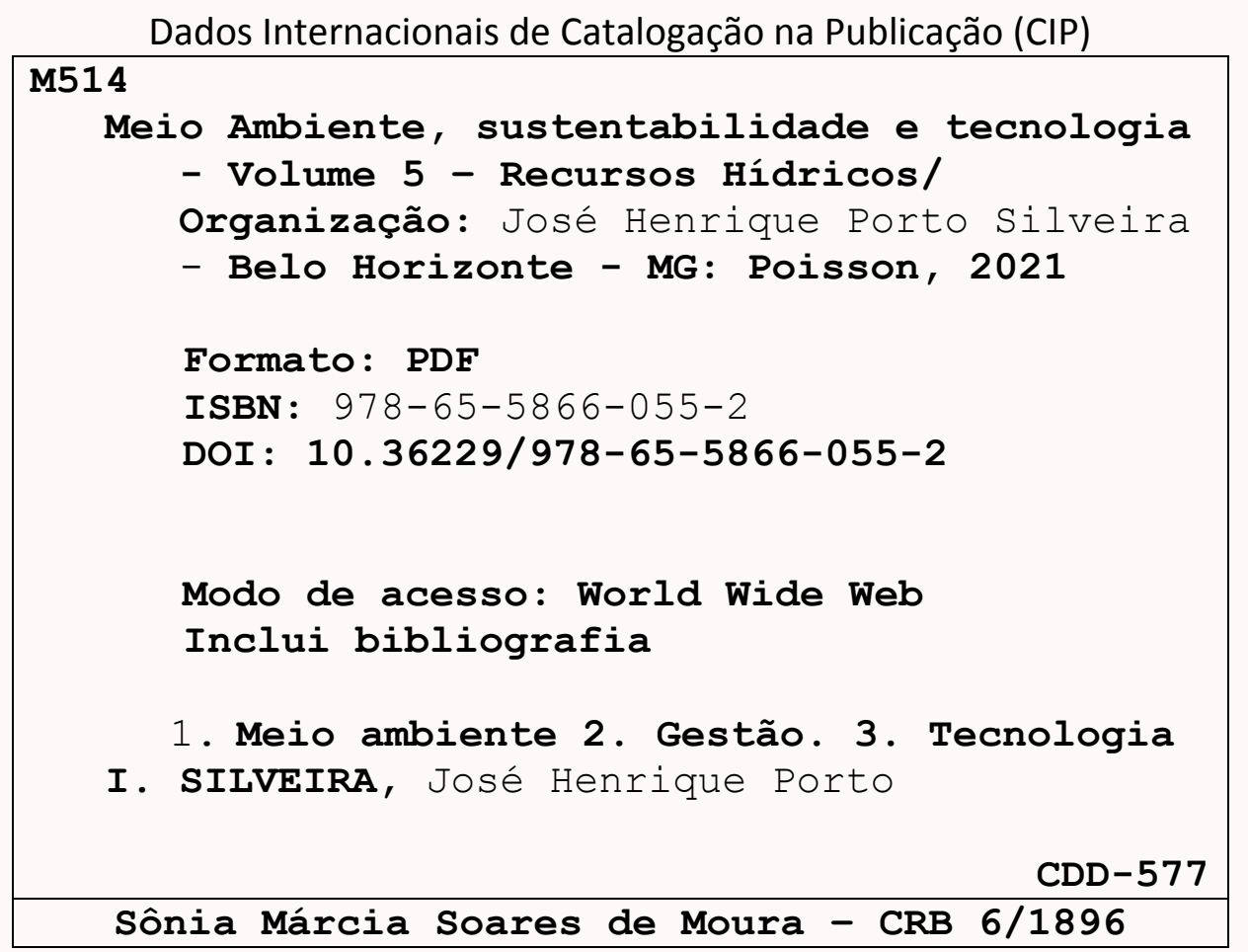

O conteúdo dos artigos e seus dados em sua forma, correção e confiabilidade são de responsabilidade exclusiva dos seus respectivos autores.

www.poisson.com.br

contato@poisson.com.br 


\section{Prefácio}

A trajetória dos seres humanos vem sendo escrita com ênfase sempre na nossa infinita capacidade de subjugar a natureza, extrair dela o que nos interessa e descartar o que não nos serve na forma de resíduos. Tais resíduos no ar, na água ou no solo representam o que deve ser evitado, mitigado ou controlado. É poluição ou degradação. Em grande parte essa trajetória desastrada é decorrente da evolução das ciências e suas tecnologias.

Mas quando se começa perceber o desastre, mesmo que lenta e gradativamente a ciências e suas tecnologias podem se constituir em reversão da catástrofe prenunciada. Novos tempos, tempos de pensar de forma sistêmica e ecológica.

Nessa perspectiva, meio ambiente e sustentabilidade são expressões fundamentais. Conceitos distintos, mas indissociáveis para podermos pensar para agir e agir para construir o futuro da humanidade. É assim que as ciências atuam, buscando respostas com a ampliação dos conhecimentos e encontrando soluções com novas tecnologias. Nesta busca incessante para criar e construir soluções para os problemas ambientais e de encontrar caminhos para manifestação dos preceitos da sustentabilidade, tecnologias são ensaiadas e sugeridas como viáveis e mesmo projetadas para execução.

E este é o verdadeiro papel das ciências nas academias e nos centros de pesquisa, envolvendo as muitas disciplinas que se integram na construção do conhecimento socioambiental: engenharia, arquitetura, sociologia, psicologia, geografia, antropologia, biologia, pedagogia e tantas outras. Quase sempre são processos que envolvem a multi, a inter e a transdisciplinaridade.

Nessa coletânea, a intenção principal é mostrar possibilidades, algumas mais outras menos detalhadas, mas todas dotadas de intencionalidades em relação à busca de um futuro melhor.

Como ambientalista e profissional com muitos anos de atuação nas áreas de avaliação de impactos e educação ambiental vejo como muito promissor as ideias e soluções técnicas que estão sendo gestadas no meio acadêmico nas áreas de meio ambiente e sustentabilidade.

Reitero que as temáticas como meio ambiente e sustentabilidade devem estar em constante interação na construção do futuro, já que inevitavelmente a nossa permanência como espécie depende da permanência de outras espécies da flora e da fauna e da boa qualidade dos elementos ar, água e solo. Nunca é tarde na busca de reverter a nossa trajetória, usando bom senso e o conhecimento proporcionado pelas ciências e pelas culturas milenares sobre o meio ambiente. 


\section{Sumário}

Capítulo 1: Mitigação de alagamentos através do dimensionamento e avaliação do desempenho hidráulico de um sistema de drenagem urbana para Campina do Monte Alegre - SP 08

Maria Julia Degli Esposti Bergamasco, Jorge Luis Rodrigues Pantoja Filho

DOI: $10.36229 / 978-65-5866-055-2 . C A P .01$

Capítulo 2: Sistema de informação geográfica aplicado no mapeamento da erodibilidade na Bacia Hidrográfica do Rio Jacuba, no estado de Goiás, Brasil. 14

Geovana Alievi, Maria Antonia Balbino Pereira, Nivalda da Costa Nunes, Hevrli da Silva Carneiro Pilatti, Wellmo dos Santos Alves, Derick Martins Borges de Moura, Wilker Alves Morais, Eder Paulo Moreira

DOI: $10.36229 / 978-65-5866-055-2 . C A P .02$

Capítulo 3: 0 estudo das características morfométricas da Bacia Hidrográfica do Médio Tocantins 19

Ana Júlia Logrado da Conceição, Cristiane Matos da Silva, Júnior Hiroyuki Ishihara

DOI: 10.36229/978-65-5866-055-2.CAP.03

Capítulo 4: Estudo da autodepuração em um trecho do Rio Sorocaba, SP - Brasil...... 24

Vinicius Moura Costa, João Pedro Gomes dos Santos, Letícia Borsato Rossi, Layssa de Moura Oliveira, Jorge Luis Rodrigues Pantoja Filho

DOI: $10.36229 / 978-65-5866-055-2 . C A P .04$

Capítulo 5: Relação entre a precipitação, temperatura e a $p \mathrm{CO}_{2}$ na Foz do Rio Amazonas 29

Diani Fernanda da Silva Less, Alan Cavalcanti da Cunha

DOI: 10.36229/978-65-5866-055-2.CAP.05

Capítulo 6: Análise de dados de precipitação de uma estação pluviométrica particular em relação aos dados da rede pública 36

Gabriel Rodrigues Barreto, Adriano Augusto de Miranda

DOI: $10.36229 / 978-65-5866-055-2 . C A P .06$

Capítulo 7: Variabilidade e tendências de padrões de chuva na bacia do Riacho Jatobá, Pernambuco 43

Aline Maria Soares das Chagas, Abelardo Antônio de Assunção Montenegro, Thayná Alice Brito Almeida DOI: 10.36229/978-65-5866-055-2.CAP.07 


\section{Sumário}

Capítulo 8: Uso de funções de pedotransferência na caracterização hidrodinâmica de solos pernambucanos 54

Marco Aurélio Calixto Ribeiro de Holanda, Diogo Botelho Correa de Oliveira, Ariela Rocha Cavalcanti, Camilla Barrêtto Rique de Barros, Willames de Albuquerque Soares

DOI: $10.36229 / 978-65-5866-055-2 . C A P .08$

Capítulo 9: Uso da análise de regressão na obtenção de funções de pedotransferência utilizadas na estimativa da condutividade hidráulica saturada de solos brasileiros... 62 Marco Aurélio Calixto Ribeiro de Holanda, Willames de Albuquerque Soares, Diogo Botelho Correa de Oliveira, Camilla Barrêtto Rique de Barros, Ariela Rocha Cavalcanti

DOI: $10.36229 / 978-65-5866-055-2 . C A P .09$

Capítulo 10: Transporte de Diclofenaco em solo do Agreste de Pernambuco 71

Ebenézer de França Santos, Manuella Virgínia Salgueiro Gondim, Antônio Celso Dantas Antonino, Valmir Felix de Lima

DOI: $10.36229 / 978-65-5866-055-2 . C A P .10$

Capítulo 11: Análise do processo de desertificação no Médio Sertão Sergipano. 80

Carolina Oliveira Souza, Daniele Suzane da Silva Pinto Teles, Soanne Hemylle de Jesus Santos, Heloísa Thaís Rodrigues de Souza, Guilherme dos Santos Teles

DOI: $10.36229 / 978-65-5866-055-2 . C A P .11$

Capítulo 12: Medidas mitigadoras da desertificação e do efeito estufa praticadas por agricultores familiares no Semiárido Paraibano.

Rosivânia Jerônimo de Lucena, Joedla Rodrigues de Lima

DOI: 10.36229/978-65-5866-055-2.CAP.12

Capítulo 13: Atenuação da vazão de pico de demanda em sistemas de suprimento de água com suporte de conceitos de automação predial. 97

Letícia Soriano, Victor de Barros Deantoni, Alberto Luiz Francato

DOI: 10.36229/978-65-5866-055-2.CAP.13

Capítulo 14: Avaliação de aplicação de dissipador de energia de um emissário no município de Campo Mourão, Paraná.

Paula Cristina de Souza, Paulo Henrique Rodrigues, Victor Augusto Menegon, Helton Rogerio Mazzer

DOI: 10.36229/978-65-5866-055-2.CAP.14 


\section{Sumário}

Capítulo 15: Telhados verdes : Caracterização das condições ótimas para o microclima da cidade de Recife-PE. 114

Teresinha Batista da Silva, Marco Aurélio Calixto Ribeiro de Holanda, Willames de Albuquerque Soares DOI: $10.36229 / 978-65-5866-055-2 . C A P .15$

Capítulo 16: Achados recentes sobre a qualidade da água do Rio Cocó em um trecho urbano da cidade de Fortaleza-CE.

Luís Gustavo Gomes Diógenes, Adriana Pereira do Nascimento, Rosa Márcia Araújo de Oliveira, Gilcenara de Oliveira, Fernando José Araújo da Silva

DOI: $10.36229 / 978-65-5866-055-2 . C A P .16$

Capítulo 17: Avaliação do potencial do reuso de água cinza no município de Campo Grande-MS 129 Ingrid Moreno Mamedes, Silvia Gonzales Sorensen Tiradentes , Paula Loureiro Paulo

DOI: $10.36229 / 978-65-5866-055-2 . C A P .17$

Capítulo 18: Contribuição da Política Nacional de Recursos Hídricos para governança da compensação ambiental interfederativa no Brasil

Patrícia Helena Gambogi Boson, Maria de Fátima Chagas Dias Coelho, Márcio Silva Pereira, Tácito Ribeiro de Matos

DOI: $10.36229 / 978-65-5866-055-2 . C A P .18$

Autores: 140 


\section{Capítulo 1}

Mitigação de alagamentos através do dimensionamento e avaliação do desempenho hidráulico de um sistema de drenagem urbana para Campina do Monte Alegre - SP

\section{Maria Julia Degli Esposti Bergamasco \\ Jorge Luis Rodrigues Pantoja Filho}

Resumo: 0 avanço da urbanização e o crescimento populacional provocam inúmeras alterações que agravam o fenômeno natural de inundação dos rios, acarretando em impactos sociais, ambientais e econômicos. Nesse contexto, tem-se Campina do Monte Alegre - SP que vem sofrendo com a ocorrência frequente destes fenômenos intensificados pela vinda da UFSCar em 2014. Sendo assim, objetiva-se dimensionar um novo sistema de microdrenagem urbana para o município a fim de minimizar os impactos causados. Para isso, delimitou-se as bacias e microbacias de contribuição, realizou-se o dimensionamento hidrológico e dos dispositivos hidráulicos superficiais e subterrâneos e simulou-se computacionalmente os dados, comparando-os com o sistema existente. A área de estudo foi dividida em três bacias de contribuição que resultaram no dimensionamento de 103 bocas de lobo distribuídas em três redes de galerias que foram avaliadas pela simulação no software SWMM. Portanto, concluiu-se que o dimensionamento das redes de microdrenagem foi realizado de maneira que não houvesse transbordamentos e recomendou-se a utilização de técnicas de baixo impacto como complemento ao dimensionamento convencional.

Palavras-Chave: Microdrenagem urbana; Dimensionamento hidráulico e hidrológico; Simulação Computacional. 


\section{INTRODUÇÃO}

Pelo fato de ser um dos elementos fundamentais à vida, o ser humano sempre se atentou em se estabelecer próximo a regiões de água doce com intuito de ter fácil acesso ao consumo próprio, à irrigação e a demais benefícios. Contudo, com o crescimento populacional e o consequente avanço da urbanização, as regiões próximas a rios passaram a sofrer inúmeras alterações e abrigar uma enorme gama populacional (OLIVEIRA, 2018).

É evidente que todo esse evento influencia diretamente no ciclo hidrológico, agravando o fenômeno natural de inundação dos rios. Isso ocorre principalmente devido aos processos de alteração da cobertura vegetal, ocupação das áreas de inundação, poluição oriunda da contaminação do ar e dos resíduos sólidos produzidos pela população (SILVEIRA, 2002).

Toda essa problemática entra em conflito direto com o funcionamento das cidades, desencadeando em diversos riscos de ordem social, econômica e ambiental, provocando danos à infraestrutura, desvalorização imobiliária, desalojamento de pessoas, redução da qualidade de vida dos moradores, diminuição do valor de aspectos ambientais e até perdas de vidas (OLIVEIRA, 2018).

Tal situação é ainda mais evidente em países em desenvolvimento, nos quais são encontradas pequenas bacias hidrográficas com alta taxa de urbanização, o que pode intensificar os problemas com inundações e evidenciar a falta de planejamento da ocupação territorial. Nesse sentido, o crescimento populacional torna-se insustentável e as obras de drenagem realizadas demonstram-se ultrapassadas, insuficientes e obsoletas (MONTEZ, 2015).

Dentre deste contexto, encontra-se o município de Campina do Monte Alegre - SP (CMA) que vem sofrendo com frequentes inundações dos rios Itapetininga e Paranapanema nas áreas urbanas e rurais de seu território. Além disso, a vinda da Universidade Federal de São Carlos - campus Lagoa do Sino ocasionou um rápido crescimento populacional, o que pode contribuir ainda mais para tais inundações.

Esta visão obsoleta a respeito dos sistemas de drenagem urbana era usada principalmente com o intuito de escoar rapidamente o excesso de água precipitada, bem como, mitigar os danos decorrentes das águas presentes nas vias públicas. De um modo geral, essas soluções limitam-se às medidas estruturais, convencionalmente denominadas de intervenções físicas e, adotadas como um modelo definitivo.

Entretanto, é de conhecimento geral que, atualmente essa percepção de drenagem urbana não se sustenta, sendo necessária a adaptação do modelo antigo para um conceito moderno. Esse conceito entende o ambiente como um conjunto de subsistemas que devem ser levados em consideração para que o sistema global de drenagem urbana seja adequado aos mais variados níveis de urbanização (MONTEZ, 2015).

Assim, técnicas como um correto planejamento urbano e rural das redes de drenagem do município podem ser vistas como uma prática para diminuição dos efeitos causados pelas inundações, visto que envolvem medidas institucionais, não-estruturais e estruturais (LAMB, 2014).

Nesse sentido, objetiva-se com esse trabalho dimensionar um novo sistema de microdrenagem urbana, através dos dispositivos hidráulicos e realizar a simulação dos fenômenos hidráulicos e hidrológicos do sistema a partir do software SWMM a fim de minimizar os impactos dos frequentes alagamentos em nível de microdrenagem e inundações relacionadas à macrodrenagem.

\section{METODOLOGIA}

\subsection{DELIMITAÇÃO DA ÁREA DE ESTUDO E DIVISÃO DAS MICROBACIAS URBANAS}

O estudo se desenvolveu na mancha urbana de Campina do Monte Alegre, visto que o local apresenta distintos pontos de alagamentos. 0 município localiza-se na região sudoeste do Estado de São Paulo, entre as coordenadas geográficas 23 $35^{\prime}$ Latitude Sul e 48 29’ Longitude Oeste (Figura 1). Possui uma área total de $184,58 \mathrm{~km}^{2}$ sendo que aproximadamente $90 \%$ da população vivendo na região urbana, que corresponde a apenas $4,30 \%$ da sua área total. 
Figura 1. Mapa de localização do Município

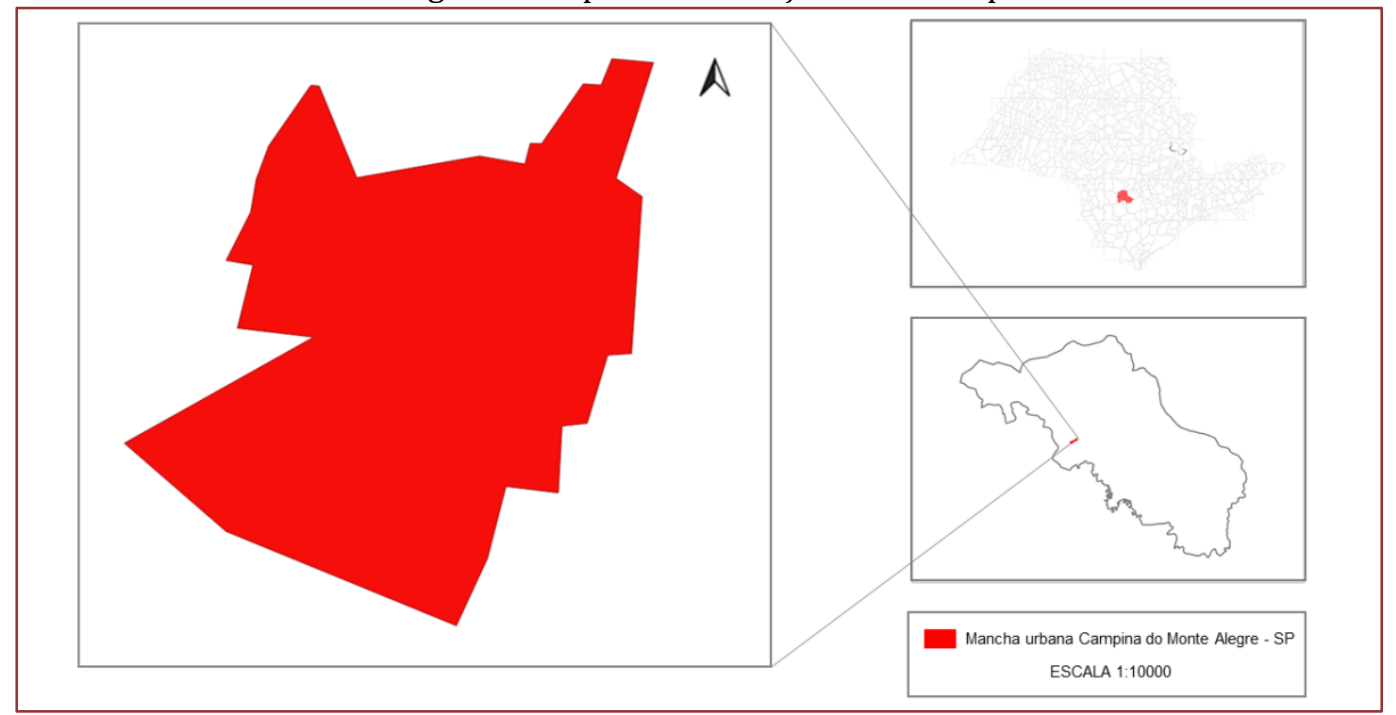

Fonte: Adaptado TCA - Soluções e Planejamento Ambiental Ltda. (2012).

Para a realização deste trabalho, primeiramente, delimitou-se a área de estudo e suas bacias hidrográficas urbanas através dos softwares Global Mapper e Civil 3D da Autodesk. As bacias foram subdividas em microbacias de acordo com a metodologia denominada "método do diagrama de telhado" descrita por Diogo e Sciammarella (2008), como demonstra a Figura 2. 0 mesmo consiste em duas etapas: (1) identificação do sentido do fluxo das águas pluviais nas vias; (2) delimitação dos quarteirões semelhantes ao projeto de um telhado, com divisores de águas.

Figura 2. Método do Diagrama de Telhado para mancha urbana de CMA.

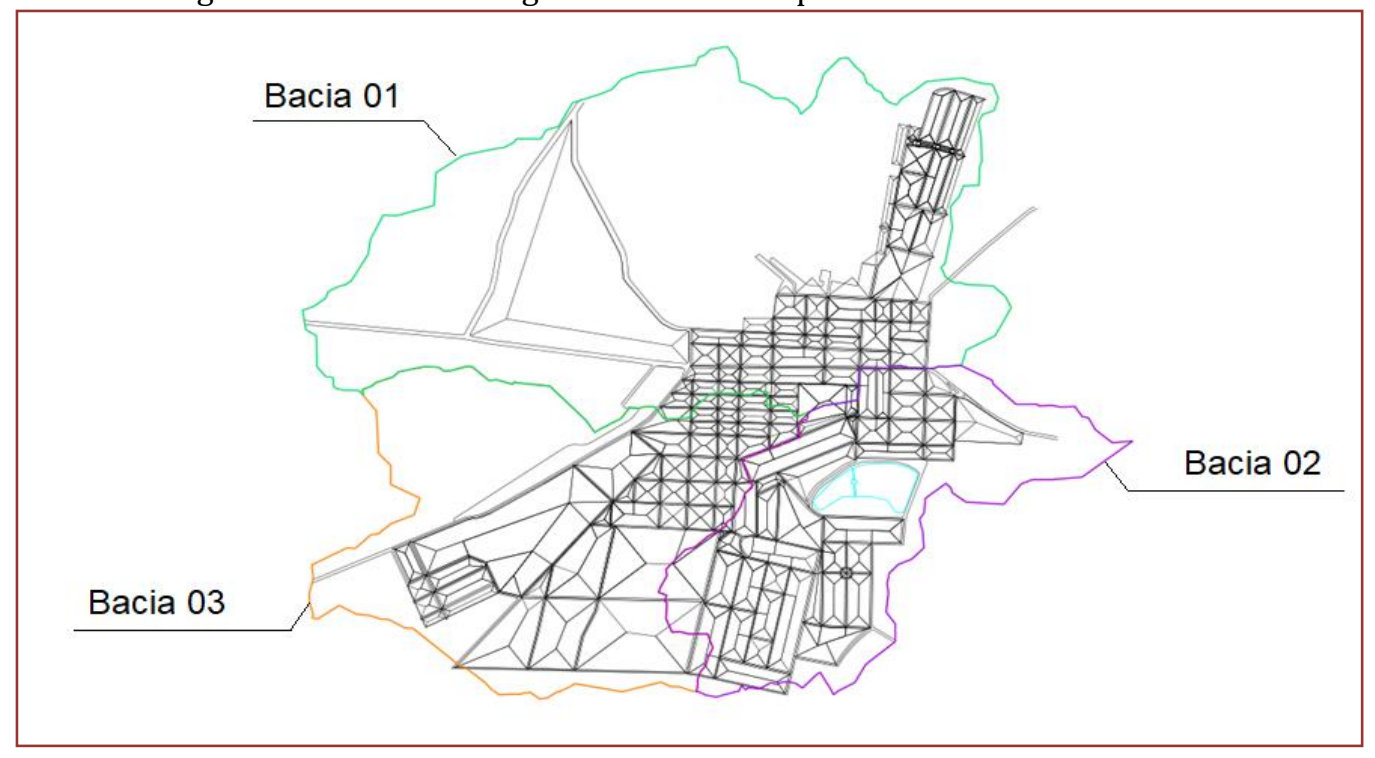

Fonte: Arquivo Pessoal.

\subsection{DIMENSIONAMENTO HIDROLÓGICO}

Na segunda etapa iniciou-se o dimensionamento hidrológico. Para isso, determinou-se o tempo de concentração utilizando-se a equação de Kirpich (Equação 1), com período de retorno de 10 anos. Obtevese também os parâmetros: intensidade de precipitação através do software Plúvio 2.1 e o coeficiente de escoamento médio, respeitando os tipos de ocupação existentes. 


$$
t_{c}=57 *\left(\frac{L^{3}}{\Delta H}\right)^{0,385}
$$

onde:

$t_{c}$ : Tempo de concentração (min);

$L$ : Comprimento do rio principal $(\mathrm{km})$;

$H$ : Diferença de cota entre o exutório o ponto mais a montante da bacia $(\mathrm{m})$;

A partir de todos os resultados obtidos pelas grandezas do escoamento superficial, determinou-se a vazão de toda a área da bacia de contribuição, através do método racional (Equação 02).

$$
Q=0,278 * C * I * A
$$

onde:

$Q$ : Vazão $\left(\mathrm{m}^{3} \cdot \mathrm{s}^{-1}\right)$;

$C$ : Coeficiente de escoamento superficial "run-off";

I: Intensidade da precipitação $\left(\mathrm{mm} \cdot \mathrm{h}^{-1}\right)$;

0,278: Fator de conversão de vazão para $\mathrm{m}^{3} \cdot \mathrm{s}^{-1}$;

$A$ : Área da bacia hidrográfica $\left(\mathrm{km}^{2}\right)$.

\subsection{DIMENSIONAMENTO HIDRÁULICO}

Posteriormente, iniciou-se o dimensionamento hidráulico que foi dividido em duas seções: escoamento superficial e subterrâneo. Na primeira seção, determinou-se a vazão de cada microbacia, utilizando-se mais uma vez o método racional descrito acima, e a capacidade de escoamento das sarjetas. Através destes dados avaliou-se a necessidade de implantação de bocas de lobo, e caso confirmada, dimensiona-se. Para tal avaliação, comparou-se a vazão da microbacia $\left(Q_{\text {micro }}\right)$ em relação à capacidade de escoamento das sarjetas $\left(Q_{\text {sarjetas }}\right)$. Sendo assim, caso $Q_{\text {micro }}$ for inferior a $Q_{\text {sarjetas, }}$ estabelece-se a necessidade mencionada.

Com a definição da necessidade de boca de lobo, dimensionou-se a rede subterrânea, composta por galerias, poços de visita e caixas de ligação, seguindo a metodologia descrita pela Prefeitura Municipal de São Paulo (1999). Com tais dados, realizou-se a simulação hidrológica e hidráulica no software SWMM 5.00.22. Por fim, realizou-se a comparação entre o sistema existente e o dimensionado no município.

\section{RESULTADOS E DISCUSSÃO}

A partir do levantamento das curvas de nível da área de estudo foram obtidas três bacias hidrográficas (Figura 3). As bacias 01 e 03 possuem como exutório pontos no rio Paranapanema. Já a bacia 02, o rio Itapetininga. Cada bacia foi dividida de acordo com o "método do diagrama de telhado" totalizando 416 microbacias. 
Figura 3. Delimitação das bacias de contribuição da mancha urbana de CMA

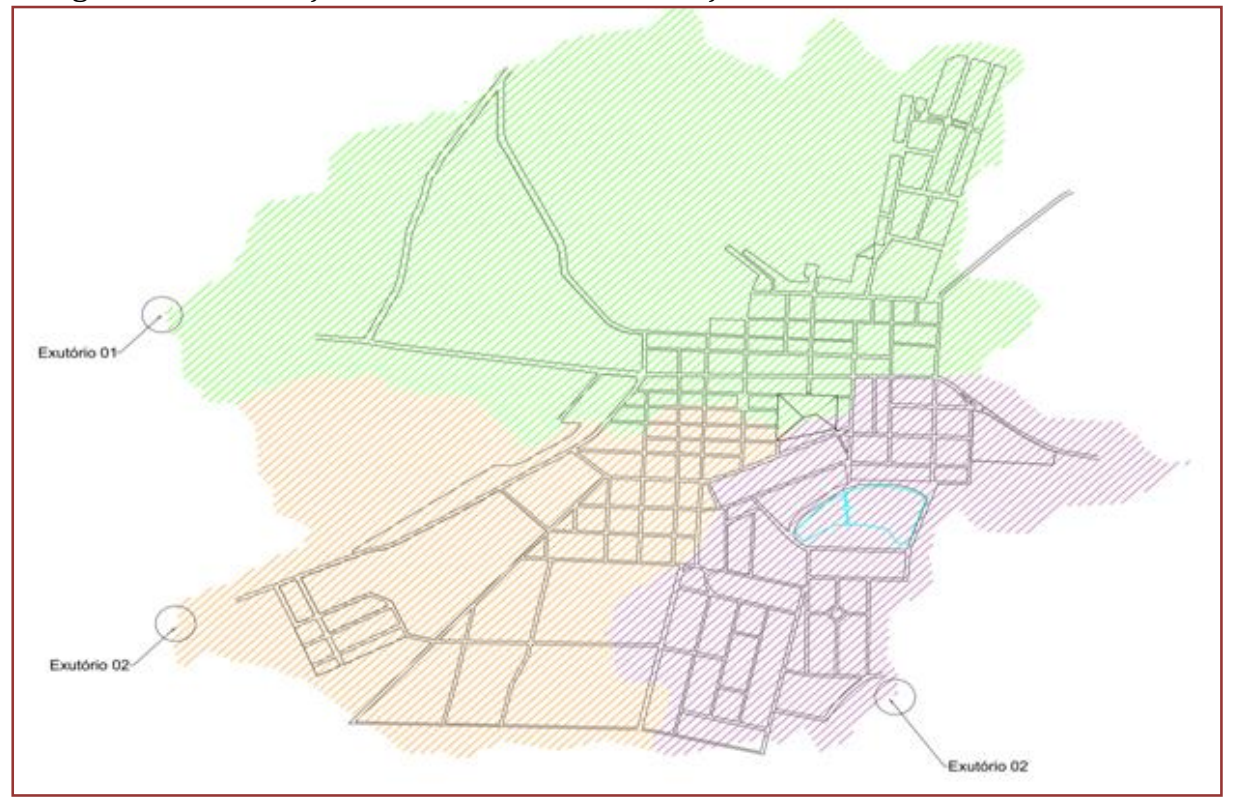

Fonte: Arquivo Pessoal.

Foram dimensionadas sarjetas e 103 bocas de lobo juntamente com seus dispositivos hidráulicos. Através do software SWMM foi possível notar que o dimensionamento foi realizado para que não houvesse transbordamentos, evitando-se assim os fenômenos de alagamentos frequentes.

É válido ressaltar que diversas sarjetas encontradas na área de estudo apresentavam-se em estado irregular, com medidas incorretas que podem ocasionar no depósito de sedimentos, sendo necessária sua adequação a partir do dimensionamento realizado.

Além disso, quando se compara o levantamento realizado empresa TCA - Soluções e Planejamento Ambiental Ltda com o sistema dimensionado, nota-se que há uma grande diferença principalmente no que se refere ao número de bocas de lobo: 36 e 103, respectivamente (Tabela 1). Destaca-se ainda que as bocas de lobos existentes no município apresentavam heterogeneidade no seu tipo e eficiência, bem como irregularidades.

Tabela 1. Comparação entre o sistema dimensionado e o sistema existente

\begin{tabular}{|c|c|c|c|c|}
\multicolumn{2}{c}{ Sistema Dimensionado } & \multicolumn{3}{c|}{ Sistema Existente } \\
\hline Bacia 01 & Margem Esquerda & Margem Direita & 1 & 1 \\
\hline Bacia 02 & 15 & 23 & 12 & 5 \\
\hline Bacia 03 & 13 & 16 & 9 & 8 \\
\hline Total & 20 & 16 & 36 \\
\hline
\end{tabular}

Essa diferença significativa pode ser considerada como a principal justificativa para os problemas de drenagem encontrados no município, visto que a falta de bocas de lobo que conduzem o volume de chuva para as galerias podem contribuir para o aumento do escoamento superficial e, consequentemente a ocorrência dos fenômenos supracitados.

Ademais, evidenciam-se dois fatores importantes que podem explicar tal diferença. 0 primeiro está relacionado com as equações de chuva utilizadas na determinação da intensidade de precipitação. Neste trabalho foram utilizados parâmetros estabelecidos para Campina do Monte Alegre - SP. Já a empresa utilizou parâmetros do município de Itararé, podendo apresentar diferenças significativas nos cálculos.

Outro fator importante está relacionado com a diferença dos tempos de retorno adotados. No presente trabalho foi utilizado o período de retorno de 10 anos e pela empresa de 25 anos. Este último não se adéqua aos cálculos de dimensionamento de microdrenagem, segundo Tucci (1995). 


\section{CONCLUSÕES}

Perante todos os resultados obtidos no dimensionamento, recomenda-se a instalação de 103 bocas de lobo que estão divididas em três redes coletoras de águas pluviais. Ademais, contatou-se a falta de tais dispositivos é o principal desencadeador dos problemas de drenagem do município.

Por fim, recomenda-se para trabalhos futuros, o dimensionamento de sistemas sustentáveis de drenagem como um complemento ao sistema dimensionado. Como alternativa, têm-se os jardins de chuva, parte constituinte das técnicas LID (desenvolvimento de baixo impacto), visto a grande quantidade de praças presentes no município.

\section{REFERÊNCIAS}

[1] DIOGO, F. J. D, SCIAMMARELLA, J. C. Manual de pavimentação urbana. 2. Ed. Rio de Janeiro: Associação Brasileira de Pavimentação, 2008.

[2] LAMB, G. S. Desenvolvimento e análise do desempenho de elementos de drenagem fabricados em concreto permeável. 2014. 152 p. Dissertação (Mestrado em Engenharia) - Universidade Federal do Rio Grande do Sul, Porto Alegre, 2014.

[3] MONTEZ, L. A. Estudo de capacidade de absorção de fluxo para drenagem superficial. 2015. 68 p. Trabalho de Conclusão de Curso (Especialização) - Divisão de Engenharia Civil do Instituto Tecnológico de Aeronáutica, São José dos Campos, 2015.

[4] OLIVEIRA, L. F. G. S. Dimensionamento e análise de desempenho hidráulico de estacionamentos com drenagem convencional e pavimento permeável, apoiado por modelagem computacional. 2018. 90 p. Trabalho de Conclusão de Curso (Especialização) - Escola Politécnica da Universidade Federal do Rio de Janeiro, Rio de Janeiro, 2018.

[5] PREFEITURA MUNICIPAL DE CAMPINA DO MONTE ALEGRE. Coordenadoria de Assistência Técnica Integral (CATI). Plano Municipal de Desenvolvimento Rural Sustentável, 2009. Disponível em: <http://www.cati.agricultura.sp.gov.br/conselhos/arquivos_mun/108_16_06_2011_PMDRSCampinaMonteAlegre.pdf >. Acesso em: 29 de agosto de 2019.

[6] SILVEIRA, A. L. L. Drenagem urbana: aspectos de gestão. 2002. 1. Ed. Instituto de Pesquisas Hidráulicas da Universidade Federal do Rio Grande do Sul, Porto Alegre, 2002.

[7] TUCCI, C. E. M. Drenagem Urbana. Porto Alegre: Editora ABRH - Universidade Federal do Rio Grande do Sul (UFGRS), 1995. 


\section{Capítulo 2}

Sistema de informação geográfica aplicado no mapeamento da erodibilidade na Bacia Hidrográfica do Rio Jacuba, no estado de Goiás, Brasil

\section{Geovana Alievi}

Maria Antonia Balbino Pereira

Nivalda da Costa Nunes

Hevrli da Silva Carneiro Pilatti

Wellmo dos Santos Alves

Derick Martins Borges de Moura

Wilker Alves Morais

Eder Paulo Moreira

Resumo: A erosão dos solos é um dos principais problemas ambientais. No contexto brasileiro, ela se torna ainda pior, uma vez que o Brasil é economicamente dependente da agropecuária e, conseguinte, de solos férteis. Nesse estudo, objetivou-se analisar a erodibilidade (fator K da Universal Soil Loss Equation - USLE) na Bacia Hidrográfica do Rio Jacuba - BHRJ, localizada no Sudoeste de Goiás, com parte da sua área pertencente a unidade de conservação do Parque Nacional das Emas. Utilizou-se o mapa de solos do Plano Diretor da Bacia Hidrográfica (BH) do Rio Paranaíba (escala 1: 250.000), sendo este atualizado conforme o atual Sistema Brasileiro de Classificação de Solos. A erodibilidade foi calculada a partir de informações reportadas na literatura e uso de Sistema de Informação Geográfica - SIG. A erodibilidade variou de alta a média, sendo o maior valor de 0,031 t.h/MJ.mm (Neossolo Quartzarênico), seguido por 0,021 t.h/MJ.mm (Gleissolo Háplico Distrófico) e 0,018 t.h/MJ.mm (Latossolo Vermelho Distrófico). A maior parte da área da bacia (58,64\%) apresentou o menor valor de erodibilidade devido ao Latossolo possuir características menos favorável à perda de solo, por exemplo, boa drenagem quando seu uso é associado a modernas técnicas de manejo e conservação do solo. Mesmo com a predominância de solos favoráveis à conservação da BH em questão, medidas de conservação devem ser implementadas nas áreas suscetíveis à perda de solos; considera-se importante também o monitoramento constante de toda a área de estudo, tendo em vista que parte dela fica localizada em uma importante Unidade de Conservação brasileira.

Palavras-chave: Erosão hídrica; Geoprocessamento; Perda de solo; Recursos hídricos. 


\section{INTRODUÇÃO}

O uso intensivo do solo decorrente de ações antrópicas implica em impactos nas bacias hidrográficas, ocasionando a erosão hídrica, um processo de redução da fertilidade e alterações na estrutura do solo, prejudicial a disponibilidade de água devido ao acúmulo de sedimentos nos cursos d'água, sendo necessárias avaliações sobre a perda de solo nesse sistema (BATISTA et al., 2017; MADENOGLU; ATALAY; ERPUL, 2020).

A erodibilidade designa a vulnerabilidade do solo ao efeito abrasivo dos fatores climáticos da erosão, ou seja, precipitação e fluxo superficial (EFTHIMIOU, 2020). É um fator chave na modelagem da erosão do solo (RENARD et al., 1996). O parâmetro depende dos atributos inerentes de cada tipo de solo (MORGAN, 2005). Há diversos modelos matemáticos que permitem estimar a perda de solo, dentre eles a Universal Soil Loss Equation (USLE), um modelo de predição que considera a interação dos fatores de erosividade $(\mathrm{R})$, erodibilidade (K), topografia (LS), cobertura e manejo do solo (C) e práticas conservacionistas (P) (WISCHMEIER; SMITH, 1978; RENARD et al., 1996; RODRIGUES et al., 2017).

Conforme Rodrigues et al. (2017), o fator $\mathrm{R}$ está relacionado ao histórico pluviométrico, o $\mathrm{K}$ à susceptibilidade do solo a erosão, o LS às influências do relevo, o C e o P às práticas de cultivo e manejo da área. Estes dividem-se em perda de solo potencial e real, sendo a primeira relacionada aos aspectos físicos naturais (fatores $\mathrm{R}, \mathrm{K} \mathrm{e} \mathrm{LS}$ ), e a segunda, às ações antrópicas (fatores $\mathrm{C}$ e P).

A priori desenvolvida para estudos em áreas restritas, a USLE, em conjunto com ferramentas dos Sistemas de Informação Geográfica (SIG), técnicas de sensoriamento remoto e geoprocessamento, permite intervir nos processos erosivos em grandes áreas, como de bacias hidrográficas (CORRÊA; MORAES; PINTO, 2015; FALCÃO; DUARTE; VELOSO, 2020). Com o uso da USLE, o parâmetro de erodibilidade representado pelo fator K, é quantificado precisamente para modelar a erosão do solo (EFTHIMIOU, 2020).

Objetivou-se analisar a erodibilidade (fator K da USLE) com SIG na Bacia Hidrográfica do Rio Jacuba (BHRJ), com o intuito de disponibilizar informações para o projeto em andamento sobre a estimativa da erosão hídrica nessa bacia. A área de estudo foi escolhida devido nela estar inserido o Parque Nacional das Emas (PNE) e por apresentar uso intensivo das terras para produção agropecuária (principalmente soja e milho).

\section{MATERIAL E MÉTODO}

A BHRJ está localizada no estado de Goiás, Brasil (Figura 1). Possui área total de 99.880 ha, sendo 55,37\% (55.298 ha) no município de Mineiros, 23,24\% (23.212 ha) em Chapadão do Céu e 21,39\% (21.369 ha) em Serranópolis. Nela está inserido, parcialmente, o PNE. Conforme Instituto Chico Mendes de Conservação da Biodiversidade (ICMBio, 2019), apresenta temperatura média de 22 graus, comum no clima tropical quente sub-úmido.

A erodibilidade foi geoespacializada a partir de: técnica de geoprocessamento, com a utilização do ArcGIS 10.6.1 ${ }^{\circledR}$ licenciado para o laboratório de Geoinformação da Universidade Federal de Goiás/Regional de Jataí; Mapa de Solos do Plano Diretor da Bacia do Rio Paranaíba, na escala 1: 250.000 (foi atualizado conforme o Sistema Brasileiro de Classificação de Solos - SiBCS de 2018); e dados sobre o fator K obtidos por Lima et al. (2013) para Latossolo Vermelho $\left(0,018 \mathrm{t} . \mathrm{m}^{2} . \mathrm{hr} / \mathrm{m}^{3} . t . \mathrm{cm}\right)$, Gleissolo Háplico $(0,021$ t.m².hr $/ \mathrm{m}^{3}$. t.cm) e Neossolo Quartzarênico $\left(0,031 \mathrm{t} . \mathrm{m}^{2} . \mathrm{hr} / \mathrm{m}^{3} . \mathrm{t} . \mathrm{cm}\right)$.

Os valores de erodibilidade foram analisados tendo como base a classificação proposta por Manningel et al. (2002): extremamente alto $(K<0,0600)$, muito alta $(0,0450<K<0,0600)$, alta $(0,0300<K<0,0450)$, média $(0,0150<\mathrm{K}<0,0300)$, baixa $(0,0090<\mathrm{K}<0,0150)$ e muito baixa $(\mathrm{K}>0,0090)$. 
Figura 1. Mapa de localização da bacia hidrográfica do Rio Jacuba.

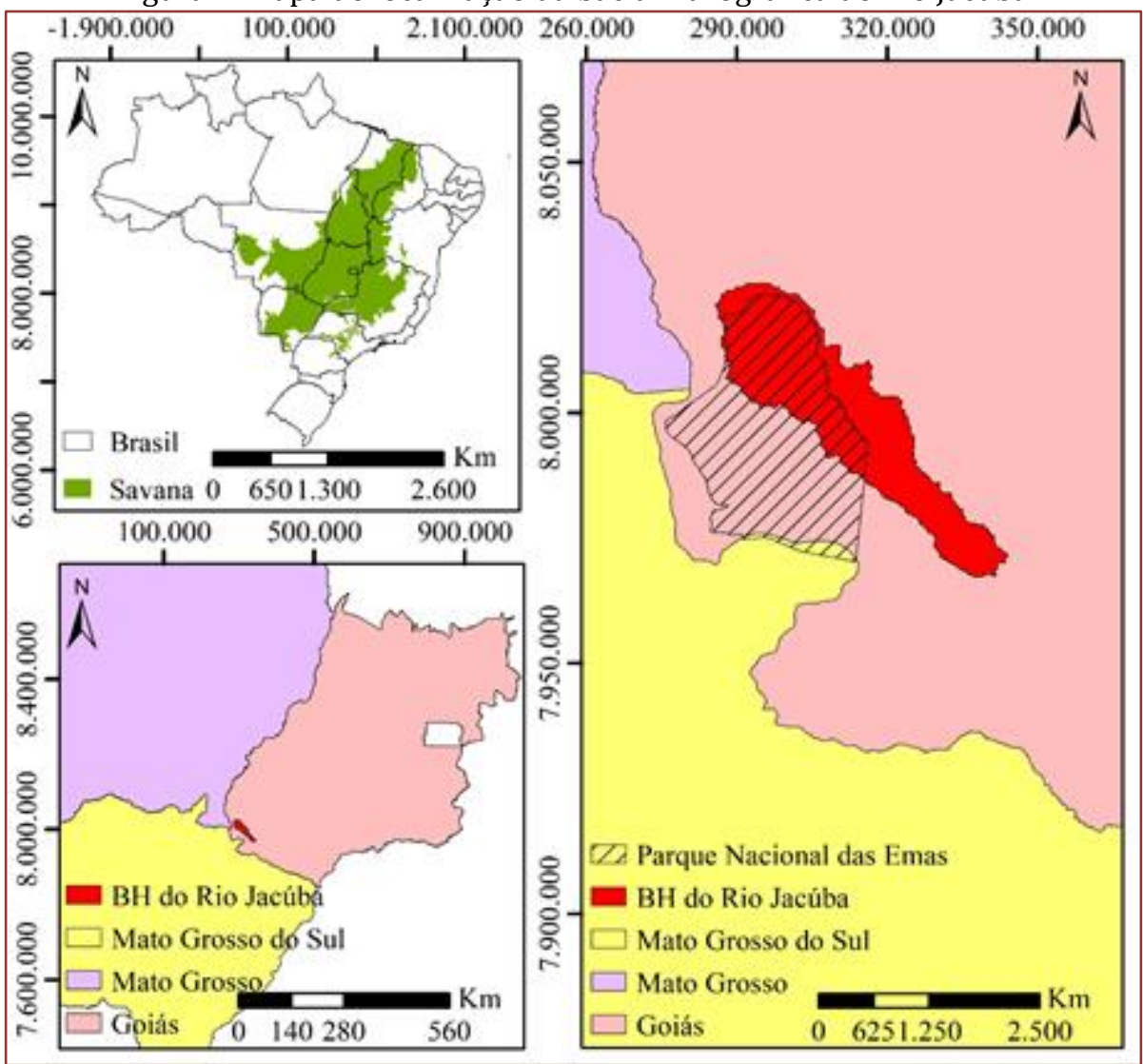

Fonte: Organizado pelos autores (2019) a partir de dados disponibilizados pelo Sistema Estadual de Geoinformação de Goiás (SIEG), na projeção UTM, Datum SIRGAS 2000, Zona 22S.

\section{RESULTADOS E DISCUSSÃO}

Na BHRJ são observados três tipos de solos: Latossolo Vermelho Distrófico, que corresponde a 58,64\% (58577,05 ha) da área total; e estão distribuídos na porção noroeste e sudeste da bacia; Neossolo Quartzarênico, 36,36\% (36073,1 ha), distribuídos na porção centro-norte e Gleissolo Háplico Distrófico, 5\% (4647 ha), distribuídos na porção centro-sudeste da bacia, margeando o curso hídrico principal.

Conforme a classificação proposta por Manningel et al. (2002), os resultados são de média e alta erodibilidade, sendo o maior valor de 0,31 th.h/ MJ. Mm (correspondente ao Neossolo Quartzarênico), seguido, em ordem decrescente, de 0,021 t.h/ MJ. Mm (correspondente ao Gleissolo Háplico Distrófico) e 0,018 t.h/ MJ. Mm (correspondente ao Latossolo Vermelho Distrófico) (Figura 2).

Conforme Beskow et al. (2009), valores de erodibilidade superiores a 0,03 t.h/ MJ. Mm indicam que estes locais possuem alta suscetibilidade à erosão hídrica, como ocorre na BHRJ devido a existência de Neossolos Quartzarênicos.

O Gleissolo Háplico Distrófico, principalmente por estarem associados às áreas planas, são menos suscetíveis aos processos erosivos. Entretanto, devido estar localizado próximo ao Rio Jacuba, em Área de Preservação Permanente (APP), e não ser favorável à mecanização agrícola (apresenta alta umidade), precisa ser preservado (OBIAHU; ELIAS, 2020). 
Figura 2. Erodibilidade na Bacia Hidrográfica do Rio Jacuba.

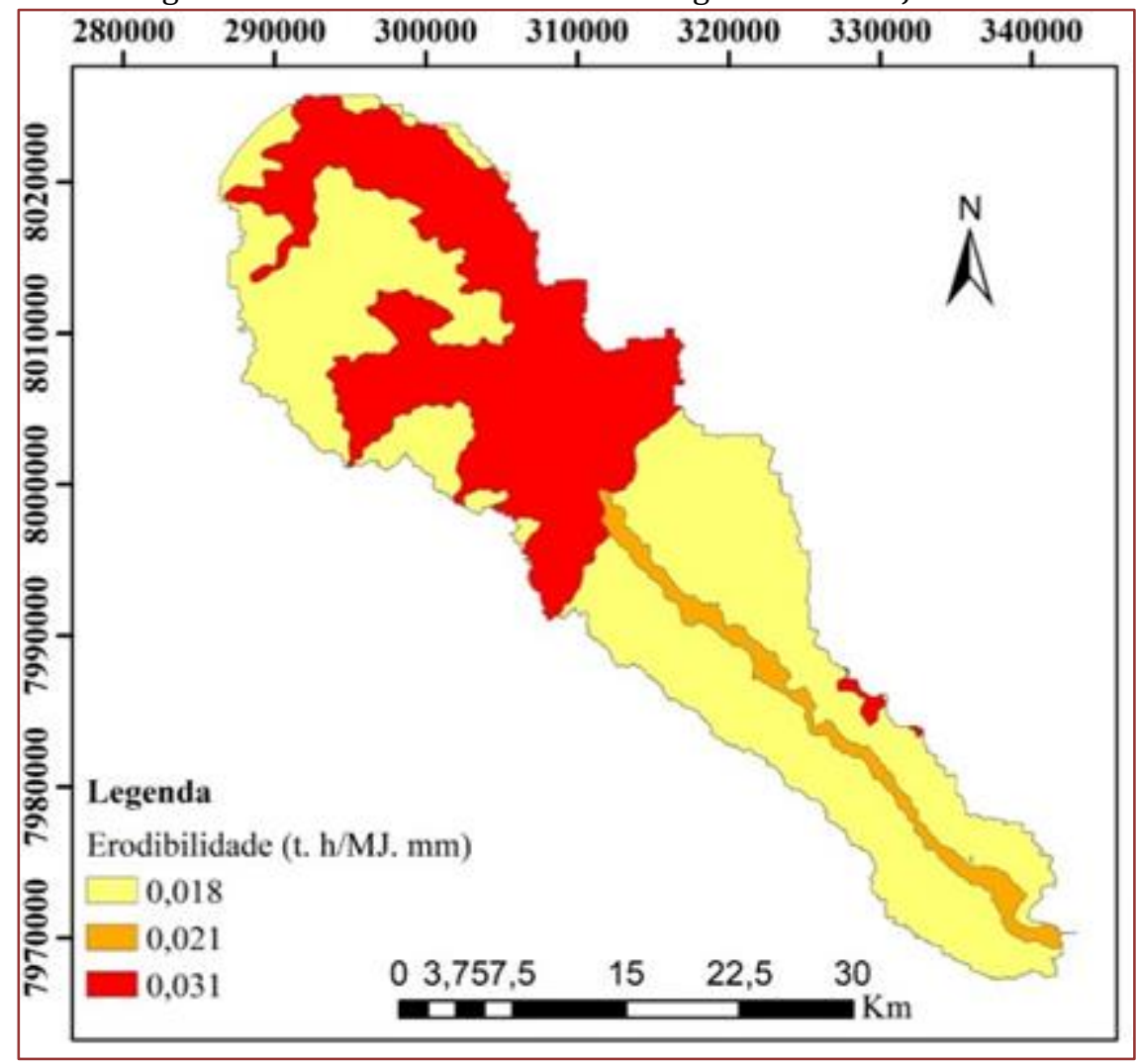

Elaborado na Projeção UTM, Datum Sirgas 2000, zona 22 S.

Os Latossolos Vermelhos Distróficos são férteis, o que resulta na intensa atividade agropastoril nesses solos (BATISTA et al., 2017). Porém, quando são manejados de forma inadequada, como o uso intensivo de mecanização agrícola, monocultura, sobrepastoreio, dentre outros, leva a maior suscetibilidade a erosão, além de causar outros impactos ambientais negativos (ALVES et al., 2017). Além disso, as mudanças climáticas podem afetar bruscamente nas perdas de solo, já que tende-se a ter cada vez mais volumes de chuva em curtos períodos de tempo, acarretando em maior arraste de partículas provocando as erosões (FENTA et al., 2020; MALTSEV; YERMOLAEV, 2020)

\section{CONCLUSÕES}

1. 0 uso de SIG, do Mapa de Solos do Plano Diretor da Bacia Hidrográfica do Rio Paranaíba e dados disponibilizados na literatura possibilitaram a espacialização do fator $\mathrm{K}$ da USLE na BHRJ, sendo observadas erodibilidade média (predominante) e alta. A próxima etapa desse trabalho será a de quantificar a perda de solos potencial e real, utilizando modelo matemático, no intuito de indicar áreas suscetíveis à perda de solos.

2. Este estudo é uma etapa importante para subsidiar a modelagem da perda de solos na BHRJ (pesquisa em andamento) com a utilização da USLE, tendo em vista disponibilizar dados para os gestores dessa unidade hidrográfica para tomada de decisão alinhada com o desenvolvimento econômico e a preservação e conservação ambiental. 


\section{REFERÊNCIAS}

[1] ALVES, W. S; SCOPEL, I.; MARTINS, A. P. Análise da fragilidade ambiental da bacia do Ribeirão das Abóboras, em Rio Verde, Sudoeste de Goiás. GeoFocus. Revista Internacional de Ciencia y Tecnología de la Información Geográfica, v. 1, n. 19, p. 81-108, 2017.

[2] BATISTA, P. V. G. et al. Modelling spatially distributed soil losses and sediment yield in the upper Grande River Basin-Brazil. Catena, v. 157, n. 1, p. 139-150, 2017.

[3] BESKOW, S.; MELLO, C. R.; NORTON, D. L.; CURI, N.; VIOLA, M.R.; AVANZI, J. C. Soil erosion prediction in the Grande River Basin, Brazil using distributed model. Catena, v.79, p. 49-59, 2009.

[4] CORRÊA, Edvania A.; MORAES, Isabel C.; PINTO, Sérgio dos A. F. Estimativa da erodibilidade e tolerância de perdas de solo na região do Centro Leste Paulista. São Paulo, UNESP, Geociências, v. 34, n. 4, p.848-860, 2015.

[5] EFTHIMIOU, N. The new assessment of soil erodibility in Greece. Soil and Tillage Research, v. 204, p. 104720, 2020. https://doi.org/10.1016/j.still.2020.104720.

[6] FALCÃO, C. J. L. M.; DUARTE, S. M. A; VELOSO, A. S. Estimating potential soil sheet Erosion in a Brazilian semiarid county using USLE, GIS, and remote sensing data. Environmental Monitoring and Assessment, v. 192, n. 1, p. 47, 2020.

[7] FEnTA, A. A.; TSUnEKAWA, A.; HAREgEWEYN, N.; POESEN, J.; TSUBO, M.; BORRElli, P.; PANAGOS, P.; VANMAERCKE, M. BROECKX, J.; YASUDA, H. KAWAI, T. KUROSAKI, Y. Land susceptibility to water and wind erosion risks in the East Africa region. Science of The Total Environment, v. 703, n.10, 2020. Disponível em: https://doi.org/10.1016/j.scitotenv.2019.135016. Acesso em: 08-12-2020.

[8] ICMBio - Instituto Chico Mendes de Conservação da Biodiversidade. Parque Nacional das Emas. Disponível em: <http://www.icmbio.gov.br/portal/visitacao1/unidades-abertas-a-visitacao/204-parque-nacional-das-emas>. Acesso em: 10 set 2019.

[9] LIMA, J. E. F. W., et al. Desenvolvimento de base de dados de solos para a aplicação do modelo SWAT em bacia do Bioma Cerrado. Anais do XX Simpósio Brasileiro de Recursos Hídricos, 2013, 17.

[10] MADENOGLU, S.; ATALAY F.; ERPUL G. Uncertainty assessment of soil erodibility by direct sequential Gaussian simulation (DSIM) in semiarid land uses. Soil and Tillage Research. Volume 204, 2020, 104731, ISSN 0167 1987, https://doi.org/10.1016/j.still.2020.104731.

[11] MALTSEV, K.; YERMOLAEV, O. Assessment of soil loss by water erosion in small river basins in Russia. Catena, v. 195, 2020. Disponível em: https://doi.org/10.1016/j.catena.2020.104726. Acesso em: 08-12-2020.

[12] MANNINGEL, A. R. et al. Fator erodibilidade e tolerância de perda dos solos do Estado de São Paulo. Acta Scientiarum, v. 24, 2002.

[13] MORGAN, R. P. C. A simple approach to soil loss prediction: a revised Morgan-Morgan-Finney model. Catena. 44 p. 305-322. 2001.

[14] OBIAHU, O. H.; ELIAS, E. Effect of land use land cover changes on the rate of soil erosion in the Upper Eyiohia river catchment of Afikpo North Area, Nigeria. Environmental Challenges, v. 1, 2020. Disponível em: https://doi.org/10.1016/j.envc.2020.100002. Acesso em: 08-12-20.

[15] RENARD, K. G.; FOSTER, G. R.; WEESIES, G. A.; MCCOOL, D. K.; YODER, D. C. Predicting Soil Erosion by Water: A Guide to Conservation Planning With the Revised Universal Soil Loss Equation. USDA Agric. HB No. 703, Washington DC. 1996.

[16] RODRIGUES, Jéssica A. M.; MELLO, Carlos R.; VIOLA, Marcelo R.; RODRIGUES, Maykmiller C. Estimativa da vulnerabilidade dos solos à erosão hídrica na Bacia Hidrográfica do Rio Cervo - MG. São Paulo, UNESP, Geociências, v. 36, n. 3, p. 531 - 542, 2017.

[17] WISCHMEIER, W. H.; SMITH, D. D. Predicting rainfall erosion losses: a guide to conservation planning. Department of Agriculture, Science and Education Administration, 1978. 


\section{Capítulo 3}

O estudo das características morfométricas da Bacia Hidrográfica do Médio Tocantins

\section{Ana Júlia Logrado da Conceição \\ Cristiane Matos da Silva \\ Júnior Hiroyuki Ishihara}

Resumo: A caracterização de uma bacia influencia nos diversos comportamentos hidrológicos e serve como auxílio nos estudos relacionados à disponibilidade hídrica, aptidão agrícola, picos de enchentes, entre outros. Este trabalho objetivou caracterizar morfometricamente a bacia hidrográfica do médio Tocantins através dos parâmetros de densidade hidrográfica, densidade de drenagem, índice de sinuosidade, altitude e declividade média. Foi utilizado o software da AUTODESK AUTOCAD 2018 - STUDENT VERSION para auxiliar no cálculo dos parâmetros, e feito a determinação destes no software AUTOCAD. As características morfométricas de declividade média, altitude média foram gerados através do Software QGIS 3.0 Girona onde também foram confeccionados os mapas pertinentes a cada um destes parâmetros. A bacia apresentou uma baixa capacidade de formar novos cursos d'água, e uma drenagem pobre. Além de apresentar canais com formas transicionais, o que reforça a teoria de que a bacia possui baixa tendência a proporcionar grandes enchentes. Verifica-se também, que a bacia apresenta o maior percentual na classe de declividade suave ondulado, e uma altitude média de aproximadamente $259 \mathrm{~m}$.

Palavras-Chave: Bacia do médio Tocantins. Características Morfométricas. 


\section{INTRODUÇÃO}

A caracterização de variáveis morfométricas de bacias hidrográficas é uma análise representativa e investigativa do comportamento do relevo, que envolvem a hidrografia, relevo e outros parâmetros (AZEVEDO et al., 2017). 0 uso de parâmetros morfométricos de uma bacia hidrográfica tem por finalidade prover suporte na elaboração de indicadores ambientais, por meio de técnicas de sensoriamento remoto e geoprocessamento na caracterização de bacias hidrográficas (MELO et al., 2018).

Silva e Tonello (2014) afirmam que a caracterização morfométrica de uma bacia hidrográfica é um procedimento indispensável para conhecimento da dinâmica ambiental local e regional, permitindo a qualificação de alterações ambientais e análise de vulnerabilidade, por revelarem indicadores físicos específicos para um dado local. Além de permitir compreender, através de um conjunto de parâmetros, a dinâmica da bacia como um todo, seus diferentes compartimentos e sua fragilidade natural (ALMEIDA e BAYER, 2016).

Logo, a descrição de características morfológicas e hidrológicas de uma bacia hidrográfica, aliada ao conhecimento do uso do solo, auxilia no processo de avaliação de possíveis efeitos de perturbação das características do ecossistema em suas condições naturais de equilíbrio, visando estabelecer parâmetros adequados de exploração pelo homem (OLSZEVSKI et al., 2011).

Por tudo ora comentado, este estudo visa caracterizar morfometricamente a bacia hidrográfica do médio Tocantins através dos parâmetros de densidade hidrográfica, densidade de drenagem, índice de sinuosidade, altitude e declividade média.

\section{MATERIAL E MÉTODOS}

A área selecionada para o estudo (Figura 1) corresponde à bacia hidrográfica do médio Tocantins, onde o rio principal é o rio Tocantins e, como complementar, o rio Manuel Alves Grande e Pequeno. De acordo com Silva et al. (2019), esta bacia apresenta uma área de 70.615,11 km² correspondendo a um percentual de 7,68 \% da área total da bacia hidrográfica do Tocantins-Araguaia, que conta com uma extensão territorial de $920 \mathrm{mil} \mathrm{km}^{2}$ segundo dados da Agência Nacional de Águas (2015).

Figura 1- Área de estudo

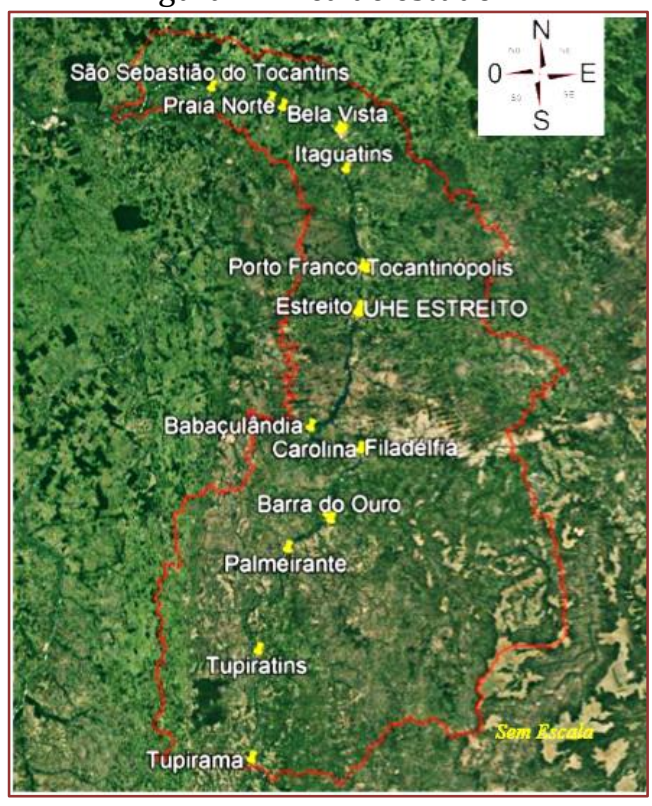

A caracterização morfométrica da bacia foi realizada com base na metodologia proposta por Ferrari et al. (2013) através dos cálculos dos seguintes parâmetros: Área total (A), Perímetro Total (P), Densidade Hidrográfica (Dh), Declividade média, Altitude média, Densidade de drenagem (Dd), Índice de Sinuosidade (IS), conforme as equações descritas no Quadro 1. 
Quadro 1 - Descrição dos Parâmetros morfométricos.

\begin{tabular}{|l|c|c|c|}
\multicolumn{1}{c|}{ Parâmetro } & Abreviação & Unidade & Equação \\
\hline Área Total & $\mathrm{A}$ & $\mathrm{km}^{2}$ & - \\
\hline Perímetro Total & $\mathrm{P}$ & $\mathrm{Km}$ & - \\
\hline Densidade Hidrográfica & $\mathrm{Dh}$ & canais.km-2 & $D h=\frac{N}{A}$ \\
\hline Declividade Média & - & $\mathrm{m} \cdot \mathrm{m}^{-1}$ & - \\
\hline Altitude Média & - & $\mathrm{M}$ & - \\
\hline Densidade de Drenagem & $\mathrm{Dd}$ & $\mathrm{km} \cdot \mathrm{km}^{-2}$ & $D d=\frac{\sum L}{A}$ \\
\hline Índice de Sinuosidade & IS & Admensional & $I=\frac{L i}{d v}$ \\
\hline
\end{tabular}

Fonte: Silva, 2019.

Onde:

$\mathrm{A}=$ Área da bacia hidrográfica $-\mathrm{km}^{2}$;

$\mathrm{P}=$ Perímetro da bacia hidrográfica $-\mathrm{km}$;

$\mathrm{L}=$ Comprimento do eixo da bacia hidrográfica $-\mathrm{km}$;

$\mathrm{N}$ = Número de rios ou cursos d'água;

$\sum \mathrm{L}=$ Comprimento total dos drenos - km;

$\mathrm{Li}$ = Comprimento do canal principal $-\mathrm{km}$;

Dv = Distância vetorial do canal principal $-\mathrm{km}$

Foi utilizado o software da AUTODESK AUTOCAD 2018 - STUDENT VERSION para auxiliar no cálculo dos seguintes parâmetros: Área total (A), Perímetro (P), Comprimento do eixo da bacia hidrográfica (L), Comprimento total dos drenos $(\Sigma \mathrm{L})$, Comprimento do canal principal (Li), Número de rios ou cursos d'água (N) e Distância vetorial do canal principal (Dv). Após a determinação destes no software AUTOCAD, os resultados foram inseridos em uma planilha eletrônica, onde foram inseridas as equações e realizada a tabulação dos resultados obtidos. Após esta etapa, foram geradas através de planilha eletrônica as tabelas com os resultados das características morfométricas (densidade hidrográfica (Dh), densidade de drenagem (Dd) e índice de sinuosidade (IS)). As características morfométricas de declividade média, altitude média foram gerados através do Software QGIS 3.0 Girona onde também foram confeccionados os mapas pertinentes a cada um destes parâmetros.

\section{RESULTADOS E DISCUSSÃO}

A análise das características morfométricas é de suma importância em um estudo hidrológico, pois através delas pode-se inferir sobre as condições de relevo de uma bacia hidrográfica (SILVA, 2019). Na Tabela 1 são apresentados os resultados encontrados para a densidade hidrográfica (Dh), densidade de drenagem (Dd) e índice de sinuosidade (IS) da bacia hidrográfica do médio Tocantins.

Tabela 1 - Características morfométricas da bacia hidrográfica.

\begin{tabular}{|l|c|c|}
\multicolumn{1}{|c|}{ Parâmetro } & Resultado & Unidade \\
\hline Densidade hidrográfica & 0,018 & canais. $\mathrm{km}^{-2}$ \\
\hline Densidade de drenagem & 0,18 & $\mathrm{~km}^{-2} \mathrm{~km}^{-2}$ \\
\hline Índice de sinuosidade & 1,66 & adimensional \\
\hline
\end{tabular}

Fonte: Silva, 2019.

Observa-se que a bacia em estudo apresentou um valor baixo de densidade hidrográfica $(0,018$ canais. $\mathrm{km}^{2}$ ), o que indica que a bacia possui baixa capacidade de gerar novos cursos d'água. Ao analisar a densidade de drenagem, o valor encontrado, $0,18 \mathrm{~km} \cdot \mathrm{km}^{2}$, indica que a bacia possui uma drenagem pobre. Logo, estas características corroboram com a baixa tendência de propiciar grandes enchentes apresentada pelas características físicas da bacia.

Quanto ao índice de sinuosidade da bacia, o valor encontrado de 1,66 indica que ela possui tendência a apresentar canais com formas transicionais, uma vez que nos valores apresentados por Alves e Castro (2003), demonstram que se este índice for aproximadamente igual a 1,0, os canais da bacia tenderiam a ser retilíneos e, se por outro lado o índice de sinuosidade fosse maior que 2,0 os canais tenderiam a ser tortuosos. Logo, faz-se possível inferir que a bacia possui canais transicionais, o que mais uma vez 
corrobora com a densidade de drenagem e com a densidade hidrográfica da bacia e reforça a teoria de que a bacia possui baixa tendência a proporcionar grandes enchentes (SILVA, 2019).

Na Tabela 2 encontra-se a descrição das classes de declividade da bacia hidrográfica do médio Tocantins, com os respectivos percentuais de ocupação dentro da área da bacia hidrográfica. Verifica-se também, que a bacia possui na maior parte, declividade de 0 a $20 \%$, com variação de relevo plano a ondulado e apresenta o maior percentual na classe de declividade suave ondulado (51,60 \%). De acordo com Silva (2019) ao considerar a declividade como um parâmetro hidrológico que influencia na velocidade do escoamento superficial, pode-se determinar que esta bacia possui uma tendência a ter uma baixa velocidade de escoamento, consequentemente um maior tempo de concentração da água na bacia, o que corrobora com menores índices de erosão quando associados a uma boa cobertura vegetal e manejo adequado do uso do solo.

Tabela 2 - Distribuição das classes de declividade na bacia hidrográfica do médio Tocantins.

\begin{tabular}{|c|c|c|}
\hline Declividade (\%) & Classes de declividade & $\%$ \\
\hline $\mathbf{0}-\mathbf{3}$ & Plano & 28,10 \\
\hline $\mathbf{3 - 8}$ & Suave ondulado & 51,60 \\
\hline $\mathbf{8 - 2 0}$ & Ondulado & 16,40 \\
\hline $\mathbf{2 0 - 4 5}$ & Forte Ondulado & 3,30 \\
\hline $\mathbf{4 5 - 7 5}$ & Montanhoso & 0,05 \\
\hline $\mathbf{> 7 5}$ & Escarpado & 0,10 \\
\hline \multicolumn{3}{|c|}{ Total } \\
\hline
\end{tabular}

Fonte: Silva, 2019.

Na Figura 2 é possível verificar que a altitude da bacia variou de $1 \mathrm{~m}$ a $711 \mathrm{~m}$, apresentando uma altitude média de aproximadamente $259 \mathrm{~m}$. As declividades mais acentuadas (20 a 75\%) da bacia se encontram próximos aos topos de morro, nas áreas coincidentes com os divisores de água da bacia hidrográfica. Ainda é possível observar que, as maiores altitudes estão dispostas nas áreas mais próximas aos divisores de água da bacia, indicando se tratar nesta situação de áreas de topos de morro.

Figura 2 - Mapa de Altitude Média da Bacia Hidrográfica do Médio Tocantins.

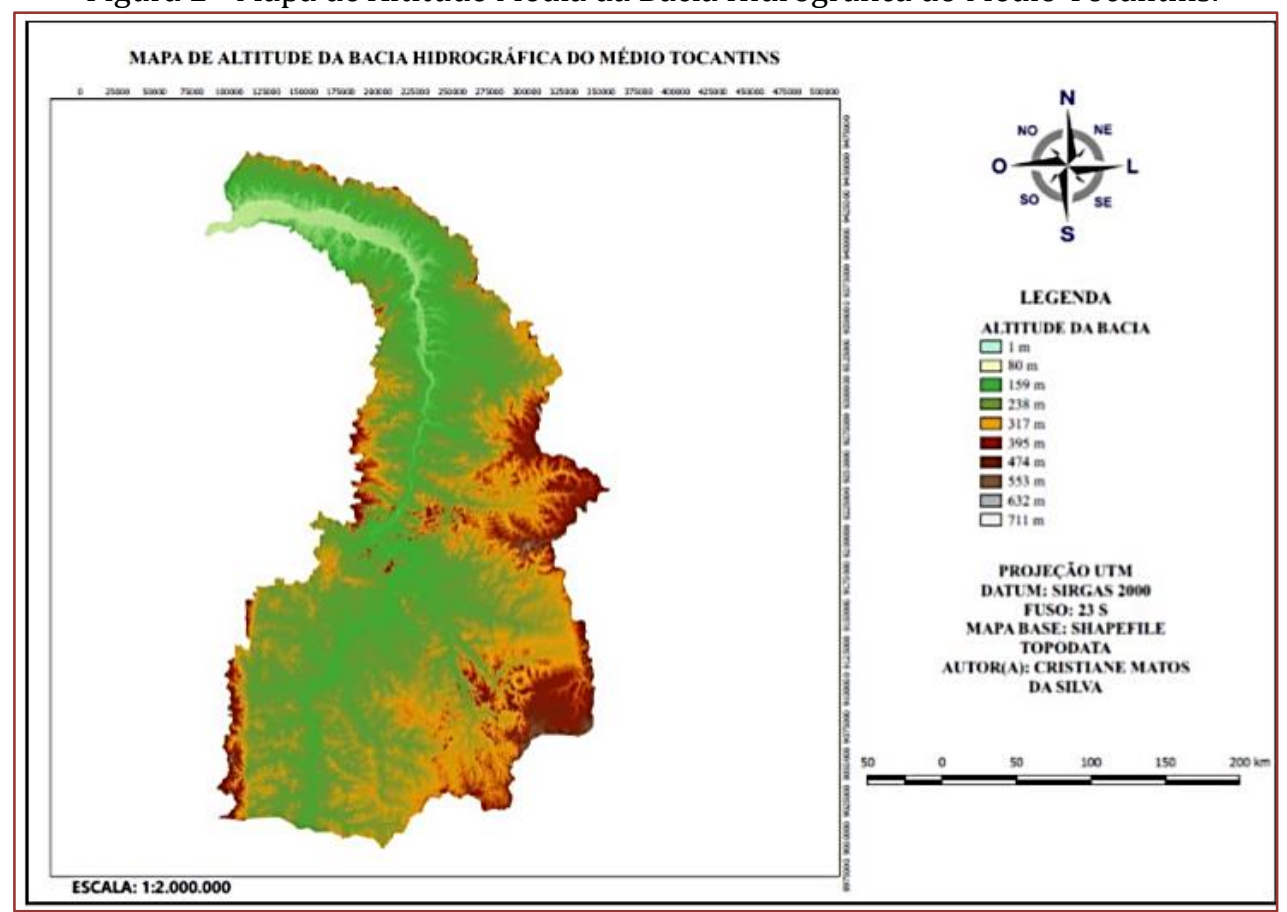




\section{CONCLUSÕES}

Conclui-se com este estudo que a bacia hidrográfica do médio Tocantins possui uma caracterização morfométrica que indica uma tendência baixa a propiciar grandes enchentes, mas sem descartar que, de acordo com a utilização do solo e das interferências nos mananciais, possa desencadear enchentes significativas na bacia.

\section{AGRADECIMENTOS}

Gostaria de agradecer a professora Cristiane Matos da Silva que me ajudou na elaboração deste trabalho. E a minha instituição UEMASUL por todo o apoio científico.

\section{REFERÊNCIAS}

[1] ALMEIDA, R.F.B.; BAYER, M. Compartimentação Morfométrica da Bacia do Rio Coco como Subsídio A análise de Fragilidade Ambiental. Mercator. Fortaleza, v.15, n.4, p.83-94, out./dez., 2016.

[2] AZEVEDO, E.P.G.; CAMPOS, S.; PIZA, M.W. de T.; SARTOR, M.B.; SILVEIRA, G.R.P. Estudo Morfométrico da Bacia do Córrego da Forquilha, Conchal /SP: : Aspectos do relevo e Drenagem. Tekhne e Logos, Botucatu, SP, v.8, n.1, abril, 2017.

[3] FERRARI, J.L.; SILVA, S. F.; SANTOS, A. R.; GARCIA, R.F. Análise morfométrica da sub-bacia hidrográfica do córrego Horizonte, Alegre, ES. Agrária - Revista Brasileira de Ciências Agrárias. v.8, n.2, p.181-188, abr-jun. 2013. DOI:10.5039/agraria.v8i2a1575.

[4] MELO, M.T.de; QUEIROZ, T.M. de; CASSETTARI, G.A. Morfometria da bacia do riacho queima pé em Tangara da Serra/MT. Nucleus, v.15, n.1, abr, 2018.

[5] SILVA, I.O.; SILVA, C.M.; ISHIHARA, J.H.; SOUSA, A.P.B.; MENEZES, L.L.O.R.; SILVA, R.B. Características físicas da bacia hidrográfica como ferramenta de planejamento e gestão de recursos hídricos. Anais do VI Congresso Nordestino de Engenharia Florestal - II Workshop do Projeto Caatinga. Engenharia Florestal no nordeste: identidade e desenvolvimento/ organizadores. Carlos José da Silva et al. - Mossoró: Queima Bucha, 2019.940p.

[6] SILVA, J.L.; TONELLO, K.C. Morfometria da bacia hidrográfica do Ribeirão dos Pinheirinhos, Brotas - SP. Irriga, Botucatu, v. 19, n. 1, p. 103 -114, jan-mar, 2014.

[7] OLSZEVSKI, N.; FILHO, E. I. F.; COSTA, L.M. da; SCHAEFER, C.E.G.R.; SOUSA, E. de; COSTA, O.D.A.V. Morfologia e aspectos h idrológicos da bacia hidrográfica do rio Preto, divisa dos estados do Rio de Janeiro e de Minas Gerais. Revista Árvore. Viçosa -MG, v.35, n.3, p. 485-492, 2011. 


\section{Capítulo 4}

\section{Estudo da autodepuração em um trecho do Rio Sorocaba, SP - Brasil}

\section{Vinicius Moura Costa}

João Pedro Gomes dos Santos

Letícia Borsato Rossi

Layssa de Moura Oliveira

Jorge Luis Rodrigues Pantoja Filho

Resumo: 0 processo de recuperação natural de um curso d'água é denominado autodepuração, o qual pode ser determinado utilizando-se a concentração de oxigênio dissolvido. Um dos principais modelos matemáticos que estuda este fenômeno é de Streeter-Phelps, servindo como base para o programa Ad' Água 2.0TM. No presente trabalho, buscou-se simular o consumo de oxigênio dissolvido, após o despejo pontual de esgoto, em um trecho do rio Sorocaba nos períodos seco e chuvoso, possibilitando comparar os resultados com os dados da Companhia Ambiental do Estado de São Paulo. 0 trecho de estudo está inserido nos municípios de Votorantim e Sorocaba, e foi dividido em duas secções. Seis cenários distintos dentro do período do ano hidrológico foram analisados, onde avaliou-se a influência do volume do rio na dinâmica da autodepuração, e, ainda, verificou-se a validade do software, por meio da comparação dos valores de oxigênio dissolvido simulado com o mensurado pelo órgão responsável. Observou-se que no período seco a anaerobiose foi atingida quilômetros antes quando comparada ao período chuvoso, devido a concentração de matéria orgânica presente no rio ser maior. A disparidade dos valores ao realizar-se a comparação foi evidente, podendo ser explicada pela diferença na natureza dos dados utilizados, além do modelo base do software possuir restrições teóricas. Embora o programa apresente limitações, o estudo é totalmente válido para o entendimento da variação da concentração de oxigênio dissolvido em um curso d'água. Logo, espera-se que os municípios o utilizem como aporte teórico.

Palavras-chave: Oxigênio dissolvido; Streeter-Phelps; Ad'Água 2.0; Matéria orgânica. 


\section{INTRODUÇÃO}

De acordo com Von Sperling (2014), a autodepuração de um curso d'água é um fenômeno que reestabelece o equilíbrio da biota aquática por mecanismos essencialmente naturais. Para a determinação do grau de poluição e de autodepuração em cursos d'água tem se utilizado o oxigênio dissolvido (OD), sendo seu teor expresso em concentrações quantificáveis e passíveis de modelagem matemática.

Um dos principais modelos matemáticos aplicados à qualidade da água foi desenvolvido por Streeter e Phelps (1925), o qual relaciona o impacto causado pela descarga de águas residuárias com a concentração de oxigênio do rio. Este modelo é a base do programa Ad' Água 2.0 2 TM, onde a concentração do material em estudo é considerada homogênea numa mesma seção transversal de um canal (SARDINHA et al, 2008).

A região da Unidade de Gerenciamento de Recursos Hídricos (UGRHI) 10, possui densa e crescente urbanização (CBH-SMT, 2016), quando associado à falta de planejamento, pode gerar impactos negativos no rio Sorocaba. Portanto, objetiva-se com este trabalho simular, utilizando dados secundários, o consumo de oxigênio dissolvido em um trecho do rio Sorocaba nos períodos seco e chuvoso, após o despejo pontual de esgoto, possibilitando a comparação dos resultados com os dados de OD mensurados pela Companhia Ambiental do Estado de São Paulo (CETESB).

\section{METODOLOGIA}

A área de estudo corresponde a um trecho do rio Sorocaba, pertencente à Bacia Hidrográfica Sorocaba/Médio Tietê - UGRHI 10, que percorre os municípios de Votorantim e Sorocaba (CETESB, 2018; SAAE, 2019), onde possui 3 pontos de amostragem da CETESB.

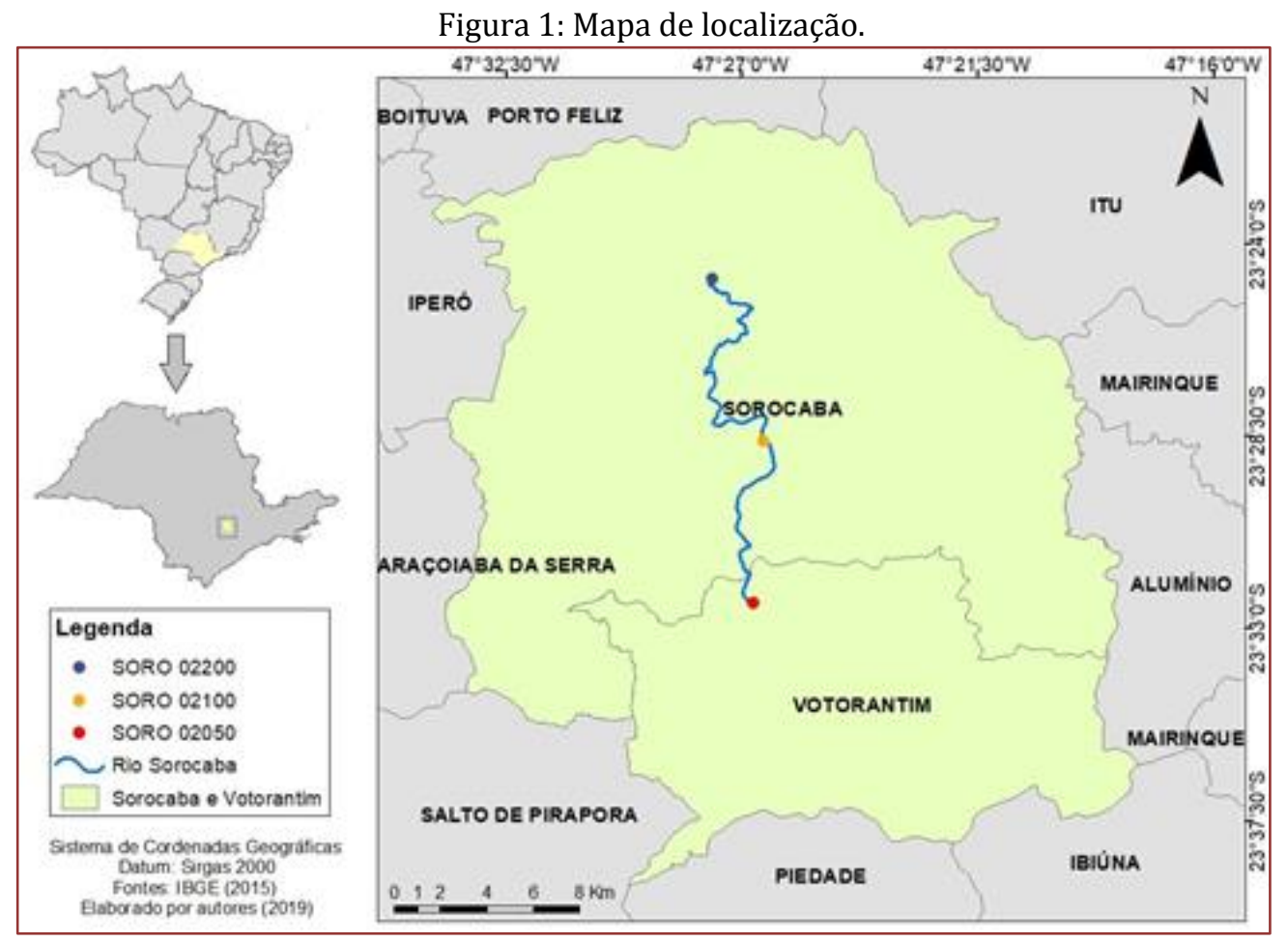

Para realizar a simulação, dividiu-se o trecho de estudo em duas seções, através de um software SIG (Sistemas de Informações Geográficas), nomeadas de seção I, contida entre os pontos, SORO 02050 e SORO 02100, e seção II, entre SORO 02100 e SORO 02200, contendo 13,95 Km e 8,87 Km de extensão, respectivamente.

A fim de estimar o volume de esgoto gerado, de acordo com Von Sperling (2014), utilizou-se dados da população absoluta (IBGE, 2019), e da coleta e tratamento do esgoto de Votorantim e Sorocaba (CBH-SMT, 2018). Posteriormente, apurou-se informações sobre o consumo médio de água por habitante brasileiro e o coeficiente de retorno (VON SPERLING, 2014). Para simulação, aplicou-se o software Ad'Água 2.0 ${ }^{\mathrm{TM}}$ com 
base em dados obtidos na literatura e relatórios públicos (FERNANDES, 2012; VON SPERLING, 2014; CETESB, 2018). Logo, os dados de entrada do efluente foram: Vazão $\left(\mathrm{m}^{3} . \mathrm{s}^{-1}\right), \mathrm{DBO}_{5}\left(\mathrm{mg}^{\left.-\mathrm{L}^{-1}\right), \mathrm{K}_{1}\left(20^{\circ} \mathrm{C}\right)}\left(\mathrm{dia}^{-1}\right)\right.$ e OD (mg. $\left.\mathrm{L}^{-1}\right)$. Já para o curso d'água foram: Vazão $\left(\mathrm{m}^{3} \cdot \mathrm{s}^{-1}\right)$, Temperatura $\left({ }^{\circ} \mathrm{C}\right)$, Comprimento do trecho de estudo $(\mathrm{Km}), \mathrm{DBO}_{5}\left(\mathrm{mg} . \mathrm{L}^{-1}\right), \mathrm{OD}\left(\mathrm{mg}^{-\mathrm{L}^{-1}}\right), \mathrm{K}_{2}\left({ }_{20}{ }^{\circ} \mathrm{C}\right)\left(\right.$ dia $\left.^{-1}\right)$, Classe do rio (un.) e Altitude média $(\mathrm{m})$. Para análise da simulação, foram avaliados cenários distintos do período do ano hidrológico. Desta forma, avaliou-se a influência do volume do rio na dinâmica da autodepuração, e, ainda, verificou-se a validade do software, por meio da comparação de OD simulado e mensurado.

\section{RESULTADOS E DISCUSSÃO}

As Figuras 2, 3 e 4 representam os perfis longitudinais de oxigênio dissolvido simulados do trecho de estudo do rio Sorocaba.

Figura 2: Cenários A e B.

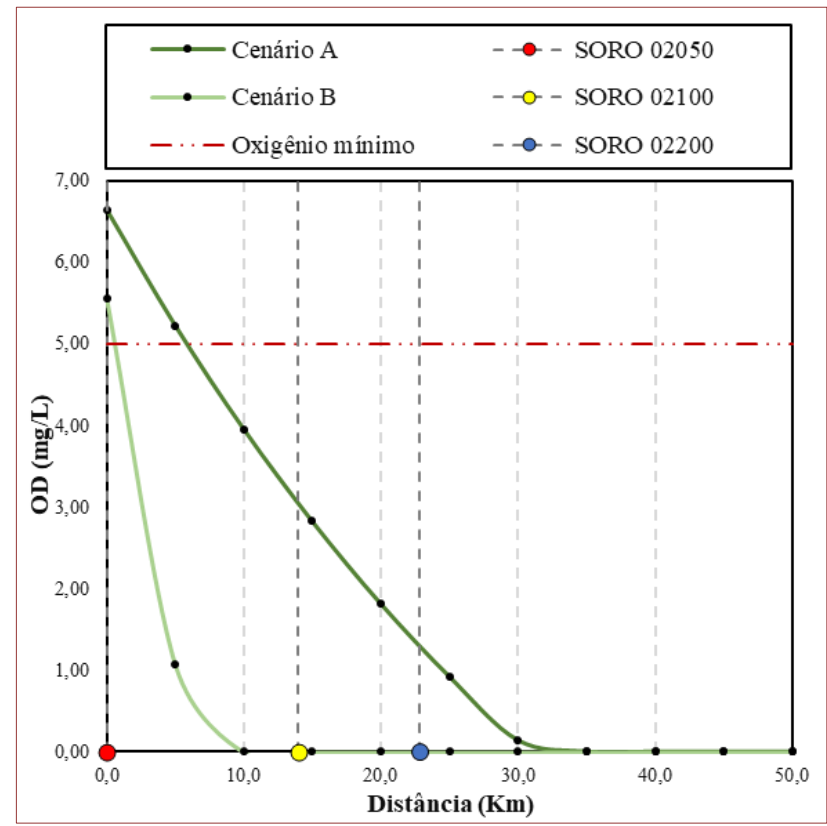

Figura 3: Cenários C e D.

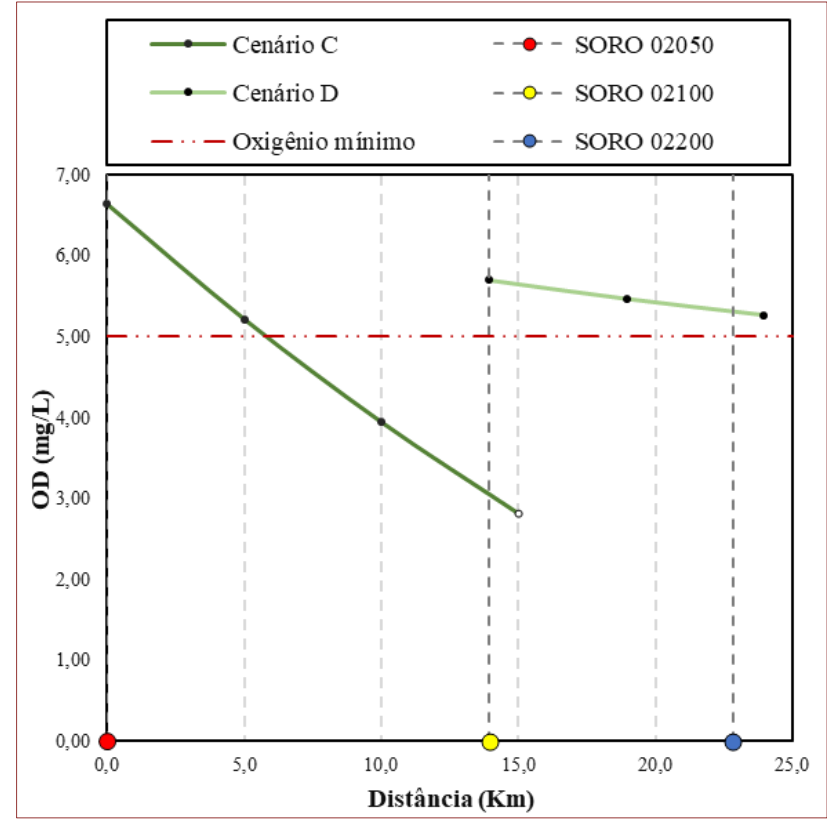


Figura 4: Cenários E e F

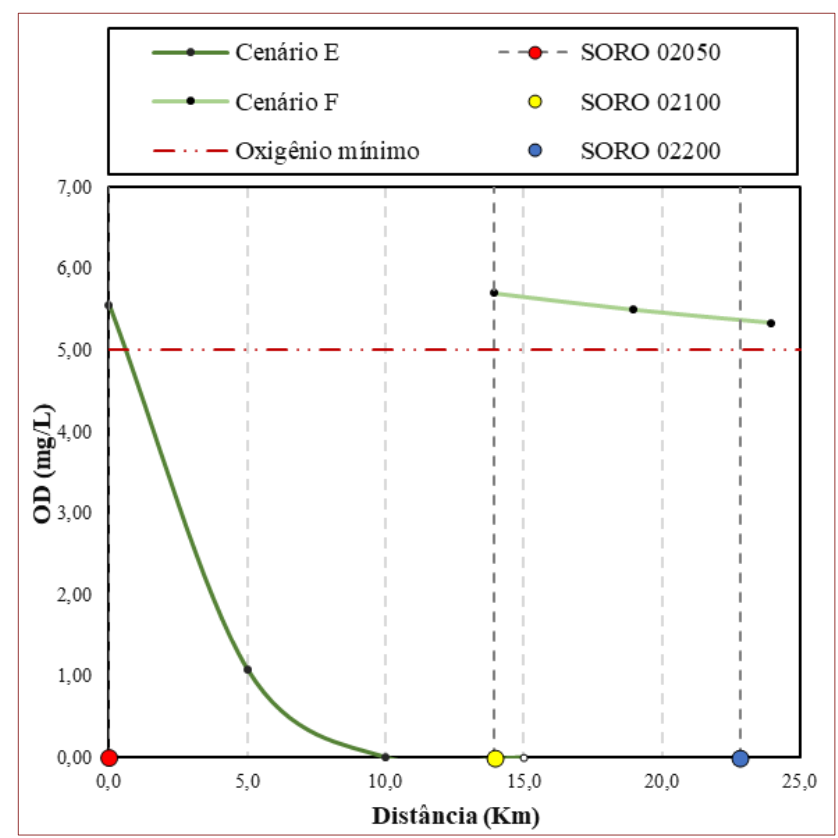

O despejo de esgoto se localiza em SORO 02050, onde os dados são os mesmos. Em relação ao curso d'água, há uma variação de alguns parâmetros, uma vez que a análise é feita para os períodos seco e chuvoso. No entanto, os dados de $\mathrm{OD}$ e $\mathrm{DBO}_{5}$ são os mesmos, já que são disponibilizados pela CETESB (2018). Assim a Figura 2 refere-se a simulação integrada das seções, cujo período chuvoso é o cenário A, e o seco o cenário B. Com a divisão das seções, de forma a introduzir os dados de OD e $\mathrm{DBO}_{5}$ no ponto SORO 02100 fornecidos pela CETESB (2018), foram produzidas as Figuras 3 e 4, representando o período chuvoso e seco, respectivamente.

Nota-se na Figura 2 que a anaerobiose (OD $=0 \mathrm{mg} . \mathrm{L}^{-1}$ ) é atingida muito antes no período seco do que no chuvoso, tendo uma diferença de quase $20 \mathrm{Km}$. Isso também é notado na Figura 4 quando comparada com a Figura 3, em que a anaerobiose ocorre somente no período seco, especificamente no trecho I, por volta de $10 \mathrm{Km}$. Tal fato indica que o consumo de OD pelos organismos presentes na massa líquida é maior no período seco, devido, principalmente, a concentração da matéria orgânica ser maior, apesar das características do efluente serem as mesmas. 0 relatório disponibilizado pela CETESB (2018) informa os seguintes índices de OD: 5,70 mg. $\mathrm{L}^{-1}$ para SORO 02100, e 2,40 mg.L-1 para SORO 02200. Dessa maneira, ao comparar com os valores simulados na Figura 2, nota-se que o cenário A apresenta valores próximos a 3,00 mg. $\mathrm{L}^{-1}$, no ponto SORO 02100; e a 1,50 mg.L-1, no SORO 02200. No entanto, o cenário B encontra-se em anaerobiose em ambos os pontos. Já a Figura 3, apresentou valores próximos a 3,00 mg. $\mathrm{L}^{-1}$ no término da seção I, ponto SORO 02100, e a 5,3 mg. $\mathrm{L}^{-1}$ no término da seção II, SORO 02200. E a Figura 4 indica a anaerobiose no ponto SORO 02100, e valor próximo a 5,40 mg.L.-1 no SORO 02200.

Desta maneira é evidente a disparidade de valores nos dados publicados pela CETESB (2018) com os resultados da simulação, no entanto observa-se na Figura 3 uma convergência dos resultados simulados para com os publicados. A disparidade pode ser explicada pela diferença na natureza dos dados utilizados com a base de dados da CETESB, uma vez que os cenários representam períodos extremos, chuvoso e seco, e a CETESB realiza uma média dos valores mensurados no ano de 2017. Além disso, o modelo base do software, o Streeter-Phelps, possui restrições teóricas, tais como: o regime do rio é uniforme, o escoamento é unidimensional e o despejo de carga pontual de efluente, são fatores aplicados que não retratam a realidade do curso d'água. Contudo a convergência de valores, possivelmente, se justifica pela suposta proximidade de valores do período chuvoso com os da média anual do rio. E, não menos importante, a segregação do trecho do rio em seções menores, somado a aplicação de valores oficiais no início de cada seção, provoca aproximação com o valor base de comparação, exemplificado no cenário D da Figura 3. 


\section{CONSIDERAÇÕES FINAIS}

Embora o Ad'Água 2.0 ${ }^{\mathrm{TM}}$ apresente limitações, os resultados são válidos para o entendimento da variação de OD em um curso d'água após o despejo de esgoto. Portanto espera-se que este trabalho sirva como subsídio técnico para tomada de decisões por parte dos municípios.

\section{REFERÊNCIAS}

[1] CBHSMT - COMITÊ DA BACIA HIDROGRÁFICA-SOROCABA MÉDIO TIETÊ. Plano de Bacia Hidrográfica: 20162017: relatório técnico. Sorocaba, 2016.

[2] CBHSMT - COMITÊ DA BACIA HIDROGRÁFICA-SOROCABA MÉDIO TIETÊ. Relatório de situação 2018: relatório técnico. Sorocaba, 2018.

[3] COMPANHIA AMBIENTAL DO ESTADO DE SÃO PAULO (CETESB). Relatório de Qualidade das Águas Interiores do Estado de São Paulo. São Paulo, 2018.

[4] FERNANDES, A.M. Características hidrogeoquímicas da bacia de drenagemdo rio Sorocaba, SP: processos erosivos mecânicos e químicos.2012.241f. Tese (Doutorado) - Centro de Energia Nuclear na Agricultura, Universidade de São Paulo,Piracicaba, 2012

[5] IBGE - INSTITUTO BRASILEIRO DE GEOGRAFÍA E ESTATÍSTICA (Brasil). Cidades. 2019. Disponível em: $<$ https://cidades.ibge.gov.br/>. Acesso em: 03 jun. 2020.

[6] PAULA, Liliane Magnavaca de. Avaliação da qualidade da água e autodepuração do rio Jordão, Araguari (MG). 2011. 196 f. Dissertação (Mestrado) - Curso de Engenharia Civil, Universidade Federal de Uberlândia, Uberlândia, 2011.

[7] SAAE - SERVIÇO AUTÔNOMO DE ÁGUA E ESGOTO DE SOROCABA (Sorocaba). Descida revela a vida e a qualidade da água do Rio Sorocaba. 2019. Disponível em: <www.saaesorocaba.com.br/descida-revela-a-vida-e-aqualidade-da-agua-do-rio-sorocaba>. Acesso em: 03 jun. 2020.

[8] SARDINHA, D. S. et al. Avaliação da qualidade da água e autodepuração do ribeirão do meio, Leme (SP). Engenharia Sanitária e Ambiental, Rio de Janeiro, v. 13, n. 3, p. 329-338, set. 2008.

[9] STREETER, H. W. PHELPS, E. B. A Study of the pollution and natural purification of the Ohio river: III. Factors concerned in the phenomena of oxidation and reaeration. Public Health Bulletin: № 146, Washington, p. 1-75, fev. 1925

[10] VON SPERLING, M. Introdução à qualidade das águas e ao tratamento de esgotos. 4. ed. Belo Horizonte: Editora Ufmg, 2014. 


\title{
Capítulo 5
}

Relação entre a precipitação, temperatura e a p $\mathrm{CO}_{2}$ na Foz do Rio Amazonas

\author{
Diani Fernanda da Silva Less \\ Alan Cavalcanti da Cunha
}

Resumo: Os rios são extremamente importantes para o ciclo global de carbono porque são uma fonte significativa de CO2 para atmosfera. Apesar do potencial de concentração e emissão ser atualmente mais conhecido, há lacunas de conhecimento sobre como ocorrem as interações entre o meio aquático, terrestre e atmosférico, especialmente quais são os fatores que controlam a pressão parcial de dióxido de carbono (pCO2) e os fluxos (FCO2) na interface ar-água. 0 presente estudo objetiva contribuir com a análise da influência de variáveis físicas precipitação e temperatura da água na supersaturação de dióxido de carbono em uma seção da foz do Rio Amazonas. Nesse sentido, a metodologia de investigação teve como objetivo testar a hipótese de que na foz do rio Amazonas (Canal Norte) a precipitação local e a temperatura da água atuam como fatores controladores da pCO2 da água. Para isso, foram quantificados a pressão parcial do CO2 em campanhas de campo, realizadas durante o período entre 2014 e 2016 no Canal Norte do Rio Amazonas, utilizando um equilibrador acoplado a um Analisador de Gás por Infravermelho, a temperatura da água foi aferida utilizando um peagômetro portátil, os valores de precipitação mensal foram obtidos em consulta ao banco dados do Instituto Nacional de Meteorologia (INMET, estação 82098 em MACAPÁ - AP e estação 82178 em Óbidos-PA). Para avaliar a relação entre as variáveis utilizou-se a correlação de Spearman $(\mathrm{p}<0,05)$, a variabilidade anual e sazonal dos parâmetros foi avaliada com o teste de Kruskal-Wallis e Mann-Whitney, respectivamente ( $p<0,05)$. A pCO2 média mais elevada foi obtida em 2016 (3105,75 $\pm 1273,92$ ppm), a temperatura média da água em 2015 e 2016 foi igual $\left(29,63^{\circ} \mathrm{C}\right)$ e superior à de 2014 , a maior precipitação acumulada foi observada em 2014 tanto em Macapá (2528,7 mm) como em Óbidos (1811,7 mm). Os resultados mostraram a influência significativa e positiva da precipitação $(0.87, \mathrm{p}<0,01)$ e negativa da temperatura da água $(-0.85, \mathrm{p}<0,01)$ na pCO2 na foz do rio Amazonas. Todos as variáveis apresentaram variabilidade sazonal significativa (Kruskal-Wallis, p <0,05). Estes resultados evidenciam que alterações na precipitação e temperatura podem intensificar a supersaturação e a emissão de CO2 na na foz do Rio Amazonas. Estas variáveis são fatores controladores com capacidade de alterar os ciclos regionais e globais do carbono.

Palavras-chave: rios tropicais, ciclo do carbono, clima. 


\section{INTRODUÇÃO}

O dióxido de carbono $\left(\mathrm{CO}_{2}\right)$ é responsável por $70 \%$ do aquecimento global (NNOBY, 1997), sendo que a sua concentração na atmosfera aumentou cerca de $145 \%$ quando comparada aos níveis pré-industriais. Atualmente, a concentração média é de $403,3 \mathrm{ppm}$ e cresce aproximadamente $1,9 \mathrm{ppm}$ por ano (ORGANIZAÇÃO METEOROLÓGICA MUNDIAL, 2016). Neste cenário, ganham cada vez mais importância os estudos voltados ao entendimento do ciclo global e regional do carbono, seus agentes e fatores influenciadores.

Recentemente houve uma mudança de paradigma que considera que os rios atuam como uma fonte significativa de emissão de dióxido de carbono para atmosfera (COLE et al., 2007; MALHI; GRACE, 2000). Globalmente, as águas continentais geram, transportam, sedimentam e emitem em seus leitos cerca de 5,7 $\mathrm{Pg} \mathrm{C}$ ano-1, sendo que $75 \%$ desta quantidade é emitida para a atmosfera na forma de $\mathrm{CO}_{2}$, valor superior ao das emissões antrópicas de carbono (2,8 Pg C ano-1) (LE QUÉRÉ et al., 2015; SAWAKUSCHI et al., 2017).

Até o momento, são poucos os estudos relacionados a variação temporal da $p \mathrm{CO}_{2}$ e $\mathrm{FCO}_{2}$ e principalmente sobre os fatores intervenientes dessas taxas de emissões nos grandes rios tropicais, em especial no Rio Amazonas (COLE et al., 2007). Apesar da região do Baixo Rio Amazonas ser considerado uma importante parcela dos sistemas fluviais tropicais, são escassos as pesquisas relacionadas ao seu papel no balanço regional e global do carbono realizados até o momento, sendo que a maioria das mesmas atuaram de maneira localizada, principalmente nas áreas de várzea e lagos (MOREIRA-TURCQ et al., 2004; KIM et al., 2012; ABRIL et al., 2014). No que se refere à região estuarina, o conhecimento acerca de da $p \mathrm{CO}_{2}$ e dos fluxos de $\mathrm{CO}_{2}$ é ainda mais limitado, são poucos os estudos realizados na área (BRITO, 2013; MEDEIROS et al.; 2015; SAWAKUSCHI et al., 2017; WARD et al.; 2013).

A $p \mathrm{CO}_{2}$ do Rio Amazonas é caracterizada por um balanço dinâmico entre as entradas de $\mathrm{CO}_{2}$ provenientes principalmente da respiração da matéria orgânica no canal principal e na várzea e as saídas da produtividade primária in situ (ABRIL et al., 2014; RICHEY et al., 2002; SAWAKUCHI et al., 2017; WARD et al., 2018). Este balanço é diretamente influenciado pelo ciclo hidrológico, evidenciando a importância da análise dos efeitos de variáveis meteorológicas como a precipitação e a temperatura na concentração de $\mathrm{CO}_{2}$ (RICHEY et al., 2002).

Neste contexto, o presente estudo tem como objetivo analisar a influência da precipitação e da temperatura da água na pressão parcial de $\mathrm{CO}_{2}$ em uma seção do Canal Norte da Foz do Rio Amazonas, para isso foram realizadas treze campanhas de campo entre o período entre 2014 e 2016.

\section{MATERIAL E MÉTODOS}

Foram realizadas 13 campanhas entre 2010 e 2016 em uma estação do Canal Norte $\left(00^{\circ} 02^{\prime} 872 "\right.$ S 0510.'616" W) do Rio Amazonas, próximo à cidade de Macapá (Figura 1).

Figura 1. Localização do ponto de amostragem localizado no Canal Norte da Foz do Rio Amazonas.

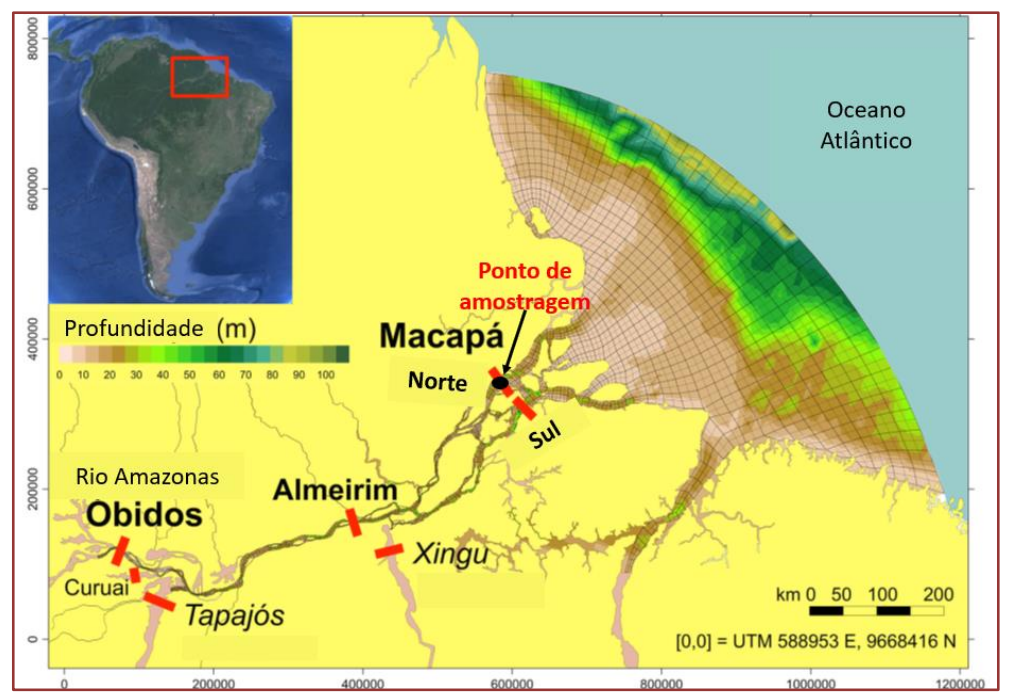

Fonte: Adaptado de Ward et al., (2015). 
A média anual da precipitação e velocidade do vento segundo a última Normal Climatológica (1981-2010, Instituto Nacional de Meteorologia-INMET, 2019) é de $2450 \mathrm{~mm} \mathrm{e} 3 \mathrm{~m} \mathrm{~s}^{-1}$, respectivamente. A precipitação média mensal para os meses do período chuvoso (janeiro a junho) entre 2010 e 2016 foi de $379 \pm 119 \mathrm{~mm}$ e $92 \pm 29 \mathrm{~mm}$ para o período menos chuvoso (INMET, 2020).

\section{COLETA E ANÁLISE DOS DADOS}

Para a determinação da $p \mathrm{CO}_{2}$ utilizou-se uma câmara plexigas de equilibração preenchida com esferas de vidro, para aumentar a superfície de troca e reduzir o volume de ar, acoplada a um Analisador de Gás por Infravermelho (LICOR Instruments, LI-820) (FRANKIGNOULLE, BORGES; BIONDO, 2001). A água coletada a aproximadamente a $30 \mathrm{~cm}$ de profundidade por uma bomba submersa (Rule 360 Bilge pump) passa pela câmara, de cima para baixo, em um fluxo de aproximadamente $1,5 \mathrm{~L} \mathrm{~min}^{-1}$. Uma minibomba de diafragama (AS-200; Spectrex), promove um circuito fechado de ar $\left(150 \mathrm{~mL} \mathrm{~min}^{-1}\right)$ que circula pelo equilibrador (de baixo para cima) passando por um "trap" retentor de umidade (Drierite) conectado ao analisador de gás (RASERA et al., 2008, SAWAKUSCHI et al., 2017).

A temperatura da água foi medida in situ usando um peagâmetro portátil ORION 4-STAR. Os dados mensais de precipitação local (Macapá) e no início do Baixo Amazonas (Óbidos-PA) foram obtidos em consulta ao Banco de Dados Meteorológicos do Instituto Nacional de Meteorologia (INMET, estação 82098 e 82178).

Todas as variáveis foram analisadas por meio de estatística descritiva, por meio da qual foram geradas as médias e desvios-padrão. Além disso, foi aplicado o teste de Shapiro-Wilk $(p<0,05)$ para testar a normalidade da distribuição das variáveis. Para testar a hipótese das diferenças significativas anuais e sazonais (cheia e seca), foram aplicados os testes não paramétricos de Kruskal-Wallis e Mann-Whitney, respectivamente. A correlação de Spearman e regressão linear foram usados para correlacionar as variáveis dependentes $\left(p \mathrm{CO}_{2}\right)$ e independentes (precipitação e temperatura da água). Nas análises estatísticas foi aplicado um nível de confiança de 95\% ( $p<0,05)$, com o software $\mathrm{R}$ (http://www.rproject.org).

\section{RESULTADOS E DISCUSSÃO}

\subsection{VARIAÇÃO ANUAL E SAZONAL DA PCO 2 , TEMPERATURA DA ÁGUA E PRECIPITAÇÃOO}

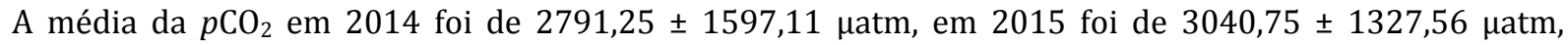
atingindo a maior média em 2016 com 3105,75 \pm 1273,92 $\mu$ atm (Figura 2a). Com relação a variação sazonal na estação cheia a média foi de 4057,35 $\pm 1124,34 \mu$ atm e 2286,08 $\pm 970,55 \mu$ atm na estação seca (Figura 2b), com variação significativa entre os períodos (Mann-Whitney $\mathrm{p}<0,05$ ). Durante a estação chuvosa a $p \mathrm{CO}_{2}$ estava em torno de 11 vezes maior do que a concentração da atmosfera $(\sim 400 \mu$ atm $)$, evidenciando a supersaturação de $\mathrm{CO}_{2}$ e a forte influência do ciclo hidrológico (RICHEY et al., 2002). Valores similares foram obtidos por Brito (2013) e Sawakuchi et al., (2017) na mesma área de estudo e em outras seções do Rio Amazonas.

Figura 2. Variação anual (a) e sazonal (b) da $p \mathrm{CO}_{2}$ no Canal Norte da Foz do Rio Amazonas para o período entre 2014 e 2016.

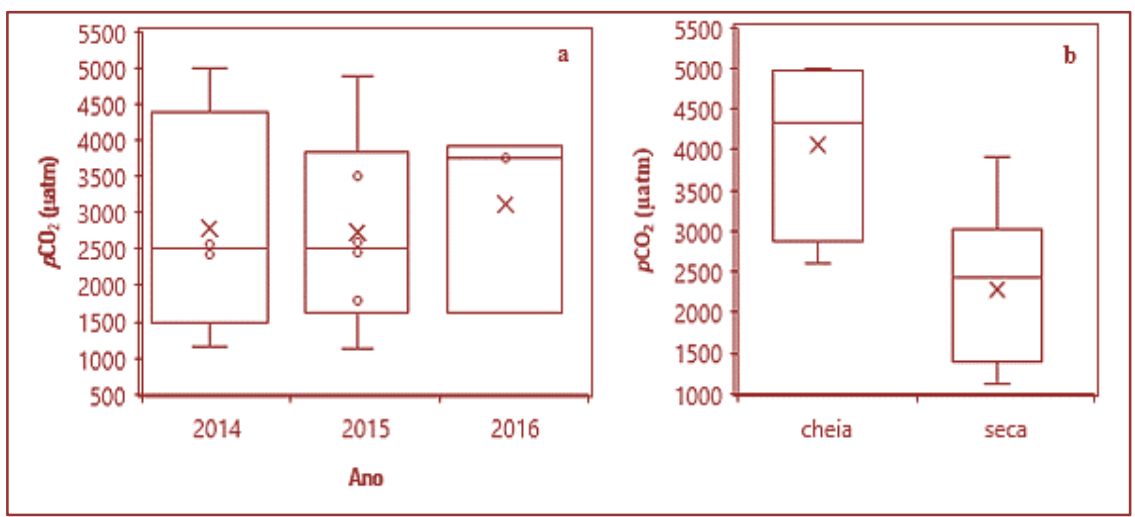


A temperatura média da água em 2014 foi de $29,52 \pm 0,56{ }^{\circ} \mathrm{C}$, em 2015 foi de $29,63 \pm 1,13{ }^{\circ} \mathrm{C}$ e em 2016 foi de $29,63 \pm 0,71{ }^{\circ} \mathrm{C}$ (Figura 3a). Contatou-se significativa variação sazonal (Mann-Whitney p <0,05) com $28,65 \pm 0,24{ }^{\circ} \mathrm{C}$ na cheia e $30,02 \pm 0,73{ }^{\circ} \mathrm{C}$ na seca (Figura $3 \mathrm{~b}$ ). Os valores medidos foram similares aos obtidos por Alin et al., (2011) em outras seções do Rio Amazonas, os autores também constataram a baixa variação temporal da temperatura da água, característica dos grandes rios.

Figura 3. Variação anual (a) e sazonal (b) da temperatura da água no Canal Norte da Foz do Rio Amazonas para o período entre 2014 e 2016.

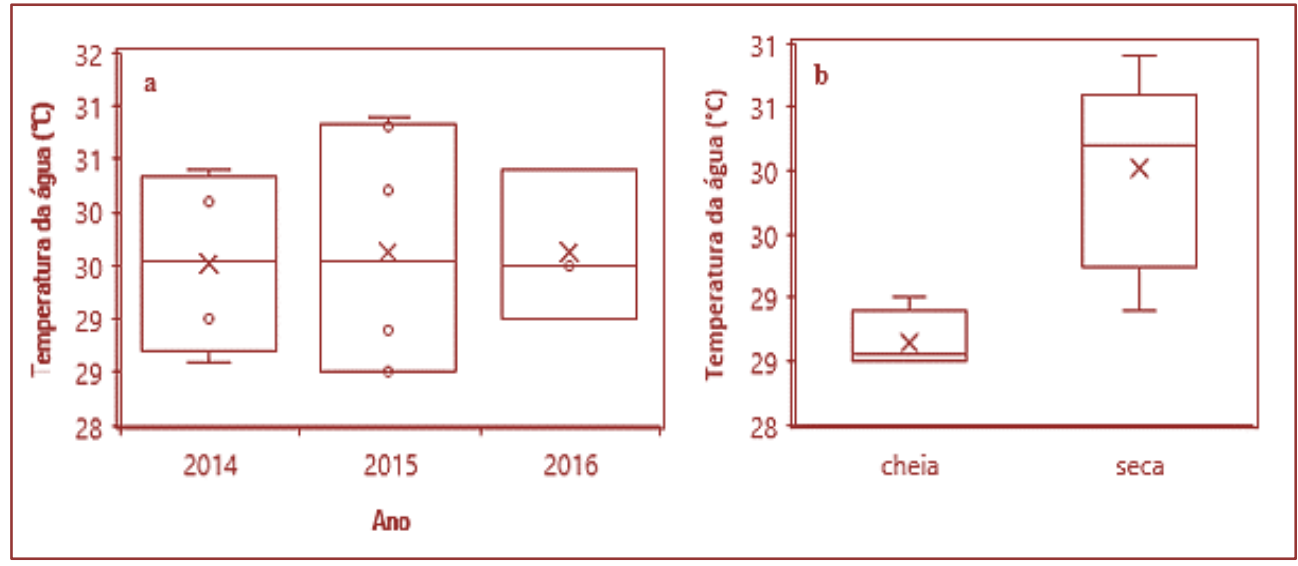

A precitação acumulada no ano de 2014 foi de 2528,7 mm e 1811,7 mm para Macapá e Óbidos, respectivamente (Figura 4a e 5a). Em 2015, os valores foram de 2421,8 mm e 1464,9 mm e em 2016, 2490 mm e 1530,4 mm. Considerando que o ciclo hidrológico é controlado pelo regime pluviométrico, obteve-se significativa variabilidade sazonal (Mann-Whitney p <0,05) com precipitação média na cheia de 341,87 \pm 211 mm em Macapá e 258,78 \pm 115,75 mm em Macapá. No período seco, a média foi de 124,92 \pm 141,76 mm em Macapá e 45,07 \pm 43,77 mm em Óbidos (Figura 4b e 5b).

As anomalias na temperatura da superfície do mar nos Oceanos Pacífico e Atlântico influenciam o volume e distribuição da precipitação e consequentemente a vazão dos rios na Bacia Amazônica (GAREL; D'ALIMONTE, 2017; MARENGO 2009; MARENGO et al., 2011; SCHÖNGART; JUNK 2007; VALE et al., 2016). Nesse sentido, a ocorrência dos eventos de El Niño e La Niña resultam em redução e aumento da precipitação na região (Cunha and Sternberg 2018; Vale et al. 2016). Entre 2015 e 2016 ocorreu um evento de El Niño de forte intensidade (JIMÉNEZ-MUÑOZ et al. 2016) que reduziu o volume de precipitação na região, como pode ser observado nas Figuras 4a e 5a.

Figura 4. Variação anual (a) e sazonal (b) da precipitação em Macapá para o período entre 2014 e 2016.

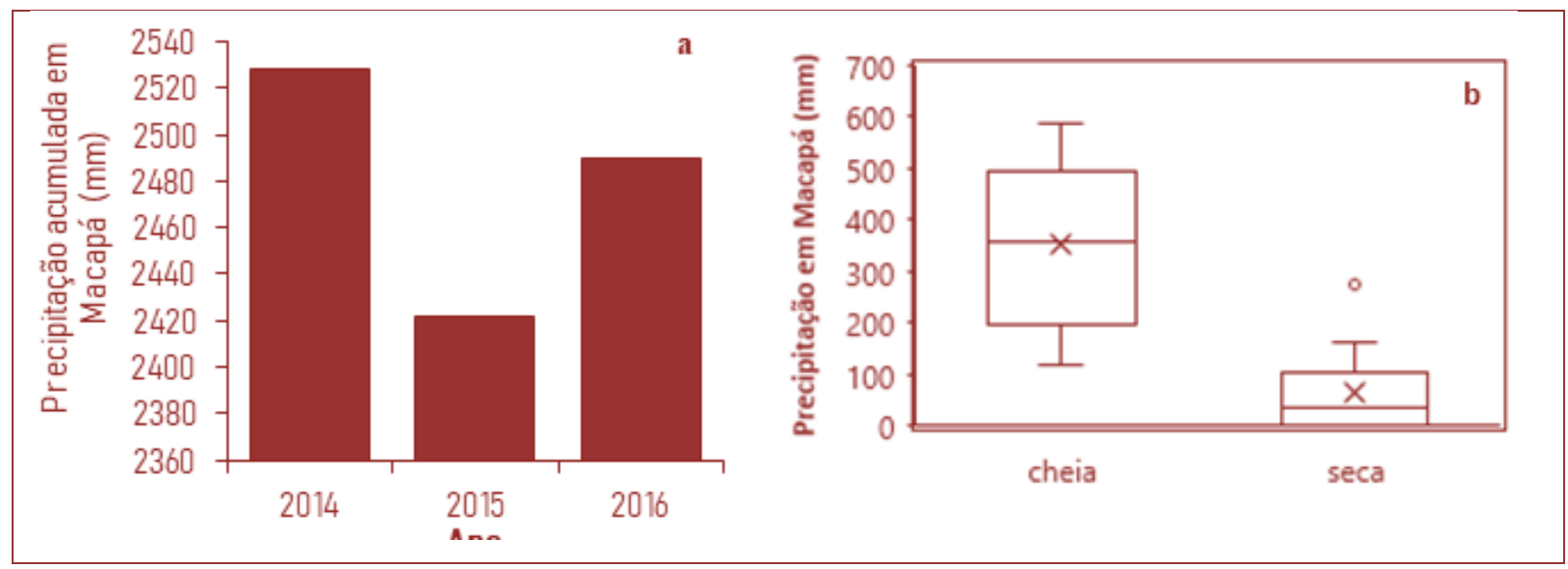


Figura 5. Variação anual (a) e sazonal (b) da temperatura da água no Canal Norte da Foz do Rio Amazonas para o período entre 2014 e 2016.

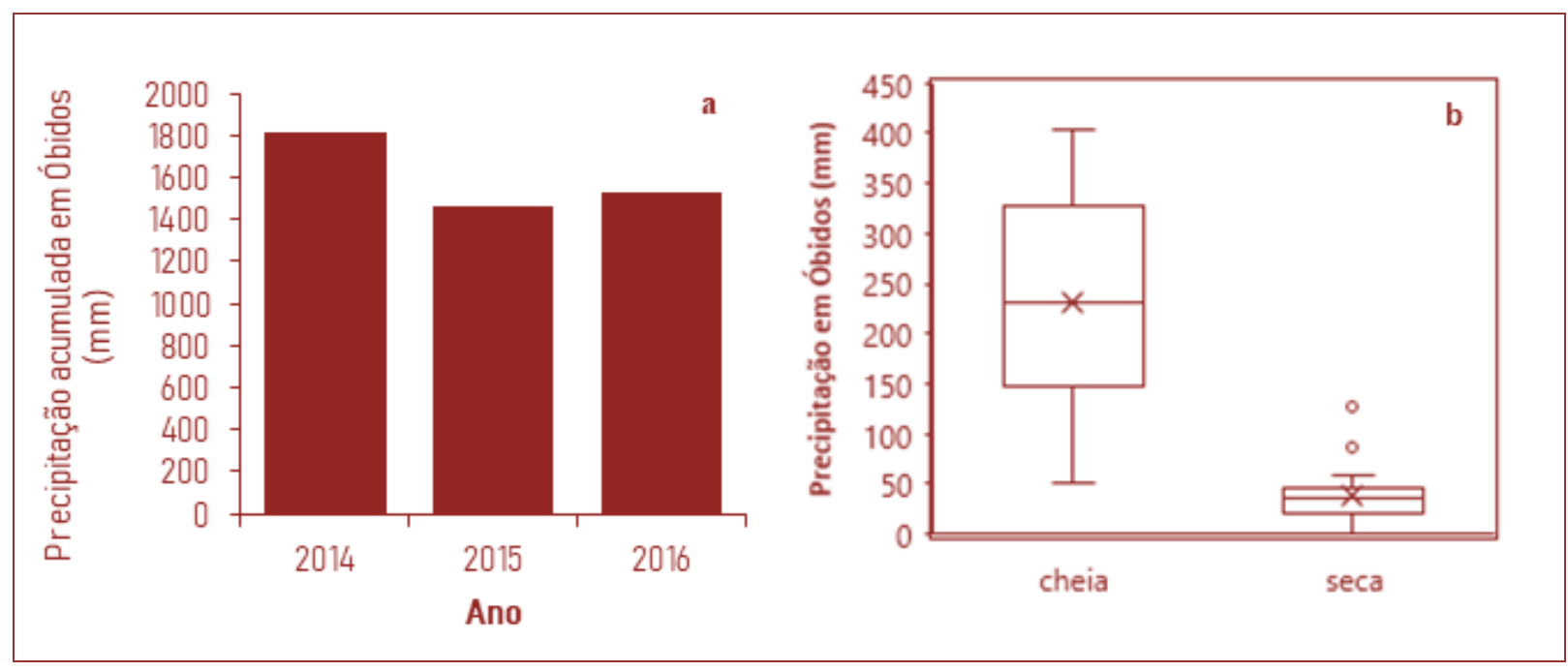

\subsection{RELAÇÃO ENTRE A PCO ${ }_{2}$, TEMPERATURA DA ÁGUA E PRECIPITAÇÃO}

Obteve-se correlação significativa forte entre todas as variáveis analisadas. Entre a $p \mathrm{CO}_{2}$ e a precipitação em Macapá e Óbidos os coeficientes de correlação foram positivos, $r s=0,87$ e $r s=0,81(\mathrm{p}<0,01)$, respectivamente (Figura $6 \mathrm{a}$ e b). Entre a $p \mathrm{CO}_{2}$ e a temperatura da água a relação foi negativa $(r s=-0,85, \mathrm{p}$ $<0,01$, Figura 6c), assim como a relação entre a temperatura e a precipitação, com $r s=-0,93$ para Macapá e $r s=-0,83$ para Óbidos $(\mathrm{p}<0,01)$.

A $p \mathrm{CO}_{2}$ do Rio Amazonas é caracterizada por um balanço dinâmico entre as entradas de $\mathrm{CO}_{2}$ provenientes principalmente da respiração da matéria orgânica no canal principal e na várzea e as saídas da produtividade primária in situ (ABRIL et al., 2014; RICHEY et al., 2002; SAWAKUCHI et al., 2017; WARD et al., 2018). Este balanço é diretamente influenciado pelo ciclo hidrológico que promove a variação sazonal da $\mathrm{pCO}_{2}$ (RICHEY et al., 2002; SAWAKUCHI et al., 2017), conforme observado no estudo, e também das emissões de $\mathrm{CO}_{2}$.

Figura 6. Relação entre a $p \mathrm{CO}_{2}$, precipitação em Macapá $\left(\mathrm{R}^{2}=0,65\right)$ e em Óbidos $\left(\mathrm{R}^{2}=0,58\right)$ e a temperatura da água $\left(R^{2}=-0,66\right)$.

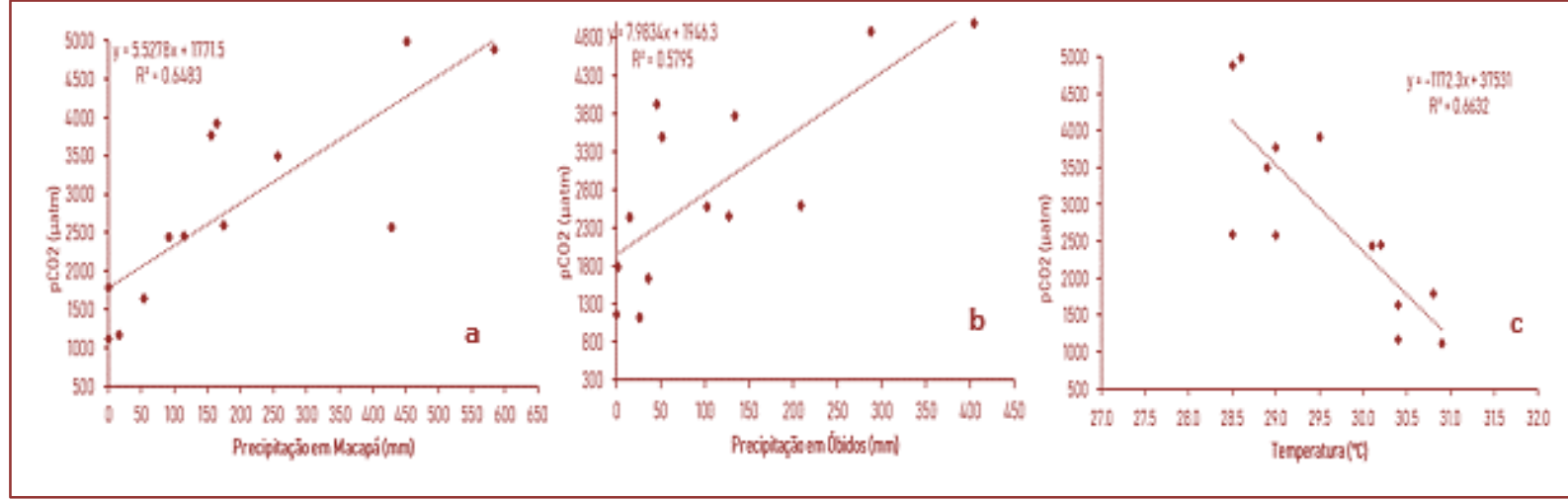

Nesse sentido, a relação significativa e positiva entre a $p \mathrm{CO}_{2}$ e a precipitação local e regional evidenciam que a mesma por meio do escoamento superficial, é o principal fator de entrada da matéria orgânica alóctone no canal principal do rio e consequentemente uma das variáveis controladoras mais importantes (GERMER et al., 2007; WARD et al., 2016).

Com relação a temperatura, a mesma pode reduzir a solubilidade dos gases (Lei de Henry) o que contribui para a menor $p \mathrm{CO}_{2}$ observada na estação seca (ALIN et al., 2011, LI et al., 2012, WARD et al., 2018). A 
relação negativa também foi obtida para a precipitação, na estação chuvosa ocorre uma redução na temperatura do ar que somada a maior vazão do rio ocasionam a diminuição da temperatura da água.

\section{CONCLUSÃO}

Constatou-se a variação sazonal da $p \mathrm{CO}_{2}$, precipitação e temperatura da água entre 2014 e 2016 no Canal Norte da Foz do Rio Amazonas. A p $\mathrm{CO}_{2}$ alcançou a maior média anual em 2016, com 3105,75 \pm 1273,92 $\mu a t m$, a média sazonal foi de 4057,35 $\pm 1124,34 \mu$ atm na cheia, sendo 1,8 vezes maior em comparação ao período seco. Em 2015 e 2016 a temperatura média anual $\left(29,63^{\circ} \mathrm{C}\right)$ foi levemente superior a de 2014 , na estação cheia a média foi de $30,02^{\circ} \mathrm{C}$, sendo $1,37^{\circ} \mathrm{C}$ superior ao período seco. A precipitação acumulada foi maior em 2014, com 2528,7 mm em Macapá e 1811,7 mm em Óbidos, evidenciando os efeitos da influência no El Niño entre 2015 e 2016.

A influência significativa da precipitação e da temperatura da água na $p \mathrm{CO}_{2}$ foi observada, conforme o esperado. As variáveis apresentaram correlação significativa forte, corroborando os efeitos da precipitação e consequentemente do escoamento superficial no transporte de matéria orgânica alóctone para o ambiente aquático e na redução da temperatura da água no período da cheia. Na seca observou-se a redução na $p \mathrm{CO}_{2}$ que pode estar relacionada ao menor aporte de matéria orgânica e ao aumento da temperatura da água.

A precipitação e a temperatura da água variáveis se mostraram importantes controladoras da concentração de $\mathrm{CO}_{2}$ na Foz do Rio Amazonas, sendo extremamente relevantes para o entendimento do papel dos rios nos ciclos regionais e globais do carbono. Diante disso, é necessário a realização de avaliações a longo prazo para a quantificação e o entendimento aprofundado das relações entre as mesmas.

\section{REFERÊNCIAS}

[1] ABRIL, G. et al. Amazon River carbon dioxide outgassing fuelled by wetlands. Nature, v. 505, p. 395-398, 2014.

[2] ALIN, S. R. et al. Physical controls on carbon dioxide transfer velocity and flux in low gradient river systems and implications for regional carbon budgets. Journal of Geophysical Research, v. 116, n. 1, p. 17, 2011.

[3] BRITO, D. C. Balanço de carbono e modelagem de fluxos biogeoquímicos no continuum do estuário amazônico. Tese (doutorado em Biodiversidade Tropical), Universidade Federal do Amapá-UNIFAP, Macapá-AP, 2013. $126 \mathrm{p}$.

[4] COLE, J. J. et al. Plumbing the Global Carbon Cycle: Integrating inland waters into the terrestrial carbon budget. Ecosystems, v. 10, n. 1, p. 172-185, 2007.

[5] FRANKIGNOULLE, M.; BORGES, A.; BIONDO, R. A new design of equilibrator to monitor carbon dioxide in highly dynamic and turbid environments. Water Research, v. 35, p. 1344-1347, 2001.

[6] GAREL E.; D'ALIMONTE D. Continuous river discharge monitoring with bottom-mounted current profilers at narrow tidal estuaries. Continental Shelf Research, v. 133, p. 1-12, 2017.

[7] INSTITUTO NACIONAL DE METEOROLOGIA - INMET. Média histórica da precipitação (1981 a 2010), Disponível: http://www.inmet.gov.br/portal/index.php?r=clima/normaisclimatologicas. Acesso em out. 2020.

[8] KIM, J.; ZELL, C. et al. Tracing soil organic carbon in the lower Amazon River and its tributaries using GDGT distributions and bulk organic matter properties. Geochimica et Cosmochimica Acta, v. 90, p. 163-180, 2012.

[9] LE QUÉRÉ, C. et al. Global carbon budget 2014. Earth System Science Data, v. 7, n. 1, p. 47-85, 2015.

[10] LI, S. et al. $\mathrm{CO}_{2}$ partial pressure and $\mathrm{CO}_{2}$ emission in the Lower Mekong River. Journal of Hydrology, v. 504, p. 40-56, 2012.

[11] MALHI, Y.; GRACE, J. Tropical forests and atmospheric carbon dioxide. TREE, v. 15, p. 333-337, 2000.

[12] MARENGO, J. A. Long-Terms trends and cycles in the hydrometeorology of the Amazon basin since the late 1920s. Hidrologycal Process, v. 23, p. 3236-3244, 2009.

[13] MARENGO J.A et al. Extreme climatic events in the Amazon basin. Theoretical and Applied Climatology, v. 107, p. 73-85, 2011.

[14] MEDEIROS, P. M. Fate of Amazon River dissolved organic matter in the Tropical Atlantic Ocean. Biogeochemistry Cycles, v. 29, n. 5, p. 677-690, 2015. 
[15] MOREIRA TURCQ, P. et al. Carbon sedimentation at Lago Grande de Curuai, a floodplain lake in the low Amazon region: insights into sedimentation rates. Palaeogeography, Palaeoclimatology, Palaeoecology, v. 214, n. 1-2, p. 27-40, 2004.

[16] NNOBY, R. Carbon cycle: Inside the Black Box. Nature, 388, 522-523, 1997. http://dx.doi.org/10.1038/41441.

[17] ORGANIZAÇÃO METEOROLÓGICA MUNDIAL - OMM. Greenhouse gas concentrations surge to new record (2016). Disponível em: https://public.wmo.int/en/media/press-release/greenhouse-gas-concentrations-surge-newrecord. Acesso em jan. 2020

[18] RASERA, M. F. F. L. et al. Estimating the Surface Area of Small Rivers in the Southwestern Amazon and Their Role in CO2 Outgassing. Earth Interactions, v. 12, p. 1-16, 2008.

[19] RICHEY, J. E. et al. Outgassing from Amazonian rivers and wetlands as a large tropical source of atmospheric CO2. Nature, v. 416, p. 617-620, 2002.

[20] SAWAKUSCHI, H. O. et al. Carbon dioxide emissions along the lower Amazon River. Frontiers in Marine Sciences, v. 4, 2017

[21] SCHÖNGART J., JUNK W. J. Forecasting the Flood-Pulse in Central Amazonia by ENSO-Índices. Journal of Hidrology, v. 335, n. 1, p.:124-132, 2007.

[22] VALE R.S. et al. Hydroclimatic variables associated with El Nino and La Nina events at the Curuá-Una hydroelectric reservoir, Central Amazonia. Acta Amazonica, v. 46, n. 3, p. 303-308, 2016.

[23] WARD, N. D. et al. Degradation of terrestrially derived macromolecules in the Amazon River. Nature Geoscience, v. 9, p. 1-8, 2013.

[24] WARD, N. D. et al. The compositional evolution of dissolved and particulate organic matter along the lower Amazon River-Óbidos to the ocean. Marine Chemistry, n. 177, p. 244-256, 2015.

[25] WARD, N. D. et al. Velocity-amplified microbial respiration rates in the lower Amazon River. Limnology and Oceanography, v.3, n. 3, p 265-274, 2018. 


\section{Capítulo 6}

\section{Análise de dados de precipitação de uma estação pluviométrica particular em relação aos dados da rede pública}

\section{Gabriel Rodrigues Barreto \\ Adriano Augusto de Miranda}

Resumo: As inundações são um problema recorrente no Brasil, um agravante do problema é a falta de dados sobre as precipitações, esse fator agravante pode ser atenuado através do uso de estações pluviométricas particulares. Muitas estações possuem falhas em seus dados que devem ser corrigidas para que possam ser utilizadas e alguns dados não são confiáveis para serem usados como base para planejamento de medidas de proteção contra inundações, examinando uma estação particular e utilizando o método da ponderação regional para corrigir suas falhas, foi possível analisar sua confiabilidade através de comparação com estações de órgãos públicos que se encontravam na mesma região. Mesmo fazendo correções nos dados e considerando a diferença percentual descrita pelo fabricante para o modelo da estação particular os valores em relação aos dados da estação pública se encontram em 89\% dos meses com diferenças acima da descrita, com base nisso os dados não são confiáveis. Para que se possa entender se esse é um caso isolado ou outras estações particulares também não são recursos confiáveis é necessário um estudo complementar.

Palavras-Chave: Pluviômetro, pluviômetro particular, pluviômetro de rede pública. 


\section{INTRODUÇÃO}

Atualmente no Brasil as inundações são um problema bem comum no cotidiano das pessoas, sendo responsável por grande parte dos mortos e perdas patrimoniais em desastres naturais no Brasil. Segundo Monteiro e Kobiyama (2014), para se minimizar os desastres é necessário realizar o mapeamento de risco de inundações, mas existe falta de dados sobre o clima o que inclui a falta de dados sobre precipitação.

Com base nesse problema, o objetivo desse trabalho é o exame e a correção dos dados de uma estação pluviométrica particular, para que se possa determinar se os dados desse tipo de aparelho são confiáveis para se realizar as análises necessárias para o planejamento de medidas de proteção contra inundações, como esclarecido por Back et al(2017) a identificação de possíveis alterações nos registros meteorológicos é de grande importância para os estudos de engenharia pois tanto simulações quanto teorias estatísticas de probabilidade levam em conta que os dados devem ser homogêneos .

\section{METODOLOGIA}

Todos os dados recolhidos das estações pluviométricas se encontram dentro do estado do Paraná e segundo o Instituto das Águas do Paraná dentro da área de influência da bacia de Balsa Nova.

Para que se pudessem analisar os dados, foi necessário decidir qual seria a referência para a verificação de proximidade com a realidade da precipitação na região, como o estudo foi realizado na região de Curitiba no Paraná e o órgão INMET (Instituto Nacional de Meteorologia) possui uma estação meteorológica instalada dentro da cidade essa foi escolhida como referência.

Como era crucial se encontrar uma estação pluviométrica particular na mesma região que possuísse dados referentes às chuvas, foi utilizado como caso de estudo uma estação meteorológica com essa qualidade no bairro Ahú dentro de Curitiba, logo após isso, 3 anos e 2 meses de dados foram recolhido de ambas as fontes citadas e os devidos ajustes necessários foram realizados, alguns dos dados de cada estação estavam em falta por isso foi utilizado o método de ponderação regional que possibilitou o preenchimento dos valores faltantes, esse método possui a seguinte equação:

$$
y=\frac{1}{3}\left[\frac{x 1}{x m 1}+\frac{x 2}{x m 2}+\frac{x 3}{x m 3}\right] y m
$$

$\mathrm{y}=$ Precipitação do posto a ser estimada (mm);

$\mathrm{x} 1, \mathrm{x} 2, \mathrm{x} 3$ = Precipitações correspondentes das estações vizinhas em relação ao mês que se quer preencher; $\mathrm{xm} 1, \mathrm{xm} 2, \mathrm{xm} 3$ = Precipitações médias das estações vizinhas;

ym = Precipitação média da estação que se quer preencher.

Para garantir que os dados obtidos estavam de acordo com a realidade da precipitação da região foram recolhidos também dados das mesmas datas em diferentes estações pluviométricas espalhadas pela região que foram armazenados pelo SIMEPAR e que contribuíram para melhorar a precisão do método.

A estação particular em estudo é um equipamento importado e por isso seus dados se encontram em polegadas que é o sistema de medição americano, foi necessário se fazer a transformação desses dados para o sistema de unidades utilizado no Brasil, foram recolhidos dados diários que para poderem ser analisados foram transformados em valores mensais. Depois de todo esse tratamento para adequar os dados, para que se pudessem analisar os dados da estação foram usados às precipitações médias de cada uma dessas estaç̃oes, o método da dupla massa desenvolvido pelo Geological Survey (USA), o erro percentual de cada uma delas em relação à precipitação média da estação de referência e foram criados gráficos de comparação para facilitar o exame dos dados.

Os dados também foram examinados para descobrir se a diferença entre as estações era maior do que a descrita pelo fornecedor da estação privada, existe um erro percentual ligado ao posicionamento da estação meteorológica e as redondezas dessa posição, o local em que a estação foi posicionada foi visitado e conforme o guia de instrumentos meteorológicos e métodos de observação da organização meteorológica mundial foi examinado o erro que esse posicionamento poderia acarretar aos dados recolhidos. 


\section{RESULTADOS}

Os dados que primeiro foram recolhidos foram os da estação de referência na área de estudos, a estação possui os seguintes dados:

Tabela 1 - Dados da estação pluviométrica do INMET

\begin{tabular}{|c|c|c|c|c|c|c|c|c|c|c|c|c|}
\hline jul/16 & ago/16 & set/16 & out/16 & nov/16 & dez/16 & jan/17 & fev/17 & mar/17 & abr/17 & mai/17 & jun/17 \\
\hline 114,3 & 172,3 & 95 & 172,1 & 102,7 & 76 & 191,2 & 86,7 & 40 & 69 & 88,1 & 181,3 \\
\hline jul/17 & ago/17 & set/17 & out/17 & nov/17 & dez/17 & jan/18 & fev/18 & $\mathrm{mar} / 18$ & abr/18 & $\mathrm{mai} / 18$ & jun/18 \\
\hline 7,8 & 92,9 & 36,2 & 212,2 & 129,4 & 144,8 & 371,9 & 96,8 & 327,6 & 23,2 & 27,4 & \\
\hline jul/18 & ago/18 & set/18 & out/18 & nov/18 & dez/18 & jan/19 & fev/19 & $\mathrm{mar} / 19$ & abr/19 & $\mathrm{mai} / 19$ & jun/19 \\
\hline & 46,9 & 58,4 & 250,2 & 57,3 & 114,7 & 190,6 & 301,2 & 67,4 & 119,3 & 206 & 123,1 \\
\hline jul/19 & ago/19 & & & & & & & & & & \\
\hline 12,4 & 35,5 & & & & & & & & & & \\
\hline
\end{tabular}

Dois meses de dados da estação como pode se ver na tabela 1 não possuíam dados, para completar essas falhas foram recolhidos os dados de outras estações próximas que foram utilizadas para melhorar o método de ponderação regional, todas as estações utilizadas se encontram na tabela 2:

Tabela 2 - Estações pluviométricas

\begin{tabular}{|l|c|c|c|c|}
\multicolumn{1}{c|}{ Pluviômetro } & \multicolumn{1}{c|}{ Código } & \multicolumn{1}{c|}{ Latitude } & Longitude & Altitude \\
\hline Estação INMET & 83842 & $-25,45$ & $-49,23$ & 923,25 \\
\hline Estação privada - Ahú & - & $-25,4$ & $-49,26$ & 930,86 \\
\hline Mandirituba - Copel & 2549062 & $-25,77$ & $-49,32$ & 920 \\
\hline Quatro Barras & 2549042 & $-25,37$ & $-49,07$ & 936 \\
\hline Colombo - Copel & 2549090 & $-25,29$ & $-49,23$ & 977 \\
\hline
\end{tabular}

Alguns dados de cada uma das estações também estavam em falta o mesmo método foi utilizado para que se pudesse encontrar o valor mais próximo da realidade, após os ajustes se chegou aos resultados descritos na tabela 3 para os meses em falta da estação do INMET:

Tabela 3 - Dados descobertos pelo método de ponderação regional

\begin{tabular}{|l|l|}
\hline Jun/2018 & Jul/2018 \\
\hline 49,35522 & 4,498301 \\
\hline
\end{tabular}

Após encontrar os valores que faltavam em cada estação, foi o momento da estação pluviométrica do Ahú ser examinada, os seus dados recolhidos estavam em polegadas e foram transformados em milímetros e são os seguintes:

Tabela 4 - Dados recolhidos da estação privada

\begin{tabular}{|c|c|c|c|c|c|c|c|c|c|c|c|}
\hline jul/16 & ago/16 & set/16 & out/16 & nov/16 & dez/16 & jan/17 & fev/17 & mar $/ 17$ & abr $/ 17$ & mai/17 & jun/17 \\
\hline 1,016 & 2,286 & 3,048 & 27,178 & 85,09 & 101,854 & 226,568 & 81,534 & 33,02 & 2,286 & 1,016 & 2,42914 \\
\hline jul/17 & ago/17 & set/17 & out/17 & nov/17 & dez/17 & jan/18 & fev/18 & mar/18 & abr $/ 18$ & mai/18 & jun/18 \\
\hline 1,27 & 0,762 & 2,54 & 10,6806 & 108,204 & 257,048 & 248,288 & 87,122 & 125,73 & 0 & 0,254 & 2,032 \\
\hline jul/18 & ago/18 & set/18 & out/18 & nov/18 & dez/18 & jan/19 & fev/19 & mar/19 & abr/19 & mai/19 & jun/19 \\
\hline 1,27 & 3,048 & 73,914 & 313,976 & 190,715 & 123,698 & 375,92 & 202,946 & 54,2943 & 126,492 & 196,088 & 31,496 \\
\hline jul/19 & ago/19 & & & & & & & & & & \\
\hline 21,59 & 77,724 & & & & & & & & & & \\
\hline
\end{tabular}


Depois de recolhidos os dados era necessário descobrir qual o valor do erro possível que estaria acumulado nesses dados, com o modelo da estação pluviométrica que era WS-1400-IP, foi possível encontrar seus detalhes, segundo o fabricante o erro percentual de uma leitura deveria ser de aproximadamente $10 \%$.

Recolhidos os dados e completados foi verificado o erro percentual entre as precipitações de cada mês, que revelaram o seguinte resultado:

Tabela 5 - Erro percentual mensal

\begin{tabular}{|c|c|c|c|c|c|c|c|c|c|c|c|}
\hline \multicolumn{12}{|c|}{ Erro percentual } \\
\hline jul/16 & ago/16 & set/16 & out/16 & nov/16 & $\mathrm{dez} / 16$ & jan/17 & fev/17 & mar/17 & $\mathrm{abr} / 17$ & $\mathrm{mai} / 17$ & jun/17 \\
\hline $99 \%$ & $99 \%$ & $97 \%$ & $84 \%$ & $17 \%$ & $-34 \%$ & $-18 \%$ & $6 \%$ & $17 \%$ & $97 \%$ & $99 \%$ & $99 \%$ \\
\hline jul/17 & ago/17 & set/17 & out/17 & nov/17 & $\mathrm{dez} / 17$ & jan/18 & fev/18 & mar/18 & abr/18 & mai/18 & jun/18 \\
\hline $84 \%$ & $99 \%$ & $93 \%$ & $95 \%$ & $16 \%$ & $-78 \%$ & $33 \%$ & $10 \%$ & $62 \%$ & $100 \%$ & $99 \%$ & $96 \%$ \\
\hline jul/18 & ago/18 & set/18 & out/18 & nov/18 & $\mathrm{dez} / 18$ & jan/19 & fev/19 & mar/19 & abr/19 & $\mathrm{mai} / 19$ & jun/19 \\
\hline $72 \%$ & $94 \%$ & $-27 \%$ & $-26 \%$ & $-233 \%$ & $-8 \%$ & $-97 \%$ & $33 \%$ & $19 \%$ & $-6 \%$ & $5 \%$ & $74 \%$ \\
\hline jul/19 & ago/19 & & & & & & & & & & \\
\hline$-74 \%$ & $-119 \%$ & & & & & & & & & & \\
\hline
\end{tabular}

Examinando os erros percentuais era possível notar uma diferença muito grande acima de $10 \%$ em mais de $89 \%$ dos dados, o próximo passo foi gerar um gráfico para que se conseguisse examinar visualmente a distribuição dos dados.

Gráfico 1- Precipitação INMET x Ahu.

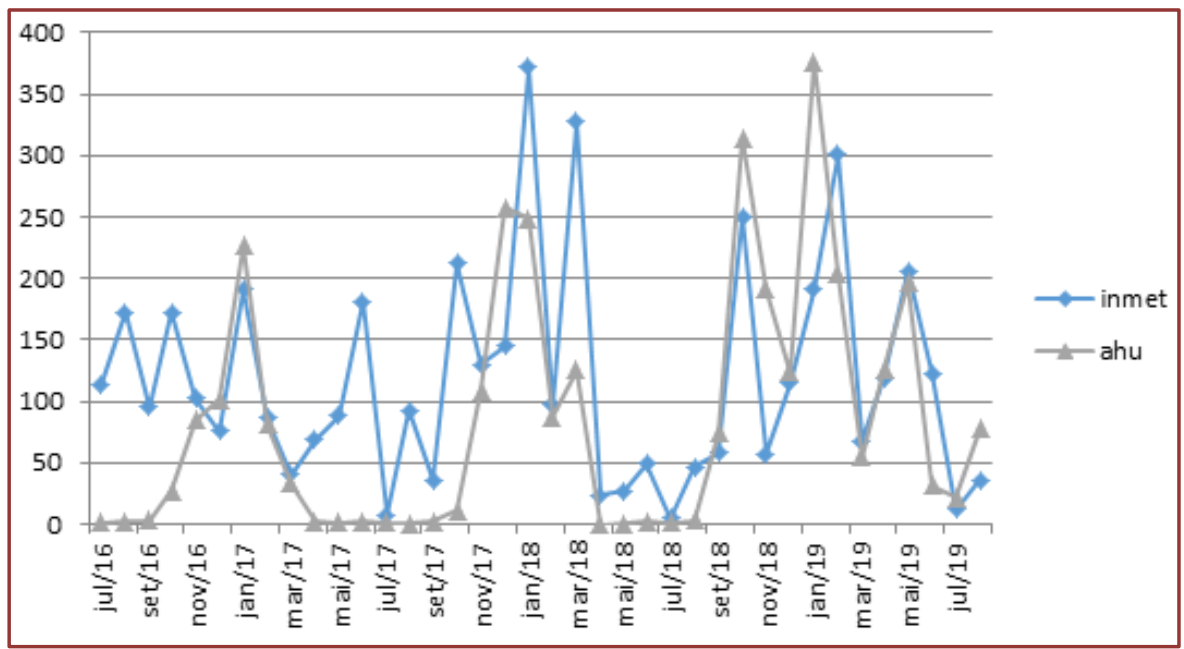

Com a ajuda do gráfico foi possível verificar que os dados seguiam a mesma forma, estavam sujeitos às mesmas condições registrando precipitações mais altas nas mesmas épocas e registrando menores precipitações em épocas de menor precipitação.

Após examinar o gráfico visualmente, a precipitação média para cada estação foi calculada, e os seguintes resultados foram encontrados.

Tabela 6 - Precipitação média e erro percentual.

\begin{tabular}{|l|c|c|} 
& \multicolumn{1}{|c|}{$\begin{array}{c}\text { Precipitação } \\
\text { média (mm) }\end{array}$} & $\begin{array}{c}\text { Erro percentual } \\
(\%)\end{array}$ \\
\hline INMET & 117,01 & $0 \%$ \\
\hline Ahú & 84,33 & $27,93 \%$ \\
\hline
\end{tabular}


Considerando um erro de $10 \%$ que é descrito como sendo o erro percentual da estação e ajustando os valores para essa margem de erro com o objetivo de aproximar os valores, temos que o erro percentual diminui para:

Tabela 7 - Precipitação média e erro percentual corrigido.

\begin{tabular}{|c|c|c|}
\multicolumn{2}{|c|}{$\begin{array}{c}\text { Precipitação } \\
\text { média (mm) }\end{array}$} & $\begin{array}{c}\text { Erro percentual } \\
(\%)\end{array}$ \\
\hline INMET & 117,01 & $0 \%$ \\
\hline Ahú & 92,76 & $20,73 \%$ \\
\hline
\end{tabular}

Utilizando o método da dupla massa, considerando a média acumulada dos dados recolhidos de todas as estações, foi possível gerar o seguinte gráfico para a estação do INMET.

Gráfico 2 - Relação entre precipitação acumulada da Estação INMET x Média das estações.

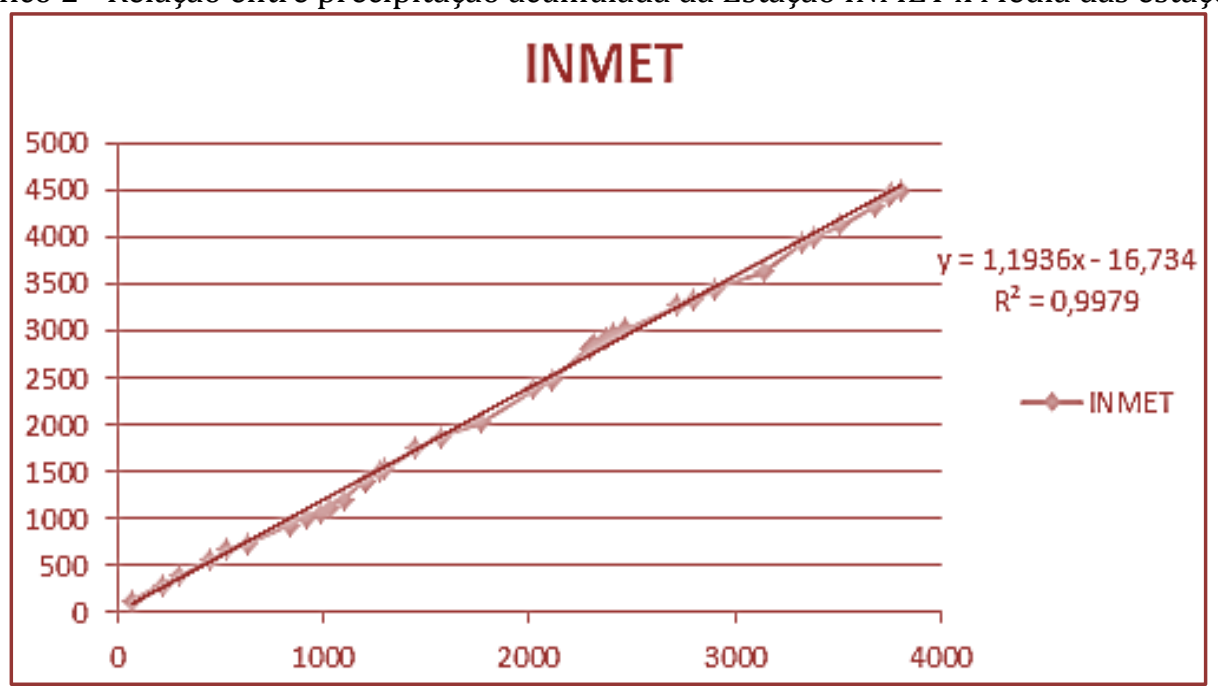

Examinando o gráfico é possível entender que pelo método da dupla massa essa é uma série histórica de dados sem inconsistências e observando o coeficiente $\mathrm{R}^{2}$ de uma regressão linear podemos notar uma pequena variabilidade nos dados, utilizando o mesmo método para examinar os dados da estação no Ahú temos o seguinte resultado:

Gráfico 3 - Relação entre a precipitação acumulada da estação Ahú x Média das estações.

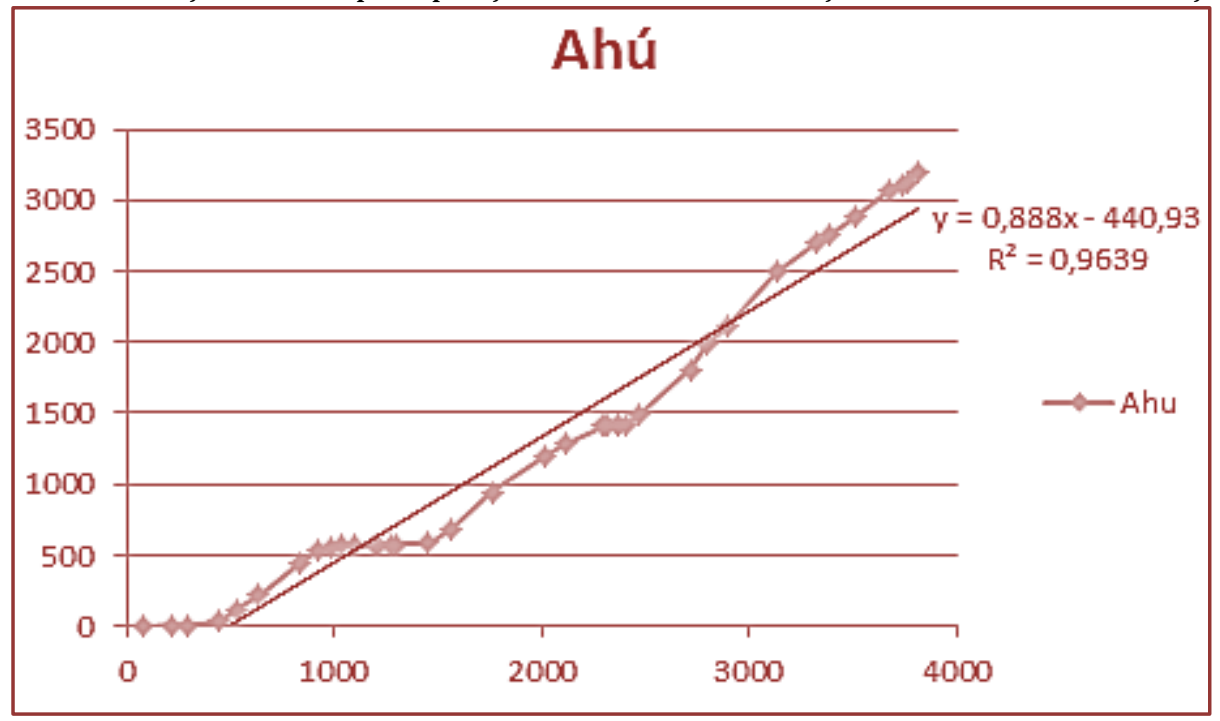


Examinando os dados utilizando o mesmo método utilizado no gráfico anterior, temos como resultado que pode haver erros de transcrição ou diferentes regimes acontecendo, em relação ao coeficiente $\mathrm{R}^{2}$ pode-se notar uma variabilidade maior entre os dados da estação do Ahú.

Foi também examinado o local e a forma como a estação se encontrava instalada, indo até o local e retirando as medidas necessárias, o local pode ser visto na figura 1.

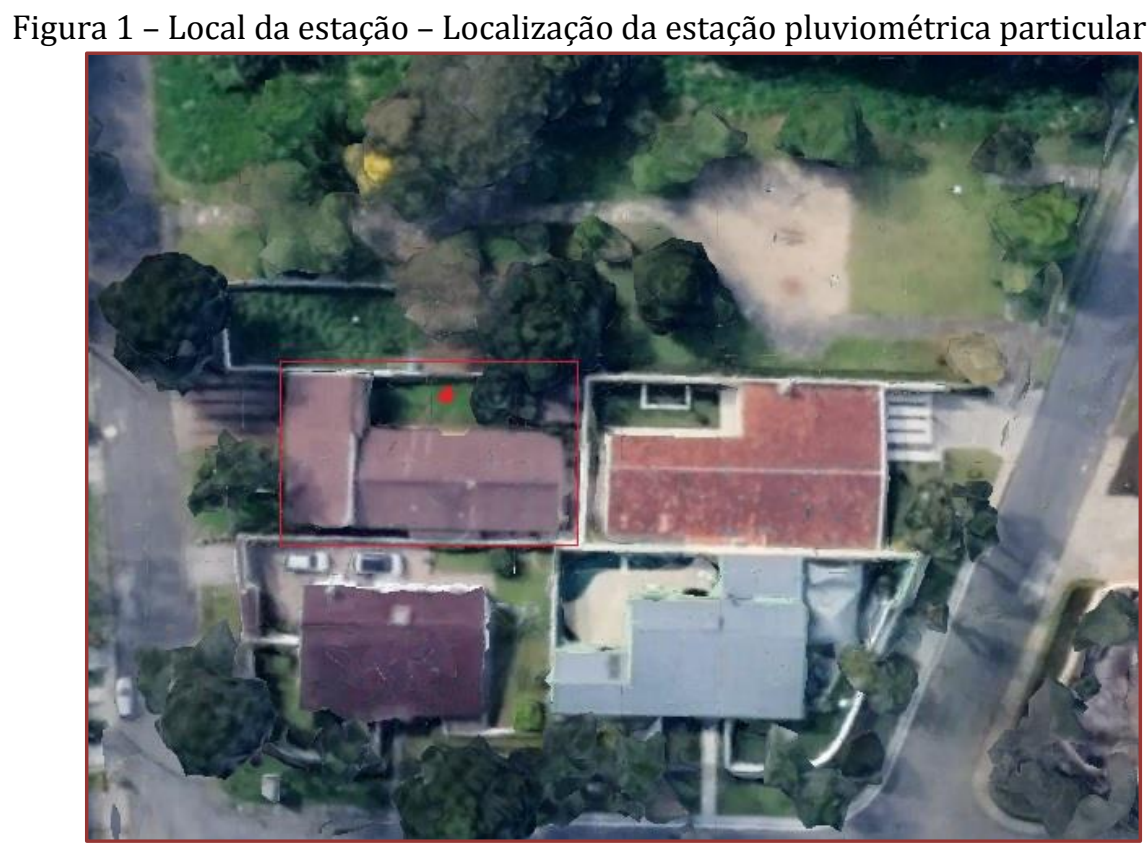

Com base no guia de instrumentos meteorológicos e métodos de observação da organização meteorológica mundial foi possível classificar o posicionamento da estação e o erro que essa forma de instalação poderia acarretar nas medidas, com relação à medição da chuva está estação pluviométrica visitada está a aproximadamente 2,3 metros em relação ao chão, o ângulo formado com os obstáculos mais próximos que são a casa e uma árvore no quintal são aproximadamente $22^{\circ}$ e $14^{\circ}$. Baseado nas informações a relação entre as distâncias e alturas dos obstáculos se encontram dentro do intervalo de classificação da classe 1 para medição de precipitação descrita no manual. Equipamentos da classe 1 não possuem incerteza em seus dados relacionada a sua forma de instalação.

\section{CONCLUSÃO}

Os dados da estação em estudo que foram analisados mostraram uma variação em torno do valor real maior do que o valor indicado de pelo fabricante de $10 \%$, mesmo a precipitação média anual possui um erro superior ao descrito pelo fabricante, mesmo ajustando os dados conforme o erro possível à diferença entre o valor real e os dados passa muito do descrito, embora as precipitações indicadas sejam muito distantes da realidade da precipitação podem ser usadas para identificar os períodos de menor ou maior precipitação na bacia em que o aparelho foi instalado, essa diferença pode ser um caso isolado e pode estar relacionada a forma como o aparelho registra a precipitação ou a algum componente defeituoso em um estudo complementar com dados de mais estações particulares e de órgãos públicos poderia se identificar se o erro percentual da estação estudada é comum a outras estações do mesmo tipo, com base no que foi descoberto os dados da estação pluviométrica em estudo não são confiáveis para o uso em estudos de engenharia. 


\section{REFERÊNCIAS}

[1] AGUASPARANÁ/SIMEPAR. Dados Horários das Estações Pluviométricas. Disponível em: <http://www.simepar.br/aguasparana/relatorios/estacoes/horaria/pluviometricas.shtml>.Acesso em: 8 de Setembro de 2019.

[2] BACK, A. J. Et.al. Análise de tendências nas séries de precipitação das regiões hidrográficas de Santa Catarina. XXII Simpósio Brasileiro de Recursos Hídricos, 2017.

[3] INMET. Dados de precipitação diária da estação 83842 - Curitiba - Paraná. Disponível em: <http://www.inmet.gov.br/projetos/rede/pesquisa/mapas_c_diario.php>.Acesso em: 21 de Setembro de 2019.

[4] MONTEIRO, R.L.; KOBIYAMA, M.(2014). Influências da distribuição temporal de precipitação no mapeamento de inundação. Revista de Gestão de Água da América Latina, v.11, n.2, p. 25-35.

[5] TUCCI, Carlos E. M. Hidrologia: ciência e aplicação. 4. ed. Porto Alegre: Ed. da UFRGS, 2013. 943 p. (Coleção ABRH de recursos hídricos ; v. 4) ISBN 978-85-7025-924-0 (broch.)

[6] WORLD METEOROLOGICAL ORGANIZATION. Guide to Meteorological Instruments and Methods of Observation. 2014. ed. Geneva. 1166 p. ISBN 978-92-63-10008-5. p 34-35. 


\section{Capítulo 7}

Variabilidade e tendências de padrões de chuva na bacia do Riacho Jatobá, Pernambuco

\section{Aline Maria Soares das Chagas}

Abelardo Antônio de Assunção Montenegro

Thayná Alice Brito Almeida

Resumo: As regiões semiáridas são marcadas pela elevada variabilidade e irregularidade dos eventos chuvosos, que impactam a disponibilidade hídrica. Desse modo, faz-se necessário um frequente monitoramento pluviométrico, e a investigação dos padrões temporais de chuva visando um melhor planejamento e gestão. Desta forma, o presente trabalho objetivou investigar o comportamento temporal das chuvas em bacia experimental no Agreste de Pernambuco, no período de 2000 a 2018, focando na disponibilidade pluviométrica ao longo do ano e em período usualmente adotado pelos agricultores para cultivo de sequeiro. Registros de 5 (cinco) pluviômetros foram considerados, e analisados totais precipitados e número de dias chuvosos, bem como a existência de tendências, com base no Método de Mann-Kendall e filtradas através do procedimento Trend-Free Pre-Whitening (TFPW). Verificou-se que não existem tendências de decréscimo do número totais de dias de chuva, entretanto o número de eventos que apresentam lâminas de precipitação maiores que 5 e $10 \mathrm{~mm}$ apresentaram padrão significativo de redução antes da utilização do filtro TFPW. Após a utilização do TFPW, as tendências foram consideradas não significativas, podendo-se concluir que não existe tendência para nenhuma lâmina avaliada. A avaliação isolada das tendências do número de número de dias de chuva no período chuvoso não apresentou tendência significativa na bacia estudada, sendo este um resultado satisfatório para a região local, não afetando calendário agrícola neste período.

Palavras-Chave: variabilidade, pluviometria, Mann-Kendall 


\section{INTRODUÇÃO}

O semiárido apresenta marcante irregularidade de chuvas, impactando a disponibilidade hídrica para os diversos usos nas bacias hidrográficas (Ferreira et al., 2017). Marengo et al. (2011) destacam que as elevadas dinâmicas no espaço e tempo das chuvas são típicas do semiárido do Nordeste brasileiro, e que têm sido agravadas pelas mudanças climáticas.

A caracterização de tais padrões de chuva, conforme Carvalho \& Ruiz (2016), influencia diretamente a disponibilidade de água, uma vez que a precipitação é usualmente a principal variável de entrada nos balanços hídricos. Neste contexto, a análise de séries temporais é de grande importância, possibilitando identificar tendências e oscilações de variáveis climáticas (Costa et al., 2013).

Carvalho et al. (2020) verificaram o agravamento da escassez hídrica no semiárido brasileiro, observandose diminuição nos totais pluviométricos e do número de dias chuvosos, impactando os balanços hídricos, e a umidade do solo.

Vários estudos hidrológicos têm sido desenvolvidos nas bacias hidrográficas do Agreste Pernambucano, alguns deles através de Redes Cooperativas, como a Rede REHISA (Rede de Hidrologia do Semiárido), reunindo diversas universidades da região Nordeste, para desenvolver estudos em bacias experimentais e representativas. Dentre as bacias experimentais adotadas, destaca-se a bacia do Jatobá, objeto de análise neste documento. Silva et al. (2013) investigaram os padrões de chuva na Bacia do Jatobá, enquanto que Silva et al. (2006) analisaram o comportamento das chuvas de alta intensidade. Estudos relacionados com a dinâmica de umidade do solo e de escoamento em parcelas experimentais localizadas na bacia foram desenvolvidos por Montenegro et al. (2019) e por Lopes e al. (2019).

Desse modo, o objetivo deste estudo é analisar a dinâmica temporal de chuvas na Bacia do Jatobá, de modo a verificar a disponibilidade hídrica em período usualmente adotado para plantio de sequeiro, entre março e junho.

\section{METODOLOGIA}

\section{1. ÁREA DE ESTUDO}

O estudo foi desenvolvido na Bacia Experimental do Riacho Jatobá, localizada no município de Pesqueira $\mathrm{PE}$, região Agreste do semiárido Pernambucano, situada entre as coordenadas $8^{\circ} 34^{\prime} 17^{\prime \prime}$ e $8^{\circ} 18^{\prime} 11^{\prime \prime}$ de Latitude Sul e $37^{\circ} 1^{\prime} 35^{\prime \prime}$ e $36^{\circ} 47^{\prime} 20^{\prime \prime}$ de Longitude Oeste (Figura 1). A microbacia do Jatobá está inserida na Bacia representativa do Riacho do Mimoso, pertencente ao rio Ipanema, e possui uma extensão de 6,6 $\mathrm{km}$, uma área de 13,50 $\mathrm{km}^{2}$ e um perímetro de $16 \mathrm{~km}$, tendo sido estabelecida e instrumentada no ano de 2000, no âmbito da Rede REHISA, e sendo monitorada pelo Laboratório de Água e Solo da UFRPE.

O clima da região é BSsh, semiárido, muito quente, segundo a classificação de Köppen, com precipitação média anual de aproximadamente $600 \mathrm{~mm}$, temperatura média de $23 \stackrel{\circ}{\circ} \mathrm{C}$ e evapotranspiração de referência (ETr) de cerca de $2.000 \mathrm{~mm}$ por ano (Silva Júnior et al., 2016). 0 período chuvoso ocorre entre os meses de fevereiro a julho, e o período seco de agosto a janeiro (SILVA et al., 2013). 
Figura 1. Localização da Bacia Experimental do Riacho do Jatobá, Pesqueira-PE. Imagem do pluviógrafo 2 e de plantio de sequeiro, próximo ao pluviógrafo 1.
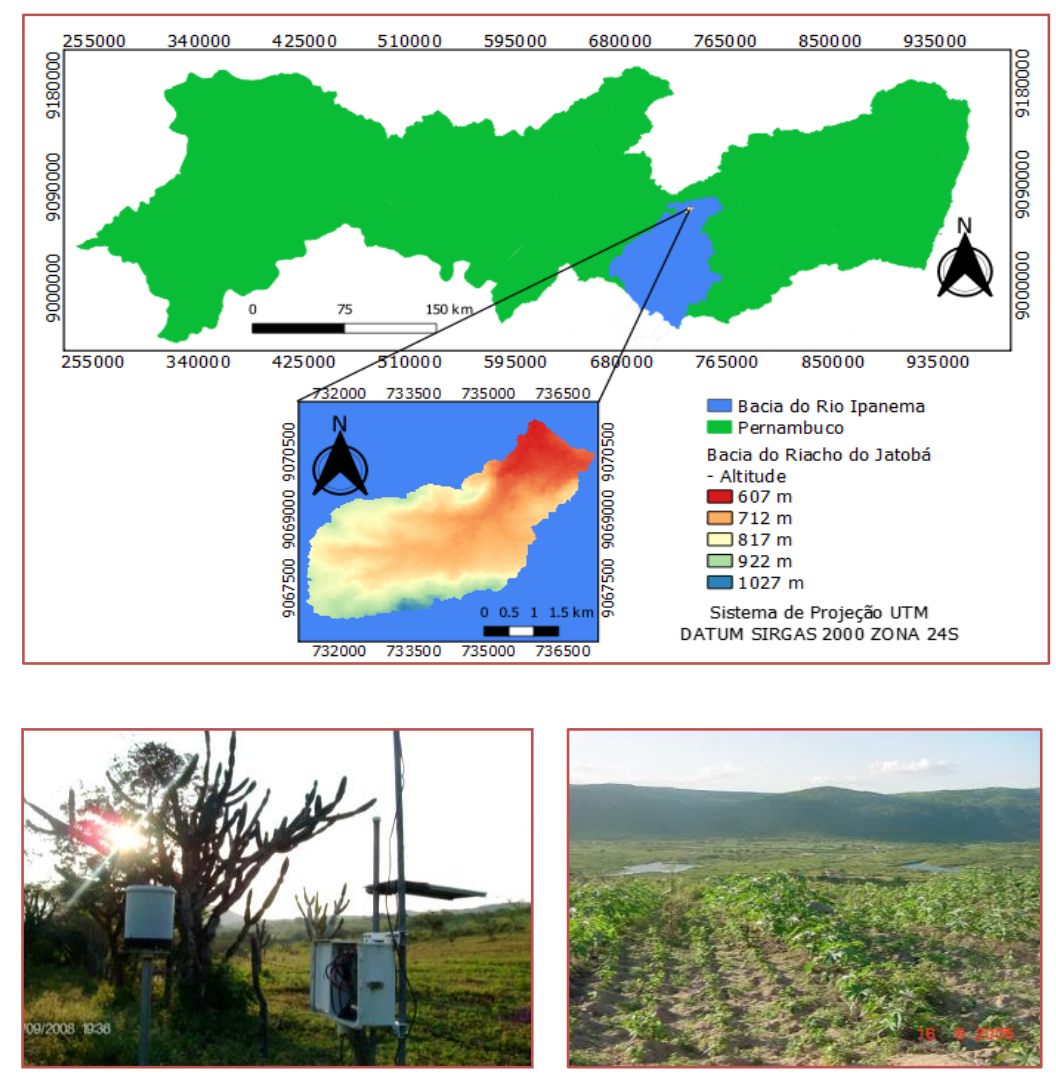

\section{COLETA DE DADOS}

Para o presente estudo foram adotadas estações pluviométricas distribuídas em cinco postos, conforme coordenadas apresentadas na Tabela 1. Foram analisados registros diários e mensais de 3 pluviógrafos automáticos (modelo Campbell Scientific), 1 pluviômetro manual tipo Ville de Paris, e 1 pluviógrafo operado pelo Instituto Nacional de Meteorologia (INMET), no período de 2000 a 2018.

Tabela 8. Coordenadas das Estações de monitoramento pluviométrico.

\begin{tabular}{|c|c|c|c|c|c|}
\hline Monitoramento & $\begin{array}{c}\text { Pluviógrafo } \\
\text { automático } \\
\text { (PLUV 1) }\end{array}$ & $\begin{array}{c}\text { Pluviógrafo } \\
\text { automático } \\
\text { (PLUV 2) }\end{array}$ & $\begin{array}{c}\text { Pluviógrafo } \\
\text { automático } \\
\text { (PLUV 3) }\end{array}$ & $\begin{array}{l}\text { Pluviógrafo } \\
\text { INMET } \\
\text { (PLUV 4) }\end{array}$ & $\begin{array}{c}\text { Pluviômetro } \\
\text { (PLUV 5) }\end{array}$ \\
\hline Latitude (W) & $36 \div 51^{\prime} 50^{\prime \prime}$ & $36^{\circ}-52^{\prime} 30^{\prime \prime}$ & $36^{\circ}-53^{\prime} 42^{\prime \prime}$ & $37^{\circ} 4^{\prime} 48^{\prime \prime}$ & 36응' \\
\hline Longitude (S) & 824'47" & 825’19" & 825’37" & 824'36" & $8=25^{\prime} 26^{\prime \prime}$ \\
\hline Altitude (m) & 709 & 750 & 850 & 680,7 & 757 \\
\hline
\end{tabular}

\section{ANÁLISE DE DADOS}

Foram realizadas análises com as séries temporais diárias, e com o número de dias chuvosos e de precipitação acima ou igual $5 \mathrm{~mm}$ e $10 \mathrm{~mm}$ para uma distribuição mensal e anual, no período de 2000 a 2018 nos cinco posto monitorados. Foi avaliada também a dinâmica temporal da distribuição do número de dias chuvosos do período chuvoso, entre os meses de março e junho, por ser historicamente o período de maior atividade agrícola local, em função das festas regionais e da crença popular relacionada ao dia de São José, que marca o início do calendário agrícola de toda região. 
A análise de tendência foi realizada por meio do teste não paramétrico de Mann-Kendall (Eq. 1), cuja hipótese nula ( $\mathrm{H} 0)$ é de que os dados da série temporal não apresentam tendência, e na hipótese alternativa (HA), na qual os dados apresentam tendência na série temporal. 0 teste de tendência aponta se há tendência positiva ou negativa de acordo com o teste $\mathrm{S}$ para um determinado nível de confiança.

$$
\mathrm{S}=\sum_{k=1}^{n-1} \sum_{j=k+1}^{n} \operatorname{sgn}(\mathrm{x}(\mathrm{j})-\mathrm{x}(\mathrm{i}))
$$

sendo n é o número de pontos de dados, x(j) e x(i) são os valores de dados da série temporal.

Cada ponto x(i) é usado como ponto de referência de $(j)$, e os resultados são registrados como $\operatorname{sinal}(\theta)(1$, $\theta>0 ; 0, \theta=0 ;-1, \theta<0)$. Se o conjunto de dados for distribuído de forma idêntica e independente, então a média de $S$ é zero e a variação de $S$ é:

$$
\operatorname{Var}(S)=\frac{\left[n(n-1)(2 n+5)-\sum_{t=1}^{q} t(t-1)(2 t+5)\right]}{18}
$$

em que $\mathrm{n}=$ tamanho do conjunto de dados; $\mathrm{t}=$ número de dados com valores repetidos dentro de um certo grupo; e q = número de grupos que contêm valores repetidos.

Para uma série temporal longa, o valor estatístico $\mathrm{S}$ pode ser transformado em $\mathrm{Z}$, de acordo com as seguintes condições:

$$
\mathrm{Z}=\left\{\begin{array}{l}
\frac{\mathrm{s}-1}{\sqrt{\operatorname{Var}(S)}} \text { se } \mathrm{S}>0 \\
0 \text { se } \mathrm{S}_{\mathrm{k}}=0 \\
\frac{\mathrm{S}+1}{\sqrt{\operatorname{Var}(S)}} \text { se } \mathrm{S}_{\mathrm{k}}<0
\end{array}\right.
$$

A hipótese nula é rejeitada ao nível $\alpha$ de significância se $|Z|>Z_{\text {crit }}$, onde Zcrit é o valor da distribuição Normal padrão com uma probabilidade de excedência de $\alpha / 2$. A hipótese nula a ser testada no presente estudo é que não há tendência nos dados analisados.

Após a identificação das tendências, sua magnitude foi estimada através a metodologia de declive "Sen's slope" (Sen, 1968), utilizando-se valores médios anuais. Este teste não paramétrico é calculado conforme a Equação 4.

$$
\int \beta=\frac{x_{j}-x_{k}}{j-k} \text {, para } \mathrm{j}=1,2,3 \ldots, \mathrm{n}
$$

sendo $\beta$ = estimador de declive de Sen. Quando os valores são positivos, a tendência é positiva e, quando os valores são negativos, a tendência é negativa; e xj e xk são os valores dados nos tempos j e k (j>k), respectivamente.

As limitações deste teste de tendência estão associadas à hipótese de que dados não são correlacionados. Buscando-se remover a influência da possível correlação serial no teste de tendência de Mann-Kendall, aplicou-se a cada uma das séries temporais avaliadas o procedimento TFPW (Trend-Free Pre-Whitening), realizado ao nível de significância de $5 \%$, para evitar detecção de uma falsa tendência.

\section{RESULTADOS E DISCUSSÃO}

A Figura 2 mostra a série temporal de precipitações no intervalo de 19 de março a 26 de junho no período de 2000 a 2018 na Bacia Experimental do Riacho do Jatobá. 
Figura 2. Série Temporal da precipitação da Bacia do Riacho do Jatobá, no período de 2000 a 2018 para os noventa dias após o dia de São José.

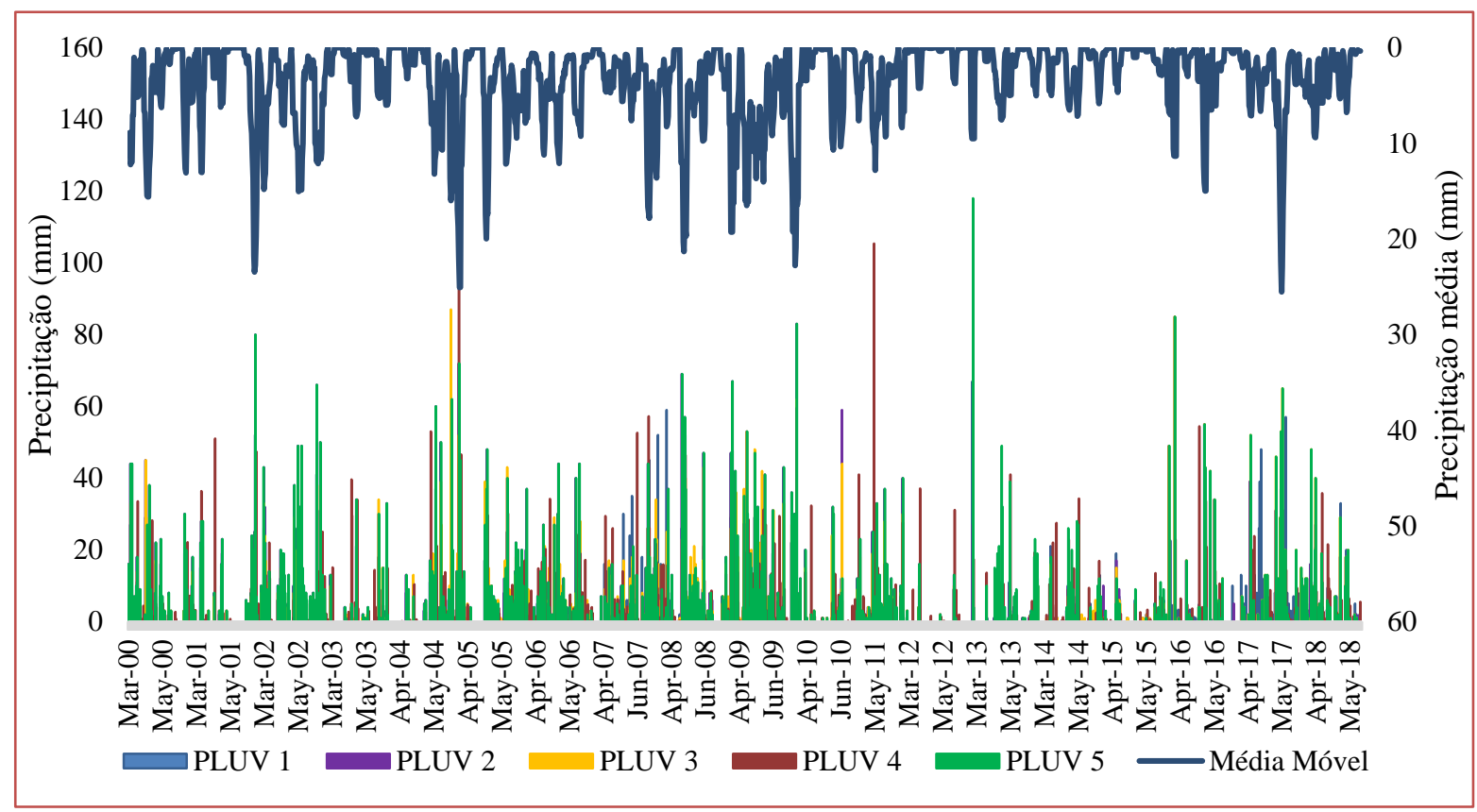

A partir da Figura 2 pode-se observar que precipitação diária mais elevada foi registrada no mês de abril no ano de 2013, com um valor de $118 \mathrm{~mm}$ de lâmina pelo pluviômetro 5. Nos meses de março e abril foram registradas as maiores precipitações no período analisado na série de dados, sendo consistente com a análise de Silva et al. (2013), que indicaram os meses de fevereiro a abril como os de precipitações mais elevadas.

A Tabela 2 apresenta o número de dias chuvosos, número de dias com precipitações maiores que 5 e 10 mm, avaliados no período de 2000 a 2018 na bacia do Jatobá. Os meses de março a julho registraram o maior número de dias chuvosos e também de chuvas maiores que 5 e $10 \mathrm{~mm}$, sendo caracterizado como período chuvoso na bacia, favorecendo ao cultivo do milho na região semiárida.

De acordo com o estudo de Chagas et. al (2020) sobre a caracterização pluviométrica na bacia do Jatobá, a região apresenta dois períodos de transição: o período de agosto a outubro, que apresentou diminuição do número de dias chuvosos, antecedendo o período de estação seca de novembro a janeiro; e o período de fevereiro a abril, marcado pelo aumento de dias chuvosos, que antecede a estação chuvosa no período de maio a julho.

Tabela 2. Média do número de dias chuvosos e número de dias com eventos maiores que $5 \mathrm{~mm}$ e $10 \mathrm{~mm}$, avaliados no período de 2000 a 2018.

\begin{tabular}{|c|c|c|c|c|c|c|c|c|c|c|c|c|c|}
\hline & Pluviômetros & Jan & Fev & Mar & $\mathrm{Abr}$ & Mai & Jun & Jul & Ago & Set & Out & Nov & Dez \\
\hline \multirow{5}{*}{$\begin{array}{l}\text { Dias com } \\
\text { chuva }\end{array}$} & P1 & 98 & 98 & 133 & 177 & 219 & 272 & 261 & 167 & 74 & 47 & 37 & 54 \\
\hline & P2 & 97 & 113 & 128 & 157 & 205 & 244 & 268 & 148 & 76 & 39 & 27 & 55 \\
\hline & P3 & 101 & 100 & 124 & 163 & 215 & 263 & 287 & 174 & 84 & 38 & 26 & 51 \\
\hline & $\mathrm{P} 4$ & 141 & 137 & 158 & 178 & 247 & 307 & 316 & 234 & 108 & 56 & 43 & 67 \\
\hline & P5 & 86 & 94 & 107 & 143 & 196 & 213 & 241 & 141 & 76 & 33 & 27 & 45 \\
\hline
\end{tabular}


Tabela 2. Média do número de dias chuvosos e número de dias com eventos maiores que $5 \mathrm{~mm}$ e $10 \mathrm{~mm}$, avaliados no período de 2000 a 2018.

(continuação...)

\begin{tabular}{|c|c|c|c|c|c|c|c|c|c|c|c|c|c|}
\hline & Pluviômetros & Jan & Fev & Mar & $\mathrm{Abr}$ & Mai & Jun & Jul & Ago & Set & Out & Nov & Dez \\
\hline \multirow{5}{*}{$\begin{array}{l}\text { Dias com } \\
\text { chuvas }>5 \\
\text { mm }\end{array}$} & P1 & 62 & 53 & 85 & 93 & 105 & 125 & 105 & 54 & 25 & 21 & 12 & 30 \\
\hline & P2 & 70 & 74 & 92 & 87 & 124 & 133 & 123 & 69 & 25 & 28 & 16 & 33 \\
\hline & P3 & 60 & 59 & 72 & 89 & 118 & 138 & 115 & 59 & 26 & 18 & 11 & 32 \\
\hline & $\mathrm{P} 4$ & 61 & 64 & 73 & 76 & 91 & 108 & 96 & 52 & 27 & 21 & 12 & 28 \\
\hline & P5 & 55 & 62 & 71 & 90 & 112 & 118 & 128 & 66 & 31 & 20 & 11 & 29 \\
\hline \multirow{5}{*}{$\begin{array}{l}\text { Dias com } \\
\text { chuvas > } \\
10 \mathrm{~mm}\end{array}$} & P1 & 38 & 43 & 54 & 46 & 43 & 54 & 39 & 21 & 8 & 12 & 2 & 13 \\
\hline & P2 & 39 & 53 & 70 & 59 & 73 & 66 & 61 & 35 & 11 & 18 & 4 & 22 \\
\hline & P3 & 36 & 39 & 47 & 49 & 70 & 70 & 56 & 21 & 10 & 12 & 5 & 14 \\
\hline & $\mathrm{P} 4$ & 36 & 41 & 48 & 35 & 47 & 58 & 40 & 24 & 12 & 11 & 6 & 15 \\
\hline & P5 & 35 & 46 & 57 & 61 & 61 & 56 & 57 & 29 & 9 & 14 & 3 & 22 \\
\hline
\end{tabular}

Comparando-se a Figura 2 e a Tabela 2, observa-se que apesar do período de maio a julho ser caracterizado como período chuvoso na bacia, dentro do período de março a junho, os meses de março e abril foram os que registraram as maiores precipitações. Melo et al. (2011), ao estudarem o semiárido pernambucano, constataram que a Zona de Convergência Intertropical é o principal responsável pela distribuição no período chuvoso na região, que começa a atuar em fevereiro, atingindo o máximo nos meses de março a abril.

A Figura 3 apresenta o resultado da análise do total precipitado no período de 90 dias após o dia de São José (19/03), entre 2000 a 2018.

Figura 3. Precipitação total no período de 90 dias após o dia de São José no período de 2000 a 2018 na bacia do Jatobá.

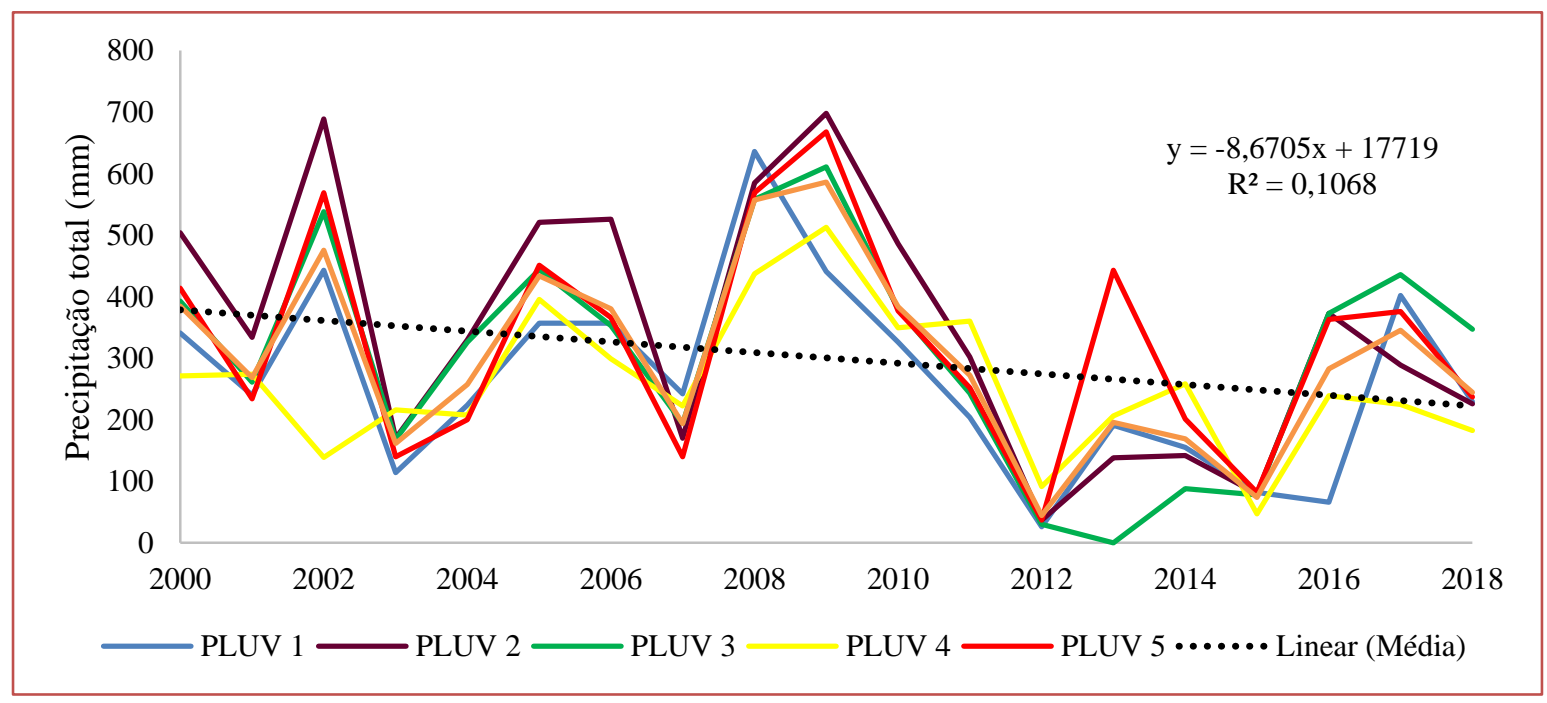


O período de 2007 a 2009 se apresentou como o período de maior lâmina de chuva precipitada na região da bacia, e o período de 2012 a 2016 como o período mais seco durante os 90 dias avaliados. Analisandose a tendência da precipitação total para o período de março a junho (19 de março a 16 de junho), observa-se que o coeficiente de determinação $\left(\mathrm{R}^{2}\right)$ da equação para a média de precipitação total na bacia foi de 0,1068. Embora esse valor seja baixo, é um valor significativo e indicativo de presença de tendência descendente na série apresentada.

Na Figura 4 observa-se a ocorrência de eventos pluviométricos no dia de São José (19 de março), que historicamente marca o início do calendário agrícola de parte da região nordeste.

Figura 4. Ocorrência de chuvas no dia de São José (19/03) no período de 2000 a 2018 na Bacia do Jatobá.

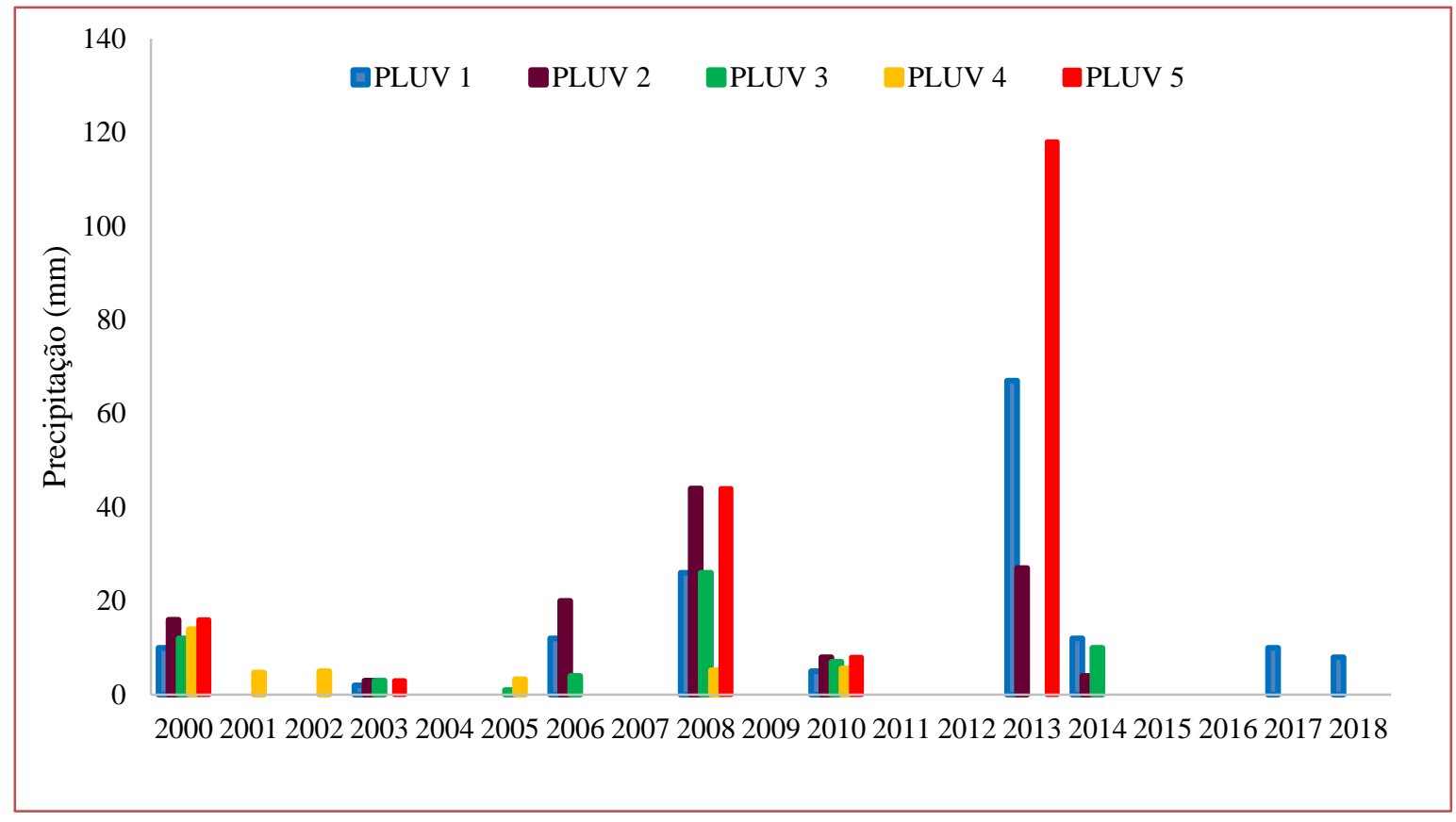

Observa-se, de modo geral, que em cerca de $40 \%$ do período avaliado houve a ocorrência de eventos pluviométricos no dia 19/03, com destaque para o ano de 2013, que apresentou a maior precipitação acumulada, registrada pelos pluviômetros 1 e 5. Os pluviômetros que apresentaram maior ocorrência de eventos, no respectivo dia, foi o pluviômetro 1, seguido do pluviômetro 4 . Nos últimos 4 anos observa-se a ausência de evento neste dia, o que representa uma possível dificuldade no plantio de sequeiro, podendo comprometer a atividade agrícola local, já que deste dia em diante diversos produtores agrícolas dedicam suas áreas ao plantio de milho, muitas vezes em consórcio com outras forragens, para a comercialização no período junino.

A Figura 5 apresenta as análises de tendência para número de dias chuvosos e com chuvas iguais ou superiores a $5 \mathrm{~mm}$ e $10 \mathrm{~mm}$. 
Figura 5. Tendência para o número de dia chuvosos (A), número de dias com chuvas maiores que $5 \mathrm{~mm}$ (B) e maiores que $10 \mathrm{~mm}$ (C) no período de 2000 a 2018.

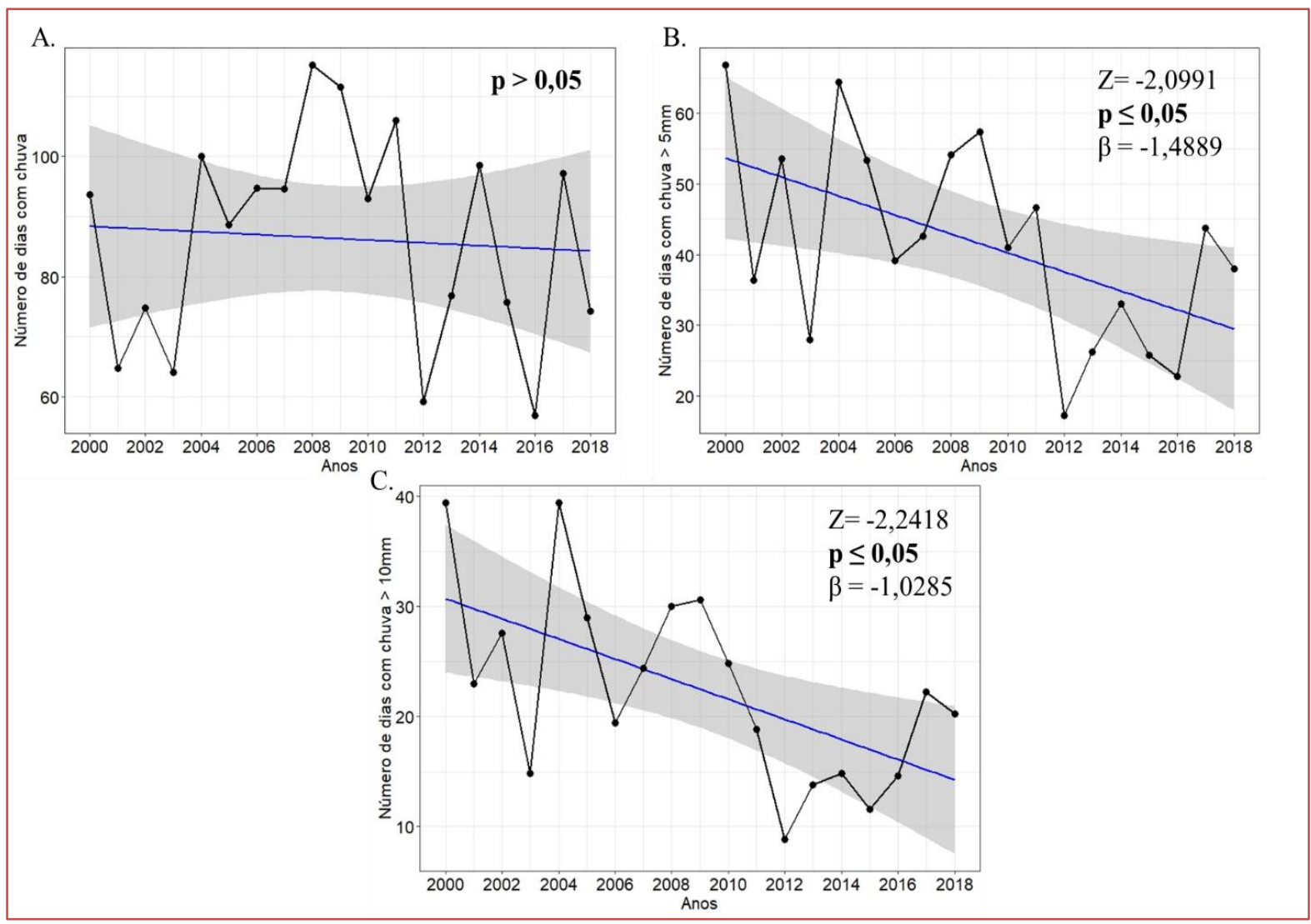

A análise de tendência pelo teste de Mann-Kendall para o número de dias chuvosos não apresentou resultado significativo ( $p>0,05)$, apontando a não existência de tendência para os dias de chuva. Entretanto, para análise para o número de dias com chuvas igual ou superior a $5 \mathrm{~mm}$ e $10 \mathrm{~mm}$, verifica-se resultado significativo $(\mathrm{p}<0,05)$, com tendência de diminuição de 1,4 dias de chuva/ano e 1 dia de chuva/ano, respectivamente. Isto significa que as chuvas maiores que $5 \mathrm{~mm}$ e $10 \mathrm{~mm}$ tendem a diminuir, tornando os eventos pluviométricos de maior magnitude mais escassos. Os resultados encontrados corroboram com Carvalho et al. (2020), que analisaram a tendência no regime de chuvas, o número de dias chuvosos e a temperatura no Nordeste do Brasil, e identificaram redução nos índices pluviométricos e no número de dias chuvosos para a região semiárida. Tal comportamento pode influenciar negativamente no umedecimento do solo e nos processos hidrológicos na Bacia do Riacho Jatobá.

A Figura 6 apresenta as análises de tendência para número de dias chuvosos e com chuvas iguais ou superiores a $5 \mathrm{~mm}$ e $10 \mathrm{~mm}$ no período do cultivo de milho, de março a junho (19 de março a 16 de junho) no período de 2000 a 2018 na Bacia do Jatobá. 
Figura 6. Tendência para o número de dia chuvosos (A), número de dias com chuvas maiores que $5 \mathrm{~mm}$ (B) e maiores que $10 \mathrm{~mm}$ (C) no período de março a junho de 2000 a 2018.

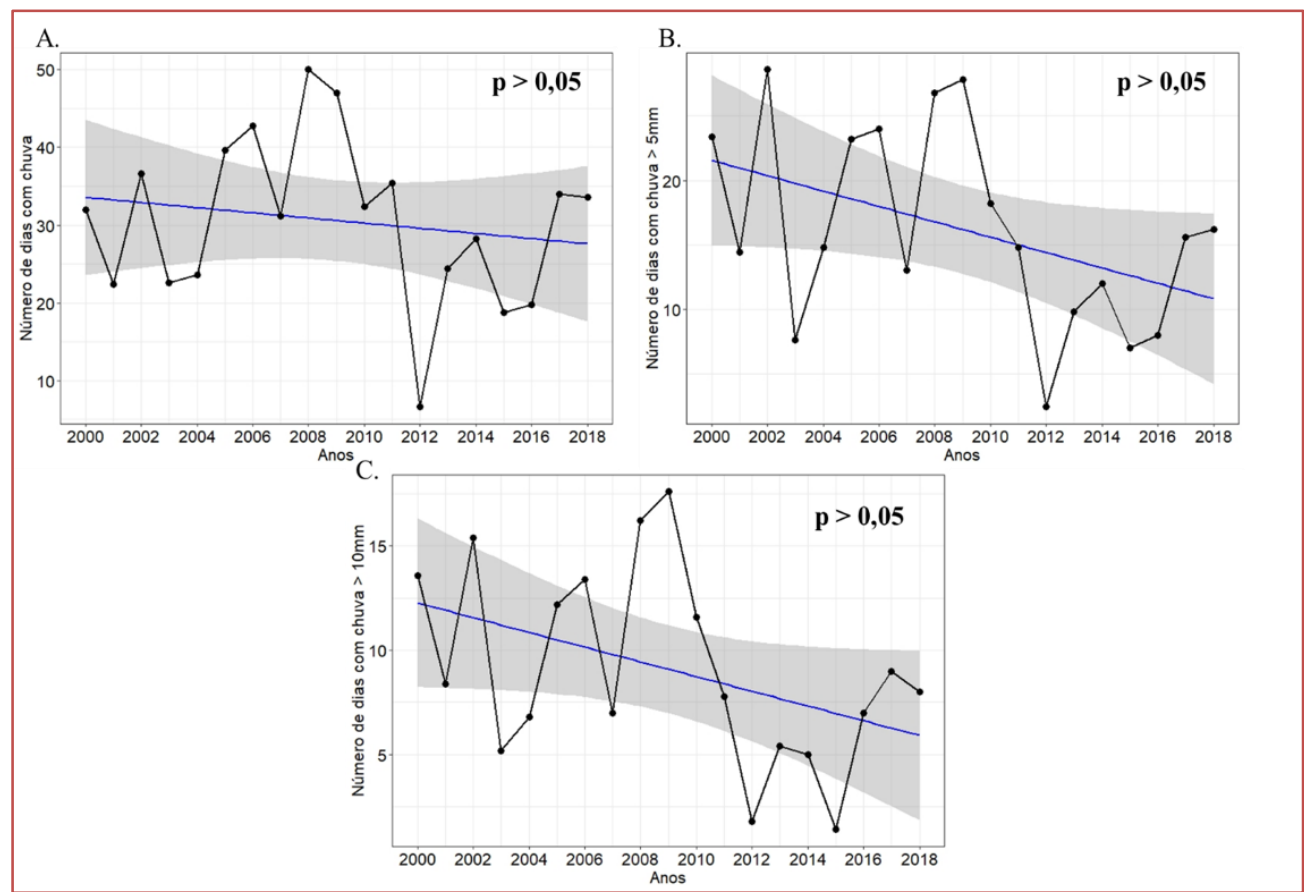

Para as três condições de dias de chuva avaliadas segundo o teste de Mann-Kendall, conforme se observa na Figura 5, nenhuma apresentou nenhum resultado significativo quanto à existência de tendência. Para o número de dias com chuvas maiores que $5 \mathrm{~mm}$ e $10 \mathrm{~mm}$, as análises apresentaram inclinação, mas não foram significativas. Comparando-se os resultados das Figuras 4 e 5, pode-se observar que a tendência de diminuição das chuvas maiores de 5 e $10 \mathrm{~mm}$ tende a ocorrer no período seco (de novembro a janeiro) e não no período de 90 dias após o dia de São José, o que configura um resultado de importância para região, não comprometendo o calendário agrícola.

A Figura 7 apresenta a análise de tendência para a precipitação total na bacia para o período de 90 dias após o dia de São José no período de 2000 a 2018.

Figura 7. Análise de tendência para a precipitação total no período de março a junho ( 19 de março a 16 de junho) de 2000 a 2018.

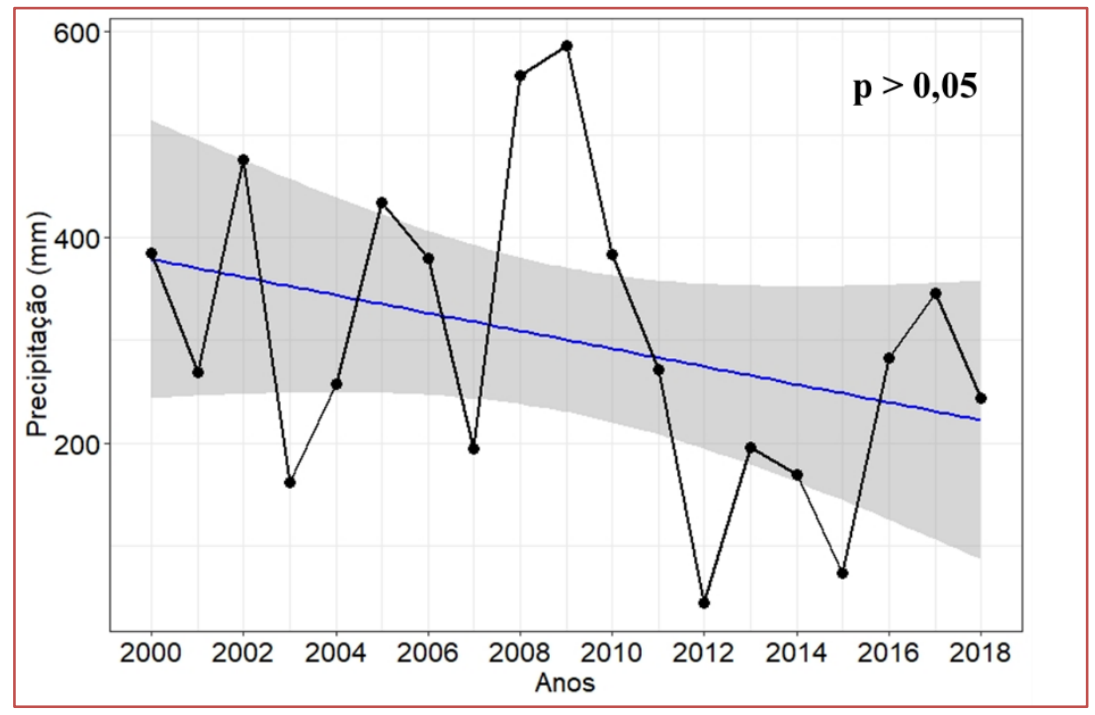


Assim como o número de dias de chuvas maiores que $5 \mathrm{~mm}$ e $10 \mathrm{~mm}$, a precipitação total para o período de 90 dias (19 de março a 16 de junho) apresentou uma inclinação, mas o resultado não foi significativo quanto à tendência de acordo com o teste do Mann-Kendall. Dessa forma, a variabilidade pluviométrica na região não está afetando significativamente o período de plantio.

Na Tabela 3 observa-se os dados referente a existência de tendência (p), a variância (Z) e o declive de Sen's slope antes e após a utilização do filtro TPFW.

Tabela 3. Teste de Mann Kendall e identificação da magnitude do conjunto de dados antes e após a filtragem através do procedimento TFPW

\begin{tabular}{|c|c|c|c|c|c|c|}
\hline & \multicolumn{3}{|c|}{ Mann Kendall + Sen's slope } & \multicolumn{3}{|c|}{ TPFW } \\
\hline & $\mathrm{p}$ & $\mathrm{Z}$ & $\beta$ & $\mathrm{p}$ & $\mathrm{Z}$ & $\beta$ \\
\hline \multicolumn{7}{|c|}{ A. Precipitação total no período de 90 dias acumulada (mm) } \\
\hline PT & 0.23 & -1.1895 & -8.667 & 0.0288 & -1.0606 & -9.143 \\
\hline \multicolumn{7}{|c|}{ B. Dias de chuva ao longo de todo ano } \\
\hline ND & 0.7796 & -0.27988 & -0.272 & 0.93961 & -0.0757 & -0.3151 \\
\hline $\mathrm{ND}>5 \mathrm{~mm}$ & 0.0367 & -2.0991 & -1.488 & 0.15 & -1.4393 & -1.109 \\
\hline $\mathrm{ND}>10 \mathrm{~mm}$ & 0.0249 & -2.2418 & -1.0285 & 0.069 & -1.8181 & -0.664 \\
\hline \multicolumn{7}{|c|}{ C. Dias de chuva do período de março a junho } \\
\hline ND & 0.7264 & -0.34986 & -0.002 & 0.879 & -0.1515 & -0.197 \\
\hline $\mathrm{ND}>5 \mathrm{~mm}$ & 0.1722 & -1.3653 & -0.556 & 0.204 & -1.136 & -0.509 \\
\hline $\mathrm{ND}>10 \mathrm{~mm}$ & 0.151 & -1.1363 & -0.317 & 0.203 & -1.136 & -0.2582 \\
\hline
\end{tabular}

*ND- número de dias com chuva; ND> 5mm - número de dias maiores que $5 \mathrm{~mm}$; ND>10mm - número de dias maiores que $10 \mathrm{~mm}$;

Conforme se observa na Tabela 3, para os testes realizados nos dias de chuva ao longo de todo o ano, o filtro TFPW alterou as significâncias das condições de dias de chuva maiores que 5 e $10 \mathrm{~mm}$, onde ambas as séries passaram a não apresentar tendência significativa, contatando-se que as tendências encontradas eram não significativas e podem estar relacionadas a forte correlação entre os dados. Entretanto, para a análise dos dias de chuva ao longo dos meses de março a junho, o filtro TFPW não alterou a significância dos testes, apresentando variâncias menores para todas as condições avaliadas.

\section{CONCLUSÕES}

1. No período usualmente adotado para plantio de sequeiro no Agreste de Pernambuco ( 90 dias a partir de 19/03), não foram detectadas tendências temporais de decréscimo no número de dias com chuva maior que $5 \mathrm{~mm}$ nem maior que $10 \mathrm{~mm}$;

2. Os totais precipitados nos 90 dias a partir de 19/03 não apresentaram tendência de decréscimo, no período de 2000 a 2018;

3. Não se verificam alterações de precipitação significativas no período usualmente adotado para cultivo de sequeiro na bacia experimental do Jatobá;

4. A utilização de filtros nas séries temporais é de grande importância para uma adequada caracterização de tendências em séries de precipitações anuais na região estudada.

\section{AGRADECIMENTOS}

Os autores agradecem ao FINEP (Financiadora de Estudos e Projetos), à FACEPE (Fundação de Amparo à Ciência e Tecnologia do Estado de Pernambuco), ao CNPq (Conselho Nacional de Desenvolvimento Científico e Tecnológico), a equipe do Laboratório de Água e Solo (LAS) por todo apoio para o 
desenvolvimento da pesquisa, e ao Instituto Nacional de Meteorologia (INMET), pela disponibilização dos registros da Estação de Arcoverde-PE.

\section{REFERÊNCIAS}

[1] CARVALHO, A.A.; MONTENEGRO, A.A.A.; SILVA, H. P.; LOPES, I.; MORAIS, J. E. F.; SILVA, T.G.F. (2020), “Trends of rainfall and temperature in Northeast Brazil". Revista Brasileira de Engenharia Agrícola e Ambiental, v.24, p.15 - 23.

[2] CARVALHO, H.P.; RUIZ, M.V.S. (2016). "Avaliação da consistência de séries históricas de chuva da Bacia Hidrográfica do Rio Araguari, em Minas Gerais". Fórum Ambiental da Alta Paulista 12(6), p.76-84.

[3] ChAGAS, A. M. S.; MONTENEGRO, A.A.A.; ALMEIDA, T.A.B. (2020). “Caracterização dos padrões de chuva na Bacia do Riacho do Jatobá, semiárido pernambucano" in Anais do XV Simpósio de Recursos Hídricos do Nordeste, ONLINE, Nov. 2020, pp. 1-10.

[4] COSTA, M. N. M.; BECKER, C. T.; DE BRITO, J. I. B. (2013). "Análise das séries temporais de precipitação do Semiárido Paraibano em um período de 100 Anos-1911 A 2010”. Revista Brasileira de Geografia Física, v.6, n.04, p.680-696.

[5] FERREIRA, P.S., GOMES, V. P., GALVÍnCIO, J. D., DOS SANTOS, A. M., DE SOUZA, W. M. (2017). “Avaliação da tendência espaço-temporal da precipitação pluviométrica em uma região semiárida do estado de Pernambuco". Revista Brasileira de Climatologia, v.21.

[6] INMET - Instituto Nacional de Meteorologia. Banco de Dados Meteorológicos para Ensino e Pesquisa BDMEP. Disponível em: < http://www.inmet.gov.br/portal/index.php?r=bdmep/bdmep >. Acesso: Janeiro de 2020.

[7] LOPES, I., MONTENEGRO, A.A.A., LIMA, J.L.M.P. (2019). "Performance of Conservation Techniques for Semiarid Environments: Field Observations with Caatinga, Mulch, and Cactus Forage Palma". Water. 11: 1-15; doi:10.3390/w11040792.

[8] MARENGO, J. A., ALVES, L. M., BESERRA, E. A., \& Lacerda, F. F. (2011). Variabilidade e mudanças climáticas no semiárido brasileiro. Recursos hídricos em regiões áridas e semiáridas, 1.

[9] MELO, E.C.S.; MELO, A.S.; MELO, E.G.S.; SILVA, T.L.V. (2011). "Estudo da variabilidade da precipitação no estado de Pernambuco". Revista de Geografia (UFPE), Recife, v.28, n.1, p.82-92.

[10] MONTENEGRO A.A.A., LOPES, I., CARVALHO, A.A, LIMA, J.L.M.P., SOUZA, T.E.M.S., ARAÚJO, H.L, LINS, F.A.C., ALMEIDA, T.A.B., MONTENEGRO, H.G.L.A. (2019). "Spatio Temporal Soil Moisture Dynamics and Runoff under Different Soil Cover Conditions in a Semiarid Representative Basin in Brazil”. Advances in Geosciences. 48(19): 19-30.

[11] SILVA, T.P.N., SANTOS, T. E. M., MONTENEGRO, A.A.A.; GUSMÃO, M.A.M., PONCIANO, I.M., GALINDO, C.T. (2006). "Índice de erosividade (EI30) das chuvas para a Bacia Experimental do Jatobá, no Semi-árido pernambucano". In: VIII Simpósio de Recursos Hídricos do Nordeste, Gravatá, 2006.

[12] SILVA, A.P., MOnTEnEgro, A.A.A., MOURA, G.B. A., SILVA, J.J.D.N., SOUZA, L.R. (2013). “Chuva mensal provável para o Agreste de Pernambuco". Revista Brasileira de Ciências Agrárias, 8(2), 287-296.

[13] SILVA JÚNIOR, V.P.; MONTENEGRO, A.A.A.; MELO, R. O. (2016) "Temporal stability of soil moisture in an experimental watershed in the Pernambuco semi-arid region". Revista Brasileira de Engenharia Agrícola e Ambiental, v.20, n.10, p.880-885.

[14] SILVA, T. F. P., MONTENEGRO, A.A.A., SILVA, J.R.L, MONTENEGRO, S.M.G.L, MOURA, A.E.S.S., OLIVEIRA, L.M.M. (2013). "Avaliação da precipitação e umidade do solo na bacia do Ipanema, no semiárido de Pernambuco". In: Simpósio Brasileiro de Recursos Hídricos, Bento Gonçalves, Nov, 2013.

[15] XU, M.; KANG, S.; WU, H.; YUAN, X. (2018). "Detection of spatio-temporal variability of air temperature and precipitation based on long-term meteorological station observations over Tianshan Mountains, Central Asia". Atmospheric Research, v.203, p.141-163. 


\section{Capítulo 8}

\section{Uso de funções de pedotransferência na caracterização hidrodinâmica de solos pernambucanos}

\section{Marco Aurélio Calixto Ribeiro de Holanda \\ Diogo Botelho Correa de Oliveira \\ Ariela Rocha Cavalcanti \\ Camilla Barrêtto Rique de Barros \\ Willames de Albuquerque Soares}

Resumo : A caracterização dos solos a partir da determinação das suas propriedades hidráulicas e hidrodinâmicas, como a relação entre o potencial matricial e a umidade volumétrica do solo, e a condutividade hidráulica saturada são cruciais para a descrição da dinâmica da água no solo. Sendo assim, objetivou-se a caracterização hidrodinâmica dos solos do nordeste brasileiro, mediante o uso de funções de pedotransferência (FPTs). Para isso, foram utilizados oito diferentes solos de Pernambuco e as FPTs propostas por Barros et al. (2013) as quais foram desenvolvidas para os solos do Nordeste brasileiro e tem como variáveis independentes os quantitativos de areia e argila. Os resultados das análises granulométricas mostraram que a classificação textural predominante foi a Franco-arenosa, mas também há solos classificados como Franco-argilo-arenosos e Areia franca. Além disso, os solos mais argilosos apresentaram maiores valores de umidade volumétrica residual $\left(\theta_{r}\right)$ e saturada $\left(\theta_{s}\right)$ e os menores valores de $\alpha$ e $n$, com ênfase para o solo de Santa Cruz da Baixa Verde $(\alpha=2,263$ e $\mathrm{n}=$ 1,571). Já os solos mais arenosos apresentaram os menores valores de $\theta_{r}$ e $\theta_{s}$, com destaque para Custódia que apresentou os menores valores $\left(\theta_{r}=0,048 \mathrm{~cm}^{3} \cdot \mathrm{cm}^{-3}\right.$ e $\theta_{s}=$ $\left.0,345 \mathrm{~cm}^{3} \cdot \mathrm{cm}^{-3}\right)$.

Palavras-chave: umidade volumétrica, curva de retenção, granulometria. 


\section{INTRODUÇÃO}

A caracterização dos solos a partir da determinação das suas propriedades hidráulicas e hidrodinâmicas, como a relação entre o potencial matricial e a umidade volumétrica do solo, é crucial para a descrição da dinâmica da água no solo (Hillel, 1998; Villarreal et al., 2019). Tais propriedades influenciam nos processos de infiltração, escoamento superficial, erosão, absorção de água pelas raízes, transporte de solutos e abastecimento e contaminação do nível freático (Silva Jr. et al., 2013; Ma et al., 2016; Filho et al., 2020).

Entretanto, estes processos podem sofrer alterações mediante o arranjo das partículas e dos poros, a densidade e a composição granulométrica do solo (Gonçalves e Libardi, 2013). Deste modo, a obtenção destas informações, atreladas aos parâmetros hidrodinâmicos é importante para a caracterização hidrodinâmica dos solos. Contudo, a quantificação destes parâmetros pode demandar muito tempo e alto custo, dependendo do método utilizado (Souza et al., 2008, Santos et al., 2019).

Os métodos diretos, executados em campo ou a partir de ensaios laboratoriais, como o Berrkan, o Beerkan Estimation of Soil Transfer (BEST) e as simulações de chuva são caros e podem demandar muito tempo e mão de obra, dependendo do tipo de solo, do acesso ao local de estudo ou do aparato laboratorial necessário (Lassabatère et al., 2006; Di Prima et al., 2018). Sendo assim, visando a diminuição do custo financeiro e temporal, muitos estudos apontam que o uso de métodos indiretos, como modelos matemáticos, pode ser uma solução precisa e econômica (Ma et al., 2010; Zeng et al. 2018; Holanda et al. 2019).

Visando a obtenção dos valores de umidade no solo, diversos autores desenvolveram funções de pedotransferência (FPTs) a partir da composição granulométrica, da densidade, da porosidade (micro e macroporosidade) e do potencial matricial (Barros et al., 2013; Auler et al., 2017). Contudo, resultados obtidos por Auler et al. (2017) deixam claro que para os solos estudados a densidade teve um papel fundamental na obtenção dos valores de umidade e que as equações propostas devem ser utilizadas apenas para compreender a retenção de água no solo. Por serem expressões empíricas, as FPTs costumam apresentar resultados melhores quando são utilizadas em solos de mesma classe textural ou em solos de uma mesma localidade (Nemes et al. 2009; Dashtaki et al. 2010)

Souza et al. (2016) avaliaram o desempenho de FPTs na determinação de parâmetros hidrodinâmicos presentes na curva de retenção de água no solo de Latossolos de Minas Gerais e concluíram que a Função de pedotransferência que apresentou os melhores ajustes para as curvas de retenção de água no solo foi aquela com o maior número de parâmetros de entrada. Contudo, as FPTs utilizadas não foram desenvolvidas especificamente para os Latossolos de mineiros e por isso, os seus resultados apresentaram uma superestimativa, quando comparados com os obtidos com o RTEC (Genuchten et al., 1991).

Bruning et al. (2019) utilizaram o modelo proposto por Arya e Paris (1981) para estimar os parâmetros da equação de van Genuchten, encontrando valores das umidades $10 \%$ menores, quando comparados com os obtidos com o método da câmara de Richards. Entretanto, os valores de $\mathrm{R}^{2}$ obtidos foram acima de 0,87 para todos os solos estudados. Ramos et al. (2016) testaram o uso de FPTs para a estimativa da densidade de Latossolos do Estado do Piauí com intuito de substituir os ensaios laboratoriais, obtendo bons resultados.

Sendo assim, este estudo tem como objetivo a caracterização hidrodinâmica dos solos do Estado de Pernambuco, mediante o uso de funções de pedotransferência que utilizam como parâmetros de entrada a composição granulométrica do solo e que foram desenvolvidas especificamente para esta região.

\section{METODOLOGIA}

A metodologia do estudo foi subdividida em duas partes: 1) Locais de estudo, onde foram apresentadas as oito localizações escolhidas e como as coletas foram realizadas e 2) Ensaios de granulométricos, em que mostrou-se como foi realizada a preparação das amostras coletadas e como foram realizados os ensaios de granulometria de cada solo. 


\subsection{LOCAL DE ESTUDO}

As amostras foram coletadas em oito cidades do estado de Pernambuco (Recife, Gravatá, Caruaru, Belo Jardim, Arcoverde Custódia, Serra Talhada e Santa Cruz da Baixa Verde), contemplando as três regiões climáticas presentes, zona da mata, agreste e sertão, Figura 1. Estas cidades margeiam a principal rota que liga a capital, Recife, ao interior (BR-232), com exceção de Santa Cruz da Baixa Verde, que é um distrito de Jatiúca e dista aproximadamente a $31 \mathrm{Km}$ da BR-232.

Figura 1. Mapa contendo a localização das cidades onde foram realizadas as coletas.

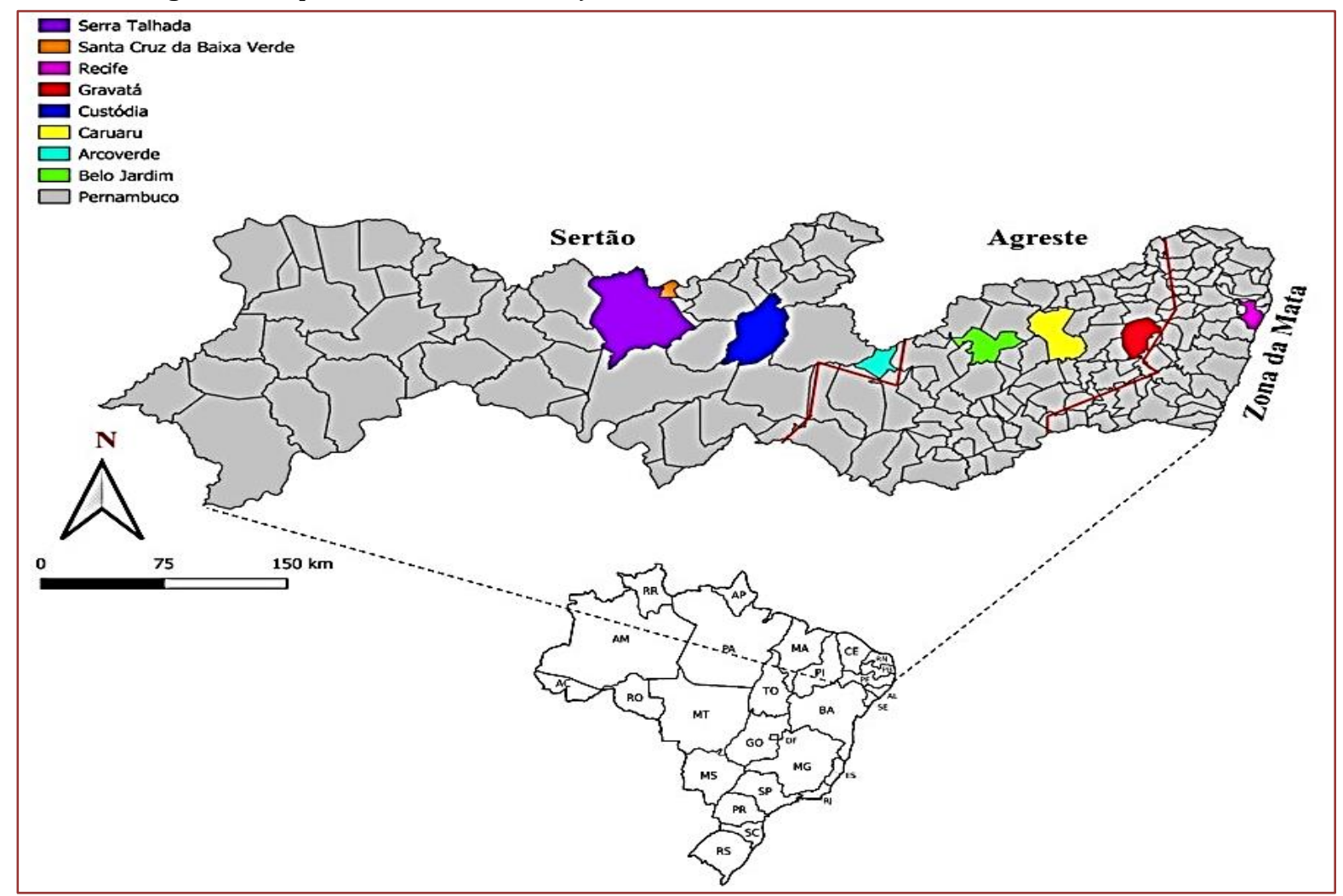

A escolha dos locais de onde as amostras foram coletadas baseou-se no nível ação antrópica recente, sendo escolhidos aqueles com a menor ação possível. 0 solo foi coletado entre 0 e $30 \mathrm{~cm}$ de profundidade utilizando-se uma enxada, uma pá e sacos de ráfia para o transporte, uma vez que não havia a necessidade de manutenção da estrutura morfológica para o desenvolvimento deste trabalho. Além do solo, também foram coletadas as informações referentes à geolocalização do ponto em que as amostras foram colhidas, as quais constam na Tabela 1.

Tabela 1. Localização dos pontos de coleta dos solos.

\begin{tabular}{|c|c|c|c|c|}
\hline Local & Latitude & Longitude & Altitude (m) & $\begin{array}{c}\text { Distância para } \\
\text { Recife }(\mathrm{Km})\end{array}$ \\
\hline Recife & S 8 1' 12.675" & W 34 57' 8.807" & 13,24 & - \\
\hline Gravatá & S 8 11' 49.672" & W 35 $35^{\prime} 2.096^{\prime \prime}$ & 480,37 & 79 \\
\hline Caruaru & S $8^{\circ} 18^{\prime} 22.034^{\prime \prime}$ & W 355 55' 59.322" & 574,38 & 131 \\
\hline Belo Jardim & S $8^{\circ} 21^{\prime} 1.355^{\prime \prime}$ & W 36잉 33.618" & 641,32 & 178 \\
\hline Arcoverde & S 8 ${ }^{\circ} 25^{\prime} 47.826^{\prime \prime}$ & W 37ㅇ' 31.079" & 666,36 & 255 \\
\hline Custódia & S 8 $4^{\prime} 56.753^{\prime \prime}$ & W 37 39' 25.324" & 556,36 & 336 \\
\hline Serra Talhada & S 7 $57^{\prime} 7.731^{\prime \prime}$ & W 38 $17^{\circ} 49.229^{\prime \prime}$ & 502,92 & 413 \\
\hline $\begin{array}{l}\text { Santa Cruz da Baixa } \\
\text { Verde }\end{array}$ & S 75 $51^{\prime} 7.533^{\prime \prime}$ & W $38^{\circ} 10^{\prime} 15.687^{\prime \prime}$ & 977,05 & 439 \\
\hline
\end{tabular}




\subsection{ENSAIOS GRANULOMÉTRICOS}

Para a realização dos ensaios de granulometria, os solos coletados foram colocados para secar ao ar livre em bandejas de alumínio por no mínimo 96 horas. Após a secagem, o material foi destorroado, peneirado em malhas de $2 \mathrm{~mm}$ e então foram retiradas três amostras de cada solo, as quais continham $70 \mathrm{~g}$ para os solos argilosos ou 120 g para os solos arenosos, bem como recomenta a NBR 6457 (ABNT, 2016a). Como são oito solos, então foram retiradas um total de 24 amostras, as quais foram colocadas em béqueres contendo $250 \mathrm{ml}$ de uma solução de água destilada e hexametafosfato de sódio numa proporção de 45,7 g.L.-1 durante 12 horas, Figura 2.

Figura 2. a) coleta do solo, b) secagem do material e c) solução com hexametafosfato de sódio.

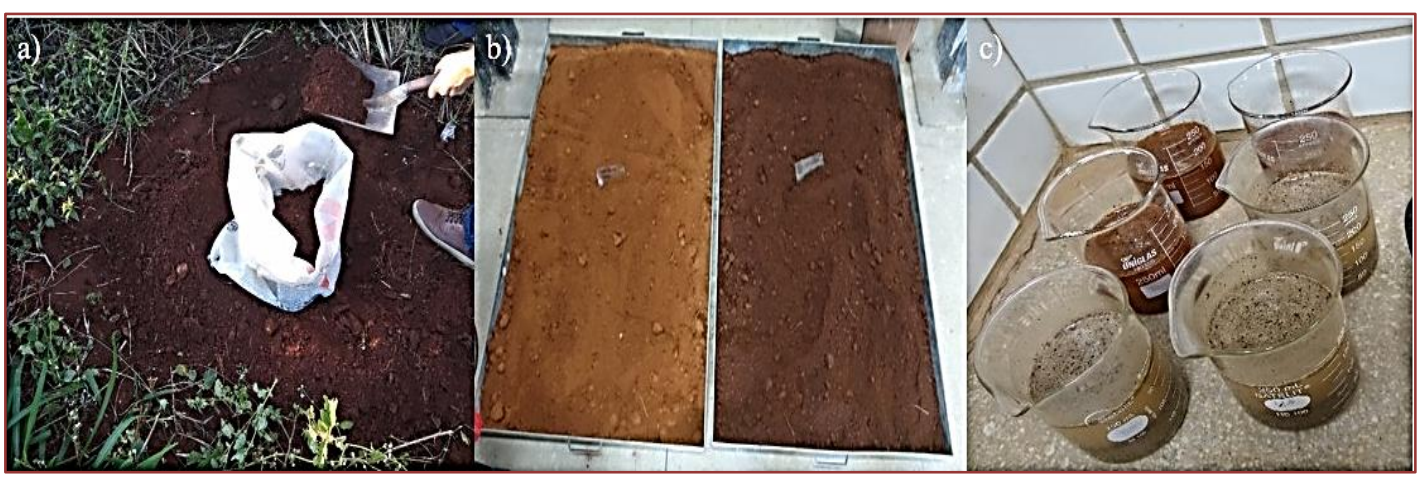

Após este período, o material encontra-se pronto para ser homogeneizado durante 15 minutos e vertido em provetas de vidro graduadas $(1000 \mathrm{ml})$, para que a sedimentação fosse realizada, mediante o auxílio de um densímetro para solos (graduado entre 0,995 e 1,050 g.cm-1), Figura 3 (ABNT, 2016b). As aferições das densidades foram realizadas em tempos predefinidos de 0,$5 ; 1 ; 2 ; 4 ; 8 ; 15 ; 30 ; 60 ; 120 ; 240 ; 480 ; 720$ e $1440 \mathrm{~min}$.

Figura 3. a) Provetas graduadas de $1000 \mathrm{ml}$ e b) Densímetro graduado entre 0,995 e 1,050 g.cm-1

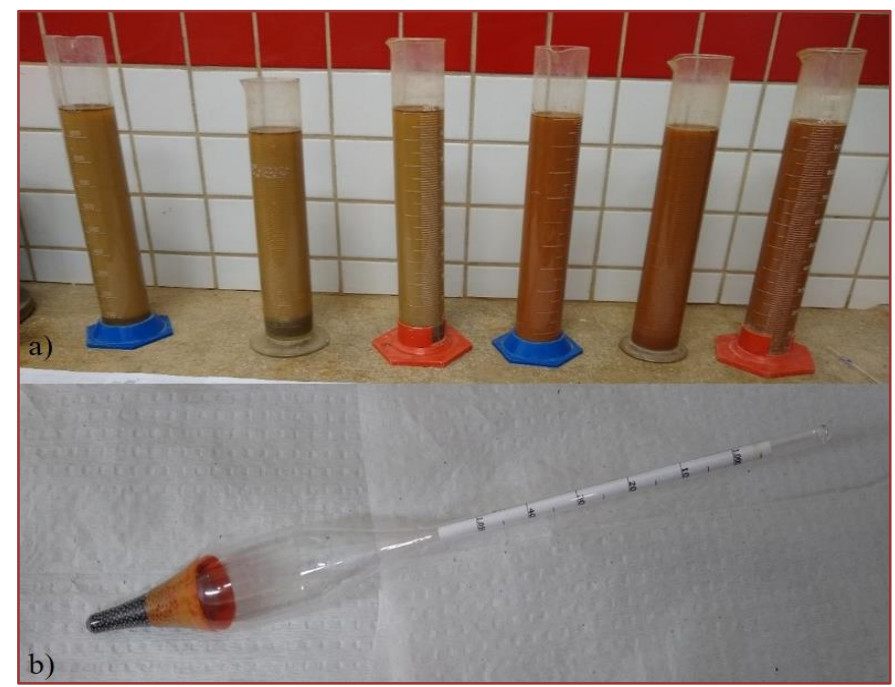

\subsection{FUNÇÕES DE PEDOTRANSFERÊNCIA E CURVAS DE RETENÇÃO}

Os parâmetros hidrodinâmicos do solo, $\alpha, n, \theta_{s}$ e $\theta_{r}$ foram obtidos mediante as funções de pedotransferência propostas por Barros et al. (2013), Equações 1-4, enquanto os valores de $K_{s}$ foram obtidos através Equação 5, proposta por Cosby et al. (1984). 


$$
\begin{aligned}
& \alpha=10^{0.93-1.60 C_{1}} \\
& n=1.53+0.33 C_{2}-0.39 C_{1} \\
& \theta_{r}=0.13-0.15 C_{2}+0.36 C_{1} \\
& \theta_{s}=0.55-0.23 C_{2}-0.12 C_{1} \\
& K_{s}=25,4+10^{\left(-0,6+0,012 C_{1}-0,0064 C_{2}\right)}
\end{aligned}
$$

Onde $\alpha$ e $n$ representam os parâmetros de forma da equação de van Genuchten (1980), Equação $5, \theta_{s}$ a umidade volumétrica saturada $\left(\mathrm{cm}^{3} . \mathrm{cm}^{-3}\right), \theta_{r}$ a umidade volumétrica residual, $C_{1}$ o quantitativo de areia presente na amostra (kg.kg-1), $\quad C_{2}$ a quantidade de argila presente na amostra $\left(\mathrm{kg}^{-\mathrm{kg}^{-1}}\right)$ e $\mathrm{K}_{\mathrm{s}}$ a condutividade hidráulica saturada $\left(\mathrm{mm} \cdot \mathrm{h}^{-1}\right)$.

Para a obtenção das curvas de retenção de água no solo, foi utilizada a Equação 6, proposta por van Genuchten (1980) com a hipótese de Mualem, em que $h$ é o potencial matricial (cm).

$$
\theta(h)=\theta_{r}+\frac{\theta_{S}-\theta_{r}}{\left(1+(\alpha h)^{n}\right)^{1-\frac{1}{n}}}
$$

\section{RESULTADOS}

Com a realização dos ensaios de granulométricos, foram obtidos os valores percentuais de areia, silte e argila, das três repetições realizadas para cada um dos oito amostras de solos coletados. A partir destes resultados foram obtidos os pontos médios do tamanho das partículas, os quais podem ser observados na Figura 4.

Figura 4. Pontos médios do tamanho das partículas para os solos estudados

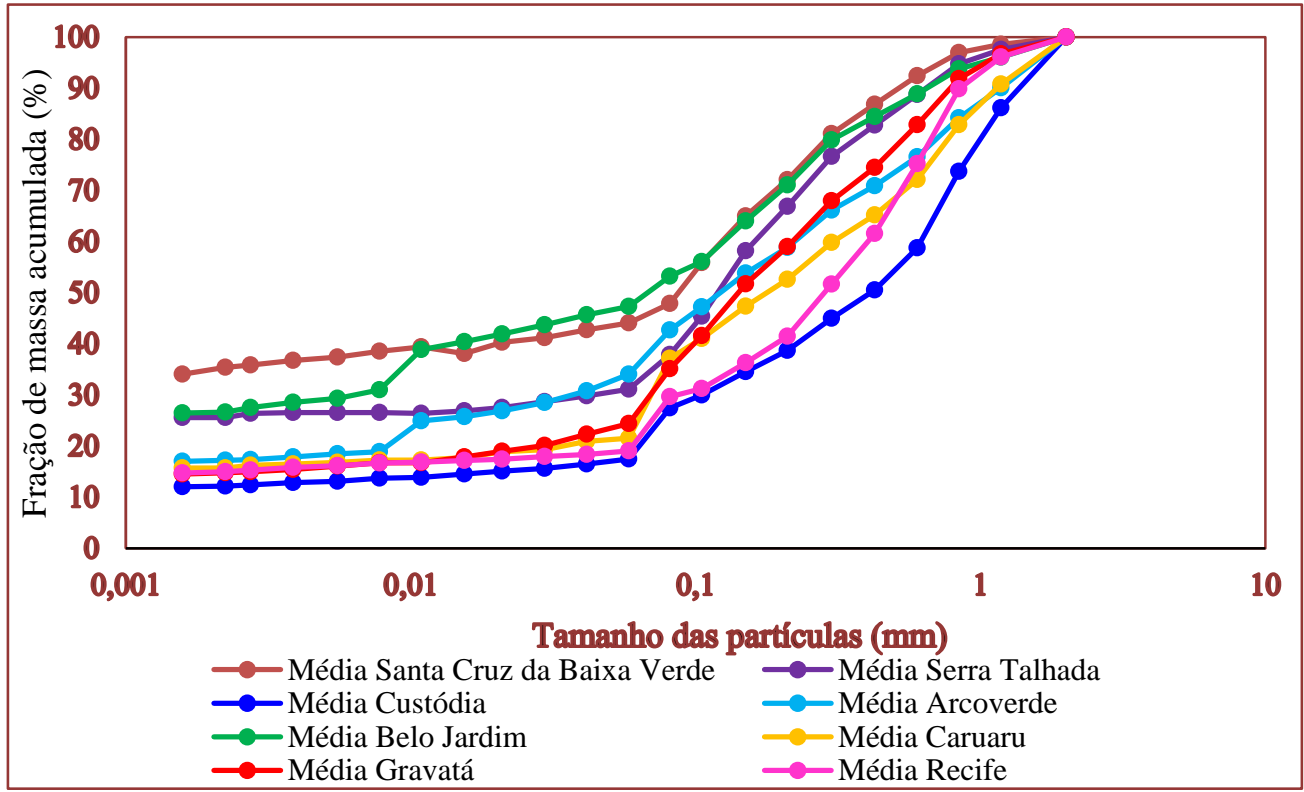

A partir da Figura 4 nota-se que as curvas referentes às localidades de Serra Talhada, Santa Cruz da Baixa Verde e Belo Jardim apontam para os solos com maiores teores de argila, enquanto que localidades como Custódia, Gravatá e Recife são as que possuem os maiores teores de areia. De modo mais detalhado, é possível observar os percentuais médios de areia, silte e argila de cada localidade, bem como as respectivas classificações dos solos de cada localidade presentes na Tabela 2. 
Meio Ambiente, Sustentabilidade e Tecnologia - Volume 5 - Recursos Hídricos

Tabela 2. Médias dos percentuais da composição granulométrica de cada solo

\begin{tabular}{|c|c|c|c|c|}
\hline Localidade & Areia $(\%)$ & Silte $(\%)$ & Argila (\%) & Classificação Textural \\
\hline Recife & 81,63 & 3,64 & 14,72 & Franco-arenoso \\
\hline Gravatá & 79,89 & 5,59 & 14,51 & Franco-arenoso \\
\hline Caruaru & 79,06 & 5,24 & 15,71 & Franco-arenoso \\
\hline Belo Jardim & 54,32 & 19,19 & 26,49 & Franco-argilo-arenoso \\
\hline Arcoverde & 69,21 & 13,76 & 17,03 & Franco-arenoso \\
\hline Custódia & 83,53 & 4,43 & 12,04 & Areia franca \\
\hline Serra Talhada & 70,18 & 4,26 & 25,56 & Franco-argilo-arenoso \\
\hline Santa Cruz da Baixa Verde & 55,91 & 8,24 & 35,85 & Franco-argilo-arenoso \\
\hline
\end{tabular}

Os resultados de alguns destes solos possuem a mesma composição granulométrica encontrada por Oliveira e Soares (2017) e Holanda e Soares (2019), onde para as amostras de Recife os percentuais de areia foram acima de 71,80\% e de Serra Talhada entre 67,18 e 71,74\% (Filho et al., 2020). Além disso, os percentuais de areia, silte e argila da Tabela 1 foram utilizados como dados de entrada para as funções de pedotransferência proposta por Barros et al. (2013), das quais foram obtidos os valores dos parâmetros que estão dispostos na Tabela 3.

Tabela 3. Valores dos parâmetros hidrodinâmicos

\begin{tabular}{|c|c|c|c|c|c|}
\hline Localidade & $\alpha$ & $n$ & $\theta_{s}\left(\mathrm{~cm}^{3} \cdot \mathrm{cm}^{-3}\right)$ & $\theta_{r}\left(\mathrm{~cm}^{3} \cdot \mathrm{cm}^{-3}\right)$ & $K_{s}\left(\mathrm{~mm} \cdot \mathrm{s}^{-1}\right)$ \\
\hline Recife & 4,918 & 1,738 & 0,346 & 0,060 & $7,59 \times 10^{-3}$ \\
\hline Gravatá & 4,956 & 1,733 & 0,350 & 0,062 & $7,57 \times 10^{-3}$ \\
\hline Caruaru & 4,742 & 1,726 & 0,351 & 0,067 & $7,55 \times 10^{-3}$ \\
\hline Belo Jardim & 3,191 & 1,602 & 0,395 & 0,143 & $7,27 \times 10^{-3}$ \\
\hline Arcoverde & 4,518 & 1,688 & 0,372 & 0,087 & $7,42 \times 10^{-3}$ \\
\hline Custódia & 5,427 & 1,755 & 0,345 & 0,048 & $7,64 \times 10^{-3}$ \\
\hline Serra Talhada & 3,302 & 1,658 & 0,360 & 0,116 & $7,39 \times 10^{-3}$ \\
\hline Santa Cruz da Baixa Verde & 2,263 & 1,571 & 0,381 & 0,174 & $7,25 \times 10^{-3}$ \\
\hline
\end{tabular}

Analisando as umidades volumétricas residual, pode-se notar que os maiores valores são 0,$143 ; 0,087$; 0,116 e 0,174 , enquanto que para a umidade volumétrica saturada são 0,395;0,372;0,360 e 0,381. Além disso, estes maiores valores estão relacionados aos solos que possuem uma maior quantidade de componentes finos, seja pela maior quantidade de argila, no caso dos solos de Serra Talhada e Santa Cruz da Baixa Verde, ou pela quantidade de silte presente nos solos de Belo Jardim e Arcoverde. Deste modo, os valores de umidade volumétrica saturada destes quatro solos são semelhantes aos valores médios encontrados por Zhang et al. (2019) $\left(0,408 \mathrm{~cm}^{3} \cdot \mathrm{cm}^{-3}\right)$ ao estudarem solos com composições granulométricas mais finas (contendo mais silte).

Os resultados de $\alpha$ e $n$ mostraram que quanto maior quanto maior o percentual de areia, maiores são estes parâmetros, sendo o solo de Custódia aquele com os maiores valores (5,427 e 1,755 respectivamente). Além disso, os valores destes dois parâmetros possuem a mesma ordem de grandeza dos resultados obtidos por Yang et al. (2004) ao estudarem solos compostos majoritariamente por areia fina (aproximadamente 1,81 e 3,19 respectivamente) e um $\theta_{s}$ de $0,41 \mathrm{~cm}^{3} \cdot \mathrm{cm}^{-3}$ e um $\theta_{r}$ de $0,034 \mathrm{~cm}^{3} . \mathrm{cm}^{-3}$. Tais resultados, ainda são lastreados pelos valores de condutividade hidráulica saturada e pelas curvas de retenção de água no solo, onde a curva de custódia está mais à esquerda e a de Santa Cruz da Baixa Verde mais à direita e possui um $\mathrm{K}_{\mathrm{s}}$ de $7,25 \times 10^{-3} \mathrm{~mm} . \mathrm{s}^{-1}$, Figura 5 . Além disso, também fica claro, a partir da Tabela 3, que os valores médios de $n$ para os solos com os maiores percentuais de silte e argila são menores, bem como foi observado por Zhou et al. (2016). 
Figura 5. Curvas de retenção de água no solo para cada uma das oito localidades.

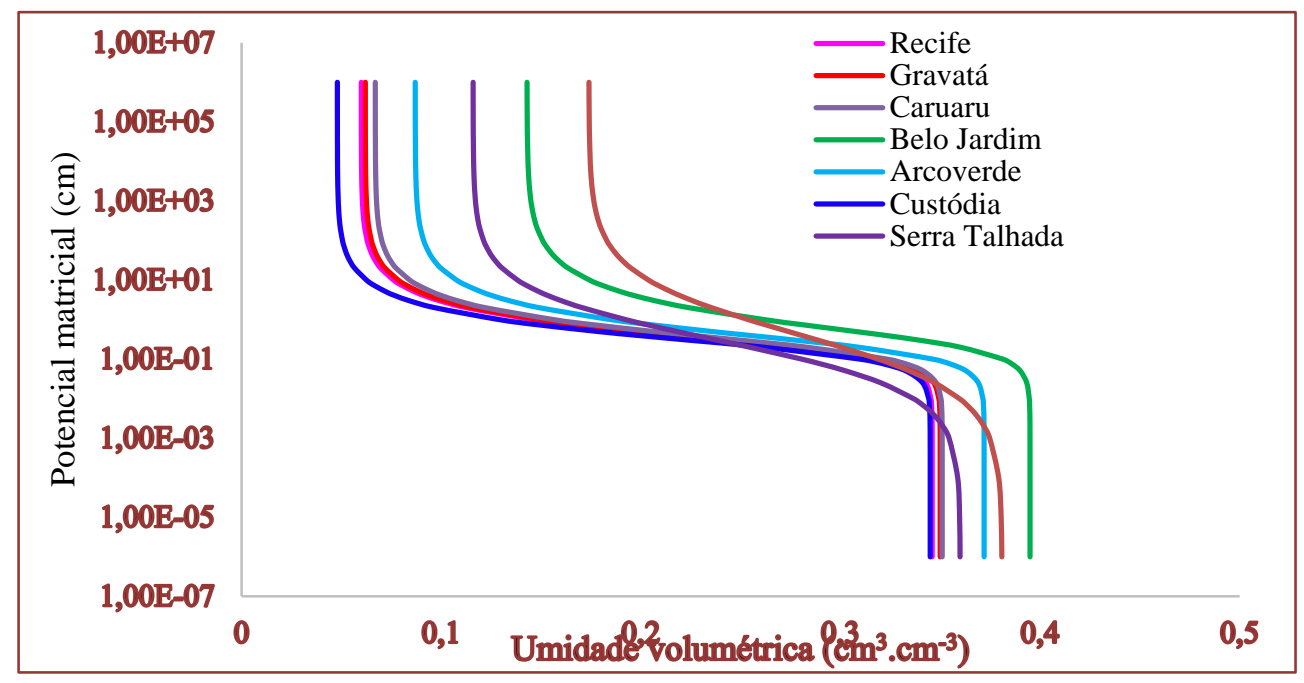

\section{CONCLUSÕES}

Os ensaios Granulométricos mostraram que os solos de Santa Cruz da Baixa Verde, Serra Talhada e Belo Jardim apresentaram os maiores percentuais de argila e foram classificados como Franco-argilo-arenosos. Já os solos de Recife, Gravatá, Caruaru e Arcoverde foram classificados como Franco arenosos e o de Custódia como Areia franca.

Os solos mais arenosos (Recife, Gravatá, Caruaru e Custódia) obtiveram os menores valores das umidades volumétricas saturada e residual, enquanto que os solos contendo mais frações finas como silte e argila (Belo Jardim, Arcoverde, Serra Talhada e Santa Cruz da Baixa Verde) apresentaram os maiores valores para estes dois parâmetros hidrodinâmicos, com destaque para o solo de Santa Cruz da Baixa Verde, em que $\theta_{r}=0,174, \theta_{s}=0,381 \mathrm{~cm}^{3} \cdot \mathrm{cm}^{-3}$ e Ks $=7,25 \times 10^{-3} \mathrm{~mm} \cdot \mathrm{s}^{-1}$.

Contudo, os quatro solos que continham os maiores percentuais de areia tiveram os maiores valores dos parâmetros $\alpha$ e $n$, com destaque para o solo que Custódia que valores respectivos de 5,427 e 1,755. Os demais solos apresentaram os menores valores, com o solo menos arenoso (Santa Cruz da Baixa Verde, com 55,91\% de areia) apresentando os menores valores para estes dois parâmetros $(2,263$ e 1,571 respectivamente).

\section{AGRADECIMENTO}

Os autores agradecem a Escola Politécnica de Pernambuco (POLI-UPE) pelo apoio.

\section{REFERÊNCIAS}

[1] ABNT- Associação Brasileira de Normas Técnicas. ABNT NBR - 6457: Amostras de Solo - Preparação para Ensaios de Compactação e Ensaios de Caracterização. Rio de Janeiro, 2016a. 08p.

[2] ABNT - Associação Brasileira de Normas Técnicas. ABNT NBR - 7181. Solo - Análise granulométrica. Rio de Janeiro: ABNT, 2016b. 16p.

[3] ARYA, L. M.; PARIS, J. F. A physicoempirical model to predict soil moisture characteristics from particle-size distribution and bulk density data. Soil Science Society of America Journal, Madison, v. 45, n. 6, p.1023-1030, 1981.

[4] BARROS, A. H. C.; LIER, Q. J. V.; MAIA, A. H. N.; SCARPARE, F. V.; Pedotransfer Functions to Estimate Water Rentention Parameters of Soils in Northeastern Brazil; Revista Brasileira de Ciências do Solo, Viçosa, v. 37, n. 2, p. 379391, Mar./Apr. 2013.

[5] Bruning, J.; Robaina, A. D.; Peiter, M. X.; Boscaini, R.; Conceição, C. G.; Gollo, E. A. Estimativa da curva de retenção de água no solo por função de pedotransferência. Revista de Ciências Agronômicas, v.28, n.1, p.97-110, 2019.

[6] COSBY, B.J.; HORNBERGER, G.M.; CLAPP, R.B. and GINN, T.R. (1984). "A statistical exploration of the relationship of soil moisture characteristics to the physical properties of soils". Water Resources Research 20(6), pp. 682-690. 
[7] DASHTAKI, S. G.; HOMAEE, M.; KHODABERDILOO, H. (2010); "Derivation and validation of pedotransfer functions for estimating soil water retention curve using a variety of soil data". Soil Use and Management 26(1), pp.6874.

[8] Di Prima, S.; Lassabatère, L.; Angulo-Jaramillho, R.; Pirastru, M.; Cerdà, A.; Keesstra, S. 2018 Laboratory testing of Beerkan infiltration experiments for assessing the role of soil sealing on water infiltration. Catena, 167, 373384.

[9] FILHO, A. M. P.; NETTO, A. M.; CORRÊA, M. M.; NETO, F. C. R.; SILVA, L. P.; MALTA, S. H. S. Hydrodynamic and hydrodispersive characterization of a fluvic cambisol in the northeast region of brazil. Revista Caatinga, v. 33, n. 1, p. 160-171, 2020.

[10] GENUCHTEN, M. T. Van. A closed-form equation for predicting the hydraulic conductivity of unsatured soils. Soil Science Society of America Journal, Pittsburgh, v. 44, n. 3, p. 892-898, 1980. doi: $10.2136 /$ sssaj1980.03615995004400050002x

[11] Genuchten, M. T. Van; Leij, F. J.; Yates, S. R. 1991. The RETC Code for Quantifying the Hydraulic Functions of Unsaturated Soils, Version 1.0. EPA Report 600/2-91/065, U.S. Salinity Laboratory, USDA, ARS, Riverside, California

[12] GONÇALVES, A.D.M.A. e LIBARDI, P.L. Análise da determinação da condutividade hidráulica do solo pelo método do perfil instantâneo. Revista Brasileira de Ciência do Solo, Viçosa - MG, v.37, p.1174-1184, 2013.

[13] HILLEL, D. Environmental soil phisics. New York: Academic Press, 1998, 771p.

[14] HOLANDA, M. A. C. R.; SOARES, W. A. Analysis of the effect of impermeability of urban soils on the infiltration of rainwater in the city of Recife, PE. Revista Ambiente e Água, Taubaté, v. 14, n. 4, p. 1-10, 2019.

[15] Holanda, M. A. C. R.; Soares, W. A.; Silva, S. R.; Oliveira, D. B. C. 2019 Sensitivity of the Hydrus-1D model to changes in hidrodynamic parameters in yellow latosol. Revista AIDIS de Ingeniéria y Ciencias Ambientales: Investigación, desarrollo y práctica, 12(3), 467-481.

[16] Lassabatère, L.; Angulo-Jaramillo, R.; Soria, J. M.; Cuenca, R.; Braud, I.; Haverkamp, R. 2006 Beerkan estimation of soiltransfer parameters through infiltration experiments - BEST. Soil Science Society of America Journal, $70,521-532$

[17] Ma, Y.; Feng, S.; Su, D.; Gao, G.; Huo, Z. 2010 Modeling water infiltration in a large layered soil column with a modified Green-Ampt model and HYDRUS-1D. Computers and Electronics in Agriculture, 71, 40-47.

[18] Ma, D., Zhang, J., Lai, J., \& Wang, Q. (2016). An improved method for determining Brooks-Corey model parameters from horizontal absorption. Geoderma, 263, 122-131.

[19] NEMES, A.; TIMLIN, D. J.; PACHEPSKY, Y. A.; RAWLS, W. J. (2009). “Evaluation of the pedotransfer functions for their applicability at the U.S. National Scale". Soil Science Society of America Journal 73(5), pp.1638-1645.

[20] OLIVEIRA, D. B. C.; SOARES, W. A. DESEMPENHO DE MODELOS DE INFILTRAÇÃO TRIDIMENSIONAL DE ÁGUA NO SOLO. Diálogos: Revista de Estudos Culturais e da Contemporaneidade, v. 3, p. 519-544, 2017.

[21] Ramos, H. M. M.; Valladares, G. S.; Soares, A. A. J. Funções de Pedotransferência para Estimativa da Densidade de Solo em Latossolos do Estado do Piauí. In Anais da III Reunião Nordestina de Ciência do Solo, Aracajú-SE. Integração e uso do conhecimento para uma agricultura sustentável no Nordeste, 2016, pp. 1-4.

[22] SANTOS, M. M. M.; PEREIRA, F. A. C.; SOUZA, L. S.; SANTOS, E. B.; SILVEIRA, F. G. F. Hidrodinâmica em solos típicos dos tabuleiros costeiros no recôncavo da Bahia. Irriga, v. 24, n. 4, p. 770-780, 2019.

[23] SILVA JR, J. J.; COLOMBO, A.; SILVA, E. L.; SCALCO, M. S. Determinação da condutividade hidráulica do solo utilizando o problema inverso do software hydrus-1d. Revista Agroambiente, v. 7, n. 3, p. 242-251, set. 2013.

[24] Souza, P. G. C.; Júnior, J. C. F. B.; Viana, J. H. M. Curva de retenção e disponibilidade total de água em Latossolos empregando funções de pedotransferência. Revista Engenharia na Agricultura, v.25, n.5, p. 417-427, 2017.

[25] Villarreal, R.; Lozano, L. A.; Melani, E. M.; Salazar, M. P.; Otero, M. F.; Soracco, C. G. (2019). Diffusivity and sorptivity determination at different soil water contents from horizontal infiltration. Geoderma, 338, 88-96. Doi:10.1016/j.geoderma.2018.11.045

[26] Yang, H.; Rahardjo, H.; Leong, E. C.; Fredlund, D.G. 2004 A study of infiltration on three sand capillary barriers. Canadian Geotechinical Journal, 41(4), 629-643.

[27] Zeng, W.; Lei, G.; Zha, Y.; Fang, Y.; Wu, J.; Huang, J. 2018 Sensitivity and uncertainty analysis of the HYDRUS1D model for root water uptake in saline soils. Crop and Pasture Science. 69(2), 163-173.

[28] ZHANG, X.; ZHU, J.; WENDROTH, O.; MATOCHA, C.; EDWARDS. D. (2019). "Effect of macroporosity on pedotransfer function estimates at the field scale". Vadose Zone 18(1), pp. 1-15.

[29] ZHOU, A.; HUANG, R.; SHENG, D. Capillary water retention curve and shear strength of unsaturated soils. Canadian Geotechinical Journal, v. 01, p. 974-987, 2017. 


\section{Capítulo 9}

Uso da análise de regressão na obtenção de funções de pedotransferência utilizadas na estimativa da condutividade hidráulica saturada de solos brasileiros

\section{Marco Aurélio Calixto Ribeiro de Holanda}

Willames de Albuquerque Soares

Diogo Botelho Correa de Oliveira

Camilla Barrêtto Rique de Barros

Ariela Rocha Cavalcanti

Resumo: A condutividade hidráulica saturada, Ks, é um parâmetro hidrodinâmico importante para qualquer estudo de infiltração de água no solo. Deste modo, estimar seu valor de forma rápida, confiável e econômica é de fundamental importância. Sendo assim, objetivou-se realizar ajustes em funções de pedotransferência (FPTs) preexistentes, por meio do uso de regressões, para a obtenção dos valores de Ks. Para isso, foram escolhidas 10 FPTs de diferentes autores e utilizou-se como parâmetros de comparação os valores do Coeficiente de Determinação Ajustado, R2ajus, e do Erro Padrão. Os valores de R2ajus para a FPT proposta por Wösten et al. (1999) foram os maiores dentre todas as 10 FPTs testadas, chegando a 41 e $42 \%$ para os solos arenosos e argilosos respectivamente. Já as funções propostas por Cosby et al. (1984) e Campbell (1985) apresentaram os percentuais mais baixos, chegando a 1\%. Apesar dos valores de R2ajus estarem abaixo de 42\%, o resultado obtido não implica que o uso da FPT foi uma escolha incorreta, uma vez que elas não levam em consideração parâmetros geomorfológicos dos solos. Sendo assim, FPTs que utilizem alguma informação relacionada a textura ou ao arranjo dos poros no solo tendem a apresentarem resultados mais expressivos.

Palavras-chave: condutividade hidráulica saturada, HYBRAS, solos brasileiros. 


\section{INTRODUÇÃO}

A Condutividade hidráulica saturada do solo descreve o modo como o sistema poroso é composto e disposto dentro do perfil. Entretanto, esta propriedade está diretamente relacionada com a composição mineralógica, a textura e o tipo de utilização do solo (Klar, 1984; Panachuki et al., 2011). Sendo assim, costuma-se encontrar altos valores de $\mathrm{K}_{\mathrm{s}}$ para solos com texturas mais grossas, pois há mais vazios (Gonçalves e Libardi, 2013). Entretanto, outros autores mostraram que o arranjo dos poros dentro do solo pode auxiliar a explicar porque solos com uma composição granulométrica mais argilosa ou siltosa possuem altos valores de $\mathrm{K}_{\mathrm{s}}$ (Souza et al., 2016).

Diversas técnicas podem ser utilizadas para estimar as propriedades hidráulicas do solo, como o $\mathrm{K}_{\mathrm{s}}$, incluindo ensaios de campo e laboratório, os quais podem ser complexos pois dependem de fatores importantes para a realização, como materiais adequado e específicos, tempo e experiência, o que acaba sendo oneroso (Di Prima, et al., 2018; Souza et al., 2008). Entretanto, estes métodos de determinação destas propriedades são considerados de difícil obtenção, e por isso tem se buscado maneiras de se determinar estes parâmetros de modo a se reduzir os custos e minimizar o tempo (Michelon et al., 2010).

Sendo assim, Pequeno et al. (2018) destacam que a utilização de modelos matemáticos para estimar propriedades físicas do solo tem sido amplamente empregados nas ciências edáficas, obtendo informações, normalmente difíceis de se determinar em campo ou laboratório, a partir de variáveis de fácil determinação. Essas expressões são chamadas de funções de pedotransferência (FPT) e são comumente utilizadas como uma alternativa para estimar as propriedades hidrodinâmicas do solo, de forma mais fácil e com custos mais baixos.

Klein et al. (2015) mostraram que o uso destas FPTs na estimativa da condutividade hidráulica saturada, tem sido uma alternativa simples. Porém a confiabilidade das estimativas destes parâmetros depende integralmente das variáveis utilizadas na montagem das funções de pedotransferência testadas. Para avaliar a confiabilidade dos valores de $\mathrm{K}_{\mathrm{s}}$ estimados, os autores utilizaram o coeficiente de determinação como parâmetro, assim como também foi proposto por Rodrigues e Maia (2011).

As FPT são comumente utilizadas para determinação de parâmetros físicos do solo como a condutividade hidráulica saturada e a curva de retenção de água no solo. Os fatores que mais afetam a estimativa destes parâmetros são a umidade, a porosidade e a densidade do solo (Silva et al., 2008). Entretanto, outros autores como Saxton et al. (1986), Vereecken et al. (1990) e Wösten et al. (1999) enunciaram que outros fatores como os percentuais de carbono orgânico, areia, silte e argila também influenciam nas estimativas.

Entretanto, muitas destas FPTs não foram criadas para solos brasileiros. Nemes et al. (2009) mostraram que funções de pedotransferências específicas para uma certa localidade não devem ser extrapoladas para qualquer outra área de estudo, pois há a possibilidade de se aumentar os erros associados a predição dos parâmetros hidrodinâmicos do solo. Além disso, Dashtaki et al. (2010) também mostraram que quanto maior for a similaridade entre as classes texturais dos solos estudados, melhor será o desempenho obtido com as FTPs.

Deste modo, pretende-se utilizar a regressão para propor ajustes em funções de pedotransferência preexistentes, as quais são utilizadas na estimativa da condutividade hidráulica saturada de solos, mediante o uso de outras informações como os percentuais de areia, silte, argila carbono orgânico, densidade aparente do solo, umidade volumétrica saturada e porosidade, visando a adequação delas aos solos brasileiros.

\section{METODOLOGIA}

Para facilitar a compreensão do que foi realizado neste estudo, foi montado um organograma mostrando como a metodologia do trabalho foi estruturada, Figura 1. 
Figura 1 - Fluxograma da metodologia aplicada

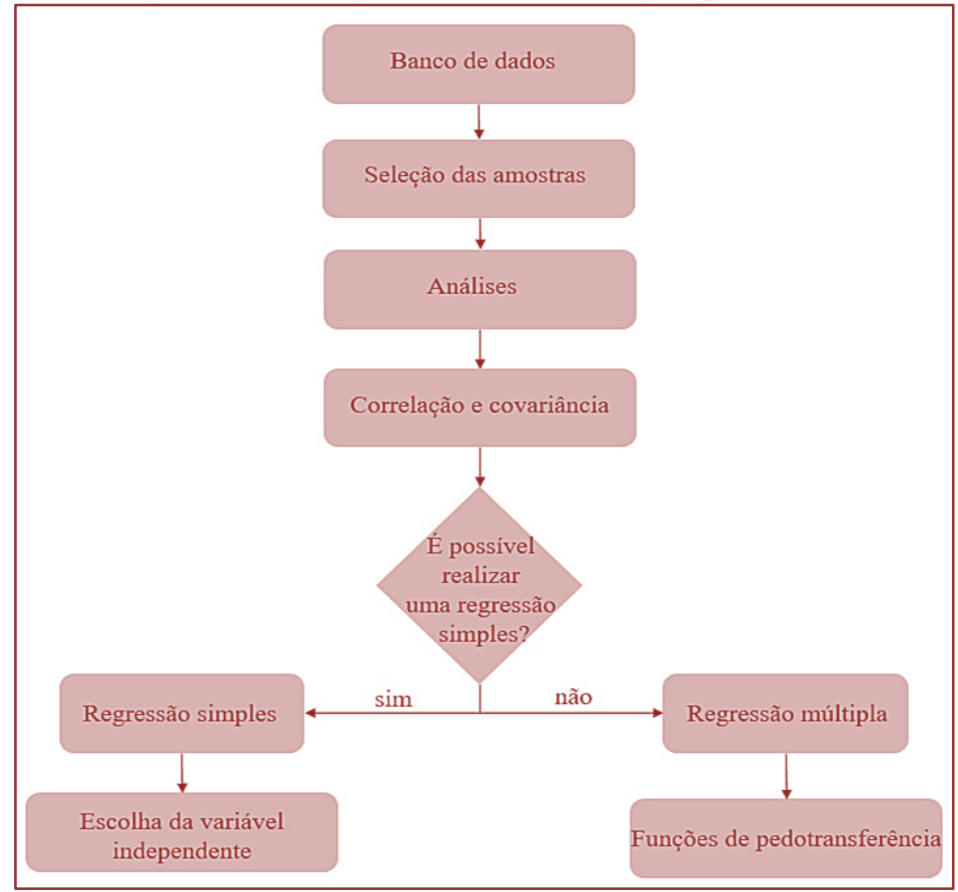

As informações utilizadas neste estudo foram obtidas a partir do banco de dados hidrofísicos de solos brasileiros, Hydrophysical Database for Brazilians Soils (HYBRAS) (Ottoni et al., 2018), o qual foi criado pelo Serviço geológico do Brasil. 0 banco conta com aproximadamente 1075 amostras, das quais foram utilizadas apenas 419, uma vez que apenas estas possuem valores para a condutividade hidráulica saturada, $\mathrm{K}_{\mathrm{s}}$, densidade aparente, umidade saturada, [ $]_{\mathrm{s}}$ e para a composição granulométrica (percentuais de areia, silte e argila). As amostras utilizadas estão representadas no triângulo textural do United States Departamento of agriculture (USDA), Figura 2.

Figura 2 - Triângulo Textural das 419 amostras utilizadas

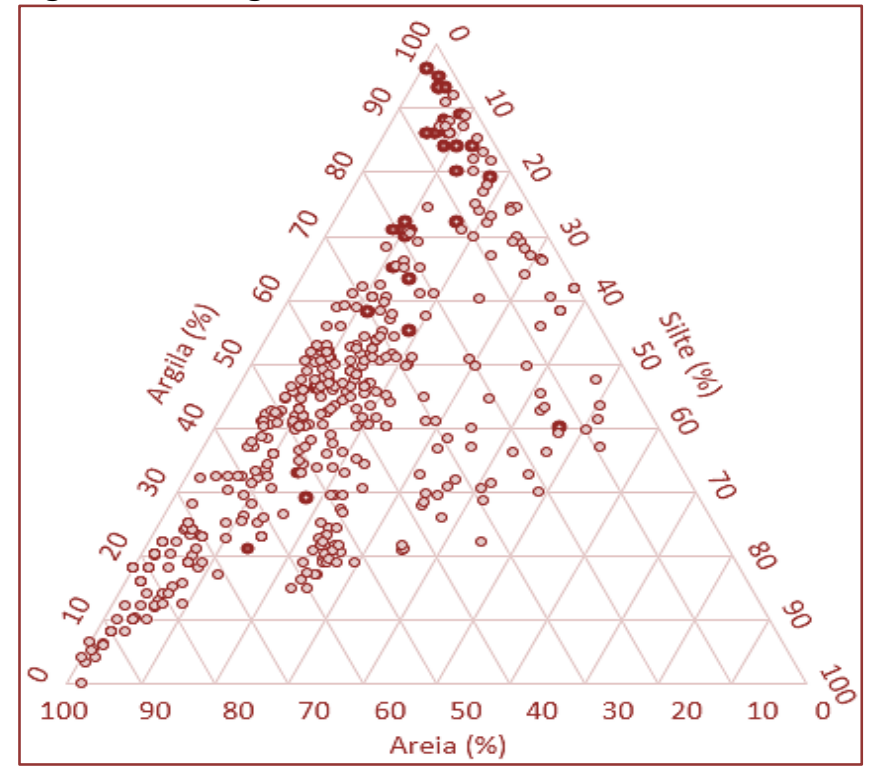


Dentre as propriedades hidrodinâmicas das amostras dos solos, presentes no banco de dados do HYBRAS, foram utilizadas a composição granulométrica, ou seja, os percentuais de areia, silte e argila, a densidade aparente do solo, os percentuais de carbono orgânico, a umidade do solo saturado, e a condutividade hidráulica saturada, os quais possuem valores máximos e mínimos representados na Figura 3.

Figura 3 - Gráfico de caixa dos parâmetros hidrodinâmicos das 419 amostras de solos

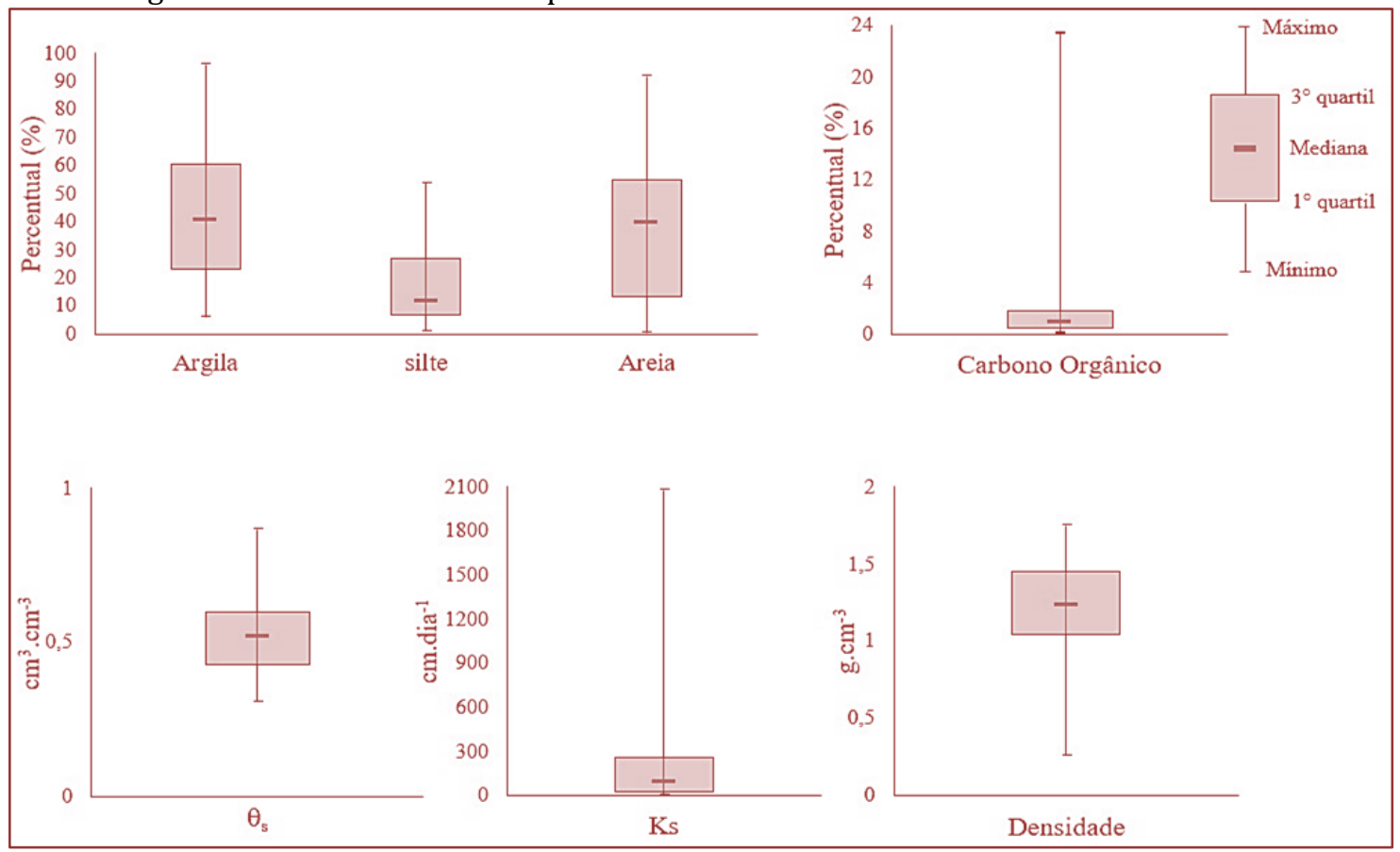

Para estas variáveis, foram realizadas as análises da covariância, da correlação, a montagem dos gráficos de dispersão entre cada uma das variáveis independentes e a condutividade hidráulica saturada (variável independente) e a regressão múltipla ou simples, dependendo da necessidade de cada variável dependente, para um nível de significância de 5\%. Caso seja necessário, a exclusão de alguma variável independente deve ser feita mediante a análise dos valores de Variance Inflation Factor (VIF), Equação 1. Neste caso, o critério de exclusão utilizado foi o VIF maior que 10. No caso das regreções múltiplas, foram utilizadas as funções de pedotransferência propostas por: Campbell (1985), Cosby et al. (1984), Cosby et al. (Modificado) (1984), Brakensiek et al. (1984), Wösten (1997) para solos arenosos e argilosos, Wösten et al. (1999), Saxton et al. (1986), Vereecken et al. (1990) e Rawls e Brakensiek (1989), Equações 2-11, respectivamente.

1) $\quad V I F=\frac{1}{1-R^{2}}$

2) $K_{S}=x_{1} * e^{-x_{2}(S+A)}$

3) $K_{S}=x_{3} * 10^{-x_{4}+x_{5} A-x_{6} C}$

4) $K_{S}=x_{3} * 10^{-x_{4}+x_{5} A-x_{6} C+D}$

5) $K_{S}=x_{7} * e^{x_{8} \theta_{S}-x_{9}-x_{10} C+x_{11} A^{2}-x_{12} C^{2}-x_{13} \theta_{S}{ }^{2}+x_{14} A * \theta_{S}-x_{15} A^{2} * \theta_{S}{ }^{2}-x_{16} C^{2} * \theta_{S}{ }^{2}+x_{17} A^{2} * C+x_{18} C^{2} * \theta_{S}+x_{19} A^{2} * \theta_{S}-x_{20} C^{2} * S}$

6) $K_{S}=x_{21} * e^{x_{22}-x_{23} D^{2}-x_{25} C O+x_{26} C O^{2}-x_{27} \ln (C A)}$

7) $K_{S}=x_{21} * e^{-x_{28} D-x_{29} D^{2}-x_{30} C O+x_{31} C O^{2}+x_{32} \ln (C O)-x_{33} C * C O-x_{34} D * C O}$

8) $K_{S}=x_{21} * e^{x_{35}+x_{36} S+x_{37} \text { topsoil }-x_{38} D^{2}-x_{39} C^{2}-x_{40} S^{2}+x_{41} S^{-1}-x_{42} C O^{-1}-x_{43} \ln (S)-x_{44} D * C-x_{45} D . C O+x_{46} \text { topsoil } * C-x_{47} \text { topsoil } * S}$ 


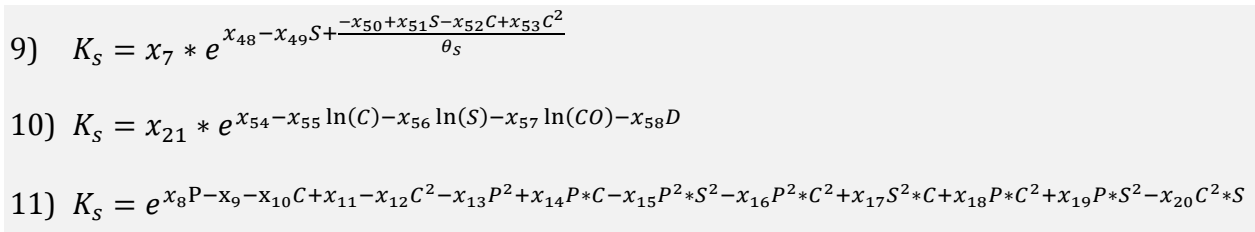

Onde $A, S$ e $C$, representam respectivamente os percentuais de areia, silte e argila, $C O$ o percentual de carbono orgânico, $D$ é a densidade aparente do solo em g. $\mathrm{cm}^{-3}, C A$ é a soma entre os percentuais de areia e argila, topsoil é uma constante unitária ou nula caso a amostra seja superficial ou subsuperficial, respectivamente, $K_{s}$ é a condutividade hidráulica saturada em $\mathrm{m}_{\mathrm{s}} \mathrm{s}^{-1}, P$ representa a porosidade e $x_{1}-X_{58}$ são constantes.

Para a realização da regressão múltipla destas funções de pedotransferência, utilizou-se o software M.S. Excel. Estas funções de pedotransferência foram analisadas para solos: i) apenas arenosos, ii) apenas argilosos e iii) para todos os tipos de solos em conjunto, com exceção da FPT de Wösten (1997) a qual não pode ser utilizada para a combinação de todos os solos. Neste caso, foram analisados o Erro Padrão e o $\mathrm{R}^{2}$ ajust, respectivamente Equações 12 e 13, como critérios de análise.

12) ErroPadrão $=\frac{\sigma}{\sqrt{n}}$
13) $R_{\text {ajust }}^{2}=1-\left(\frac{n-1}{n-(k+1)}\right)\left(1-R^{2}\right)$

Onde, $n$ representa o tamanho da amostra, $\sigma$ o desvio padrão e $k$ o grau de liberdade. Para estas análises, foi adotado um nível de significância de 5\%, logo quanto mais próximos de 0,95 estiverem os valores de $\mathrm{R}^{2}$ ajust melhor foi o desempenho da FPT. Contudo, valores acima de $56 \%$ serão muito bem apreciados, pois alguns autores como Dalbianco et al. (2008) obtiveram valores inferiores a este e ainda assim foram considerados bons resultados.

\section{RESULTADOS E DISCUSSÃo}

Os resultados das análises de covariância e da correlação, Tabelas 1 e 2, mostraram que as variáveis independentes não se correlacionam muito bem com a variável dependente, de modo que uma única variável independente pudesse ser utilizada para expressar o $\mathrm{K}_{\mathrm{s}}$. Isso fica claro quando se analisa, por exemplo, a covariância e a correlação entre o $\mathrm{K}_{\mathrm{s}}$ e o percentual de areia, onde o valor da covariância foi $o$ maior dentre todas as variáveis testadas $(2619,98)$, porém a correlação entre elas foi baixa $(0,32)$, uma vez que o maior valor que se pode obter é um.

Também é possível notar que mesmo o valor da correlação, entre a condutividade hidráulica saturada e o percentual de areia, sendo o maior dentre todos os obtidos a correlação não foi satisfatória, uma vez que foi bem inferior aos 95\%. Deste modo, não é possível se utilizar apenas os percentuais de areia ou de qualquer de qualquer outra variável para justificar o uso de uma regressão simples. Ou seja, os baixos valores do coeficiente de correlação mostram que é necessário a realização de uma regressão múltipla para avaliar a sinergia destas variáveis na previsão dos valores de $\mathrm{K}_{\mathrm{s}}$.

Tabela 1 - Valores de covariância entre as variáveis

\begin{tabular}{|c|c|c|c|c|c|c|c|}
\hline & Argila & Silte & Areia & $\begin{array}{l}\text { Carbono } \\
\text { Orgânico }\end{array}$ & $\theta_{\mathrm{s}}$ & Densidade & $\mathrm{K}_{s}$ \\
\hline Argila & 564,30 & & & & & & \\
\hline Silte & $-15,01$ & 193,73 & & & & & \\
\hline Areia & $-549,28$ & $-178,72$ & 728,00 & & & & \\
\hline Carbono Orgânico & $-9,60$ & 14,97 & $-5,37$ & 8,06 & & & \\
\hline$\theta_{\mathrm{s}}$ & 1,26 & 0,88 & $-2,14$ & 0,18 & 0,01 & & \\
\hline Densidade & $-3,28$ & $-1,81$ & 5,09 & $-0,52$ & $-0,03$ & 0,08 & \\
\hline $\mathrm{K}_{\mathrm{s}}$ & $-2824,58$ & 204,60 & 2619,98 & 56,71 & $-3,43$ & 13,08 & 91575,10 \\
\hline
\end{tabular}


Tabela 2 - Valores de correlação entre as variáveis

\begin{tabular}{|c|c|c|c|c|c|c|c|}
\hline $\mathrm{R}$ & Argila & Silte & Areia & $\begin{array}{l}\text { Carbono } \\
\text { Orgânico }\end{array}$ & 国s & Densidade & $\mathrm{K}_{\mathrm{s}}$ \\
\hline Argila & 1,00 & & & & & & \\
\hline Silte & $-0,04$ & 1,00 & & & & & \\
\hline Areia & $-0,86$ & $-0,48$ & 1,00 & & & & \\
\hline Carbono Orgânico & $-0,14$ & 0,38 & $-0,07$ & 1,00 & & & \\
\hline$\theta_{\mathrm{s}}$ & 0,47 & 0,56 & $-0,71$ & 0,58 & 1,00 & & \\
\hline Densidade & $-0,48$ & $-0,45$ & 0,65 & $-0,63$ & 0,94 & 1,00 & \\
\hline $\mathrm{K}_{\mathrm{s}}$ & $-0,39$ & 0,05 & 0,32 & 0,07 & 0,10 & 0,15 & 1,00 \\
\hline
\end{tabular}

Além disso, foram calculados os valores de $\mathrm{R}^{2}$ e VIF presentes nas Tabelas 3 e 4 . Como os valores dos coeficientes de determinação entre as variáveis independente e o $K_{s}$ não chegam a 0,95, bem como pode ser observado Tabela 3, infere-se que não é possível deixar de utilizar uma das variáveis independentes. Entretanto como o valor do $\mathrm{R}^{2}$ entre a densidade e ? ${ }_{s}$, por exemplo, é alto (mesmo que não chegue a 0,95 ), não se faz necessário o uso de ambas as variáveis, sendo possível deixar de utilizar uma delas. Tal fato é evidenciado nas funções de pedotransferência apresentadas, Equações 2-11, onde nenhuma delas faz o uso simultâneo da densidade e do $\theta_{\mathrm{s}}$.

Entretanto, é possível decidir pela exclusão de alguma variável independente mediante os valores do VIF, de modo que valores acima ou próximos de 10 apontam para uma colinearidade das variáveis independentes. Esta exclusão aumenta a confiabilidade dos valores estimados de condutividade hidráulica saturada, a qual diminui com a multicolinearidade das variáveis (Araujo et al., 2011).

Tabela 3 - Valores do coeficiente de determinação entre as variáveis

\begin{tabular}{|c|c|c|c|c|c|c|c|}
\hline $\mathrm{R}^{2}$ & Argila & Silte & Areia & $\begin{array}{l}\text { Carbono } \\
\text { Orgânico }\end{array}$ & 国s & Densidade & $\mathrm{K}_{\mathrm{s}}$ \\
\hline Argila & 1,00 & & & & & & \\
\hline Silte & 0,01 & 1,00 & & & & & \\
\hline Areia & 0,73 & 0,23 & 1,00 & & & & \\
\hline Carbono Orgânico & 0,02 & 0,14 & 0,01 & 1,00 & & & \\
\hline$\theta_{\mathrm{s}}$ & 0,22 & 0,32 & 0,50 & 0,34 & 1,00 & & \\
\hline Densidade & 0,23 & 0,20 & 0,42 & 0,39 & 0,89 & 1,00 & \\
\hline $\mathrm{K}_{\mathrm{s}}$ & 0,15 & 0,01 & 0,10 & 0,01 & 0,01 & 0,02 & 1,00 \\
\hline
\end{tabular}

Tabela 4 - Valores de Variance Inflation Factor (VIF) para as variáveis utilizadas

\begin{tabular}{|c|c|c|c|c|c|c|c|}
\hline VIF & Argila & Silte & Areia & $\begin{array}{l}\text { Carbono } \\
\text { Orgânico }\end{array}$ & 回s & Densidade & $\mathrm{K}_{\mathrm{s}}$ \\
\hline Argila & 1,00 & & & & & & \\
\hline Silte & 1,00 & 1,00 & & & & & \\
\hline Areia & 3,76 & 1,29 & 1,00 & & & & \\
\hline Carbono Orgânico & 1,02 & 1,17 & 1,00 & 1,00 & & & \\
\hline$\theta_{\mathrm{s}}$ & 1,29 & 1,47 & 2,01 & 1,51 & 1,00 & & \\
\hline Densidade & 1,29 & 1,25 & 1,73 & 1,65 & 8,86 & 1,00 & \\
\hline $\mathrm{K}_{\mathrm{s}}$ & 1,18 & 1,00 & 1,11 & 1,00 & 1,01 & 1,02 & 1,00 \\
\hline
\end{tabular}

Por meio das Equações 2-11 foi possível realizar a regressão múltipla não linear dos dados obtidos no HYBRAS, afim de verificar o quanto as variáveis dependentes estão correlacionadas com a condutividade hidráulica saturada. Como resultado destas regressões obteve-se os valores do coeficiente de determinação ajustado ( $\mathrm{R}^{2}$ ajus $)$ e do Erro Padrão, presentes na Tabela 5. 
Meio Ambiente, Sustentabilidade e Tecnologia - Volume 5 - Recursos Hídricos

Tabela 5 - Valores de $\mathrm{R}^{2}$ ajus e Erro Padrão para as diferentes FPT e texturas

\begin{tabular}{|c|c|c|c|}
\hline Referência & Textura & $\mathrm{R}^{2}$ ajus & Erro Padrão $\left(\mathrm{m} \cdot \mathrm{s}^{-1}\right)$ \\
\hline \multirow{3}{*}{ Wösten et al. (1999) } & Arenosos & 0,41 & 1,33 \\
\hline & Argilosos & 0,42 & 1,31 \\
\hline & Todos & 0,36 & 1,41 \\
\hline \multirow{3}{*}{ Wösten (1997) } & Arenosos & 0,30 & 1,45 \\
\hline & Argilosos & 0,26 & 1,46 \\
\hline & Todos & $*$ & $*$ \\
\hline \multirow{3}{*}{ Vereecken et al. (1990) } & Arenosos & 0,29 & 1,46 \\
\hline & Argilosos & 0,05 & 1,46 \\
\hline & Todos & 0,25 & 1,52 \\
\hline \multirow{3}{*}{ Saxton et al. (1986) } & Arenosos & 0,17 & 1,46 \\
\hline & Argilosos & 0,18 & 1,25 \\
\hline & Todos & 0,21 & 1,36 \\
\hline \multirow{3}{*}{ Rawls et al. (1998) } & Arenosos & 0,32 & 0,32 \\
\hline & Argilosos & 0,15 & 1,60 \\
\hline & Todos & 0,16 & 1,56 \\
\hline \multirow{3}{*}{ Brakensiek et al. (1984) } & Arenosos & 0,32 & 1,44 \\
\hline & Argilosos & 0,36 & 1,11 \\
\hline & Todos & 0,30 & 1,28 \\
\hline \multirow{3}{*}{ Cosby et al. (1984) } & Arenosos & 0,18 & 0,65 \\
\hline & Argilosos & 0,01 & 0,75 \\
\hline & Todos & 0,02 & 0,73 \\
\hline \multirow{3}{*}{ Cosby et al. (1984) (Modificado) } & Arenosos & 0,26 & 0,62 \\
\hline & Argilosos & 0,01 & 0,75 \\
\hline & Todos & 0,03 & 0,73 \\
\hline \multirow{3}{*}{ Campbell (1985) } & Arenosos & 0,18 & 1,49 \\
\hline & Argilosos & 0,01 & 1,73 \\
\hline & Todos & 0,02 & 1,67 \\
\hline
\end{tabular}

* A FPT proposta é exclusiva para solos arenosos ou argilosos, mas não para todos juntos.

Como é possível se observar na Tabela 5, os valores dos coeficientes de determinação ajustado estão entre 1 e 42\% (valores referentes as FPTs de Cosby et al. (1984) e Campbell (1985) para solos argilosos e de Wösten et al. (1999) para solos arenosos), o que podem ser considerados baixos. Entretanto, como a maior parte das variáveis utilizadas não estão relacionadas com o arranjo e a geometria dos poros, então era de se esperar que os valores de $\mathrm{R}^{2}$ ajus não fossem altos (Silva et al., 2009, Klein et al., 2014). Tais resultados corroboram com o que foi encontrado por Rodrigues \& Maia (2011), onde os autores utilizaram os dados percentuais de areia, silte e argila, densidade e matéria orgânica para encontrar as FPT e coeficientes de determinação ajustados inferiores a 34\%.

Além disso, também é notório, mediante o uso da Tabela 5, que os valores de Erro Padrão encontrados, entre 0,32 e 1,73 m.s ${ }^{-1}$ não são pequenos quando comparados com os obtidos por Rodrigues e Maia (2011). Contudo, se as funções de pedotransferências utilizadas, tivessem alguma ligação com a geometria e com o arranjo dos poros, ou seja, com o formato dos grãos e com o modo como os vazios estão distribuídos dentro perfil do solo, se esperaria que os valores de correlação encontrados fossem mais robustos, (Michelon et al., 2010; Zhang et al., 2015).

Dalbianco et al. (2008) também mostraram que o uso de funções de pedotransferência para estimativa da condutividade hidráulica saturada, que tenham como variáveis independentes os percentuais de macroporosidade, propiciou a obtenção de valores de $\mathrm{R}^{2}$ ajus de $56 \%$. Contudo, a inserção de outras variáveis, como o percentual de cascalho, tornou a equação mais complexa, entretanto mais confiável, uma vez que os valores de $\mathrm{R}^{2}$ ajus subiram para $64 \%$. Entretanto, o banco de dados do HYBRAS não dispõe de todas estas informações.

Amorim et al. (2011) mostraram que o conhecimento da distribuição espacial de propriedades físicas do solo, como a condutividade hidráulica saturada, é de suma importância. Tal inferência se deve aos resultados obtidos com a correlação realizada entre os valores de $\mathrm{K}_{\mathrm{s}}$ com o volume de poros e com a umidade do solo, os quais apresentaram alta e baixa correlação, respectivamente. Sendo assim, estes autores concluíram que a função de pedotransferência encontrada (a qual se baseia na FPT proposta por Campbell (1985)) mediante a correlação com o volume dos poros pode ser uma alternativa para a estimativa dos valores de $\mathrm{K}_{\mathrm{s}}$. Entretanto, para as 419 amostras de solos testadas, esta mesma FPT apresentou resultados inferiores aos obtidos por estes autores. 
Além disso, observa-se que os valores de $\mathrm{R}^{2}$ ajus são maiores quando os solos foram separados por classe textural, principalmente para os solos arenosos, em detrimento aos valores obtidos para todos os solos, sem segregação. Isto indica uma melhor capacidade de previsão do $\mathrm{K}_{\mathrm{s}}$, por parte das FPTs testadas, para os solos arenosos do que para os solos argilosos, ou para todo um banco de dados, sem nenhuma segregação quanto a classe textural, corroborando com o que foi enunciado por Dashtaki et al. (2010).

Os resultados obtidos para a função de pedotransferência de Cosby (1984) (modificada) foram superiores aos encontrados para a FPT inalterada, uma vez que a alteração resultou em valores de $\mathrm{R}^{2}$ iguais a 1 e $26 \%$, enquanto que função de pedotransferência proposta por Cosby (1984) obteve valores de $\mathrm{R}^{2}$ ajus iguais a 1 e 18\%, para os solos argilosos e arenosos, respectivamente. Além disso, os valores de erro padrão para a função modificada, $0,62 \mathrm{~m} \cdot \mathrm{s}^{-1}$, foi inferior ao valor apresentado pela FPT proposta $0,65 \mathrm{~m} . \mathrm{s}^{-1}$.

\section{CONCLUSÕES}

Os valores do coeficiente de determinação ajustados encontrados para os solos arenosos foram maiores que os valores encontrados para os solos argilosos, indicando que as equações de pedotransferência utilizadas, Equações 2-6 e Equações 8-11, se adequam melhor aos solos com esta classe textural. E os valores de erro padrão encontrados não são baixos, entre 0,32 e 1,73 m.s.1.

A função de pedotransferência proposta por Wöston (1997) foi criada exclusivamente para solos arenosos ou solos siltosos ou argilosos, e por isso não há estimativas da condutividade hidráulica saturada quando se pretende analisar todas as 419 amostras de solos juntas. Além disso, os resultados obtidos para a função modificada de Cosby (1984) foram melhores que os obtidos para a FPT inalterada.

As funções de pedotransferência que tenham alguma variável independente que esteja relacionada com o arranjo ou com a geometria dos poros possuem uma maior chance de obter valores de $\mathrm{K}_{\mathrm{s}}$ mais confiáveis, uma vez que os coeficientes de determinação ajustados costumam ser maiores nestes casos. Entretanto, dentre as FPTs testadas a de Wöisten et al., (1990) foi a que apresentou os melhores resultados, com $\mathrm{R}^{2}$ ajus de $42 \%$ para solos argilosos e 41\% para solos arenosos, enquanto que as FPTs de Cosby et al. (1984) e de Campbell (1985) apresentaram os piores resultados, $\mathrm{R}^{2}=1 \%$ para solos argilosos e $18 \%$ para solos arenosos.

Apesar dos valores de $\mathrm{R}^{2}$ ajus estarem abaixo de 42\%, o resultado obtido não implica que o uso da FPT foi uma escolha incorreta, uma vez que elas não levam em consideração parâmetros geomorfológicos dos solos. Sendo assim, funções de pedotransferência que utilizem alguma informação relacionada a textura ou ao arranjo dos poros no solo tendem a apresentarem valores de correlação mais expressivos.

\section{CONSIDERAÇÕES FINAIS}

Este artigo foi publicado nos anais do XV Simpósio de Recursos Hídricos do Nordeste, o qual é organizado pela Associação Brasileira de Recursos Hídricos (ABRHidro). Os Autores também agradecem a Escola Politécnica de Pernambuco-POLI(UPE) e ao Programa de Pós-Graduação em Engenharia Civil (PEC-POLI) pela infraestrutura disponibilizada e a Coordenação de Aperfeiçoamento de Pessoal de Nível Superior (CAPES) pela concessão das bolsas.

\section{REFERÊNCIAS}

[1] AMORIM, D. D.; GONTIJO, I. ; SANTOS, E. O. J.; NICOLE, L. R. (2011). “Correlação espacial entre a condutividade hidráulica e atributos físicos do solo”. Enciclopédia Biosfera 7(13), pp. 263-275.

[2] ARAUJO, G. L.; REIS, E. F.; MOREIRA, G. R. (2011). “Correlações entre variáveis climatológicas e seus efeitos sobre a evapotranspiração de referência”. Revista Brasileira de Agricultura Irrigada 5, pp. 96-104.

[3] BRAKENSIEK, D.L., RAWLS, W.J., STEPHENSON, G.R. (1984) "Modifying SCS hydrologic soil groups and curve numbers for rangeland soils". American Society of Agricultural Engenieering.

[4] CAMPBELL, G. S. (1985). Soil physics with basic: transport models for soil plant systems. Elsevier, Amsterdam, $150 \mathrm{p}$.

[5] COSBY, B.J.; HORNBERGER, G.M.; CLAPP, R.B. and GINN, T.R. (1984). "A statistical exploration of the relationship of soil moisture characteristics to the physical properties of soils". Water Resources Research 20(6), pp. 682-690.

[6] DALBIANCO, L; REICHERT, J.M.; RODRIGUES, M. F.; WINK, C.; REINERT, D.J. (2008). "Relações entre a condutividade hidráulica de solo saturado e atributos físicos de uma microbacia hidrográfica" in Anais da VII Reunião 
Sul-brasileira de Ciência do Solo, 2008, Santa Maria. Ciência do Solo no RS e SC: onde estamos e para onde vamos, pp. $1-6$.

[7] DASHTAKI, S. G.; HOMAEE, M.; KHODABERDILOO, H. (2010); "Derivation and validation of pedotransfer functions for estimating soil water retention curve using a variety of soil data". Soil Use and Management 26(1), pp.6874.

[8] DI PRIMA, S.; LASSABATÈRE, L.; ANGULO-JARAMILlHO, R.; PIRASTRU, M.; CERDÀ, A.; KEESSTRA, S. (2018). "Laboratory testing of Beerkan infiltration experiments for assessing the role of soil sealing on water infiltration". Catena, 167, pp. 373-384.

[9] GONÇALVES, A. D. M. A.; LIBARDI, P. L. (2013). “Análise da determinação da condutividade hidráulica do solo pelo método do perfil instantâneo". Revista Brasileira de Ciências do Solo 37(5), pp. 1174-1184.

[10] KLAR, A. E. (1984). A água no sistema solo-planta-atmosfera. Editora Nobel, Sao Paulo, 408p.

[11] KLEIN, C.; KLEIN, V. A.; LEVINSKI, F.; BORTOLANZA, D. R. (2015). "Predição da condutividade hidráulica do solo saturado a partir de propriedades físicas do solo". Vivências 11, pp. 191-198.

[12] MICHELON, C. J.; CARLESSO, R.; OLIVEIRA, Z. B. ; KNIES, A. ; PETRY, M. T.; MARTINS, J. D. (2010). "Funções de pedotransferência para estimativa da retenção de água em alguns solos do Rio Grande do Sul”. Ciência Rural 40, pp. 848853.

[13] NEMES, A.; TIMLIN, D. J.; PACHEPSKY, Y. A.; RAWLS, W. J. (2009). "Evaluation of the pedotransfer functions for their applicability at the U.S. National Scale". Soil Science Society of America Journal 73(5), pp.1638-1645.

[14] OTTONI, M. V. T. B.; OTTONI FILHO, M. G.; SCHAAP, M. L.; LOPES-ASSAD, R. C; ROTUNNO FILHO, O. C. (2018). "Hydrophysical database for Brazilian soils (HYBRAS) and pedotransfer functions for water retention". Vadose Zone Journal 17(1), pp. 1-17.

[15] PANACHUKI, E.; BERTOL, I.; SOBRINHO, T. A.; OLIVEIRA, P. T. S.; RODRIGUES, D. B. B. (2011). “Perdas de solo e de água e infiltração de água em Latossolo Vermelho sob sistemas de manejo". Revista Brasileira de Ciência do Solo 35, pp. 1777-1785.

[16] PEQUENO, P. L. L.; FAGUNDES, F. P.; SANTOS, R. C.; SANTINI, C. L. A.; RAMBO, M. A.; SCHLINDWEIN, J. A. (2018). "Uso de funções de pedotransferência para estimativa da retenção de água em um latosso no estado de Rondônia". Revista Eletrônica de Engenharia Civil 14(2), pp. 229-239.

[17] RAWLS, W. J.; BRAKENSIEK, D. L. (1989). "Estimation of soil water retention and hydraulic properties". In Unsaturated Flow in Hydrologic Modeling Theory and Pratice. Org. por MOREL-SEYTOUX, H. J., Kluwer Academic Publisher, pp. 275-300.

[18] RODRIGUES, L. N.; MAIA, A. H. N. (2011). "Funções de pedotransferência para estimar a condutividade hidráulica saturada e as umidades de saturação e residual do solo em uma bacia hidrográfica do Cerrado". In Anais do XIX Simpósio Brasileiro de Recursos Hídricos, Maceió. A água no mundo em transformação, 2011, pp. 1-12.

[19] SAXTON, K. E.; RAWLS, W. J.; ROMBERGER, J. S.; PAPENDICK, R.I. (1986). “Estimating generalized soil water characteristics from texture". Soil Science Society of America Journal 50, pp.1031-1036.

[20] SILVA, Á. P.; LEAO, T. P.; TORMENA, C. A.; GONCALVES, A. C. A. (2009). "Determinação da permeabilidade ao ar em amostras indeformadas de solo pelo método da pressão decrescente". Revista Brasileira de Ciência do Solo 33(6), pp. 1535-1545.

[21] SILVA, A. P.; TORMENA, C. A.; FIDALSKI, J.; IMHOFF, S.; (2008). “Funções de pedotranferência para as curvas de retenção de água e de resistência do solo à penetração". Revista Brasileira de Ciência do Solo 32(1), pp. 1-10.

[22] SOUZA, E. S.; ANTONINO, A. C. D.; JARAMILLO, R. A.; NETTO, A. M.; (2008). "Caracterização hidrodinâmica de solos: aplicação do método beerkan". Revista Brasileira de Engenharia Agrícola e Ambiental 12(2), pp. 128-135.

[23] SOUZA, E. S.; ANTONINO, A. C. D.; MACIEL NETTO, A.; SOUZA, R. M. S.; GONDIM, M. V. S.; LIMA, V. F.; LIMA, J. R. S.; ALVES, E. M.; COUTINHO, A. P.; SOARES, W. A. (2016). "Comportamento hidrodinâmico de solos em cultivos de vazante no semiárido de Pernambuco". Journal of Environmental Analysis and Progress 1(1), pp. 52-60.

[24] WAGNER, B.; TARNAWSKI, V. R.; HENNINGS, V.; MULLER, U.; WESSOLEK, G.; PLAGGE, R. (2001). "Evaluation of pedo-transfer functions for unsaturated soil hydraulic conductivity using an independent data set". Geoderma 1(102), pp. 275-297.

[25] VEREECKEN, H.; MAES, J.; FEYEN, J. (1990). “Estimating unsaturated hydraulic conductivity from easily measured soil properties". Soil Science 149, pp. 1-12.

[26] WÖSTEN, J. H. M. (1997). "Pedotransfer functions to evaluate soil quality". In Soil Quality for Crop Production and Ecosystem Health. Developments in Soils Science. Org. por GREGORICH, E. G.; CARTER, M. R., Elsevier, pp. 221-245.

[27] WÖSTEN, J. H. M.; LILLY, A.; NEMES, A.; LE BAS, C. (1999). "Development and use of a database of hydraulic properties of European soils". Geoderma 90, pp. 169-185.

[28] ZHANG, X.; ZHU, J.; WENDROTH, O.; MATOCHA, C.; EDWARDS. D. (2019). "Effect of macroporosity on pedotransfer function estimates at the field scale". Vadose Zone 18(1), pp. 1-15. 


\title{
Capítulo 10
}

\section{Transporte de Diclofenaco em solo do Agreste de Pernambuco}

\author{
Ebenézer de França Santos \\ Manuella Virgínia Salgueiro Gondim \\ Antônio Celso Dantas Antonino \\ Valmir Felix de Lima
}

Resumo: Diclofenaco é um composto fármacológico utilizados como analgésico e antipirético, encontrado em efluentes de estações de tratamento de esgoto e em águas superficiais. Este trabalho teve por objetivo construir e análisar a curva de eluição, determinar os mecanismos predominantes no transporte desse composto e quantificar os parâmetros hidrodispersivos em solo do agreste de Pernambuco, onde efluentes de estação de tratamento são utilizados para fértil-irrigação. 0 ensaio foi realizado em laboratório e a concentração do soluto determinada por cromatografia líquida de alta eficiência. Os resultados demonstraram que o modelo CDE apresentou um bom ajuste aos pontos das curvas médias de eluição do traçador $(\mathrm{KBr})$ e do diclofenaco. Os pontos das curvas médias de eluição se ajustaram bem ao modelo CDE. 0 coeficiente de dispersão hidrodinâmica variou de 30,64 a 30,09 cm2.h-1 entre as duas camadas de solo, as quais apresentaram retardamento, implicando em baixa mobilidade do soluto, o que pode ser explicado possivelmente pelas interações do diclofenaco com a matéria orgânica. A dispersividade variou de 3,80 a 3,87 cm entre as duas camadas, determinando assim a capacidade de espalhamento do diclofenaco no meio poroso. 0 processo de transporte predominante foi do tipo difusivo.

Palavras-chave: Caracterização hidrodispersiva, contaminante emergente; ensaio de coluna de solo; fármaco. 


\section{INTRODUÇÃO}

A preocupação com o destino da água e principalmente de solutos no solo crescem continuamente, à medida que aumenta a demanda pelo uso de produtos de uso agrícola, compostos farmacêuticos e de uso pessoal, subprodutos industriais, esteroides, dentre outros produtos denominados contaminantes emergentes, decorrentes do crescimento e desenvolvimento populacional, em função do potencial de contaminação do solo e de aquíferos subterrâneos que estes produtos podem provocar.

Muitos produtos farmacêuticos têm sido encontrados em diversas matrizes ambientais com o auxílio de técnicas analíticas sensíveis, capazes de determinar concentrações de até ng $\mathrm{L}^{-1}$ (ARCHER et al., 2017), por este motivo, muitos grupos de pesquisas e órgãos ambientais vêm estudando não apenas os níveis de concentração desses compostos no meio, mas a sua origem, destino e seus efeitos adversos, principalmente à biota.

o Diclofenaco (DCF) é um composto farmacológico classificado como contaminante emergente, largamente utilizado como analgésico e antipirético não-esteroide, encontrado em efluentes de estações de tratamento de esgoto e em menor concentração em águas superficiais de diversos países (ARCHER et al., 2017; BLAIR et al., 2015; KOSMA et al., 2014; OLIVEIRA, 2014; OSORIO et al., 2014; VIENO e SILLANPAA, 2014).

Os fenômenos de transporte em solos podem ser definidos como sendo o movimento de determinado composto em meio a uma ou mais camadas de solo, em ambiente saturado ou insaturado. A compreensão desses mecanismos e a análise e modelagem numérica do problema, associadas a programas de monitoramento de campo, permitem a avaliação da migração de determinados compostos no subsolo e águas subterrâneas, possibilitando desta forma a adoção de medidas preventivas ou mitigadoras do possível impacto que poderá ser ocasionado devido à aplicação de xenobióticos por certa atividade, não somente a curto, mas a médio e longo prazos no solo e recursos hídricos.

Desta forma, o objetivo deste trabalho consistiu na construção e análise das curvas de eluição, na determinação dos mecanismos predominantes no transporte de Diclofenaco (DCF) no solo, bem como na quantificação dos seus parâmetros hidrodispersivos em um solo coletado no agreste do estado de Pernambuco/Brasil.

\section{MATERIAL E MÉTODO}

\subsection{OS SOLUTOS}

Os solutos utilizados foram de dois tipos: um não reativo, utilizado como traçador, o Brometo de Potássio (KBr) na concentração de 1,0 g L-1 (GONDIM, 2014), e um reativo, o Diclofenaco (Sódico) (DCF, com pureza de 99,85\%), na concentração, $50 \mathrm{mg} \mathrm{L}^{-1}$.

\subsection{O SOLO}

As amostras de solo, classificado como Regossolo (EMBRAPA, 2001), foram extraídas na Fazenda São Francisco, localizada à Rodovia PE $200\left(8^{\circ} 17^{\prime} 02.71^{\prime \prime}\right.$ S e $36^{\circ} 34^{\prime} 42.00^{\prime \prime}$ W), no distrito de Mutuca, Zona Rural do Município de Pesqueira, Agreste de Pernambuco, distrito onde o esgoto doméstico é reutilizado na fertirrigação para fins produtivos.

O clima da região é semiárido quente, BSh, segundo Köppen-Geiger, e apresenta temperatura média de $27^{\circ} \mathrm{C}$, umidade relativa do ar de $73 \%$, com velocidades médias do vento de $2,5 \mathrm{~m} \mathrm{~s}^{-1}$ (GUSMÃO et al., 2003).

As amostras de solo foram coletadas, na camada superficial $(0,0$ a $0,20 \mathrm{~m})$ e na camada de 0,20 a $0,40 \mathrm{~m}$. As amostras indeformadas para determinação da umidade mássica foram extraídas com uso de trado tipo Uhland.

Após a coleta, as amostras foram secas ao ar, destorroadas e peneiradas em peneira de 2,0 $\mathrm{mm}$, a fim de se separar e descartar eventuais plantas, raízes e pequenas pedras. Em seguida o solo foi homogeneizado e cuidadosamente armazenado à temperatura ambiente. 


\subsection{ANÁLISES FÍSICO-QUÍMICAS}

As análises físicas do solo consistiram na determinação da umidade gravimétrica, densidade aparente e análise granulométrica, assim como na determinação da superfície específica, através de adsorção atômica (CESSA et al., 2009). A massa específica foi determinada pelo método do anel volumétrico, enquanto a análise granulométrica foi realizada através do método do densímetro (EMBRAPA, 2011) no qual as frações de silte e argila foram determinadas por sedimentação, após dispersão com hexametafosfato de sódio por agitação mecânica; e as frações de areia por peneiramento.

O método apresentado pela EMBRAPA (2011) também foi utilizado para determinação do pH em água e em $\mathrm{KCl}$, com o objetivo de determinar a carga líquida das partículas de argila, bem como na determinação do carbono orgânico.

A superfície específica das frações argila foi determinada através da adsorção de $\mathrm{N}_{2}$ no solo e construção de isotermas. Com o modelo matemático BET de Brunauer et al. (1938) apud Cessa et al. (2009), foi calculada a área superficial específica dos sólidos, conhecendo-se o volume do gás necessário para recobrir em monocamada a superfície dos sólidos (GREEG e SING, 1982 apud CESSA et al., 2009).

\subsection{ANÁLISE DO SOLUTO}

O soluto foiquantificado por Cromatografia Líquida de Alta Eficiência (CLAE) em um Cromatógrafo Dynamax, modelo SD-200 e um detector UV modelo UV-1 Rainin. As amostras foram centrifugadas a 7.000 rpm por $10 \mathrm{~min}$. Em seguida foram realizadas as análises quantitativas do sobrenadante, com as seguintes condições cromatográficas: coluna Fenomenex GEMINI C18, com $150 \mathrm{~mm}$ de comprimento, $2 \mathrm{~mm}$ de diâmetro e $5 \mu \mathrm{m}$ de espessura do filme de fase estacionária. A fase móvel foi composta de $10 \%$ de água e $89,9 \%$ de metanol e $0,1 \%$ ácido fórmico. As detecções foram por absorção ultravioleta, com comprimento de onda de $254 \mathrm{~nm}$, numa taxa de fluxo de $1,0 \mathrm{~mL} \mathrm{~min}^{-1}$. 0 volume de injeção foi de $20 \mu \mathrm{L}$ e cada amostra foi analisada em triplicata.

As curvas analíticas do DCF no Cromatógrafo foram traçadas com soluções contendo 5, 10, 20, 30, 40, 50, 60 e $70 \mathrm{mg} \mathrm{L}^{-1}$. As soluções foram preparadas através de diluições sucessivas de soluções de $70 \mathrm{mg} \mathrm{L}^{-1}$.

\subsection{ENSAIOS DE TRANSPORTE}

0 dispositivo experimental e as realizações dos ensaios adotados neste estudo foram amplamente utilizados em trabalhos anteriores (GAUDET et al., 1977; GABER et al., 1995; MARTINS e MERMOUD, 1999; MILFONT, 2006; CARMO et al., 2010; CARMO, 2012; GONDIM, 2014). Os métodos utilizados por esses autores tornaram possível caracterizar os processos de transferência de água e de solutos pela análise detalhada das curvas de eluição experimentais em solos saturados.

0 presente experimento possibilitou identificar, através da análise das curvas de eluição, os mecanismos que predominam no transporte de DCF, bem como quantificar os parâmetros hidrodispersivos do solo, fundamentais para determinação dos mecanismos de transporte desse composto no solo em estudo (GAUDET et al., 1977; GABER et al., 1995).

Os ensaios de transporte consistiram basicamente em deslocar certo volume de líquido V0 que ocupava o espaço poroso contido em uma coluna de solo, por meio de uma solução contendo o soluto (traçador ou soluto interativo) de concentração $\mathrm{C} 0$, a uma velocidade aparente média $v$. 0 soluto se difundiu ao mesmo tempo em que infiltrou, a velocidades variáveis, através dos poros do solo, originando a formação de uma zona de mistura característica do estado de dispersão do soluto.

Seguiu-se a progressão do avanço do soluto, medindo-se a concentração C do efluente no curso do tempo. A evolução da razão $\mathrm{C} / \mathrm{C} 0$ em função do número de volumes de poros do efluente coletado forneceu a curva de eluição do soluto.

Para a determinação dos parâmetros hidrodispersivos foram utilizadas colunas de solo, com paredes de acrílico, com 20,0 cm de altura e 5,0 cm de diâmetro interno, em laboratório sob regime de escoamento permanente (estado estacionário), uma bomba peristáltica com doze canais da Marca Ismaltec; um coletor de frações; um condutivímetro digital Digimed DM-31, para leitura das medidas de condutividade elétrica da solução de $\mathrm{KBr}$ efluentes de cada coluna; capilares flexíveis de borracha com 2,38 mm de diâmetro interno; e balanças digitais para determinação da massa de solução deslocadora aplicada nas colunas de solo. 
As colunas de solos foram montadas com amostras deformadas de solos, em camadas de aproximadamente $2 \mathrm{~cm}$, levemente compactadas, de forma a atingir a massa específica próxima a das condições de campo. A massa específica das partículas $\rho_{d}$ foi obtida pela relação entre a massa de solo seco $M_{S}(\mathrm{~g})$ e o volume total $V_{T}\left(\mathrm{~cm}^{3}\right)$ ocupado pelo solo no interior da coluna, conforme a equação 4.1.

$$
\rho_{d}=\frac{M_{s}}{V_{t}}
$$

Após a montagem, as colunas foram saturadas com solução iônica de 5,0 $\mathrm{g} \mathrm{L}^{-1}$ de $\mathrm{CaCl}_{2}$, na vazão de $0,2 \mathrm{~mL}$ min $^{-1}$, com carga hidráulica e fluxo ascendente, para que os colóides do solo não sofressem desestabilização, comprometendo a permeabilidade devido à diminuição da força iônica. 0 volume da $\begin{array}{llllll}\text { solução } & \text { de } & \mathrm{CaCl}_{2} & \text { utilizado } & \text { para } & \text { saturação }\end{array}$ colunas, até a formação de uma fina lâmina de água no topo das mesmas, foi utilizado como volume de poros.

Os ensaios foram realizados em triplicata, com três repetições, primeiramente com o traçador Brometo de Potássio (KBr), aplicando-se um volume de poros, na vazão de $0,25 \mathrm{~mL} \mathrm{~min}^{-1}$ e com a concentração de $1 \mathrm{~g}$ $\mathrm{L}^{-1}$ com o objetivo de fazer a caracterização hidrodispersiva nas duas camadas do solo, e em seguida empregou-se dois volumes de poros de solução contendo DCF com a concentração de $50 \mathrm{mg} \mathrm{L}^{-1}$, na vazão de $0,35 \mathrm{~mL} \mathrm{~min}^{-1}$, corresponde à precipitação média de $0,056 \mathrm{~mm} \mathrm{~h}^{-1}$ no período de 2011 a 2015 na cidade de Pesqueira.

A alimentação das colunas de solo com os solutos foi realizada utilizando-se a bomba peristáltica conectada à parte superior da coluna, sendo os efluentes da solução coletados na base da coluna por um coletor de frações.

Este tipo de ensaio corresponde ao caso em que a umidade do solo e o fluxo de água na coluna permanecem constantes ao longo do tempo. Os valores da umidade e do fluxo, neste caso, foram determinados experimentalmente, e o único valor variável no tempo foi a concentração do soluto.

O estudo foi conduzido considerando-se apenas os processos físicos envolvidos nas transferências de água e de solutos.

Os valores de concentração relativa $(\mathrm{C} / \mathrm{C} 0)$ e de seus respectivos valores de número de volume de poros foram submetidos ao software Hydrus 1D para a resolução numérica do modelo de convecção-dispersão cuja equação diferencial parcial é dada pela equação 4.2:

$$
\mathrm{R} \frac{\partial \mathrm{C}}{\partial \mathrm{t}}=\frac{1}{\mathrm{P}} \cdot \frac{\partial^{2} \mathrm{C}}{\partial \mathrm{z}^{2}}-\frac{\partial \mathrm{C}}{\partial \mathrm{z}}
$$

em que C é a concentração do soluto, expressa em massa de soluto por volume de solução [M L $\left.{ }^{3}\right] ; z^{2}$ e coordenada espacial [L]; t é o tempo [T]; P é o número de Peclet e R é o fator de retardo.

As condições de contorno para a equação:

- $\quad$ Condição inicial

- $\quad$ Condição de contorno inferior

$$
\mathrm{C}(\mathrm{z}, 0)=0
$$

$$
\frac{\partial \mathrm{C}}{\partial \mathrm{z}}(\infty, \mathrm{t})=0
$$


- $\quad$ Condição de contorno superior

$$
-\frac{1}{\mathrm{Pe}_{e}} \frac{\partial \mathrm{C}}{\partial \mathrm{z}}+\mathrm{C}= \begin{cases}\mathrm{C}_{0} & 0<\mathrm{t} \leq \mathrm{t}_{0} \\ 0 & \mathrm{t}>\mathrm{t}_{0}\end{cases}
$$

em que $\mathrm{C}_{0}$ é a concentração do soluto deslocadora [M L ${ }^{3}$ ]; t é o tempo [T]; e t $t_{0}$ é o tempo de aplicação da solução deslocadora [T].

\section{RESULTADOS E DISCUSSÃO}

\subsection{ANÁLISES FÍSICO-QUÍMICAS DO SOLO}

Através da análise granulométrica, cujos resultados estão apresentados na Tabela 1, constatou-se que o solo é classificado como Franco Arenoso, de acordo com o diagrama triangular que descreve a classificação do solo, utilizado pelo United States Department of Agriculture (USDA), que é adotado pela Sociedade Brasileira de Ciência do Solo (SBCS).

Tabela 1 - Caracterização granulométrica do solo estudado

\begin{tabular}{|c|c|c|c|c|c|c|}
\hline & Argila (\%) & Silte(\%) & $\begin{array}{c}\text { Areia Fina } \\
\text { Camadas(m) }\end{array}$ & $\begin{array}{c}\text { Areia Média } \\
(\%)\end{array}$ & $\begin{array}{c}\text { Areia Grossa } \\
(\%)\end{array}$ & $\begin{array}{c}\text { Classificação } \\
\text { Textural }\end{array}$ \\
\hline $0,00-0,20$ & 10,4 & 11,2 & 12,3 & 13,7 & 52,4 & Franco Arenoso \\
\hline $0,20-0,40$ & 12,5 & 13,8 & 14,7 & 15,2 & 43,8 & Franco Arenoso \\
\hline
\end{tabular}

Na Tabela 2 são apresentados os resultados da caracterização química do solo, em que foram quantificados os valores do potencial hidrogeniônico $(\mathrm{pH})$, do carbono oxidável e da matéria orgânica das duas camadas do solo, observando-se pela diferença entre o pH em cloreto de potássio (KCl) e em água, que a carga líquida nas duas camadas era negativa. Isto é condizente com os resultados granulométricos do solo Franco Arenoso, apresentados na Tabela 1.

Tabela 2 - Caracterização química do solo estudado

\begin{tabular}{|c|c|c|c|c|c|}
\hline Camadas (m) & $\mathrm{pH}\left(\mathrm{H}_{2} \mathrm{O}\right)$ & $\mathrm{pH}(\mathrm{KCl})$ & $\mathrm{CO}\left(\mathrm{g} \mathrm{kg}^{-1}\right)$ & $\mathrm{MO}\left(\mathrm{g} \mathrm{kg}^{-1}\right)$ & $\begin{array}{c}\text { Área Superficial }\left(\mathrm{m}^{2}\right. \\
\left.\mathrm{g}^{-1}\right)\end{array}$ \\
\hline $0,00-0,20$ & 7,24 & 6,75 & 10,19 & 17,57 & 4,33 \\
\hline $0,20-0,40$ & 8,01 & 7,28 & 8,59 & 14,81 & 4,49 \\
\hline
\end{tabular}

\subsection{VARIÁVEIS PARA OS ENSAIOS DE TRANSPORTE DO DCF}

Os valores das variáveis para os ensaios de transporte do DCF são apresentados Tabela 3, compreendendo a densidade específica do solo $\left(\rho_{\mathrm{d}}\right)$ e o tempo de aplicação do pulso $\left(\mathrm{T}_{0}\right)$, determinados experimentalmente, bem como o volume de poros $\left(\mathrm{V}_{\mathrm{p}}\right)$, umidade volumétrica $\left(\theta_{\mathrm{s}}\right)$, densidade de fluxo de Darcy (q) e a velocidade média da água nos poros $\left(\mathrm{V}_{\exp }\right)$, obtidos numericamente:

Tabela 3 - Variáveis determinadas para os ensaios de transporte de DCF

\begin{tabular}{|c|c|c|c|c|c|c|}
\hline Camadas $(\mathrm{m})$ & $\rho_{\mathrm{d}}\left(\mathrm{g} \mathrm{cm}^{-3}\right)$ & $\mathrm{V}_{\mathrm{p}}\left(\mathrm{cm}^{3}\right)$ & $\theta_{\mathrm{s}}\left(\mathrm{cm}^{3} \mathrm{~cm}^{-3}\right)$ & $\mathrm{q}\left(\mathrm{cm} \mathrm{h}^{-1}\right)$ & $\mathrm{V}_{\exp }\left(\mathrm{cm} \mathrm{h}^{-1}\right)$ & $\mathrm{T}_{0}(\mathrm{~h})$ \\
\hline $0,00-0,20$ & 1,59 & 152,79 & 0,377 & 1,906 & 5,050 & 10,28 \\
\hline $0,20-0,40$ & 1,61 & 154,94 & 0,372 & 1,904 & 5,112 & 10,02 \\
\hline
\end{tabular}




\subsection{CARACTERIZAÇÃO HIDRODINÂMICA COM KBR}

A figura 1 apresenta as curvas médias de eluição do $\mathrm{KBr}$ ajustadas pelo modelo $\mathrm{CDE}$, em colunas saturadas, com solo Franco Arenoso com presença da matéria orgânica, na vazão (Q) de $0,25 \mathrm{~mL} \mathrm{~min}^{-1}$ e com a concentração de $1,0 \mathrm{~g} \mathrm{~L}^{-1}$.

Figura 1 - Curvas médias de eluição do KBr ajustadas pelo modelo CDE, em colunas de solo na vazão de $0,25 \mathrm{~mL} \mathrm{~min}^{-1} \mathrm{e}$ na concentração de $1,0 \mathrm{~g} \mathrm{~L}^{-1}$
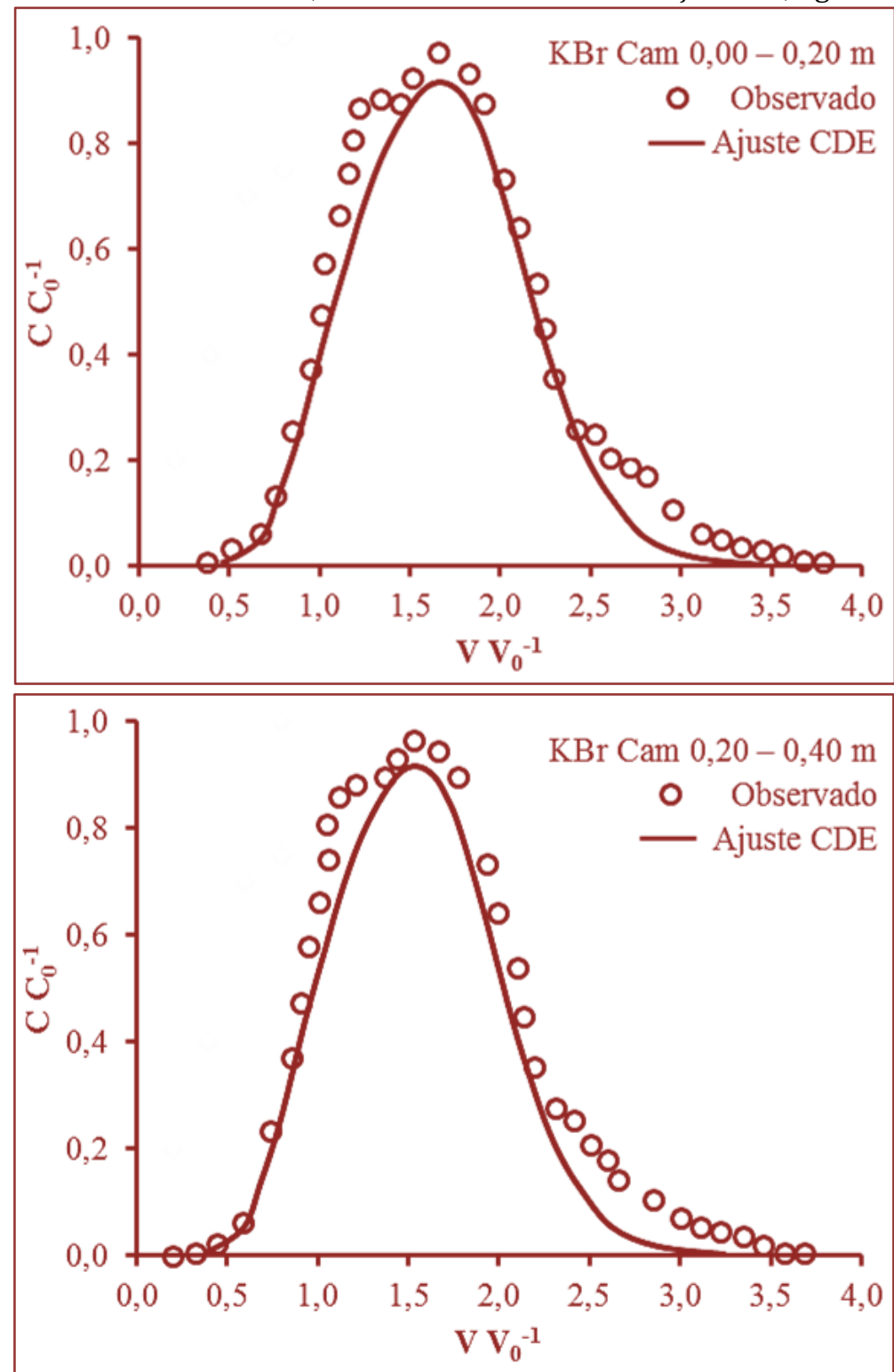

Fonte: $\mathrm{O}$ autor

Verifica-se na figura 1 que, além de ter ocorrido certa simetria no trecho ascendente e descendente de cada uma das curvas, também as curvas de eluição e as curvas ajustadas pelo modelo CDE passaram pelo ponto $\left(0,5 \mathrm{C} \mathrm{C}^{-1} ; 1,0 \mathrm{~V} \mathrm{V0} 0^{-1}\right)$, confirmando a boa qualidade do $\mathrm{KBr}$ como traçador químico, conforme os trabalhos de Gondim (2014), Carmo (2012), Carmo et al. (2010), Costa et al. (2006) e Milfont (2006).

Ainda é possível verificar o bom ajuste feito pelo modelo $\mathrm{CDE}$ aos pontos da curva de eluição do $\mathrm{KBr}$ no solo, na vazão $(Q)$ de $0,25 \mathrm{~mL} \mathrm{~min}^{-1}$ e na concentração de $1 \mathrm{~g} \mathrm{~L}^{-1}$ de $\mathrm{KBr}$, através bons valores do coeficiente de determinação $\left(\mathrm{R}^{2}\right)$, apresentados na Tabela 4 , com os demais valores médios das condições experimentais e dos parâmetros hidrodispersivos dos ensaios, compreendendo a velocidade média da água nos poros (v), coeficiente de dispersão hidrodinâmica (D), fator de retardo $(R)$, dispersividade $(\lambda)$ e número de Péclet $(\mathrm{P})$. 
Tabela 4 - Condições e parâmetros hidrodispersivos dos ensaios de deslocamento miscível com KBr no

\begin{tabular}{|c|c|c|c|c|c|c|}
\hline \multicolumn{7}{c|}{ Solo } \\
\hline Camadas $(\mathrm{m})$ & $\mathrm{v}\left(\mathrm{cm} \mathrm{h}^{-1}\right)$ & $\mathrm{D}\left(\mathrm{cm}^{2} \mathrm{~h}^{-1}\right)$ & $R$ & $\mathrm{R}^{2}$ & $\lambda(\mathrm{cm})$ & $\mathrm{P}$ \\
\hline $0,00-0,20$ & 2,01 & 1,22 & 1,15 & 0,97 & 0,61 & 32,95 \\
\hline $0,20-0,40$ & 1,98 & 1,34 & 1,13 & 0,98 & 0,68 & 29,55 \\
\hline
\end{tabular}

Fonte: 0 Autor

Observando as Tabela 4, verifica-se que os valores médios do fator de retardo $R$ ficaram próximos à unidade, indicando que o KBr não sofreu interações nessas duas camadas de solo (adsorção ou exclusão).

A dispersividade, $\lambda$, foi obtida considerando-se a relação linear entre o coeficiente de dispersão hidrodinâmico, D, e a velocidade média da água nos poros, $\mathrm{v}$, ou seja, $\mathrm{D}=\lambda \mathrm{v}$. A partir dos valores de $\mathrm{D}$ ajustados e de $\mathrm{v}$ determinou-se $\lambda$ para as duas camadas, uma vez que a dispersividade está diretamente relacionada com o diâmetro médio das partículas de solo (CARMO et al., 2010).

Em relação ao número de Péclet $(P)$, verifica-se que nas duas camadas os valores maiores que 10 , indicando que o processo predominante de transferência do KBr foi do tipo convectivo (NOVY QUADRI, 1993).

\subsection{CARACTERIZAÇÃO HIDRODINÂMICA DO DICLOFENACO}

A figura 2 apresenta os ajustes feitos pelo modelo CDE aos pontos das curvas médias de eluição do DCF, em colunas saturadas, com solo Franco Arenoso com presença da matéria orgânica, na vazão de 0,35 mL $\min ^{-1}$ e com a concentração de $50 \mathrm{mg} \mathrm{L}^{-1}$.

Figura 2 - Curvas médias de eluição do DCF ajustadas pelo modelo CDE, em colunas de solo na vazão de 0,35 mL min-1 e na concentração de 50,0 mg L-1

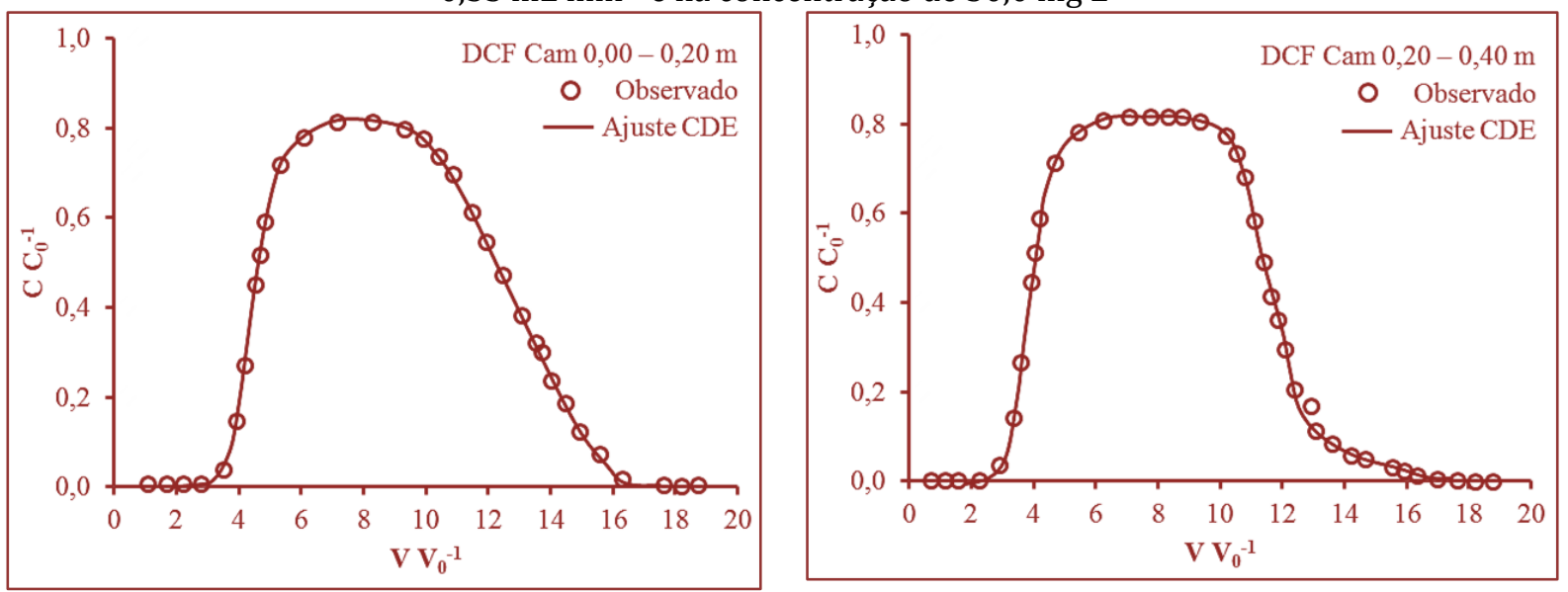

Fonte: $\mathrm{O}$ autor

Por meio da figura 2, verifica-se que os pontos das curvas médias de eluição se ajustaram bem ao modelo $\mathrm{CDE}$, nas duas camadas do solo considerado, o que é confirmado pelos valores de $\mathrm{R}^{2}$ apresentados na Tabela 5 que variaram entre 97 e 98\%. Os valores médios das condições experimentais e dos parâmetros hidrodispersivos dos ensaios de deslocamento miscíveis do DCF, na concentração de $50 \mathrm{mg} \mathrm{L}^{-1}$ e na vazão de $0,35 \mathrm{~mL} \mathrm{~min}^{-1}$ são apresentados na Tabela 5 . 
Tabela 5 - Condições e parâmetros hidrodispersivos dos ensaios de deslocamento miscível do DCF no solo

\begin{tabular}{|c|c|c|c|c|c|c|c|}
\hline & Camadas(m) & $\mathrm{v}\left(\mathrm{cm} \mathrm{h}^{-1}\right)$ & $\mathrm{D}\left(\mathrm{cm}^{2} \mathrm{~h}^{-1}\right)$ & $R$ & $\mathrm{R}^{2}$ & $\lambda(\mathrm{cm})$ & $\mathrm{P}$ \\
\hline \multirow{2}{*}{ DCF } & $0,00-0,20$ & 7,92 & 30,64 & 5,8 & 0,97 & 3,87 & 5,17 \\
\hline & $0,20-0,40$ & 7,91 & 30,09 & 5,7 & 0,98 & 3,80 & 5,26 \\
\hline
\end{tabular}

Fonte: 0 Autor

Observando a Tabela 5, verificou-se que o coeficiente de dispersão hidrodinâmica (D) variou de 30,64 a $30,09 \mathrm{~cm}^{2} \cdot \mathrm{h}^{-1}$, ressaltando a variabilidade espacial deste parâmetro. Esses valores foram um pouco mais altos em relação a outros trabalhos. Ascar et al. (2017) encontraram valores de $18,46 \mathrm{~cm}^{2} \cdot \mathrm{h}^{-1}$ para um solo argilo-siltoso e $25,4 \mathrm{~cm}^{2} \cdot \mathrm{h}^{-1}$ para um solo argilo-arenoso; Xu Jian \& Chen (2010) encontraram valores perto de $20,78 \mathrm{~cm}^{2} . \mathrm{h}^{-1} \mathrm{em}$ um solo argilo-arenoso. Segundo Reichardt. (1990), o coeficiente de dispersão hidrodinâmica é um dos parâmetros mais sensíveis aos erros de medidas.

Constata-se ainda que o solo apresentou alto retardamento, implicando em baixa mobilidade do soluto, o que pode ser explicado possivelmente pelas interações do diclofenaco com a matéria orgânica presente nesse solo.

A dispersividade $(\lambda)$ foi obtida considerando-se a relação linear entre o coeficiente de dispersão hidrodinâmico, $\mathrm{D}$, e a velocidade média da água nos poros, v, ou seja, $\mathrm{D}=\lambda \mathrm{v}$. A partir dos valores de $\mathrm{D}$ ajustados e de $v$ determinou-se $\lambda$ para as duas camadas, determinando a capacidade de espalhamento do diclofenaco no meio poroso.

Quanto ao número de Péclet $(\mathrm{P})$, verificou-se que o processo difusivo $(\mathrm{P}<10)$ foi predominante na transferência do diclofenaco.

\section{CONCLUSÕES}

Os pontos das curvas médias de eluição do traçador $(\mathrm{KBr})$ e do diclofenaco se ajustaram bem ao modelo CDE.

O coeficiente de dispersão hidrodinâmica variou de 30,64 a $30,09 \mathrm{~cm}^{2} \cdot \mathrm{h}^{-1}$ entre as duas camadas de solo, as quais apresentaram retardamento, implicando em baixa mobilidade do soluto, o que pode ser explicado possivelmente pelas interações do diclofenaco com a matéria orgânica presente neste solo.

A dispersividade variou de 3,80 a 3,87 cm entre as duas camadas de solo, obtida através da relação linear entre o coeficiente de dispersão hidrodinâmico e a velocidade média da água nos poros, determinando assim a capacidade de espalhamento do diclofenaco no meio poroso.

0 processo de transporte predominante foi do tipo difusivo.

\section{REFERÊNCIAS}

[1] ARCHER, E.; PETRIE, B.; KASPRZYK-HORDERN, B.; WOLFAARDT, G.M. The fate of pharmaceuticals and personal care products (PPCPs), endocrine disrupting contaminants (EDCs), metabolites and illicit drugs in a WWTW and environmental waters. Chemosphere. v. 174, p. 437-446, 2017.

[2] ASCAR, L.; AHUMADA, I.; MORALES, N.; GARRIDO, T. GIORDANO, A. LEIVA, KARLA. Mobility of nonsteroidal anti-inflammatory drugs in soils with and without amendment of biosolid. Journal of the Chilean Chemical Society. vol. 62. $n^{\circ}$ 3. Conjunto Concepción. 2017.

[3] BLAIR, B.; NIKOLAUS, A.; HEDMAN, C.; KLAPER, R.; GRUNDL, T. Evaluating the degradation, sorption, and negative mass balances of pharmaceuticals and personal care products during wastewater treatment. Chemosphere. v. 134, p. 395-401, 2015.

[4] CARMO, A.I.; ANTONINO, A.C.D.; NETTO, A.M.; CORRÊA, M.M. Caracterização hidrodispersiva de dois solos da região irrigada do Vale do São Francisco. Revista Brasileira de Engenharia Agrícola e Ambiental. v. 14, n. 7, p. 698-704, 2010.

[5] CARMO, A. I. Sorção e transporte reativo do naftaleno em solos urbanos da região metropolitana do Recife, PE. Recife: UFPE, 2012.

[6] CESSA, R.M.A.; CELI, L., VITORINO, A.C.T., NOVELINO, J.O.; BARBERIS, E. Área superficial específica, porosidade da fração argila e adsorção de fósforo em dois latossolos vermelhos. Revista Brasileira de Ciências do Solo, ed. 33, p. 1153-1162, 2009. 
[7] COSTA, C.T.; ANTONINO, A C.D.; NETTO, A.M. Ensaios de deslocamento de líquido miscível na determinação dos parâmetros hidrodispersivos de um solo aluvial. Revista Brasileira de Recursos Hídricos, Porto Alegre, v. 11, n. 2, p. 111-122, 2006.

[8] EMBRAPA. Manual de métodos de análise de solo. Centro Nacional de Pesquisa de Solos. 2. ed. Rio de Janeiro, 2011.

[9] EMBRAPA. Mapa Exploratório - Reconhecimento de solos do município de Pesqueira, PE. Embrapa Solos, UEP. Recife, 2001.

[10] GABER, H.M.; INSKEEP, W. P.; COMFORT, S.D. e WRAITH, J.M. Nonequilibruim transport of atrazine through large intact soil cores. Soil Science Society of America Journal, v. 59, p. 60-67, 1995.

[11] GAUDET, J.P.; JEGAT, H.; VACHAUD, G.; WIERENGA, P. Solute transfert, with exchange between mobile and stagnant water, through unsaturated sand. Soil Science Society of America Journal, v.41, n. 4, 1977.

[12] GONDIM, M.V.S. Estudo das transferências e transformações do antibiótico sulfametoxazol em solos no context tropical e temperado. Tese (Doutorado). Universidade Federal de Pernambuco. Recife, 2014.

[13] GUSMÃO, P.T.R.; ARAGÃO, J.M.S.; MONTENEGRO, S.M.G.; Diagnóstico das condições sanitárias e ambientais em comunidade rural no semi-árido nordestino (Mutuca - PE). 22ํㅡㄹ Congresso Brasileiro de Engenharia Sanitária e Ambiental, 2003.

[14] KOSMA, C.I.; LAMBROPOULOU D.A.; ALBANIS, T.A. Investigation of PPCPs in wastewater treatment plants in Greece: Occurrence, removal and environmental risk assessment. Science of The Total Environment. v. 466-467. p. 421-438, 2014.

[15] MARTINS, J. M. F.; MERMOUD, A. Sorption and degradation of four nitroaromatic herbicides in mono and multi-solute saturated/unsaturated soil batch systems, Journal of Contaminant Hydrology, v. 33, p. 187-210, 1999.

[16] MILFONT, M.S. Transporte e sorção do agroquímico Paclobutrazol em solos irrigados cultivados com manga. 2006. (Doutorado em Tecnologias Energéticas e Nucleares) - Departamento de Energia Nuclear, Universidade Federal de Pernambuco, Recife, 2006.

[17] NOVY QUADRI, M.G. Transferts de solutes dans les sols satures Et non satures application au pentachlorophenol. 1993. 204p. (Doutorado em Génie Mecanique) Laboratoire d' etude des transfers em Hydrologie et Environnement, Universite of Grenoble, France, 1993.

[18] OLIVEIRA, L.L.D. Biomarcadores enzimáticos e testes ecotoxicológicos na avaliação da toxicidade de fármacos em invertebrados aquáticos. Tese de Doutorado. São Carlos, 2014.

[19] OSORIO, V; IMBERT-BOUCHARD, M; ZONJA, B; ABAD, J. L; PÉREZ, S; BARCELÓ,D. Simultaneous determination of diclofenac, its human metabolites and microbial nitration/nitrosation transformation products in wastewaters by liquid chromatography/quadrupole-linear ion trap mass spectrometry. Journal of Chromatography A, v. $1347,2014$.

[20] REICHARDT, K. A Água em Sistemas Agrícolas. Manole, 1a ed. 1990.

[21] XU, Jian; CHEN, Weipin. Leaching potential of nonsteroidal anti-inflammatory drugs in soils. Environmental Toxicology and Chemistry, 2010.

[22] VIENO, NIINA; SILLANPAA, MIKA. Fate of diclofenac in municipal wastewater treatment plant - A review. Environment International, v. 69, 2014. 


\section{Capítulo 11}

Análise do processo de desertificação no Médio Sertão Sergipano

\section{Carolina Oliveira Souza}

Daniele Suzane da Silva Pinto Teles

Soanne Hemylle de Jesus Santos

Heloísa Thaís Rodrigues de Souza

\section{Guilherme dos Santos Teles}

Resumo: 0 processo de desertificação reflete a degradação do solo decorrente de fatores climáticos e antrópicos em diversas áreas da Terra, dentre as quais está o semiárido do nordeste brasileiro. Este trabalho teve como objetivo realizar uma análise temporal de indicadores do processo de desertificação no Médio Sertão Sergipano, entre os anos 2001 e 2017, utilizando um índice de vegetação e mapas temáticos para identificar áreas suscetível à desertificação. 0 índice de vegetação utilizado foi o Índice de Vegetação da Diferença Normalizada (NDVI), o qual foi analisado em regimes pluviométricos distintos. Também foram elaborados mapas temáticos com informações de parâmetros relacionados ao processo de desertificação. Observou-se que o território do Médio Sertão Sergipano está totalmente inserido em áreas consideradas susceptíveis a desertificação. O NDVI apresentou variações na densidade da vegetação entre os anos supracitados e seus respectivos períodos sazonais, que podem estar associadas aos fatores naturais e ao uso e ocupação do solo. Desta forma, a região do Médio Sertão Sergipano necessita de pesquisas e planejamento adicionais, a fim de evitar a degradação ambiental e o favorecimento do processo de desertificação.

Palavras-Chave: Região subúmida, Geoprocessamento, Degradação ambiental. 


\section{INTRODUÇÃO}

A desertificação constitui um processo específico de degradação ambiental, que constitui um complexo grau de depreciação do solo em áreas semiáridas, áridas e subúmidas secas da Terra, decorrentes de fatores climáticos e de atividades antropogênicas (AMBALAM, 2014), ocorrendo em países da América Latina e Caribe (ALMEIDA et al., 2012), além de países da África e Ásia (SANTOS e AQUINO, 2016). No Brasil, o processo de desertificação ocorre principalmente em regiões do semiárido, o qual tem sido considerado um dos mais graves problemas de ordem socioambiental enfrentada pela região nordeste do país (LUCENA, 2019). Segundo Garcia et al. (2019), esse fenômeno se propaga na região semiárida, pela integração do clima com a combinação da vulnerabilidade dos recursos naturais e impactos das ações antrópicas, que juntos constituem o cenário de suscetibilidade à desertificação no nordeste brasileiro.

O semiárido brasileiro é caracterizado por baixos volumes pluviométricos, alta evapotranspiração, chuvas irregulares, com número de meses de seca variando de seis a onze meses (MORO et al., 2016), e a vegetação natural dominante é uma estepe de savana conhecida por caatinga (TOMASELLA et al., 2018). A supressão dessa vegetação para o pastoreio e o uso da madeira para lenha), reduz o tempo de pousio de terras agrícolas, insuficiente para a recuperação do solo e da vegetação (TAVARES et al., 2019). 0 solo sem cobertura vegetal, associado aos processos erosivos, perda da biodiversidade e mudanças climáticas iniciam e aceleram o processo de desertificação (TAVARES et al., 2019). Sem cobertura vegetal, ocorre também perda da fertilidade do solo, diminuição do volume de água infiltrada, salinização do solo, aumento de escoamento superficial, além de alterações com o clima da região, reduzindo a precipitação (SILVA et al., 2018 e RODRIGUES et al., 2019).

No Brasil, as áreas suscetíveis à desertificação compreendem $1.340 .863 \mathrm{~km}^{2}$, englobando 1.488 municípios de nove estados da região Nordeste (MENEZES et al., 2012). A região semiárida do nordeste do Brasil é caracterizada por uma variação moderada a alta de suscetibilidade à desertificação (JESUS et al., 2019), e as áreas subúmida e úmida têm baixa vulnerabilidade no contexto climático, porém quando questões de manejo do solo associadas com os usos da terra são levadas em consideração, essas áreas tornam-se potencialmente suscetíveis à degradação/desertificação (VIEIRA et al., 2016). Assim, dentre várias regiões a serem estudadas quanto à desertificação no nordeste brasileiro, o Médio Sertão Sergipano é um território de destaque, por ser enquadrado como subúmida seca e apresentar predomínio de áreas agrícolas, pastagens e áreas urbanizadas (IBGE, 2011).

Considerando os problemas relacionados ao processo de desertificação, uma das metodologias para detecção, análise e monitoramento em uma região subúmida é a utilização de técnicas de geoprocessamento e sensoriamento remoto, as quais possibilitam utilizar informações obtidas a partir do processamento de imagens para determinar indicadores da degradação e desertificação.

Diante do exposto, o presente estudo tem como objetivo realizar uma análise temporal de indicadores do processo de desertificação no território do Médio Sertão Sergipano, entre os anos 2001 e 2017, a partir do uso do índice de vegetação e identificar áreas suscetíveis à desertificação através da elaboração de mapas temáticos.

\section{METODOLOGIA}

A região de estudo localiza-se no Nordeste do Brasil, no território do Médio Sertão Sergipano, que é composto por seis municípios: Aquidabã, Cumbe, Feira Nova, Gracho Cardoso, Itabi e Nossa Senhora das Dores. Está localizado na porção centro-norte do Estado de Sergipe (Figura 1), ocupando uma área de aproximadamente $1592 \mathrm{~km} 2$, um percentual de 7,32\% do estado (IBGE, 2011).

De acordo com dados do IBGE (2011), o território do Médio Sertão Sergipano está inserido nas bacias hidrográficas dos rios São Francisco, Japaratuba e Sergipe, e encontra-se numa faixa de transição entre a região do agreste e o sertão. Em relação às características do bioma caatinga, o Médio Sertão Sergipano apresenta uma variabilidade de precipitação média anual em torno de 100 e $80 \mathrm{~mm}$ (SANTOS e SOUSA, 2018). A vegetação é formada por espécies arbóreas e arbustivas, que desenvolveram mecanismos para sobreviver em ambientes com poucas chuvas (MAIA et al., 2017), correspondendo a um tipo singular de vegetação xerófita tropical que capaz de descartar suas folhas durante as estações secas, a fim de evitar alta taxa de transpiração (RODRIGUES et al., 2019).

Para a análise temporal dos indicadores dos processos de desertificação do Médio Sertão Sergipano, foram utilizadas a base de dados georreferenciada obtida no Atlas Digital da Superintendência de Recursos Hídricos (2014) e imagens obtidas no banco de imagens do Instituto Nacional de Pesquisas Espaciais 
(INPE). As imagens utilizadas foram obtidas do satélite Landsat-7 (dos anos de 2001 e 2003) e Landsat-8 (do ano 2017), que englobam dois regimes pluviométricos distintos, um úmido (maio/2001 e junho/2017) e um seco (janeiro/2003 e dezembro/2017). A projeção adotada foi a Universal Transversa de Mercator (UTM) e Datum Sirgas 2000, zona 24 sul. 0 processamento digital das imagens de satélite e a elaboração dos mapas temáticos foram realizados no software QGIS 3.4.8.

Figura 1 - Mapa de localização do Médio Sertão Sergipano.

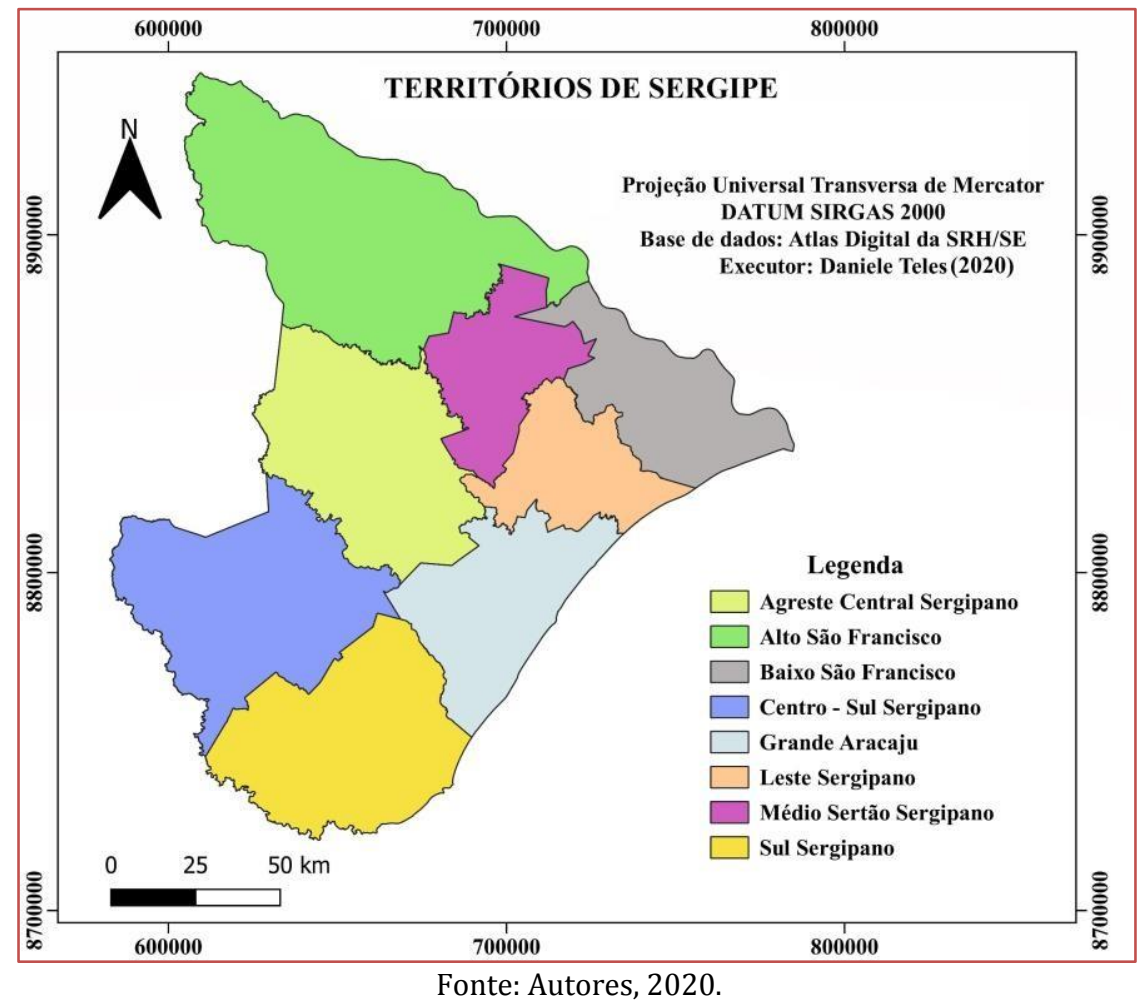

Os índices de vegetação como o Índice de Vegetação da Diferença Normalizada (NDVI) são fatores que facilitam a obtenção e modelagem de parâmetros biofísicos das plantas como a área foliar, biomassa e porcentagem de cobertura do solo. O NDVI é um indicador sensível da quantidade e condição da vegetação, cujos valores variam no intervalo de -1 a 1 . Valores mais próximo de 1 , representam uma maior densidade da cobertura vegetal. As superfícies que contêm água ou nuvens, a variação é sempre menor que 0 (BORATTO e GOMIDE, 2013). O NDVI foi calculado no software QGIS, pela razão entre a diferença das reflectâncias das bandas do infravermelho próximo - IV (banda 4 do Landsat-7 e banda 5 do Landsat8) e do vermelho - V (banda 3 do Landsat-7 e banda 4 do Landsat-8); e pela soma das reflectâncias das duas bandas supracitadas, conforme mostra a Equação 1.

$$
N D V I=\frac{I V-V}{I V+V}
$$

\section{RESULTADOS E DISCUSSÃO}

A partir dos mapas temáticos elaborados com a base de dados da SRH (2014), o Estado de Sergipe pode ser dividido segundo a caracterização em suscetibilidade à desertificação da seguinte forma: Áreas Suscetíveis à Desertificação (ASD), que abrangem o semiárido, subúmido seco e suas áreas de entorno (apresentam características semelhantes às semiáridas e subúmidas) (LUCENA, 2019). 0 território do Médio Sertão Sergipano está totalmente inserido na área subúmida seca (Figura 2a), e parte dele também está inserida no polígono da seca do Nordeste. 0 mapa da Figura $2 \mathrm{~b}$ apresenta os indicadores de desertificação no Médio Sertão, gerado pela interseção de informações como a indicação de urbanização (sedes e limites dos municípios, distribuição das rodovias) e o mapeamento florestal. 
Figura 2 - Dados e indicadores para análise do processo de desertificação no Médio Sertão Sergipano em 2014. Legenda: (a) Áreas suscetíveis à desertificação no Estado de Sergipe; (b) Região do Médio Sertão Sergipano e indicadores da suscetibilidade à desertificação.

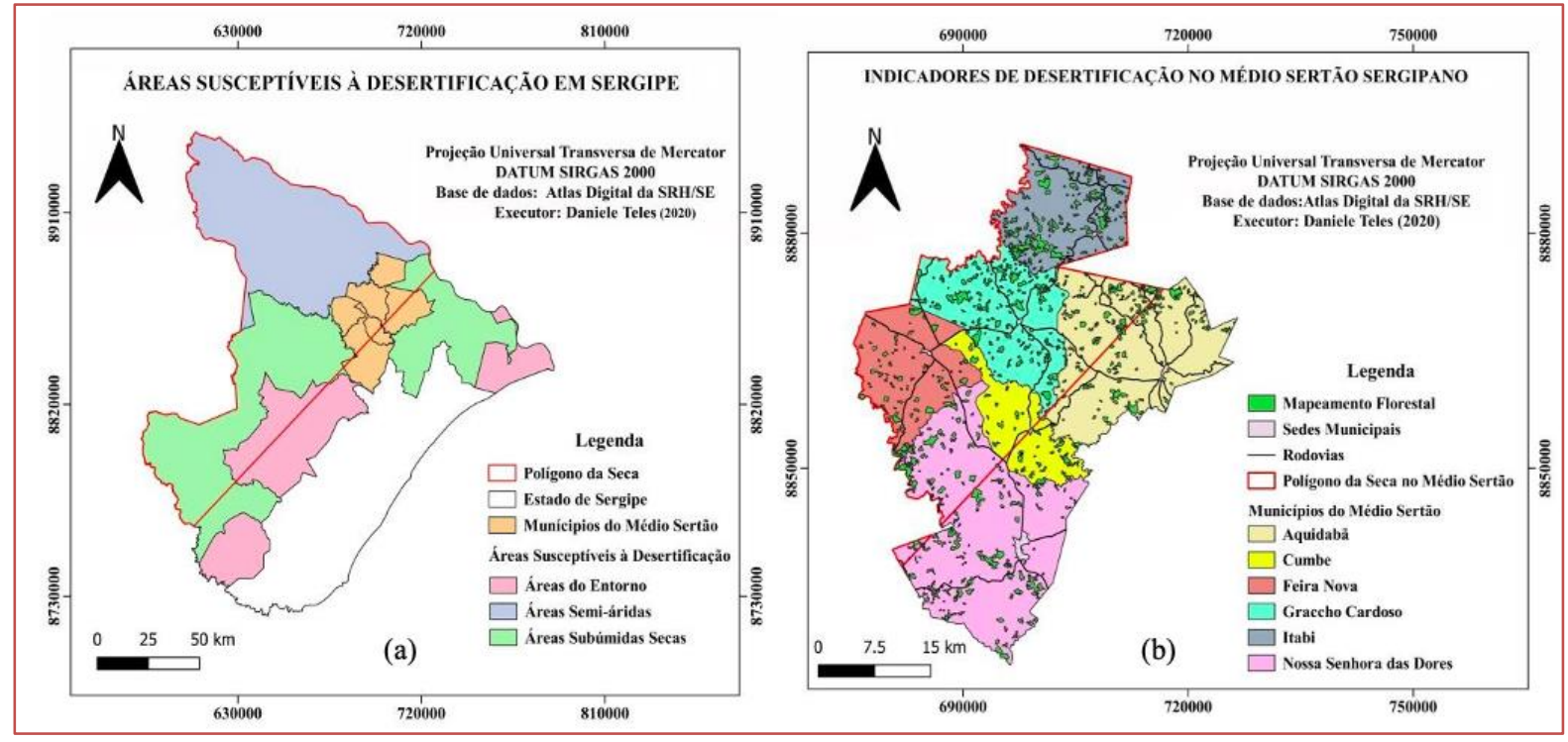

Fonte: Autores, 2020.

Ao analisar a Figura 2, ainda é possível constatar o polígono de secas demarcado no território do Médio Sertão Sergipano, o qual representa o recorte territorial de abrangência das condições de semiaridez, uma área importante para delinear políticas públicas relacionadas ao gerenciamento e gestão dos efeitos de estiagem, como também os problemas relacionados com recursos hídricos (TROLEIS e SILVA, 2018). Destaca-se que o polígono cobre totalmente os municípios de Itabi, Gracho Cardoso, Feira Nova e parcialmente os municípios de Nossa Senhora das Dores, Cumbe e Aquidabã (Figura 2b), dessa forma, grande parte do território encontra-se na área do polígono de seca, região em que há maior período de secas mais severas, menor precipitação e maior evapotranspiração. 0 mapeamento florestal da região apresenta o remanescente de floresta existente, com um pequeno quantitativo de áreas de vegetação espalhados pelo território (Figuras 2b). Segundo o Inventário Florestal Nacional (IFN, 2018), esse é um dos territórios que apresenta as menores coberturas florestais de Sergipe, com cerca de 8\% de proporção de área de floresta em relação à área total do território e cobertura vegetal original quase totalmente substituída por pastos.

Segundo Marengo et al. (2016), as secas são um fenômeno natural do Nordeste do Brasil (NEB), uma alteração do regime hidrometeorológico que afeta os moradores mais vulneráveis, criando situações de deficiência hídrica, porém não atinge todo o NEB, concentrando-se na área do polígono de secas. Neste sentido, a duração e recorrência de episódios de secas ocorridos há décadas no NEB têm afetado e continuarão afetando a economia, segurança alimentar, energética e hídrica, bem como as práticas agrícolas e pecuárias. A longo prazo, os déficits hídricos, juntamente com o aumento de temperatura, secas mais frequentes e duradouras podem exacerbar a degradação ambiental (MARENGO et al., 2016), acarretando em perda de produtividade e da capacidade em se recuperar, estabelecendo o processo de desertificação na região (SILVA, 2019).

A Figura 3 mostra os mapas das imagens processadas referente aos cálculos de NDVI, para os dois períodos estudados, um úmido e outro seco. Verifica-se que nos dois períodos ocorreram valores negativos de NDVI, que podem ser observados nos mapas na cor vermelha, representando corpos d'água, enquanto as áreas nas cores laranja e amarela representam aquelas com pouca ou nenhuma cobertura vegetal. No período seco, observa-se uma redução da cobertura vegetal entre os anos 2003 e 2017, principalmente nos municípios inseridos no polígono da seca. No período úmido, observou- se um aumento considerável na densidade da cobertura vegetal entre os anos de 2003 e 2017, sendo que o período úmido do ano de 2017, refletido nos valores mais altos de NDVI $(0,45-0,63)$. Isso pode se justificar por um período chuvoso, que resultou em uma boa disponibilidade de água no perfil de solo, proporcionando melhores condições no desenvolvimento da vegetação nativa, das culturas cultivadas na região e das áreas de pastagens. 
Os dados do IBGE (2011) compreendem informações importantes para a análise de um processo de desertificação na região subúmida de Sergipe. Neste território, a atividade de pastagem ocupa mais de 90\% deste território, com criação de animais de grande e médio porte, além de uma parcela menor da supressão da vegetação para o uso de culturas temporárias como fava, feijão, milho, mandioca e cana-deaçúcar. A ocupação do solo para pastagens e culturas, é interligada à supressão da vegetação nativa, o que também é um ponto importante para análise de uma área susceptível à desertificação.

Figura 3 - Índice de vegetação (NDVI) nos períodos seco dos anos 2003 e 2017 e úmido em 2001 e 2017. Período Seco

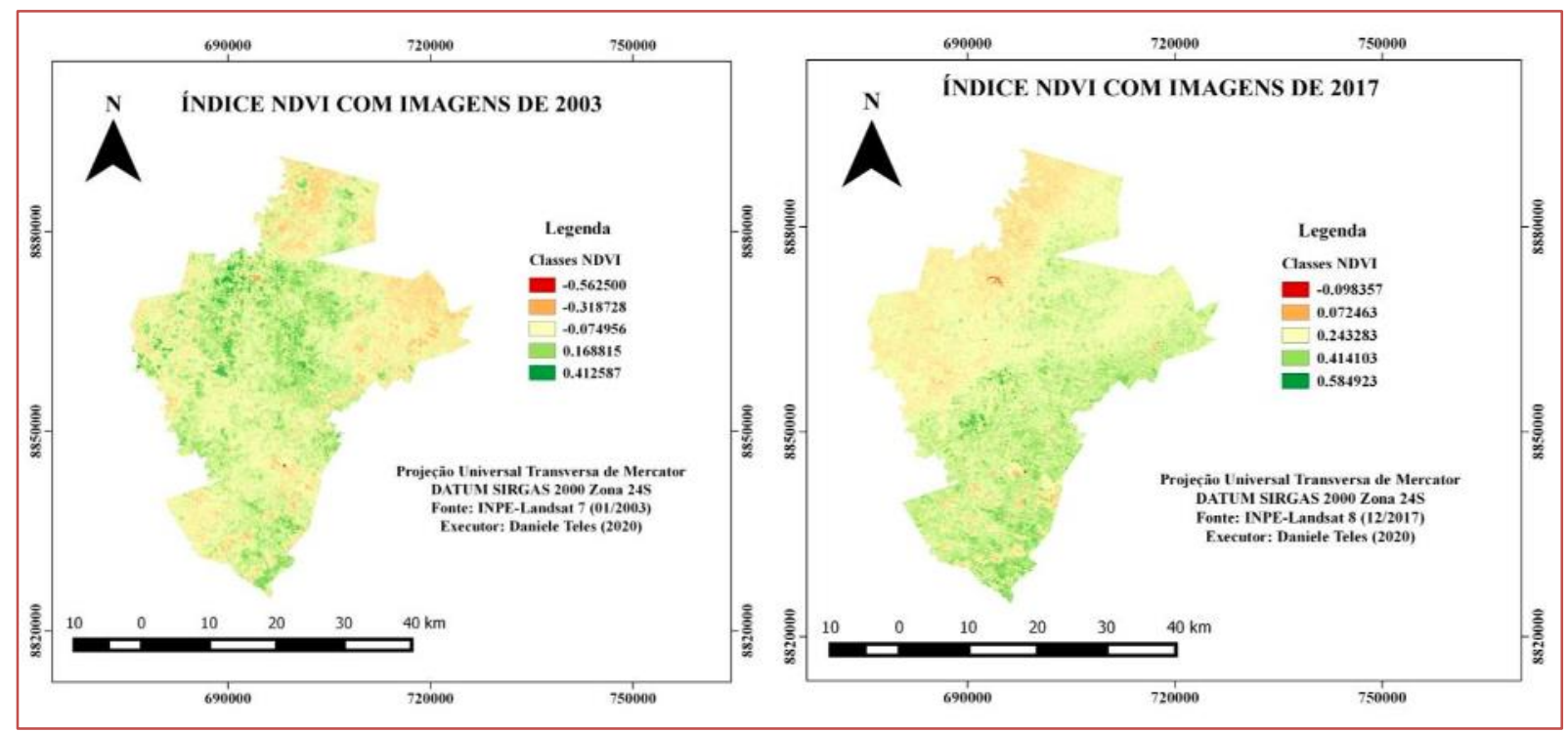

Período Úmido

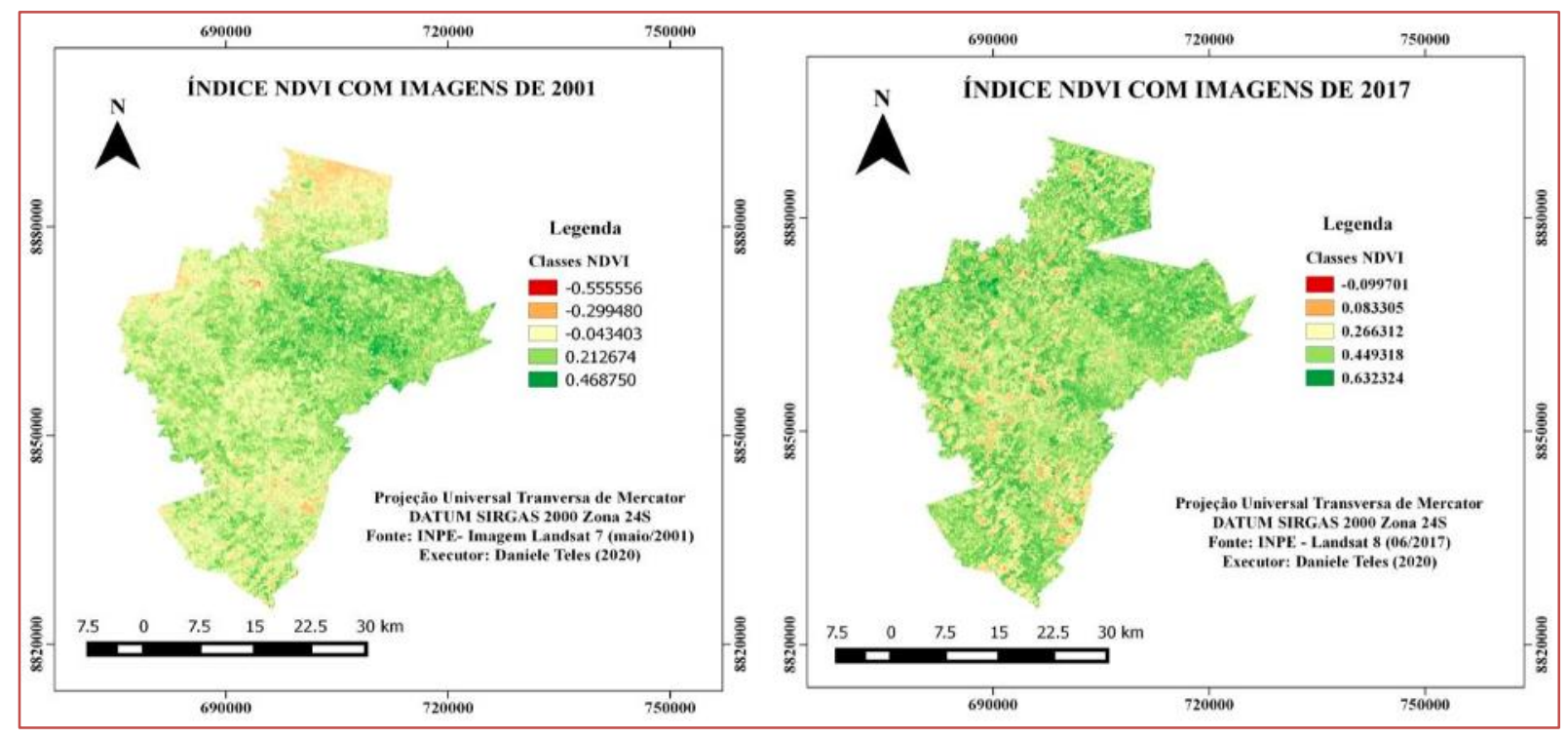

Fonte: Autores, 2020

Diante do exposto, as variações da densidade da vegetação nos períodos úmidos e secos, observadas nos anos de 2001, 2003 e 2017, podem estar associadas a fatores diversos (clima, tipo de solo, relevo, geologia) que vão influenciar as características da cobertura vegetal. Porém, as formas uso do solo como pastagem e agricultura são fatores que afetam o equilíbrio dos sistemas ambientas, por ocasionar o empobrecimento dos solos e perda da diversidade biológica, e consequentemente, podem contribuir com o processo de desertificação. 


\section{CONSIDERAÇÕES FINAIS}

Ao analisar os mapas gerados, utilizando os indicadores polígono de seca na região e vegetação nativa/mapeamento florestal, rodovias e sedes municipais/urbanização e as áreas susceptíveis à desertificação, foi possível observar que no território do Médio Sertão Sergipano encontra-se totalmente inserido na área subúmida seca, susceptível à desertificação, e possui boa parte do seu território dentro do polígono da seca do Nordeste.

Os dados do mapeamento florestal mostraram que apenas fragmentos de vegetação nativa encontram-se preservados, sendo que o território possui apenas cerca de 8\% das florestas remanescentes. Esse cenário está associado principalmente ao uso e ocupação do solo voltado para atividades como a pecuária e agricultura, bem como ao processo de urbanização.

Os índices da vegetação mostraram uma redução da densidade da cobertura vegetal no período seco entre os anos de 2003 e 2017, todavia apresentaram um aumento da densidade da vegetação no período úmido (entre 2001 e 2017). Isso pode se justificar pela disponibilidade de água no perfil do solo no período chuvoso, permitindo o desenvolvimento de culturas, pastagem e vegetação nativa. 0 uso do solo para atividades como pastagem e agricultura são fatores que podem estar associados ao processo de desertificação, pois afetam o equilíbrio natural.

Diante disso, o uso de técnicas de geoprocessamento e sensoriamento remoto podem ser utilizadas como um importante indicador na análise do processo de desertificação, uma vez que se mostrou uma ferramenta essencial para identificação do uso e ocupação do solo.

Dessa maneira, fica evidente que a ação antrópica na caatinga do Médio Sertão Sergipano, tem causado a degradação do solo, deixando-o exposto à erosão, fator que pode favorecer o processo de desertificação. Nesse contexto, o processo ainda é intensificado com ação natural da região, onde ocorrem secas recorrentes e duradouras e baixa precipitação, considerados relevantes e agravantes no tocante à desertificação.

Dessa forma, são necessárias pesquisas mais detalhadas como forma de subsídios para o planejamento e políticas públicas voltadas ao processo de desertificação em regiões subúmidas e subúmidas secas.

\section{REFERÊNCIAS}

[1] ALMEIDA, D. C.; TAVARES, D. S.; JESUS, E. S. (2012). "Uma percepção do processo de desertificação no semiárido nordestino" in Anais do SEMINÁRIO NACIONAL DE GEOECOLOGIA, 1.; SEMINÁRIO REGIONAL DE GEOECOLOGIA E PLANEJAMENTO TERRITORIAL/GEOPLAN, São Cristóvão -SE.

[2] AMBALAM, K. (2014) "United Nations Convention to Combat Desertification: Issues and Challenges". EInternational Relations. Disponível em: <e-ir.info/2014/04/30/united-nations- convention-to-combat-desertificationissues-and-challenges/>. Acesso em 19/05/2020.

[3] BORATTO, I. M. P.; GOMIDE, R. L. (2013). "Aplicação dos índices de vegetação NDVI, SAVI e IAF na caracterização da cobertura vegetativa da região Norte de Minas Gerais" in Anais do XVI Simpósio Brasileiro de Sensoriamento Remoto, Sociedade Brasileira de Sensoriamento Remoto, Foz do Iguaçu -SC.

[4] GARCIA, A. C. S. M.; ARAÚJO FILHO, J. C.; SILVA, H. P. S. P.; CARVALHO, R. M. C. M. O. (2019). "Estudo espaço temporal de áreas susceptíveis à desertificação do semiárido brasileiro". RG\&AS - Revista Gestão e Sustentabilidade Ambiental, v. 8, n. 3, pp. 352-370.

[5] GUIMARÃES, S. O.; COSTA, A. A.; VASCONCELOS JÚNIOR, F. DAS C.; SILVA, E. M.;

[6] SALES, D. S.; ARAÚJO JÚNIOR, L. M.; SOUZA, S. G. (2016). "Projeções de mudanças climáticas sobre o nordeste brasileiro dos modelos do CMIP5 e do CORDEX". Revista Brasileira de Meteorologia, São José dos Campos, v. 31, n. 3, pp. 337-365.

[7] IBGE. (2011). Instituto Brasileiro de Geografia e Estatística - Projeto Levantamento e Classificação do Uso da Terra/Uso da Terra no Estado de Sergipe. Relatório Técnico. Disponível em: <https://biblioteca.ibge.gov.br/visualizacao/livros/liv95889.pdf>. Acesso em 21/05/2020.

[8] IFN. (2018). Inventário Florestal Nacional Sergipe - Serviço Florestal Brasileiro. Ministério do Meio Ambiente. Série Relatórios Técnicos - IFN. Brasília - DF.

[9] JESUS, J. B.; SOUZA, B. B.; OLIVEIRA, A. M. S.; GAMA, D. C. (2019). "Aridity index and climatic risk of desertification in the semi-arid state of Sergipe". Revista Brasileira de Climatologia, a. 15, v. 24, pp. 214-227. 
[10] LUCENA, M. S. (2019). “Aspetos ambientais das áreas susceptíveis à desertificação e características socioambientais do núcleo de desertificação do Seridó do Rio Grande do Norte (RN) e Paraíba (PB)”. Revista HOLOS, a. 35 , v. 5, pp. 1-17.

[11] MAIA, J. M.; SOUZA, V. F. O.; LIRA, E. H. A.; LUCENA, A. M. A. (2017) "Motivações socioeconômicas para a conservação e exploração sustentável do bioma caatinga". Revista Desenvolvimento e Meio Ambiente, v. 41, pp. 295310 .

[12] MARENGO, J. A.; CUNHA, A. P.; ALVES, L. M. (2016). “A seca de 2012-15 no semiárido do Nordeste do Brasil no contexto histórico". Climanálise, v. 3, pp. 49-54.

[13] MENEZES, R. S. C.; SAMPAIO, E. V. S. B.; GIONGO, V. PÉREZ-MARIN, A. M. (2012). "Biogeochemical cycling in terrestrial ecosystems of the Caatinga Biome". Braz. J. Biol., v. 72, n. 3, pp. 643-653.

[14] MORO, M. F.; LUGHADHA, E. N.; ARAÚJO, F. S.; MARTINS, F. R. (2016). "A phyto geographical meta analysis of the semiarid caatinga domain in Brazil". The Botanical Review.

[15] RODRIGUES, T. M. F.; SENNA, M. C. A.; CATALDI, M. (2019). "Simulation of climatic impacts of desertification in Northeast Brazil". Eng Sanit Ambient, v. 24, n. 5, pp. 1037-1047.

[16] SANTOS, F. A.; AQUINO, C. M. S. (2016). "Panorama da desertificação no Nordeste do Brasil: características e suscetibilidade”. INTERESPAÇO - Revista de Geografia e Interdisciplinaridade, v. 2, n. 7, pp. 144-161.

[17] SANTOS, E. F. N.; SOUSA, I. F. (2018). “Análise estatística multivariada da precipitação do estado de sergipe através dos fatores e agrupamentos". Revista Brasileira de Climatologia, a. 14, v. 23, pp. 205-222.

[18] SILVA, I. A. S. (2019). "Conexões entre clima e desertificação: trajetórias e suscetibilidade no nordeste brasileiro". Revista Equador, v. 8, n. 2, pp. 468-488.

[19] SRH. (2014). Superintendência de Recursos Hídricos de Sergipe, Informações sobre o Atlas Digital sobre Recursos Hídricos de Sergipe. Disponível em <https://www.semarh.se.gov.br/recursoshidricos/?page_id=486>. Acesso em 10/07/2020.

[20] TAVARES, V. C.; ARRUDA, I. C. P.; SILVA, D. G. (2019). "Desertificação, mudanças climáticas e secas no semiárido brasileiro: uma revisão bibliográfica". GEOSUL, v. 34, n. 70, pp. 385-405.

[21] TOMASElla, J.; VIEIRA, R. M. S. P.; BARBOSA, A. A.; RODRIGUEZ, D. A.; SANTANA, M. O.; SESTINI, M. F. (2018). "Desertification trends in the Northeast of Brazil over the period 2000- 2016". Int J Appl Earth Obs Geoinformation, v. 73, pp. 197-206.

[22] TROLEIS, A. L.; SILVA, B. L. (2018). "Do polígono das secas à vulnerabilidade ao colapso hídrico: uma análise do território do rio grande do norte". Revista GeoSertões, v. 3, n. 5, pp. 24-40.

[23] VIEIRA, R. M. S. P.; SESTINI, M. F.; TOMASELLA, J.; RODRIGUEZ, D. A.; BARBOSA, A. A.; CAMPELLO, F. C. B.; SANTANA, M. O.; OMETTO, J. P. H. B.; VALLES, G. F. (2016). "Avaliação do impacto da desertificação no ambiente e na população do Semiárido brasileiro por meio de uma base de dados geográficos". Sustentabilidade em Debate Brasília, v. 7, pp. 52-68. 


\section{Capítulo 12}

Medidas mitigadoras da desertificação e do efeito estufa praticadas por agricultores familiares no Semiárido Paraibano

\section{Rosivânia Jerônimo de Lucena}

Joedla Rodrigues de Lima

Resumo: Ao longo das últimas décadas, as expressões Desertificação e Mudanças Climáticas invadiram de forma substancial os meios de comunicação e transcenderam o mundo técnico-científico. Essas mudanças vêm sendo sentidas de forma significativa na região semiárida brasileira, e a agricultura praticada nessa região sofre drasticamente com os efeitos desses fenômenos. 0 presente estudo tem como objetivo entender a percepção sobre mudanças climáticas e desertificação de agricultores familiares no semiárido paraibano, quais práticas estão sendo adotadas por estes agricultores para mitigar os efeitos desses fenômenos em seus agroecossistemas, incluindo os efeitos nos solos. Foram avaliadas quatro experiências de agroecossistemas familiares no sertão paraibano, sendo uma no Sítio Trincheiras, município de Patos-PB; duas no município de São José do Sabugi-PB, sendo que a primeira está Sítio Nova Conquista e a segunda no Sítio Paquetinha. A outra situa-se no município de Santana dos Garrotes-PB, no Sítio Curral Velho. Foi avaliada a percepção dos agricultores sobre os impactos provocados pelas mudanças climáticas e desertificação, as práticas mitigadoras desenvolvidas pelos agricultores e, especificamente, nas duas áreas com SAFs, foi realizada a avaliação da fertilidade do solo dos dois sistemas. De acordo com agricultores entrevistados, o principal efeito sentido atribuído às mudanças climáticas é o aumento na irregularidade da chuva na região, o que provoca o prolongamento dos períodos de estiagem e o aumento da temperatura. Com relação à desertificação, o principal efeito sentido foi a perda da fertilidade do solo. As principais medidas mitigadoras adotadas pelos agricultores foram o armazenamento da água da chuva; a proteção dos solos e a recomposição da vegetação nativa. 0 solo das áreas com SAFs apresentaram uma boa fertilidade, indicados para recuperar a fertilidade solo e mitigar os efeitos provocados pela desertificação.

Palavras-chave: mudanças climáticas; sistemas agroflorestais; fertilidade dos solos. 


\section{INTRODUÇÃO}

As expressões Desertificação e Mudanças Climáticas transcenderam ao longo das últimas décadas o mundo técnico-científico e invadiram, de forma substancial, os meios de comunicação. Jornais, rádios, revistas e a televisão tratam desses fenômenos em suas pautas e reportagens de forma corriqueira e sempre como algo importante para o bem estar humano e a sobrevivência de várias espécies (LIMA, CALVACANTE; PEREZ- MARIN, 2011).

A principal causa dessas mudanças no clima está relacionada ao aumento da emissão de gases de efeito estufa, a exemplo do $\mathrm{CO}_{2}$ e do metano, provocados pela queima de combustíveis fósseis, principalmente carvão e derivados de petróleo, indústrias, refinarias, motores, queimadas etc. Ao se queimarem combustíveis fósseis, está sendo liberado um velho e profundo reservatório que há muito era mantido à parte. Com relação ao gás metano, os grandes vilões de sua emissão no Brasil são, em primeiro lugar, o setor agropecuário, pois o país é o segundo maior produtor de gado no mundo, seguido pelos aterros sanitários e lixões. Dessa forma, é alterado drasticamente o equilíbrio do ar e consequentemente, a temperatura do planeta (LIMA, 2017; SILVA; PAULA, 2009; WALKER; KING, 2008).

Para Primavesi, Arzabe, Pedreira (2007) essas alterações geram calor em excesso, retido pela camada de gases de efeito estufa, e agravam o problema causado pelas áreas degradadas. Essas alterações já não são mais difíceis de se perceber e podem ser tratadas sob três causas principais: redução das áreas verdes, cobertas por vegetação permanente; aumento das superfícies irradiantes e produtoras de calor em excesso; redução de água residente, iniciando processo de aridização e de desertificação.

Desse modo, recompor a vegetação dessas áreas é um meio para conter tais efeitos, uma vez que a vegetação contribui para o sequestro de carbono, como também para garantir o equilíbrio químico e físico do solo.

Essas mudanças vêm sendo sentidas de forma significativa na região semiárida brasileira, e a agricultura praticada nessa região sofre drasticamente com os efeitos desses fenômenos. Diante deste quadro, Santos et al. (2011) alertam que o dimensionamento dos efeitos dos cenários futuros de mudanças climáticas globais sobre a agricultura é estratégico para o semiárido brasileiro e permitirá a proposição de medidas de adaptação dos sistemas produtivos e de mitigação de seus impactos. Para Lima, Cavalcante, PerezMarin (2011), a desertificação e as mudanças climáticas no semiárido brasileiro são problemas interligados de dimensões globais que devem ser discutidos conjuntamente, a fim de se obterem soluções para a mitigação e adaptação aos mesmos.

Para buscar soluções para tais problemas, antes de tudo, é necessário entender a percepção dos agricultores que vivem na região semiárida e como esses fenômenos afetam seu cotidiano, sobretudo, a agricultura praticada por eles. De acordo com Silva; França (2018), as preocupações sobre mudanças do clima surgem de estudos de modelos matemáticos e de elaboração de cenários que não levam em consideração expectativas, anseios, satisfações e insatisfações, julgamentos e condutas de pessoas em relação aos seus meios vivenciais. Tais autores afirmam ainda que, no bioma Caatinga, as consequências das mudanças do clima parecem confirmar as previsões do Painel Intergovernamental Sobre Mudanças Climáticas (IPCC), resultando, nos últimos anos no aumento da temperatura, baixo índice pluviométrico e elevado índice de aridez nas áreas geográficas do semiárido do Nordeste do Brasil.

Diante desse contexto, faz-se necessário entender como agricultores familiares vêm enfrentando essas mudanças e buscando mitigar seus efeitos, a partir de seus saberes e práticas nos agroecossistemas e, dessa maneira, mostrando-nos que é possível conviver com as adversidades da região semiárida, respeitando seus limites naturais e explorando suas potencialidades. Para Silva, França (2018), são raras as pesquisas científicas têm se debruçado sobre o que pensam e como agem os sertanejos do semiárido a respeito das mudanças do clima, formas de mitigação e adaptação.

Desse modo, o presente estudo tem como objetivo destacar a percepção sobre mudanças climáticas e desertificação de agricultores familiares no semiárido paraibano, quais práticas estão sendo adotadas por estes agricultores para mitigar os efeitos desses fenômenos em seus agroecossistemas e seus efeitos no solo. 


\section{MATERIAL E MÉTODOS}

\subsection{CARACTERIZAÇÃO DAS ÁREAS DE ESTUDO}

Foram avaliadas quatro experiências de agroecossistemas familiares, sendo uma no Sítio Trincheiras, município de Patos-PB, voltada para produção animal e sistema agroflorestal, duas no município de São José do Sabugi-PB, sendo que primeira está Sítio Nova Conquista e possui um Sistema Agrofloresta e a segunda no Sítio Paquetinha que é voltada para captação de água e manejo do solo. A outra situa-se no município de Santana dos Garrotes-PB, no Sítio Curral Velho voltada para criação animal, armazenamento de forragem e recuperação de área degradada.

Figura 1-Localização dos municípios de Patos, Santana dos Garrotes e São José do Sabugi, estado da Paraíba.

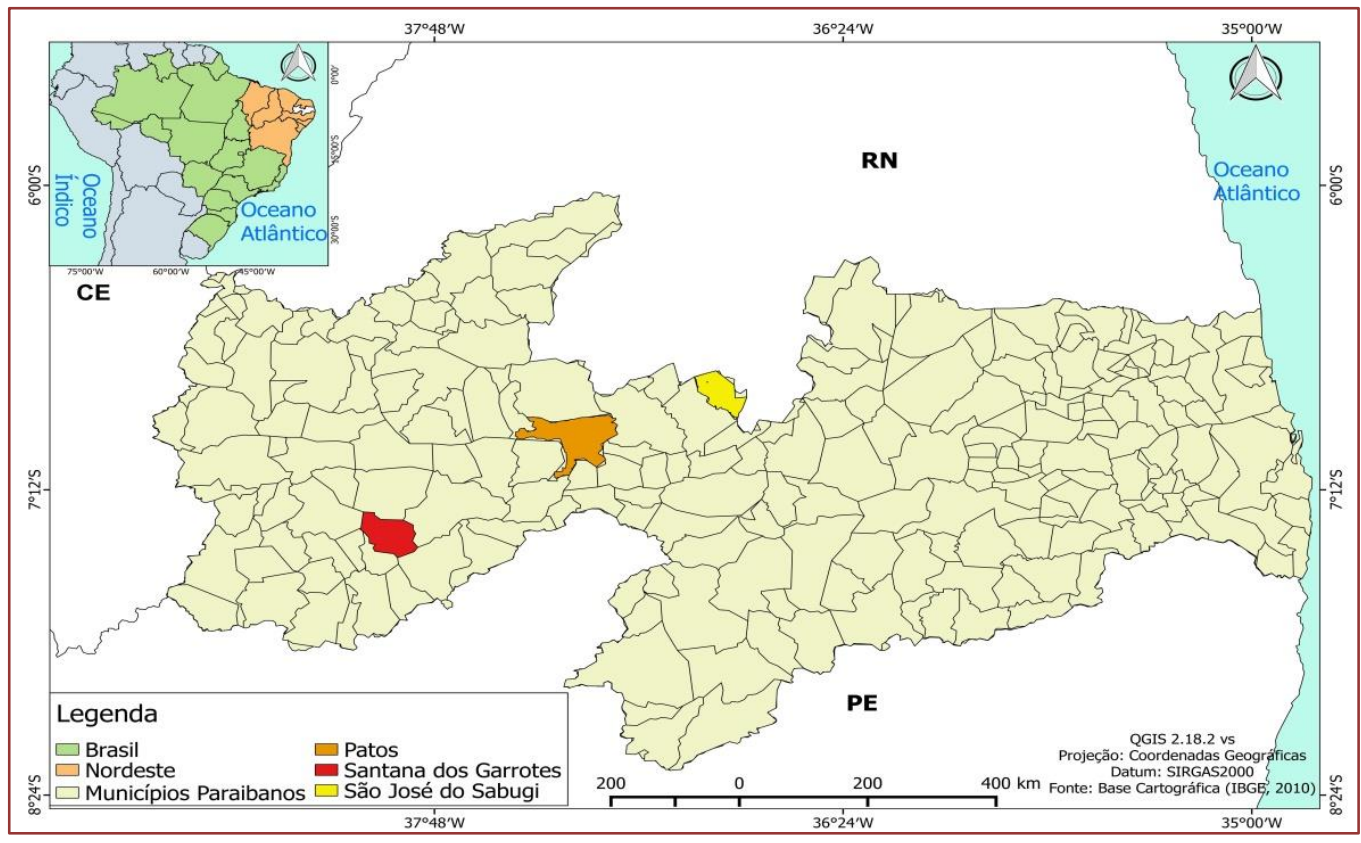

Os três munícipios apresentam um clima do tipo Bsh, classificado, segundo Köppen (1996), como quente e seco, com duas estações bem definidas, uma chuvosa e outra seca, com precipitação média anual de 600 $\mathrm{mm}$ e uma temperatura média de $30^{\circ} \mathrm{C}$ e unidade relativa do ar em torno de 55\% (ALVARES et al., 2013).

Quanto ao histórico de ocupação dos solos nos três municípios, a mesma ocorreu basicamente a partir do cultivo do algodão e da criação extensiva de bovinos. Atualmente, no município de Santana dos Garrotes, predomina também o cultivo do arroz vermelho, tal cultura tornou o município conhecido como a "terra do arroz vermelho".

\subsection{COLETA DE DADOS}

Para avaliar a percepção sobre as mudanças no clima e os efeitos da desertificação sobre agroecossistemas, foram realizadas entrevistas semiestruturadas com os agricultores responsáveis por cada experiência. As entrevistas foram gravadas para posterior avalição e obtenção dos resultados.

Foi realizado um levantamento das principais práticas e/ou tecnologias sociais adotadas pelos agricultores em suas experiências como forma de mitigar os efeitos das mudanças climáticas e da desertificação em seus agroecossistemas. Para obtenção desses dados, foram utilizados questionários semiestruturados e o registro fotográfico dessas práticas e tecnologias em campo.

Tendo em vista que o solo é base para desenvolvimento das culturas vegetais, sejam elas agrícolas ou florestais, e que o processo de desertificação está intimamente ligado à perda da fertilidade do solo, fator de fundamental importância para mitigar os efeitos desse fenômeno, foi realizada uma avaliação dos atributos químicos dos solo, especificamente nas áreas dos dois Sistemas Agroflorestais (SAFs) estudados. 
Para isso, foram coletadas amostras de solos no SAFs do Sítio Nova Conquista e no SAF do Sítio Trincheiras. A coleta de solos foi realizada através de amostragem composta descrita por Cavalcanti (1998). Em cada área, foi realizado o caminhamento em ziguezague para obtenção de 20 amostras simples por área, a uma profundidade de 0 a 0,20m (Figura 3).

Figura 3 - Coleta realizada para avaliação dos atributos químicos do solo em área de Sistema Agroflorestal.
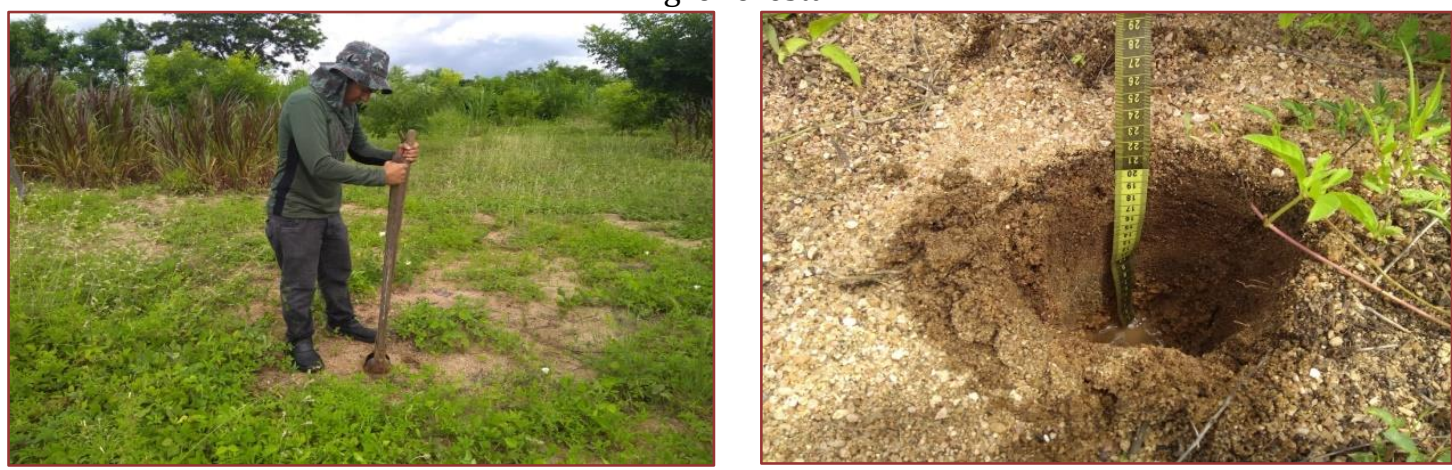

Em seguida, as amostras simples foram homogeneizadas de modo a se obter uma amostra composta de solo para cada área. As amostras compostas foram devidamente identificadas e encaminhadas para o Laboratório de Solos da Universidade Federal de Campina Grande (UFCG), campus de Patos-PB, onde foram analisados os seguintes atributos químicos do solo: pH, matéria orgânica, fósforo e potássio disponíveis; alumínio, cálcio e magnésio trocáveis.

\subsection{ANÁLISES DOS DADOS}

Os dados coletados por meio das entrevistas foram descritos através de textos reproduzindo as falas dos agricultores. Os demais dados foram tabulados e submetidos a softwares de planilhas eletrônicas, sendo posteriormente confeccionadas tabelas e figuras para a discussão dos resultados.

\section{RESULTADOS E DISCUSSÃO}

\subsection{IMPACTOS PROVOCADOS PELAS MUDANÇAS CLIMÁTICAS E DESERTIFICAÇÃO}

De acordo com os entrevistados, o principal impacto provocado pelas mudanças climáticas foi a diminuição do período chuvoso na região. Em relação à desertificação o principal impacto citado foi a perda das áreas mais férteis dificultando a prática da agricultura, como podemos observar na fala do agricultor do Sítio Paquetinha, em São José do Sabugi-PB.

"O homem com sua ganância de produzir e consumir desenfreadamente sem medir as consequências de que isso iria causar, veio acelerar as consequência desse processo que seria a mudança dos tempos. Os cientistas diz que os primeiros seres a vir a sentir essas mudança seria os seres marítimos, mas nós também camponeses que lida com terra e vive nessa região semiárida, principalmente que vive na região do Seridó, que uma região que caminha pra uma desertificação a longo passo, também sentimos esses efeitos das mudanças climáticas e da desertificação. Podemos dizer assim que uma das mudanças que é bem comum e vem acontecendo é a irregularidade da distribuição de chuva aqui na nossa região, porque no tempo deu jovem essas chuvas era muito mais intensa e distribuída". (Trecho da entrevista realizada com o agricultor do Sítio Paquetinha, em São José do Sabugi-PB). 
O relato acima é confirmado em estudo realizado por Andrade, Silva, Souza (2014), ao avaliarem as percepções sobre as variações e mudanças climáticas e as estratégias de adaptação dos agricultores familiares do Seridó potiguar, constataram que, de forma geral, os agricultores familiares seridoenses vêm percebendo alterações climáticas na região. Eles incluíram as mudanças no regime de chuvas e aumento da temperatura, sendo mais relatadas chuvas mais fortes, imprevisibilidade e deslocamento da época das precipitações.

Para Marengo (2008), as mudanças climáticas no Brasil tendem a intensificar as dificuldades de acesso à água. A combinação das alterações do clima, sentidas na forma de falta de chuva ou pouca chuva, acompanhada de altas temperaturas e elevadas taxas de evaporação e com a competição por recursos hídricos, podem levar a uma crise potencialmente catastrófica, sendo os agricultores pobres os mais vulneráveis, a exemplo dos que praticam a agricultura de subsistência na área do semiárido do Nordeste.

Ainda com relação ao processo de desertificação, o agricultor do Sítio Curral Velho, no munícipio de Santana dos Garrotes-PB, atribui que tal fenômeno está ligado à retirada da vegetação nativa, o que provoca a erosão solo, diminuindo sua fertilidade:

Onde tira as matas e não fica nem os garranchos como é que vai segurar as águas? Dá a erosão nas terras altas e acaba as terras baixas também porque aterra, tudo isso acaba com a gente nos termos das plantação. E agora vem a quentura, só que antigamente tinha as árvores pra proteger o solo e hoje não existe mais. (Trecho da entrevista realizada com o Agricultor do Sítio Curral Velho, em Santana dos Garrotes-PB).

Com relação às áreas onde são desenvolvidos sistemas agroflorestais, os agricultores entrevistados afirmam que também sentem que as mudanças no clima afetam o regime das chuvas, provocando períodos de estiagens cada vez mais prolongados, tendo como uma das principais consequências a morte de espécies dentro do sistema.

Tudo isso que tá aparecendo pra nós essa alta temperatura, que não volta mais aqueles tempos sem essa quenturona, foi as ações sem o homem respeitar a natureza, só degradando. No meu Sistema Agroflorestal que eu iniciei em 2007 eu já tive muitas perca consequência dessas estiagem e dessas altas temperaturas. (Trecho da entrevista realizada com agricultor do Sítio Nova Conquista, em São José do Sabugi-PB).

Quanto mais você destrói a vegetação mais diminui a expectativa de chuva, se a gente não destruísse a natureza, as árvores que a gente tem na beira dos rio, açude e tudo, eu acredito que era diferente. Por exemplo esses anos aí tá tão quente que onde a gente ver é tanta tempestade nas áreas de chuva que tá passando é inclusive essa temperatura tão alta que tá né. (Trecho da entrevista realizada com agricultor do Sítio Trincheiras, em Patos-PB)

Vários autores concordam que a vulnerabilidade às consequências das mudanças climáticas já se constitui um problema de grande porte nas regiões áridas, semiáridas e subúmidas secas e vão além, ao afirmarem que, caso não haja alterações nas condições climáticas atuais, os cenários para as próximas décadas tendem a agravar-se em função da diminuição da produtividade e do aumento da população sem acesso a opções alternativas de meios de renda (CAVALTANTI; COUTINHO; SELVA, 2006).

\subsection{PRÁTICAS MITIGADORAS DA DESERTIFICAÇÃO E MUDANÇAS CLIMÁTICAS}

É crescente a preocupação com ações que buscam minimizar os impactos provocados pelas mudanças no clima de maneira geral. Dentre as medidas mitigadoras que estão sendo debatidas e incentivadas podemos destacar a preservação de florestas nativas, a implantação de florestas e sistemas agroflorestais e a recuperação de áreas degradadas (PAULINO; TEIXEIRA, 2010)

Entre os agricultores, também são crescentes essas preocupações e ações. Na Tabela 1, temos o resultado do levantamento das práticas desenvolvidas pelos agricultores em seus agroecossistemas para mitigar os efeitos da desertificação e mudanças climáticas em suas propriedades. 
Tabela 1 - Práticas desenvolvidas pelos agricultores consideradas medidas mitigadoras da desertificação e mudanças climáticas.

\begin{tabular}{|c|c|c|c|c|}
\hline \multirow{2}{*}{ Práticas mitigadoras } & \multicolumn{4}{|c|}{ Localidades } \\
\hline & Sítio Nova Conquista & Sítio Paquetinha & Sítio Trincheiras & Sítio Curral Velho \\
\hline MANEJO DA ÁGUA & $\begin{array}{l}\text { Armazenamento da } \\
\text { água da chuva, } \\
\text { barragem subterrânea, } \\
\text { irrigação por } \\
\text { gotejamento reuso de } \\
\text { águas cinzas. }\end{array}$ & $\begin{array}{l}\text { Armazenamento da } \\
\text { água da chuva, irrigação } \\
\text { por gotejamento reuso } \\
\text { de águas cinzas. }\end{array}$ & $\begin{array}{l}\text { Armazenamento de } \\
\text { água da chuva. }\end{array}$ & $\begin{array}{l}\text { Armazenamento } \\
\text { de água da chuva, } \\
\text { irrigação por } \\
\text { microaspersão. }\end{array}$ \\
\hline MANEJO DO SOLO & $\begin{array}{l}\text { Recuperação de áreas } \\
\text { degradadas, } \\
\text { compostagem. }\end{array}$ & $\begin{array}{l}\text { Recuperação de áreas } \\
\text { degradadas, } \\
\text { compostagem. }\end{array}$ & $\begin{array}{l}\text { Compostagem e } \\
\text { deposição da } \\
\text { matéria orgânica no } \\
\text { solo. }\end{array}$ & $\begin{array}{l}\text { Recuperação de } \\
\text { área degradada. }\end{array}$ \\
\hline $\begin{array}{l}\text { MANEJO DA } \\
\text { VEGETAÇÃO }\end{array}$ & $\begin{array}{l}\text { Recomposição da mata } \\
\text { nativa, } \\
\text { reaproveitamento da } \\
\text { madeira (cerca e } \\
\text { estaca). }\end{array}$ & $\begin{array}{l}\text { Recomposição da mata } \\
\text { nativa. }\end{array}$ & $\begin{array}{l}\text { Recomposição da } \\
\text { mata nativa. }\end{array}$ & $\begin{array}{l}\text { Recomposição da } \\
\text { mata nativa. }\end{array}$ \\
\hline OUTRAS PRÁTICAS & - & - & $\begin{array}{l}\text { Biodigestor e fogão } \\
\text { ecológico. }\end{array}$ & \\
\hline
\end{tabular}

Tendo em vista que o principal efeito sentido pelos agricultores é a diminuição e irregularidade da precipitação pluviométrica na região, observamos que a principal prática com relação ao manejo da água é o armazenamento das águas das chuvas, feito principalmente através de cisternas de placas. Após o armazenamento dessa água, vem a preocupação com a utilização da mesma, através de irrigação, utilizando-se métodos de maior eficiência em economia de água, a exemplo do gotejamento ou microaspersão.

Lima, Silva, Sampaio (2011) afirmam que, através do conhecimento das potencialidades e limitações do semiárido, é possível desenvolver tecnologias adequadas para o manejo sustentável dos recursos naturais existentes na localidade e, no trato das questões pertinentes ao acesso à água, é importante destacar que a água de chuva tem papel relevante nesse processo.

No Sítio Nova Conquista e no Sítio Paquetinha, ambos no município de São José do Sabugi-PB, ocorre também a prática do reuso das águas cinzas, por meio de filtro biológico (Tabela 1 e Figura 4). Através dessa prática, é possível reutilizar a água proveniente das pias da cozinha, lavanderia, banheiro e do banho para irrigação de plantas ao redor da casa. Antes de ser destinada para as plantas, a água coletada passa por um processo de filtragem em caixas coletoras que contêm materiais como pedra, brita, areia e carvão. Após esse processo, a água é armazenada e distribuída para as plantas ao redor da casa.

Figura 4 - Filtros biológicos utilizados para reuso das águas cinzas: (A) Sítio Nova Conquista; (B) Sítio Paquetinha.

(A)

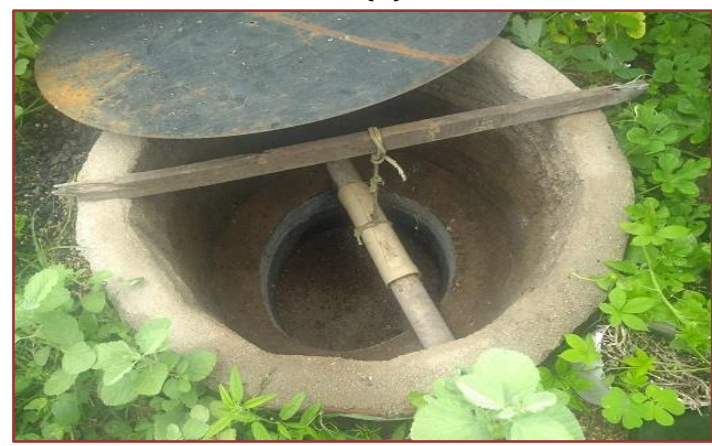

(B)

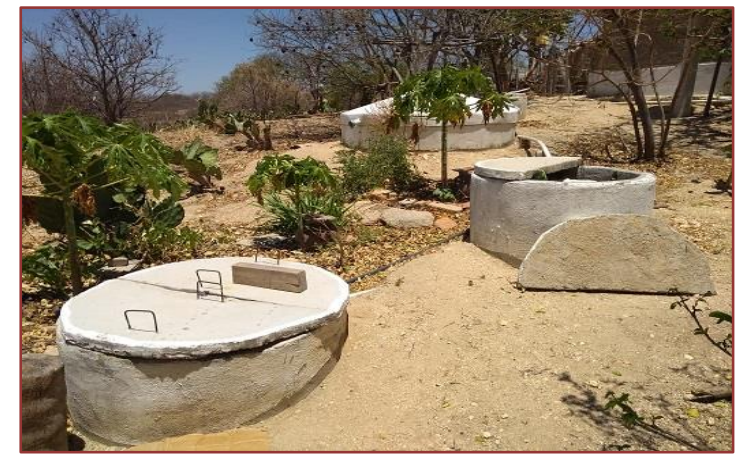


0 reuso das águas residuais pode trazer benefícios econômicos, sociais e ambientais para as comunidades em que essa prática é inserida, é também considerada uma alternativa no combate à escassez de água na região semiárida, que apresenta taxas anuais de evaporação, em média, cinco vezes maiores que as de precipitação, gerando uma condição natural de semiaridez que deve ser entendida como forma de estimular novas ideias e práticas de uso e reuso da água (SCHAER-BARBOSA; SANTOS; MEDEIROS, 2014).

Na Tabela 1, com relação ao manejo solo, observa-se que as principais práticas desenvolvidas pelos agricultores são a recuperação de áreas degradadas e o uso da compostagem, que têm como principais funções melhorar as condições química e física do solo incorporando o resto das culturas, ao invés de queimá-las. Tais ações são de fundamental importância e respondem ao processo de desertificação, tendo em vista que visam à recuperação da fertilidade do solo. Na recuperação dessas áreas, são desenvolvidas técnicas como barramento de pedras para conter a erosão e recomposição da vegetação, como podemos observar na Figura 5.

Figura 5 - Utilização de técnicas com barramentos de pedra e recomposição da vegetação para recuperação de áreas degradadas.
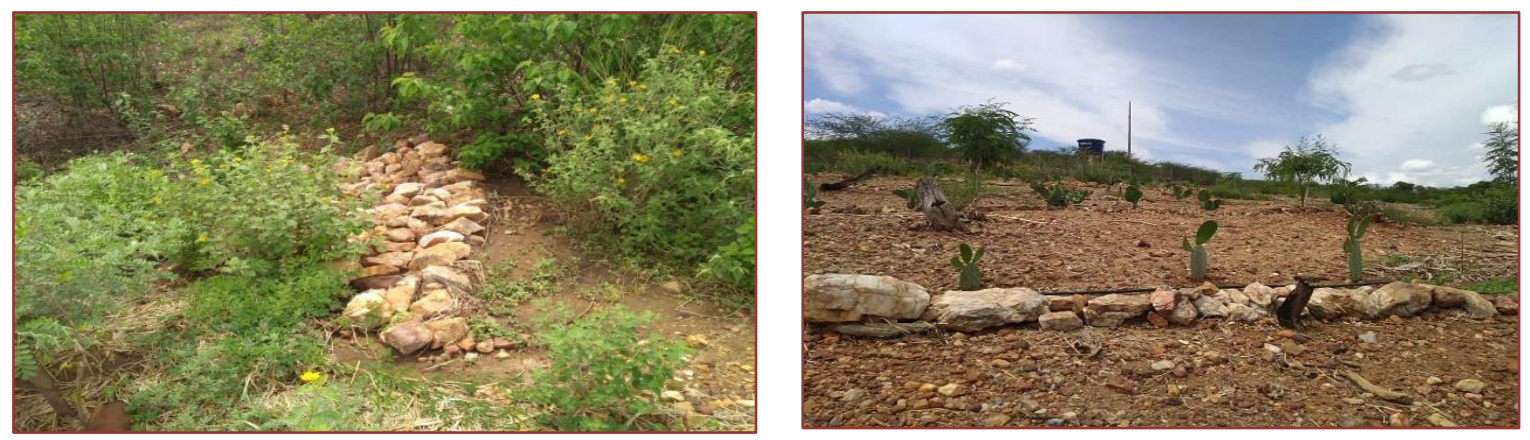

As práticas de da recomposição da vegetação nativa são comuns a todas as propriedades. Apenas no Sítio Trincheiras existem tecnologias sociais como biodigestor e o fogão ecológico (Tabela 1 e Figura 6).

Figura 6 - Tecnologias sociais do fogão ecológico e biodigestor identificadas no Sítio Trincheiras, Patos-PB.
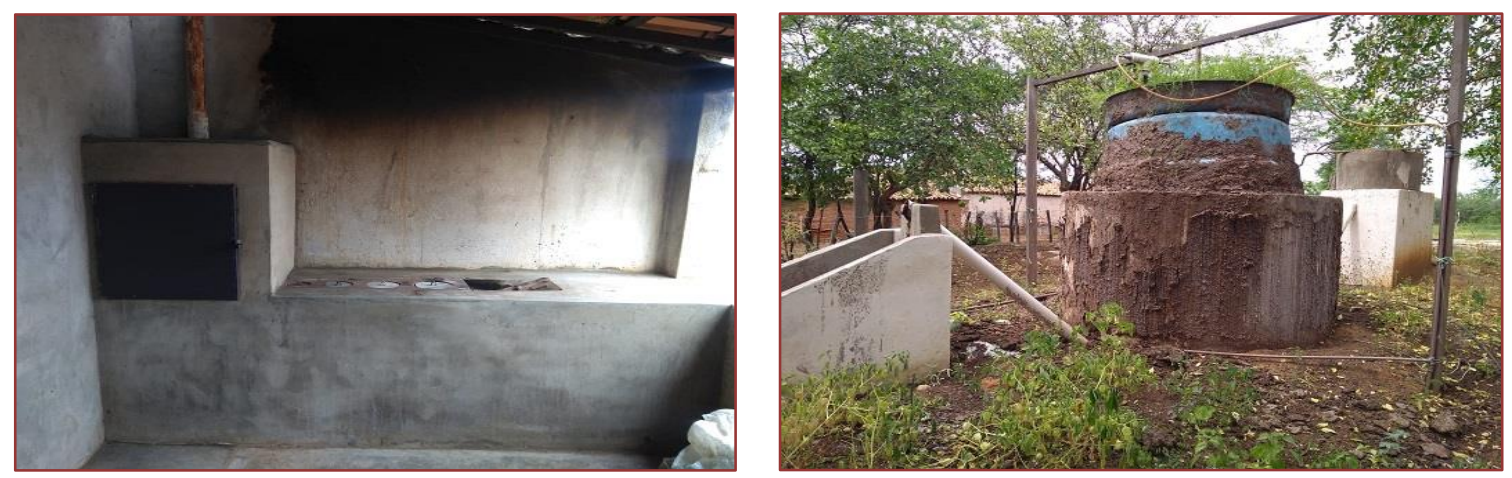

No biodigestor são utilizados dejetos dos animais (bovinos) da propriedade para produção do gás metano, além de ser uma medida mitigadora, gera também uma economia para família, uma vez que é possível substituir o botijão de gás convencional utilizado para preparação das refeições. 0 fogão ecológico é um modelo mais eficiente na queima da lenha, consegue produzir o calor necessário para preparar os alimentos com menos lenha e reduzida fumaça. 


\subsection{ANÁLISE DA FERTILIDADE DO SOLO DOS SISTEMAS AGROFLORESTAIS}

Na Tabela 2 temos o resultado da análise do solo dos dois Sistemas Agroflorestais estudados. Observa-se que os solos dos dois Sistemas Agroflorestais (SAFs) apresentam-se quimicamente equilibrados. Provavelmente esse equilíbrio se deve ao fato do manejo aplicado nas duas áreas, como a não utilização do fogo e, principalmente, pela dinâmica das culturas adotadas nas áreas de SAFs, uma vez que nestes sistemas de cultivo, há uma maior diversificação das culturas, diferentemente do que ocorre em monocultivos.

Com relação ao $\mathrm{pH}$, os SAFs localizados no Sítios Trincheiras e Nova Conquista apresentaram-se praticamente neutros, 6,5 e 6,4, respectivamente. Apesar de haver incorporação de matéria orgânica (M.O.) no solo através de práticas como a compostagem, a quantidade de M.O. nas duas áreas é considerada baixa, sendo que o SAF no Sítio Trincheiras apresentou um valor maior de M.0. $\left(15,86 \mathrm{~g}^{\left.-\mathrm{dm}^{-3}\right)}\right.$

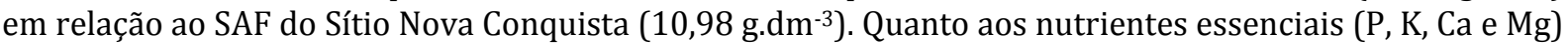
as duas áreas apresentaram níveis bastante satisfatórios, podendo o P, Ca e Mg serem considerados em níveis altos e Ca apresentando nível médio (Tabela 2).

TABELA 2 - Resultado da análise química dos solos dos Sistemas Agroflorestais localizados no Sítio Trincheiras (ST), Patos-PB, e no Sítio Nova Conquista (SNC), São José do Sabugi-PB.

\begin{tabular}{|c|c|c|c|c|c|c|c|c|c|c|}
\hline \multirow{3}{*}{ Local } & $\mathrm{pH}$ & M.O. & P & $\mathrm{Ca}$ & Mg & K & $\mathrm{Na}$ & $\mathrm{H}+\mathrm{Al}$ & CTC & V \\
\hline & $\mathrm{CaCl}_{2} 0,01 \mathrm{M}$ & g.dm ${ }^{-3}$ & mg.dm-3 & & & $--\mathrm{cm}$ & $\mathrm{Im}^{-3}-$ & & -- & $\%$ \\
\hline & 6,5 & 15,86 & 52,9 & 5,0 & 3,3 & 0,25 & 1,52 & 1,1 & 11,17 & 90,16 \\
\hline SNC & 6,4 & 10,98 & 57,3 & 7,0 & 2,6 & 0,30 & 0,22 & 1,2 & 11,32 & 89,40 \\
\hline
\end{tabular}

Ainda na Tabela 2, podemos constatar que a quantidade de sódio ( $\mathrm{Na}$ ) presente no solo do SAF do Sítio Trincheiras $\left(1,52 \mathrm{cmol}_{\mathrm{c}} \mathrm{dm}^{-3}\right)$ apresentou-se um pouco mais elevada em relação ao SAF do Sítio Nova Conquista $\left(0,22 \mathrm{cmol}_{\mathrm{c}} \mathrm{dm}^{-3}\right)$, no entanto a presença desse elemento não é considerada prejudicial para as duas áreas. Quanto à capacidade de troca de cátions (CTC), as duas áreas apresentam capacidade moderada, enquanto que a porcentagem de saturação por base (V) foi considerada alta de acordo com parâmetros propostos por Mello et al. (1983). Solos com esses valores de V são solos considerados eutróficos, ou seja, solos de altíssima fertilidade.

Os valores de CTC e V são de grande importância no que diz respeito à fertilidade do solo. A CTC indica a capacidade que solo tem de adsorver cátions em forma trocável, os quais, em geral, irão servir de nutrientes para as plantas. Considera-se que um valor de $\mathrm{V}$ acima de $50 \%$ indica que, provavelmente, um solo sem ou com baixo teor de alumínio seja considerado eutrófico, ou seja, de boa fertilidade (LEITE et al., 2012; MELLO et al., 1983).

Solos com essa qualidade são de fundamental importância para o estabelecimento de qualquer cultura, seja agrícola ou florestal, sendo os SAFs uma forma de produção que contribui significativamente para o equilíbrio e dinâmica da fertilidade dos solos do semiárido.

\section{CONCLUSÕES}

De acordo com a percepção dos agricultores entrevistados, o principal efeito sentido por estes, e que é atribuído às mudanças climáticas, é a irregularidade das chuvas na região o que provoca o prolongamento dos períodos de estiagem e o aumento da temperatura.

Com relação à desertificação, o efeito mais citado foi a diminuição da fertilidade do solo e, consequentemente, a perda da capacidade produtiva.

As principais medidas mitigadoras adotadas pelos agricultores foram o armazenamento da água das chuvas; a recuperação dos solos e a recomposição da vegetação nativa.

0 solo das áreas com Sistemas agroflorestais (SAFs) dos Sítios Trincheiras e Nova Conquista apresentaram uma boa fertilidade, sendo os SAFs uma forma de cultivo indicada para recuperar a fertilidade solo e mitigar os efeitos provocados pela desertificação. 


\section{AGRADECIMENTO}

As autoras agradecem ao Conselho Nacional de Pesquisa (CNPq) pela concessão de bolsa de Estudos para o Programa de Pós-Graduação em Ciências Florestais da Universidade Federal de Campina Grande (PPGCF/UFCG).

Agradece a todos que contribuíram na construção deste trabalho, em especial, os agricultores familiares do sertão paraibano.

\section{REFERÊNCIAS}

[1] ALVARES, C. A.; STAPE, J. L.; SENTElHAS, P. C.; GONÇALVES, J. L. M.; SPAROVEK, G. Köppen's climate classification map for Brazil. Meteorologische Zeitschrift, 22 (6), 711-728, 2013. Disponível em: http://www.lerf.eco.br/img/publicacoes/Alvares_etal_2014.pdf.

[2] ANDRADE, A. J. P.; SILVA, N. M.; SOUZA, C. R. As percepções sobre as variações e mudanças climáticas e as estratégias de adaptação dos agricultores familiares do Seridó Potiguar. Revista Desenvolvimento e Meio Ambiente, 31, 77-96, 2014. Disponível em: https://revistas.ufpr.br/made/article/view/32955.

[3] CAVALCANTI, E. R.; COUTINHO, S. F. S.; SELVA, V. S. F. Desertificação e desastres naturais na região do semiárido brasileiro. Revista Cadernos de Estudos Sociais. 22 (1). jan./jun., 2006. Disponível em: http://www.fundaj.gov.br/geral/nesa/desastres_naturais.pdf.

[4] CAVALCANTI, F. J. A. Recomendações de adubação para o estado de Pernambuco. (2ª aproximação). Recife: IPA, 2. ed., 1998.

[5] LEITE, M. J. H.; SANTOS, R. V.; BEZERRA, R. M. R.; LUCENA, R. J.; SOUSA, K. L. Avaliação da fertilidade do solo em perímetros irrigados: Engenheiro Arcoverde e São Gonçalo, PB. Revista Verde. 7(4), 214 - $225,2012$. https://www.gvaa.com.br/revista/index.php/RVADS/article/view/1249/pdf_667.

[6] LIMA, A. E. F.; SILVA, D. R.; SAMPAIO, J. L. F. As tecnologias sociais como estrat. de convivência com a escassez de água no semiárido cearense. Conexão Ciência e Tecnologia, 5(3), 9-21, 2011. Disponível em: http://www.conexoes.ifce.edu.br/index.php/conexoes/article/view/402/301.

[7] LIMA, J. R. Resíduos orgânicos: geração de metano, efeito estufa e alternativas de mitigação. In: Silva, E. (org). Temas em ecologia e educação ambiental. São Paulo: Gramma, p. 73-97, 2017.

[8] LiMA, R. C. C.; CAVAlCANTE, A. M. B.; PEREZ-MARIN, A. M. Desertificação e mudanças climáticas no semiárido brasileiro - Campina Grande: INSA-PB, 2011. Disponível em: https://www.researchgate.net/profile/Jemison_Dos_Santos/publication/305285396_Estrategias_de_convivencia_par a_a_conservacao_dos_recursos_naturais_e_mitigacao_dos_efeitos_da_desertificacao_no_semiarido/links/5786f86708a ef321de2c72cc/Estrategias-de-convivencia-para-a-conservacao-dos-recursos-naturais-e-mitigacao-dos-efeitos-dadesertificacao-no-semiarido.pdf.

[9] MARENGO, J. A. Vulnerabilidade, impactos e adaptação à mudança do clima no semi-árido do Brasil. Parcerias Estratégicas, $13(27), \quad 1-28,2008 . \quad$ Disponível http://seer.cgee.org.br/index.php/parcerias_estrategicas/article/view/329.

[10] MELLO, F.A.F.; BRASIL SOBRINHO, M.O.C.; ARZOLLA, S.; SILVEIRA, R.I.; COBRA NETTO, A.; KIEHL, J.C. Fertilidade do solo. São Paulo: Nobel, 1983.

[11] PAULINO, V.T.; TEIXEIRA, E.M.L.C. Sustentabilidade de pastagens - Manejo adequado como medida redutora da emissão de gases de efeito estufa. PUBVET, 4(24), 2-18, 2010. Disponível em: http://www.pubvet.com.br/artigo/2360/p-styletext-align-justify-aligncenterstrongsustentabilidade-de-pastagensndash-manejo-adequado-como-medida-redutora-da-emissatildeo-de-gases-de-efeito-estufastrongp.

[12] PRIMAVESI, O.; ARZABE, C. PEDREIRA, M. S. Mudanças climáticas: visão tropical integrada das causas, dos impactos e de possíveis soluções para ambientes rurais ou urbanos. São Carlos: Embrapa Pecuária Sudeste, 2007. Disponível em: http://queimadas.cptec.inpe.br/ rqueimadas/material3os/2007_Primavesi_etal_Mudancas_EMBRAPA_DE3os.pdf>.

[13] SANTOS, P. M.; VOLTOLINI, T. V.; CAVALCANTE, A. C. R.; PEZZOPANE, J. R. M.; MOURA, M. S. B.; SILVA, T. G. F.; BETTIOL, G. M.; CRUZ, P. G. Mudanças Climáticas Globais e a Pecuária: Cenários Futuros para o Semiárido Brasileiro. Revista Brasileira de Geografia Física, 2011. Disponível em: https://www.alice.cnptia.embrapa.br/handle/doc/922978.

[14] SCHAER-BARBOSA, M.; SANTOS, M. E. P.; MEDEIROS, Y. D. P. Viabilidade do reuso de água como elemento mitigador dos efeitos da seca no semiárido da Bahia. Ambiente \& Sociedade, São Paulo, 17(2), 17-32, 2014. Disponível em: https://www.tratamentodeagua.com.br/wp-content/uploads/2016/03/Viabilidade-do-re\%C3\%BAso-de\%C3\%A1gua-como-elemento-mitigador-dos-efeitos-da-seca-do-semi\%C3\%A1rido-para-Bahia.pdf. 
[15] SILVA, R. W. C., PAULA B. L. Causa do aquecimento global: antropogênica versus natural. Terra e Didática, 5(1):42-49, 2009. Disponível em: http://www.ppegeo.igc.usp.br/index.php/TED/article/view/8365/7636.

[16] SILVA, V. P.; FRANÇA, G. L. S. Percepções de mudanças do clima, impactos e adaptação para sertanejos do semiárido. Revista Brasileira de Climatologia, 22, $2018 . \quad$ Disponível em: https://revistas.ufpr.br/revistaabclima/article/view/55958/35036.

[17] WALKER, G.; KING, S. D. O tema quente: como combater o aquecimento global e manter as luzes acessas. Rio de Janeiro: Objetiva, 2008. 286p 


\section{Capítulo 13}

Atenuação da vazão de pico de demanda em sistemas de suprimento de água com suporte de conceitos de automação predial

\section{Letícia Soriano}

Victor de Barros Deantoni

Alberto Luiz Francato

Resumo: Sistemas urbanos de abastecimento de água dependem de um conjunto de infraestrutura instalada e de da operação da instalação. 0 presente trabalho faz uma avaliação do impacto que a utilização de um sistema integrado, onde o abastecimento através de um reservatório urbano é complementado em horários pré-definidos pela operação dos reservatórios das unidades consumidoras. Em dois cenários hipotéticos adotados foi possível estabelecer o impacto na atenuação de picos de vazões (e por consequência pressões) em uma rede de abastecimento, complementarmente foi possível através de uma técnica de otimização determinar a quantidade de unidades consumidoras que representaria o maior nível de atenuação (16\%).

Palavras-Chave: Abastecimento urbano, redes de água, otimização, operação de reservatórios 


\section{INTRODUÇÃO}

A água é um componente vital da cadeia de produção industrial, agrícola e comercial, conferindo a ela, portanto, valor econômico. Perante esse cenário, algumas estatísticas são alarmantes, Goujon e Prié (2010) relatam que 9 países são detentores de $60 \%$ de fonte de água doce na terra e quase 1 bilhão de pessoas não tem acesso à água potável no mundo.

Nas áreas com maiores fluxos econômicos e produtivos, como as regiões metropolitanas, o problema do abastecimento está relacionado com a necessidade de infraestrutura complexa, alta demanda e sua variabilidade ao longo do dia. Ademais, a utilização dos mananciais para o abastecimento dos grandes centros urbanos se dá, comumente, por intermédio de sistemas que suprem várias cidades de forma simultânea e interligada. Deste modo, o planejamento, execução e operação da infraestrutura hídrica, são ações complexas e que requerem uso de tecnologias apropriadas.

À visto disso, com o suporte de técnicas de automação predial é factível de se garantir a utilização racional de energia e água, também como corrobora para um provimento contínuo de dados que, analisados adequadamente, viabilizam o gerenciamento e a operação parcimoniosos dos serviços ou funções da edificação, bem como sua alta integridade (Braga, 2007).

Com o aporte dessa ótica, há projetos que impõem restrições ao desperdício, perseguindo soluções compatíveis com as premissas da sociedade. Segundo Neto (2008), para alcançar a sustentabilidade pretendida, há que se adotar obrigatoriamente soluções que reduzam o desperdício.

Os reservatórios residenciais de água são responsáveis por efetuar a intermediação entre o sistema de abastecimento público e os pontos de consumo residenciais, no entanto, pouco se utiliza, de fato, a função de armazenamento dos mesmos. É nesse cenário que a automatização de sistemas de abastecimento é uma importante ferramenta para o monitoramento da operação, com a intenção de facilitar, tanto para o proprietário quanto para a Estação de Tratamento de Água (ETA), o acompanhamento da operação de abastecimento.

\section{REVISÃO BIBLIOGRÁFICA}

Ao decorrer da história, foram se tornando diversificadas e exigentes, em quantidade e qualidade, as necessidades de uso de água. As sociedades externaram uma maior complexidade e a garantia de sua sobrevivência passou a exigir, sincronicamente, mais segurança no suprimento de água e maiores aportes tecnológicos que, por sua vez, também vieram a demandar maior quantidade de recursos hídricos.

Os sistemas de abastecimento de água são responsáveis por levar água potável para consumo nos diversos setores da sociedade: residências, indústrias, comércio, serviço público etc. Seu funcionamento se resume basicamente na captação de água de um manancial, tratamento desta água e distribuição para os pontos de consumo da população.

O Manual de Usos Consuntivos da Água no Brasil, elaborado pela Agência Nacional de Águas (ANA, 2019), traça um panorama das com históricos e previsões de demanda por recursos hídricos em todos os municípios brasileiros entre 1931 e 2030. Nele, as informações constatadas são que, a cada segundo, foram utilizados, em média, 2 milhões e 83 mil litros de água no Brasil (ou 2.083 metros cúbicos por segundo) no ano de 2017. Em 1931, eram utilizados apenas 131 mil litros por segundo - 6,3\% do uso atual. Ainda segundo o documento, o uso da água deverá crescer $24 \%$ até 2030 , superando a marca de 2,5 milhões de litros por segundo.

No estudo de demanda elaborado pela ANA, os usos da água são estimados por setor, usuário e município. A agricultura irrigada, o abastecimento urbano e a indústria de transformação são responsáveis por 85\% das retiradas de água em corpos hídricos. Na projeção da pesquisa, todos os usos continuarão se expandindo nos próximos anos, com exceção do abastecimento humano rural, que deverá sofrer uma queda devido à redução da população no meio rural.

Os sistemas de abastecimento de água contam com reservatórios que podem executar duas funções principais: acomodar a variação de consumo de água da população, visto que a captação de água do manancial é feita, normalmente, com vazão constante (neste caso, o reservatório é também chamado de pulmão); reservar água para momentos em que não é possível captar ou tratar água com vazão suficiente para atender à demanda. Esta última função de armazenar água exige reservatórios com uma capacidade razoavelmente elevada se comparada com os pulmões, que somente variam seu nível para acomodar as variações de consumo. 
As caixas d'água das unidades consumidoras, como por exemplo as residenciais, não funcionam como um sistema de armazenamento, mas sim como uma reserva para eventuais períodos sem abastecimento. No entanto, existe a possibilidade de controlar o fornecimento de água para determinada unidade consumidora aproveitando-se da sua capacidade de reservação. É possível, por exemplo, reduzir o fornecimento de água para determinada unidade nos momentos em que o sistema de abastecimento é mais demandado como um todo sem prejuízos para o consumidor, que possui água armazenada em seu reservatório para estes momentos.

Operações como estas devem ser cuidadosamente planejadas para atingir duas condições: minimizar os gastos com energia elétrica do sistema de abastecimento e, ao mesmo tempo, garantir o suprimento de água suficiente para a demanda do consumidor.

Do ponto de vista do consumidor, atualmente, não há vantagem em atenuar picos de consumo de água, visto que o preço pelo seu consumo é fixo, ou seja, não ocorre qualquer tipo de variação conforme a época do ano ou período do dia. Por este motivo, não há incentivo direto para o consumidor alterar o funcionamento convencional do reservatório, que utiliza uma chave-boia para manter constantemente no máximo seu nível e sem transbordamento. Neste tipo de operação, ao ocorrer o consumo de água por qualquer equipamento hidráulico, ocorre variação negativa do nível da caixa d'água e, ao detectar tal variação, a chave-boia permite a entrada de água advinda do sistema público de maneira instantânea através de um acionamento mecânico. Por fim, novamente, a chave-boia irá cessar a entrada de água quando se atingir a sua capacidade máxima através do fechamento da válvula de entrada.

Em consequência à nova modalidade horária de cobrança pelo uso da energia elétrica, é natural que as concessionárias de fornecimento de água também busquem se adaptar ao mercado através de uma cobrança semelhante aos seus usuários, visto que processos de captação, adução e tratamento utilizados para garantir a disponibilidade hídrica nas condições adequadas consomem grande volume de energia elétrica e, portanto, em horários de maior demanda por água, maior será o seu custo.

Em um cenário de tarifa horária de consumo de água, o funcionamento tradicional da chave-boia é extremamente ineficiente, visto que, mesmo em horários de pico, o mecanismo permitirá o consumo de água da rede para enchimento do reservatório mesmo que não haja necessidade, acarretando despesas financeiras desnecessárias para o consumidor.

Perante a problematização descrita acima, o presente trabalho visa otimizar o processo de abastecimento do reservatório residencial através da automação.

\section{METODOLOGIA}

Valendo-se de um sistema conectado em qual a operação, portanto o controle do enchimento das caixas residenciais, seja feito com auxílio de automação e controlado pelo serviço de abastecimento de cada cidade, é factível de se começar a utilizar o potencial de reserva que existe em cada reservatório das unidades consumidoras (reservatórios residenciais) para o bem do sistema como um todo.

Tomando um sistema hipotético - uma cidade - onde há um reservatório municipal de abastecimento com um dado volume e um grupo de residências que tem como fonte de alimentação esse reservatório é possível criar cenários de abastecimento distintos, como demonstrados:

- $\quad$ Somente o reservatório municipal é operado;

- $\quad$ O reservatório municipal e uma parcela dos reservatórios residenciais são operados.

A Figura 1 a seguir ilustra o esquema hipotético da rede de abastecimento proposto para ambos os cenários que serão estudados. 
Figura 1 - Rede de abastecimento proposta para o estudo

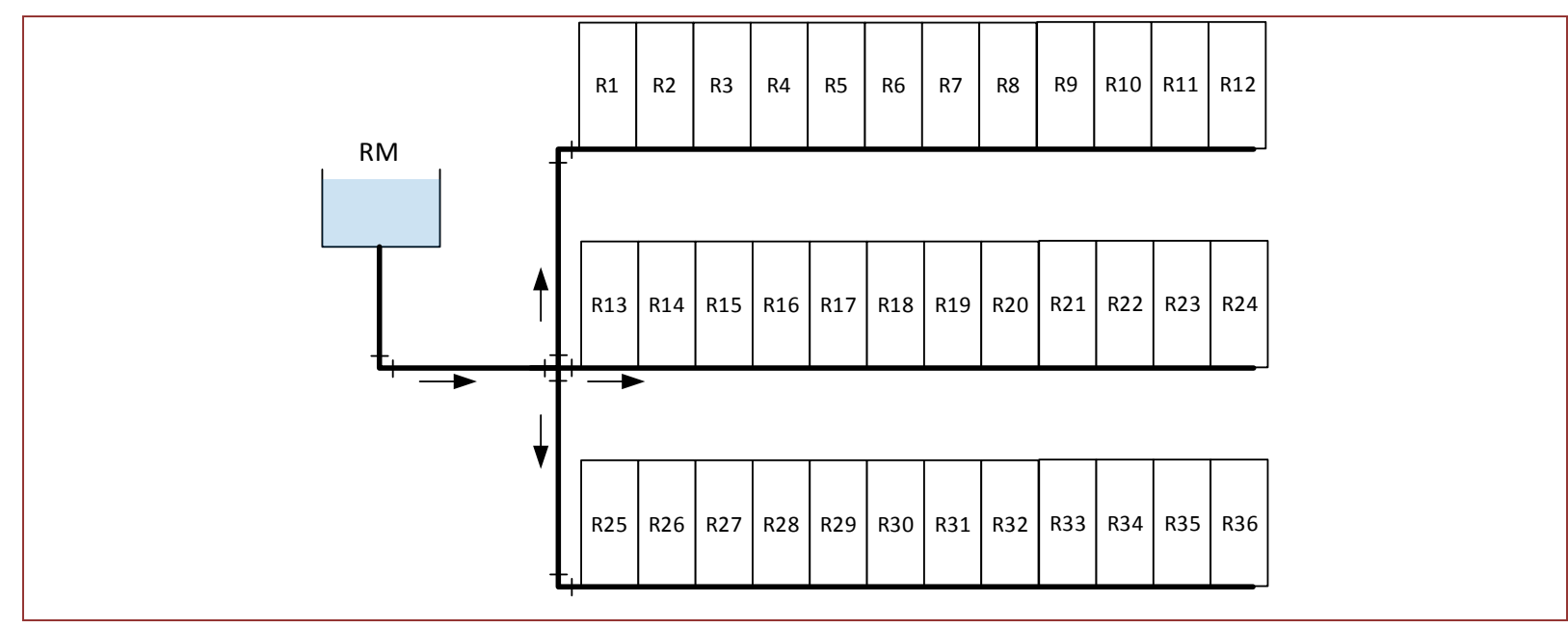

O volume armazenado de cada caixa, seja o reservatório municipal (RM) ou os reservatórios individuais $R_{i}(1 \leq i \leq 36)$, podem ser descritos pela seguinte equação:

$$
\operatorname{Arm}(\%)=\frac{V_{t}}{V T} * 100
$$

Onde $V_{t}$ é o volume no intervalo de tempo $t$ e $V T$ é o volume total do reservatório, portanto a sua capacidade.

A curva de demanda adotada para a cidade hipotética do estudo se comportará como demonstrada no gráfico abaixo da Figura 2, a qual foi retirada de um artigo "Análise da Variação do Consumo de Água Utilizando Dados Obtidos por Sistemas Supervisores Remotos. Estudo de Caso: Munícipio de Franca" baseado na ABES - Associação Brasileira de Engenharia Sanitária e Ambiental - e a AESABESP Associação dos Engenheiros da SABESP.

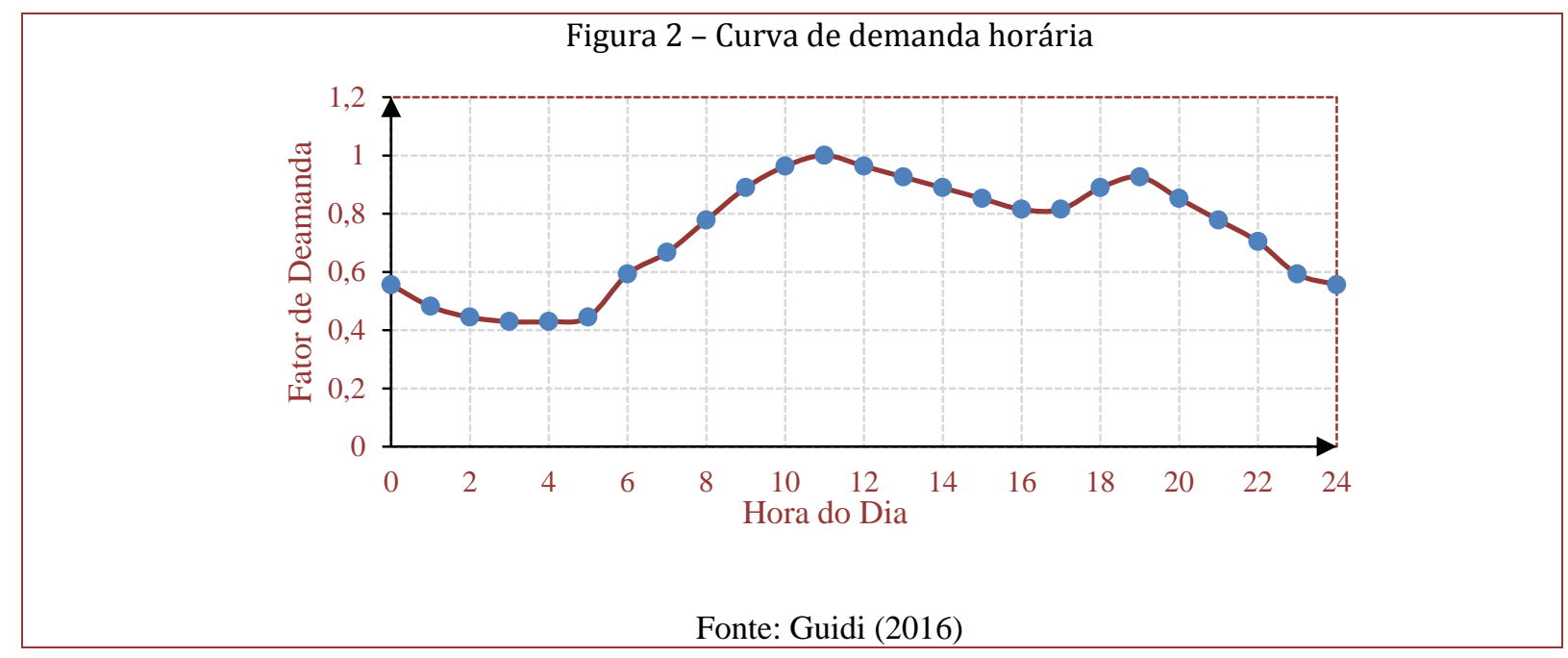

Desta forma considerando os seguintes dados para a modelagem:

- População de cada residência: 5 pessoas com consumo de 200L/hab.dia

- Considerando 36 residências, portanto um total de habitantes de 180 pessoas. 
Pode-se então calcular os parâmetros de vazão para a cidade, sendo a vazão média diária $\left(Q_{M E D}\right)$ estabelecida pela Eq. (2). 0 fator de demanda médio $(K)$ da Figura é de 0,737, pode-se computar a vazão máxima diária $\left(Q_{M A X}\right)$ pela Eq. (3) e a mínima diária $\left(Q_{M I N}\right)$ por intermédio da Eq. (4)

$$
\begin{aligned}
& Q_{M E D}=\frac{n^{\circ} \text { total de habitantes } * \text { Consumo Diário }\left(\frac{L}{\text { hab.dia }}\right)}{24 \text { horas } * 60 \text { minutos } * 60 \text { segundos }}=\frac{180 * 200}{24 * 60 * 60}=0,417 \frac{L}{\mathrm{~S}} \\
& Q_{M A X}=\frac{n^{\circ} \text { total de habitantes } * \text { Consumo Diário }\left(\frac{L}{\text { hab.dia }}\right)}{24 \text { horas } * 60 \text { minutos } * 60 \text { segundos }} *\left(\frac{1}{K}\right)=\frac{180 * 200}{24 * 60 * 60} *\left(\frac{1}{0,737}\right)=0,565 \frac{L}{\mathrm{~S}} \\
& Q_{M I N}=\frac{n^{\circ} \text { total de habitantes } * \text { Consumo Diário }\left(\frac{L}{\text { hab.dia }}\right)}{24 \text { horas } * 60 \text { minutos } * 60 \text { segundos }} * K=\frac{180 * 200}{24 * 60 * 60} * 0,737=0,307 \frac{\mathrm{L}}{\mathrm{S}}
\end{aligned}
$$

Efetuando os devidos cálculos, obtém-se que a Vazão Média diária $\left(Q_{M E D}\right)$ é de $0,417 \mathrm{~L} / \mathrm{s}$ e a vazão máxima ( $Q_{M A X}$ ) e mínima diária $\left(Q_{M I N}\right)$ são respectivamente $0,565 \mathrm{~L} / \mathrm{s}$ e $0,307 \mathrm{~L} / \mathrm{s}$. Tendo posse dos devidos valores inicia-se assim o estudo comparativo dos cenários.

Barros Filho (2005) menciona o controle de pressões e vazões das redes de distribuição de água como um dos meios de atuação para uma gestão eficaz de um Sistema de Abastecimento de Água. Deve-se considerar, neste ponto, que as altas pressões podem corroborar aos danos às tubulações de água, ocasionando vazamentos na rede. Por outro lado, baixas pressões ocasionam a entrada de ar na rede, causando infiltrações que afetam a qualidade da água. Ademais, a crescente demanda em horários de pico faz com que o uso da bomba hidráulica seja imprescindível, e como ressaltado anteriormente o subsídio na energia para as empresas de Saneamento está sendo retirado de forma gradativa levando com que a diferenciação no custo horário de energia suscita em custo oneroso sobre o recurso energético utilizado em tais empresas.

\subsection{SOMENTE RESERVATÓRIO MUNICIPAL É OPERADO}

Adotando como premissa para esse primeira conjuntura em qual apenas o reservatório seria controlado, foi feita uma simulação simplificada considerando que o mesmo se encontra em sua capacidade máxima de reservação no início do tempo de análise e que tem disponibilidade de abastecimento para mais de um dia (Figura 3), a curva ilustrada referente ao armazenamento do reservatório foi lograda através da subtração da capacidade total pela multiplicação da vazão média diária com o fator de demanda em questão. A vazão na rede é apresentada Figura 4 com discretização horária.

\subsection{O RESERVATÓRIO MUNICIPAL E UMA PARCELA DOS RESERVATÓRIOS RESIDENCIAIS SÃO OPERADOS}

Segundo Babbitt et al (1973), os reservatórios nos sistemas de abastecimento de água podem ter finalidades diversas, podendo ser usados pata represar a água, acumular água, equilibrar vazões, equilibrar pressões no sistema de distribuição, entre outros usos. De acordo com as finalidades citadas os reservatórios podem ser denominados em: reservatório de acumulação, de compensação e de distribuição (Brasil, 2008).

A redução das perdas físicas tem influência direta nos custos de produção, devido à redução do consumo de energia nas diversas partes do sistema, de produtos químicos no tratamento da água, entre outros fatores. Isso ocorre devido ao fato de que altos índices de perdas geram a necessidade de captar um volume de água maior para a distribuição ou, por outro lado, a expansão do SAA (Sistema de Abastecimentos de Água). Com a redução das perdas, contudo, pode-se fazer uso das mesmas instalações para aumentar a oferta de água, sem necessidade, portanto, de expandir o sistema produtor (Barroso, 2005).

Com a finalidade de se galgar uma situação ótima em qual o suprimento de água é executado e conjuntamente é obtido uma eficiência energética para a empresa, analisa-se o cenário cujo qual apresenta a quantidade porcentual ótima de residências participantes do programa de controle de abastecimento de 
seus reservatórios. Esse ponto ótimo proporcionará uma curva do esvaziamento do reservatório principal mais próximo ao comportamento linear, permitindo um controle maior no momento de encher e esvaziar o reservatório podendo-se acionar a bomba em horários pré-definidos (fora do horário de pico de energia) e contando com a capacidade de armazenamento dos reservatórios das unidades consumidoras finais, fato que respaldará em um equilíbrio de pressão e vazão na rede.

Para tal estudo, como há uma variação na demanda ao longo do dia, estabeleceu-se que sempre que o fator de demanda for superior a 73,7\% (K=0,737) o consumo das residências se dá pela utilização da caixa d'água interna e não mais pela rede como um todo.

Para uma primeira hipótese considera-se que apenas $10 \%$ das residências estejam participando do programa, ou seja, entre $08 \mathrm{~h} 00$ e $20 \mathrm{~h} 59$, além do reservatório principal essa porcentagem das residências utilizassem o seu próprio reservatório.

Sempre que o nível de demanda horária superar 73\%, entra em funcionamento o abastecimento das residências pelo reservatório próprio, quando se volta a um nível abaixo de $73 \%$ as caixas são reabastecidas pela rede municipal. Neste cenário o volume utilizado nas residências é reposto nas horas de menor consumo de água e também o custo da energia utilizada no bombeamento seja ínfero, portanto, um horário entre $23 \mathrm{~h} 00$ e $5 \mathrm{~h} 59 \mathrm{~min}$.

Posteriormente foi feita a análise com $20 \%$ das residências participando. Com isso é possível notar que nas distintas situações é possível manter a vazão em uma faixa menor de oscilação, o que implica em menores variações de pressão na rede e maior facilidade na operação do reservatório.

Utilizando um sistema simples de otimização que consiste em minimizar o desvio padrão quadrático das vazões na rede tem-se:

$$
D E S V_{T O T}=\sum_{i=1}^{24}\left(Q_{t}-Q_{M E D}\right)^{2}
$$

A função objetivo é:

$$
\min Z=D E S V_{T O T}
$$

Empregando o Solver do software MS Excel e buscando menor desvio padrão, a planilha indica o nível de participação das residências em que se estabelecerá o resultado ótimo.

\section{RESULTADOS}

\subsection{SOMENTE RESERVATÓRIO MUNICIPAL É OPERADO}

Com os dados demonstrados no gráficos das Figuras 3 e 4, fez-se por intermédio de ferramentas contidas no Microsoft Excel o cálculo da diferença máxima entre a vazão horária de demanda e sua média $(\mu)$ obtendo o valor de 10,08 L/min e, concomitantemente o seu desvio padrão $(\sigma)$ da ordem de 6,64 L/min. Isto posto, nota-se que há uma oscilação de vazão na rede que é proporcional ao fator de demanda, com vazões máximas de $35 \mathrm{~L} / \mathrm{min}$ em horários de pico de demanda, normalmente nos horários entre $11 \mathrm{~h} 00$ min e $12 \mathrm{~h} 00 \mathrm{~min}$, e uma vazão mínima estabelecida durante a madrugada (entre as $02 \mathrm{~h} 00 \mathrm{~min}$ e $05 \mathrm{~h} 00 \mathrm{~min}$ ) de $15 \mathrm{~L} / \mathrm{min}$. 


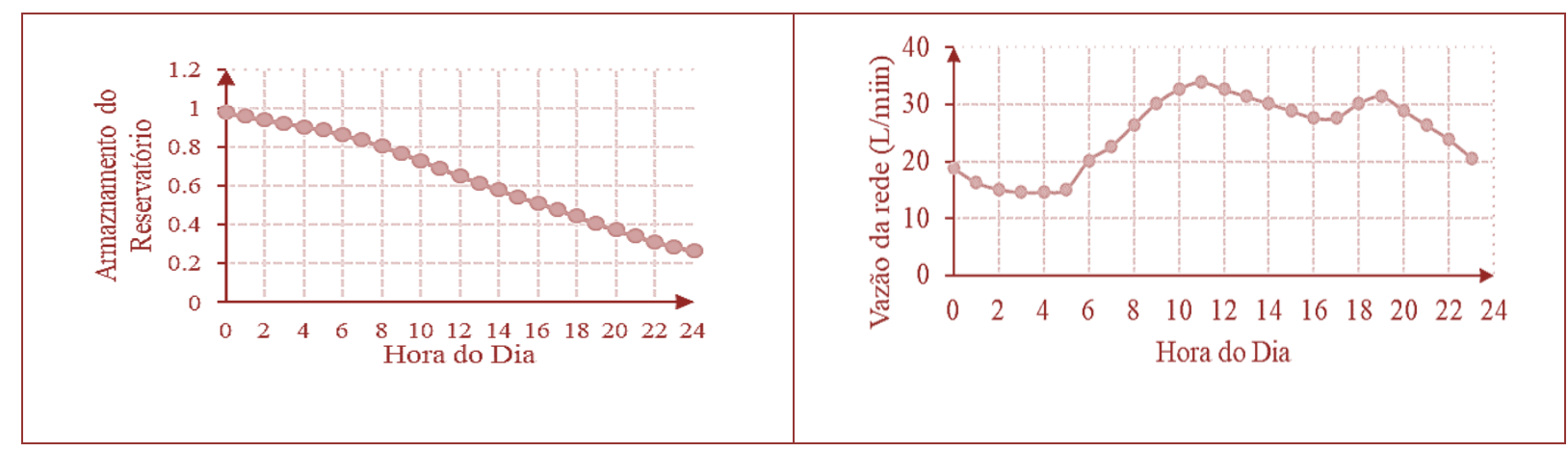

\subsection{O RESERVATÓRIO MUNICIPAL E UMA PARCELA DOS RESERVATÓRIOS RESIDENCIAIS SÃO OPERADOS}

Como dissertado anteriormente, no primórdio desse cenário foi estabelecido que $10 \%$ das residências fariam parte do programa, a Figura 5 a seguir demonstra o comportamento da rede frente a essa imposição. Vale relembrar que a condição de uso dos reservatórios dos consumidores finais é imposta quando há uma demanda superior à média da vazão diária.

Por intermédio das equações que são concernentes ao MS Excel, o cálculo da diferença máxima entre a vazão horária de demanda e sua média $(\mu)$ foi de 6,15 L/min e, concomitantemente o seu desvio padrão $(\sigma)$ da ordem de 3,81 L/min. Logo, nota-se que o desvio padrão da atual situação em debate é inferior ao $\sigma$ representado quando apenas o reservatório principal é controlado $(\sigma=6,64 \mathrm{~L} / \mathrm{min})$, representando uma queda nesse valor de $42,62 \%$.

Figura 5 - Vazão da rede (L/min) 10\% de participação

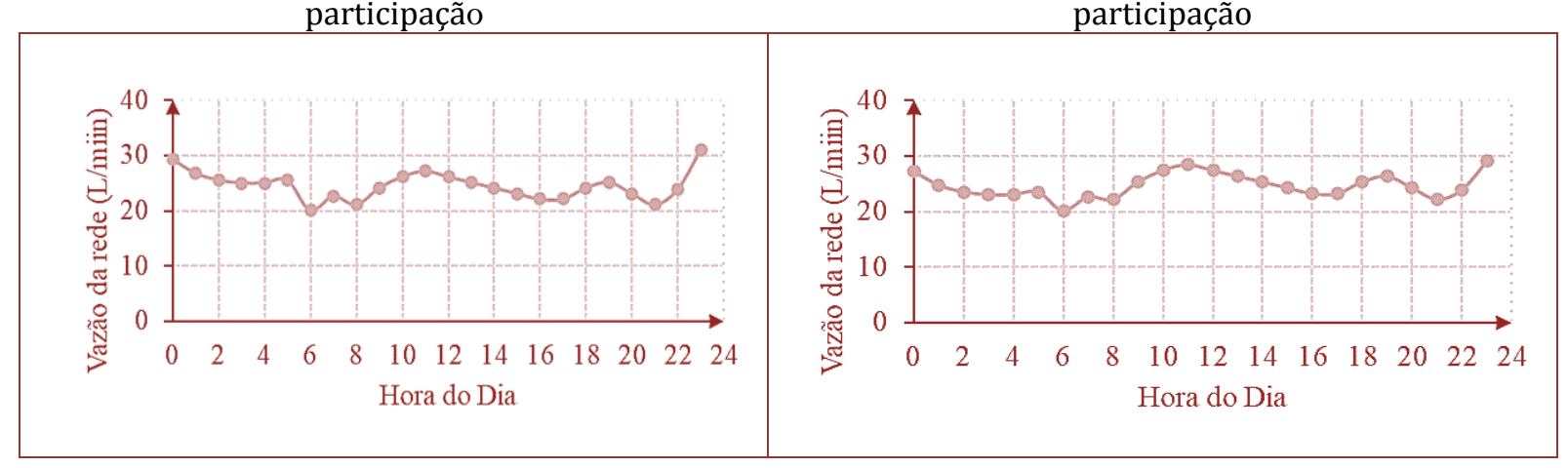

Posteriormente, foi mandatório de que $20 \%$ das residências fossem participantes e então com o auxílio do Microsoft Excel plotou-se o gráfico da Figura 6 e obteve-se os valores almejados para se fazer a análise. A diferença máxima entre a vazão horária de demanda e sua média $(\mu)$ foi de $6,95 \mathrm{~L} / \mathrm{min}$ e, concomitantemente o seu desvio padrão $(\sigma)$ da ordem de 3,39 L/min. À visto disso, nota-se que o desvio padrão sofreu uma queda de $11 \%$ quando se opta por utilizar $20 \%$ das residências ao invés de apenas $10 \%$ e comparando com o desvio padrão do reservatório principal, o $\sigma 20 \%$ simboliza cerca de $51,05 \%$ do valor obtido através dos cálculos.

Ulteriormente as análises em qual se fixava a porcentagem de residências constituintes do programa de controle em qual se valendo de artifícios da inteligência artificial são controlados, o estudo empregou o Solver do Excel, impondo como condição para quando a demanda diária fosse maior que a média diária calculada, a água utilizada na residência se derivaria da própria caixa de água do consumidor e quando a demanda na rede fosse inferior a média, a caixa do consumidor fosse reabastecida e visando como objetivo o resultado ótimo que derivaria um desvio padrão mínimo, o programa apontou uma porcentagem de $16,13 \%$ das residenciais que participando do programa de operação geraria o gráfico de vazão de rede 
ilustrado na Figura 7, com os valores de diferença máxima entre a vazão horária de demanda e sua média $(\mu)$ de 4,83 L/min e, concomitantemente o seu desvio padrão $(\sigma)$ da ordem de 3,09 L/min.

Figura 7 - Vazão da rede (L/min) na situação do resultado otimizado

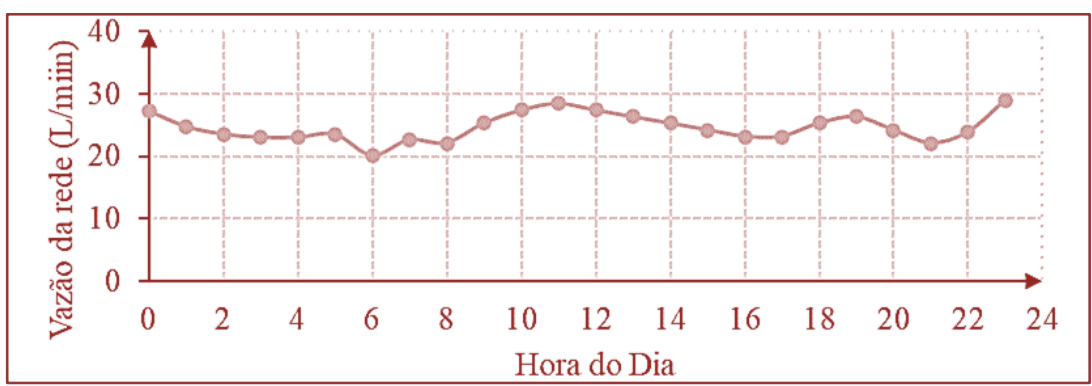

\section{CONCLUSÃO}

Conclui-se que quando se atinge uma situação em que o resultado se demonstra vantajoso para distintos aspectos, esta se tratado então de um ótimo global. No presente trabalho se almeja dimensionar um cenário em qual a finalidade é equilibrar a pressão e a vazão na rede através da atenuação da vazão de pico de demanda hídrica com o auxílio da utilização da capacidade de armazenamento dos reservatórios dos consumidores finais. Ademais esse abrandamento da vazão corrobora para que o bombeamento hídrico seja efetuado em tempos propícios economicamente para a SAA, ou seja, fora do horário de pico de energia em qual o valor agregado desse recurso está mais elevado.

Elaborando cenários discrepantes e comparando os resultados obtidos, a conjuntura mais propícia é de que $16,13 \%$ das residenciais constituintes da rede de abastecimento trabalhe com o seu recurso hídrico estocado em seus reservatórios quando a demanda na rede tenha excedido a média estipulada da mesma, fundamentando-se de que com o essa disposição o desvio padrão alcançado é o de menor valor, portanto otimizado.

\section{REFERÊNCIAS}

[1] ANA-Agência Nacional de Águas. (2019). “Manual de Usos Consuntivos no da Água no Brasil”. Brasília.

[2] BABBITT, H. E.; DOLAND, J. J.; CLEASBY, J. L. (1973). “Abastecimento de água”. Trad. de Zadir Castelo Branco. São Paulo: Edgard Blücher.

[3] BARROS FILHO, M. B. B. de. (2005). "Desenvolvimento de sistema de geoinformação como suporte ao gerenciamento das redes de distribuição de água". Dissertação (Mestrado em Ciências Geodésicas e Tecnologia da Geoinformação). Universidade Federal de Pernambuco, Departamento de Ciências Geodésicas e Tecnologia da Geoinformação, Centro de Tecnologia e Geociências da Universidade Federal de Pernambuco. Recife, 2005.

[4] BARROSO, L. B. (2005). "Estudo da minimização das perdas físicas em sistema de distribuição de água utilizando o modelo EPANET". Dissertação (Mestrado em Engenharia Civil). Universidade Federal de Santa Maria, Centro de Tecnologia. Programa de Pós-graduação em Engenharia Civil. Santa Maria, RS, 2005.

[5] BRAGA, L. C. (2007). "Estudo de Aspectos de Eficiência Energética de Edificações com uma Abordagem de Automação Predial”. Dissertação (Mestrado) - Engenharia Elétrica - Universidade Federal de Minas Gerais, Belo Horizonte.

[6] BRASIL. Ministério da Saúde. Fundação Nacional de Saúde. "Manual de saneamento". 3. ed. rev. Brasília: FUNASA, 2004.

[7] EOS. (2018). "Cobrança pelo uso da água: divergências entre consumidores e concessionárias" Brasil. Disponível em: https://www.eosconsultores.com.br/sistema-de-abastecimento-de-agua-

[8] funcionamento/. Acesso em: 9 mar. 2020.

[9] GOUJON L.; PRIÉ G. (2010). “Les Voyageurs Del l’eau”. Dunod. Paris.

[10] GUIDI, J. M. M. (2016). “Análise da variação do consumo de água utilizando dados obtidos por sistemas supervisores remotos: estudo de caso: município de Franca-SP”. Orientador: Prof. Dr. Edevar Luvizotto Junior. 2016. Tese de Mestrado (Mestrado em Engenharia Civil) - Faculdade de Engenharia Civil, Universidade Estadual de Campinas. 
[11] MME - Ministério De Minas e Energia. (2019). “Balanço Energético Nacional 2019”. Brasília.

[12] NETO, M. S. A. (2008). "Medidas de Eficiência Energética em Serviços de Distribuição de Água e Saneamento”. Dissertação (Mestrado em Engenharia Eletrotécnica e de Computadores - Especialização em Energias Renováveis) Faculdade de Engenharia da Universidade do Porto, Porto.

[13] SNIS - Sistema Nacional De Informações Sobre Saneamento. (2019). “Diagnóstico dos Serviços de Água e Esgoto 2018”. Brasília. 


\section{Capítulo 14}

Avaliação de aplicação de dissipador de energia de um emissário no município de Campo Mourão, Paraná

\section{Paula Cristina de Souza}

Paulo Henrique Rodrigues

Victor Augusto Menegon

Helton Rogerio Mazzer

Resumo: Um correto dimensionamento do sistema de galerias de drenagem urbana tem como efeito direto uma eficiente remoção das águas pluviais de centros urbanos, sem causar danos ou impactos ambientais e com segurança à população. Visando tais informações, o presente trabalho tem como principal objetivo a análise do dimensionamento e das atuais condições de um final de emissário do sistema de galerias de drenagem contribuintes do Rio do Campo no município de Campo Mourão, Paraná, Brasil. A delimitação da bacia e vazão do local foram fornecidas pelo Instituto de Águas Paranaense. 0 local contava com rochas para dissipação de energia parcial, no entanto, apresentava situação de erosão. Foram analisadas opções de implantação e aplicabilidade de dissipadores de energia, os quais foram calculados conforme metodologia tradicionais e analisadas as viabilidades de cada modelo, verificou que o dissipador por rampa dentada, pode ser uma boa alternativa, no entanto verificou que 0 dissipador por escada hidráulica seria o mais indicado para o local de estudo.

Palavras-Chave: Drenagem urbana, erosão, dissipador de energia. 


\section{INTRODUÇÃO}

O crescimento urbano das cidades brasileiras tem provocado impactos significativos na população e no meio ambiente. Ocasionam o aumento da frequência e do nível das inundações, prejudicando a qualidade da água, e aumento da presença de materiais sólidos no escoamento pluvial. A falta de planejamento, controle do uso do solo, ocupação de áreas de risco e sistemas de drenagem inadequados são as causas para esses acontecimentos (Manual de Drenagem Urbana do Paraná, 2002).

Segundo Miguez, Veróz e Rezende (2016), o plano de drenagem urbana consiste na vinculação, de forma simultânea, dos aspectos ligados ao manejo das águas pluviais com o projeto de ordenamento territorial, agregando soluções para os problemas relacionados às águas pluviais.

A falta de um sistema de drenagem urbana ou a má execução e dimensionamento do mesmo, pode ocasionar diversos problemas, afetando o solo de uma região, comprometendo áreas rurais ou urbanas. Dentre os problemas, o Manual de Drenagem Urbana cita, aumento de vazões máximas devido à ampliação da capacidade de escoamento de condutos e canais gerados pela impermeabilização das superfícies; aumento da produção de sedimentos; deterioração da qualidade da água superficial e subterrânea devido a lavagem das ruas, transporte de material sólido e contaminação de aquíferos; inundações.

Tendo em vista os impactos causados pela precariedade das redes de drenagem, o problema recorrente que será priorizado no estudo é o da erosão. Conceitua-se a erosão como o processo de carreamento dos solos. Os agentes podem ser a água, os ventos ou outros. Em geral, os principais processos erosivos, nos centros urbanos, são causados pelas águas (Tucci, 2015).

Para evitar o problema da erosão causado pela falta ou má dimensionamento de uma rede de distribuição hidráulica, em alguns casos, se faz necessário o dissipador de energía, que tem como objetivo compatibilizar a velocidade do escoamento com as características de resistência do meio físico a jusante (Baptista e Lara, 2010).

O dissipador de energia será escolhido conforme a maneira mais eficiente e barata para a necessidade do local, custo benefício quanto impactos ambientais na região e maximização do escoamento para o local.

O objetivo do estudo e analizar o dimensionamento e as condições de um final de emissário do sistema de galerias de drenagem contribuintes do Rio do Campo no municipio de Campo Mourão, Paraná, Brasil. Foram analisadas opções de implantação e aplicabilidade de dissipadores de energia, os quais foram calculados conforme metodologia tradicionais e analisadas as viabilidades de cada modelo.

\section{METODOLOGIA}

O local de estudo foi o ponto de lançamento de emissário de água pluvial em Campo Mourão - Paraná, situado a 596 metros de altitude, com as seguintes coordenadas geográficas: Latitude: $24^{\circ} 2^{\prime} 46^{\prime \prime}$ Sul, Longitude: $52^{\circ} 23^{\prime} 2^{\prime \prime}$ Oeste.

O levantamento do emissário analisado se fez através de visitas in loco. Os dados de vazão, delimitação de bacia e diâmetros foram levantados atraves de análise dos projetos disponibilizados pelo poder público.

Observou no local uma erosão com cerca de 4 à 5 metros de altura. Foi constatada uma aparente tentativa de amenizar o problema posicionando rochas de grande e médio porte na parte superior à tubulação e por cerca de 10 metros contínuos à frente do emissário, porém tal solução não resolveu o problema.

Área de influência e vazão foram fornecidos pelo Instituto Paranaense de Águas. Tendo os valores geométricos, velocidade de escoamento e vazão, foi possível dimensionar experimentalmente os dissipadores de energia.

Foram considerados o dimensionamento de dissipador de energia, selecionados a partir da compatibilidade com o emissário e seus valores de vazão e velocidade de escoamento encontrados. Os quatro dissipadores de energia à serem apresentados são: dissipador por bloco de impacto, de degrau vertical, de escada hidráulica (contínua) e de rampas dentadas.

Para o dimensionamento do dissipador de blocos de impacto, foi utilizado o critério de dissipador tipo Bradley-Peterka, descrito por Baptista (2010). Para o dimensionamento do dissipador de rampa dentada também empregou a metodologia do mesmo autor.

0 dimensionamento do dissipador de degrau vertical, definido por Costa, 2007, baseasse-se na definição da variável denominada número de queda, dada pela Equação 1: 


$$
D n=\frac{q^{2}}{g h^{3}}
$$

Onde

- Dn: número de queda;

- $\quad$ q: vazão por unidade de largura, em $\mathrm{m}^{3} / \mathrm{s.m}$;

- h: altura do degrau, em m.

Sendo as dimensões necessárias para o dissipador em degrau vertical obtidas pelas seguintes expressões, todas em função de Dn.

$$
\begin{aligned}
& \frac{L d}{h}=4,3 D n^{0,27} \\
& \frac{Y p}{h}=1,0 D n^{0,22} \\
& \frac{Y 1}{h}=0,51 D n^{0,425} \\
& \frac{Y 2}{h}=1,66 D n^{0,27}
\end{aligned}
$$

Onde :

- Ld: comprimento da queda, em m;

- Yp: profundidade da água na parte anterior da queda, em m;

- Y1: profundidade da água na parte posterior da queda, em m;

- Y2: profundidade conjugada jusante do ressalto, em $\mathrm{m}$.

- $\quad$ comprimento L corresponde ao comprimento do ressalto.

No dimensionamento do dissipador tipo escada hidráulica adotou o modelo descrito por Gonçales et al, 2005, desenvolvendo vórtices abaixo do pseudo fundo (alinhamento formado pelas extremidades externas dos degraus) que são mantidos pela transmissão da tensão tangencial do fluido escoando pelas extremidades dos degraus. Segundo o autor para a largura da escada hidráulica, utiliza-se a Equação 6:

$$
\mathrm{B} \geq 2,0 \times \mathrm{D}
$$

Sendo:

- $\quad B=$ largura da escada hidráulica e largura do canal no início da escada (m)

- $\mathrm{D}=$ diâmetro do tubo $(\mathrm{m})$

Com os dados de vazão determina-se a área molhada $(\mathrm{m} 2)$ e a velocidade final $(\mathrm{m} / \mathrm{s})$, e calcula o número de Froude (F), pela Equação 7 e o comprimento de transição (L) pela Equação 8. 


$$
\begin{aligned}
& F=\frac{V}{(g \cdot D)^{0,5}} \\
& L=\frac{(3 . F)-(B-D)}{2}
\end{aligned}
$$

Estimativa da altura do degrau (h) e comprimento do degrau (b), primeiramente calculando a profundidade crítica (dc) da água no início da escada hidráulica, pela Equação 9.

$$
d c=\left(\frac{q^{2}}{g \cdot B^{2}}\right)^{1 / 3}
$$

Verifica-se a condição para o regime de escoamento analisado, se o mesmo será skimming flow. (dc/h > $0,91-0,14 . h / b)$, caso confirmado, da sequencia ao dimensionamento, calculando a altura da agua + ar, atraves da Equação 10 e da água (d1) pela Equação 11.

$$
\begin{aligned}
& \tan (\theta)=h / b \\
& \mathrm{~d} 1=0,4 \times \mathrm{h} \times \mathrm{F}^{\wedge} 0,6
\end{aligned}
$$

Assim, definindo Altura da parede da escada hidráulica (H1), pela Equação 12.

$$
\mathrm{H} 1=\mathrm{d} 1+\mathrm{Fb}
$$

\section{RESULTADOS E DISCUSSÕES}

- Bloco de Impacto

Temos as dimensões a serem usadas no dissipador de energia por bloco de impacto dadas a partir da vazão e da largura de saída do emissário. A vazão fornecida, considerando os critérios de segurança foi de $3,8 \mathrm{~m}^{3} / \mathrm{s}$. A espessura mínima de concreto da ordem de $0,15 \mathrm{~m}$.

A Figura 01 representa a vista em planta do dissipador.

Figura 01 - Dissipador bloco de impacto- Vista em planta

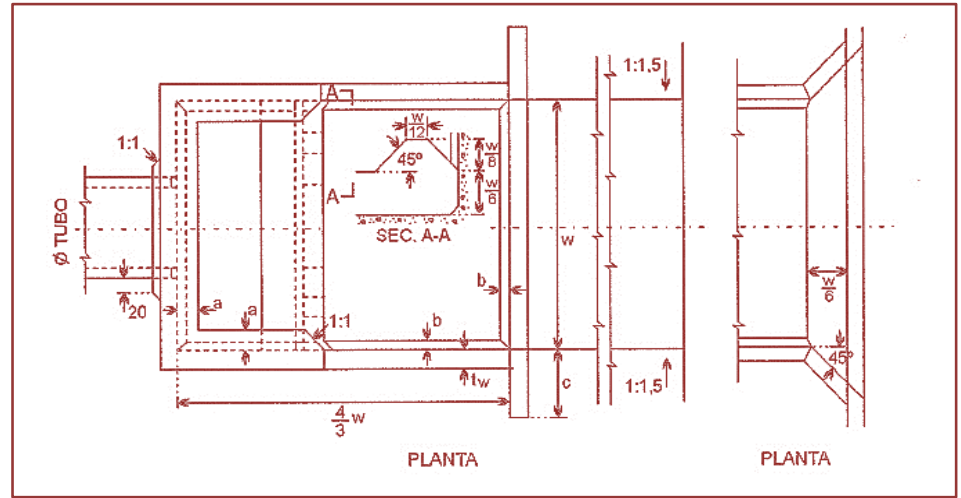

Fonte: Baptista (2010) 
Figura 02 mostra o dissipador em bloco tipo Bradley-Peterka adaptado por Peterka, onde podemos observar as variáveis estabelecidas.

Figura 02 - Dissipador bloco de impacto- Vista em corte

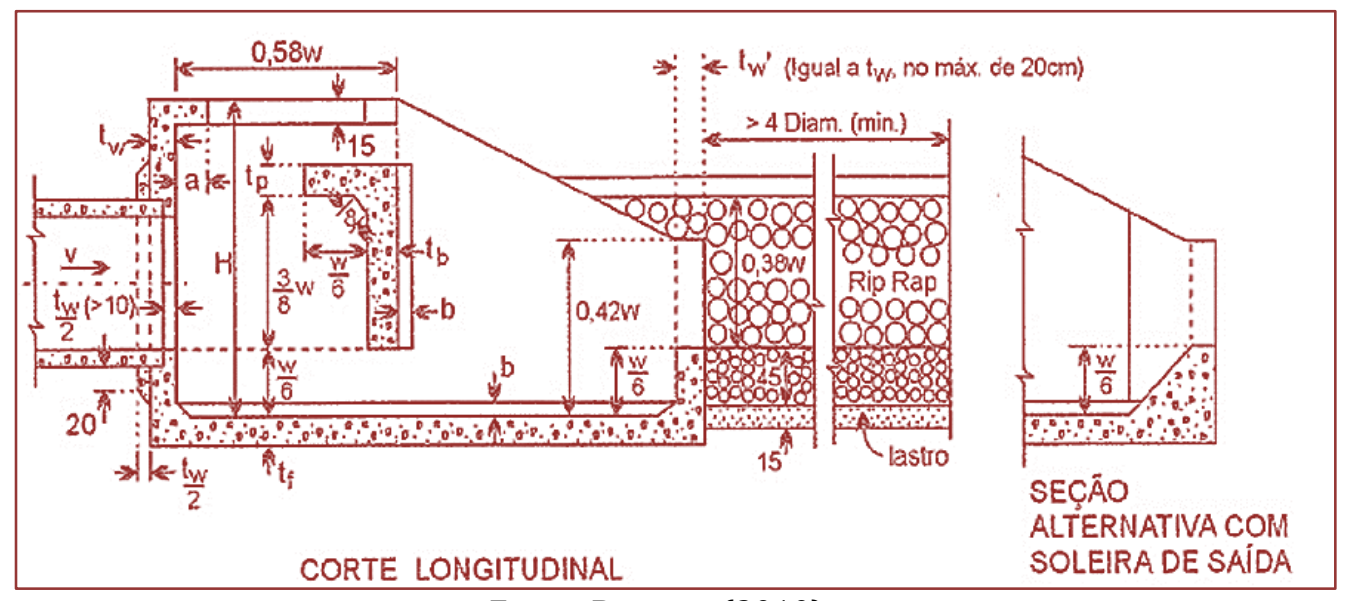

Fonte: Baptista (2010)

A partir da vazão definida, o critério de dissipador tipo Bradley-Peterka, descrito por Baptista (2010), faz um dimensionamento das demais variáveis, as quais podem ser observadas no Quadro 01.

\begin{tabular}{|c|c|c|c|c|c|c|c|c|c|}
\hline \multirow{2}{*}{$\begin{array}{l}\text { Vazão } \\
\text { (m3/s) }\end{array}$} & \multicolumn{2}{|c|}{ Largura (W) } & \multicolumn{7}{|c|}{ Dimensões (m) } \\
\hline & Máxima & Mínima & $\mathrm{a}$ & b & c & tw & $\mathrm{tf}$ & tb & $\mathrm{tp}$ \\
\hline 6 & 3,50 & 2,90 & 0.30 & 0,10 & 1,00 & 0,25 & 0,30 & 0,25 & 0,20 \\
\hline
\end{tabular}

Observou que no local, para a utilização do dissipador por bloco de impacto, conforme os dados obtidos, seria necesario um aterramento para sua execução, tornando essa opção pouco satisfatória para o problema levantado.

- Rampas dentadas :

O dimensionamento para rampas dentadas foi efetuado a partir da vazão anteriormente estabelecida, determinando uma velocidade de operação obtida atraves da expressão 13 , sendo que a velocidade obtida não deve ser inferior ao valor $\sqrt[3]{g} \cdot q$.

$$
V \leq \sqrt[3]{g} \cdot q-1,6
$$

O valor obtido para velocidade foi de $1,776 \mathrm{~m} / \mathrm{s}$, mesmo estando nas condições ideais definidas por Baptista (2010), não ultrapassa a condição de risco.

Para a altura do bloco dissipador $(\mathrm{H})$, recomenda a ordem de $0,8 \mathrm{hc}$, onde o valor de hc se obtém com o auxílio da Equação 14, onde q é a vazão (m3/s) anteriormente estabelecida e g aceleração da gravidade $(\mathrm{m} / \mathrm{s} 2)$.

$$
h c=\sqrt[3]{q^{2} / g}
$$

Baptista (2010), define que as larguras e os espaçamentos em uma mesma linha devem situar-se no entorno de 1,5 vezes a altura dos blocos. A distância entre duas fileiras de blocos deve ser duas vezes a altura. Caso a altura do bloco for menor que $0,90 \mathrm{~m}$, o espaçamento pode ser superior a este valor, enquanto não ultrapassar $1,80 \mathrm{~m}$. 
Os muros laterais deverão ter uma altura igual a três vezes a altura dos blocos, devendo ser protegidos lateralmente com enrocamentos.

Portanto obteve para as condições estabelecidas um hc de 1,1 metros e uma altura do bloco (H) de 0,88 metros, arredondando para 0,90 metros. Todas as dimensões são definidas a partir desse valor.

Figura 03 - Rampas dentadas ou calhas dissipadoras.

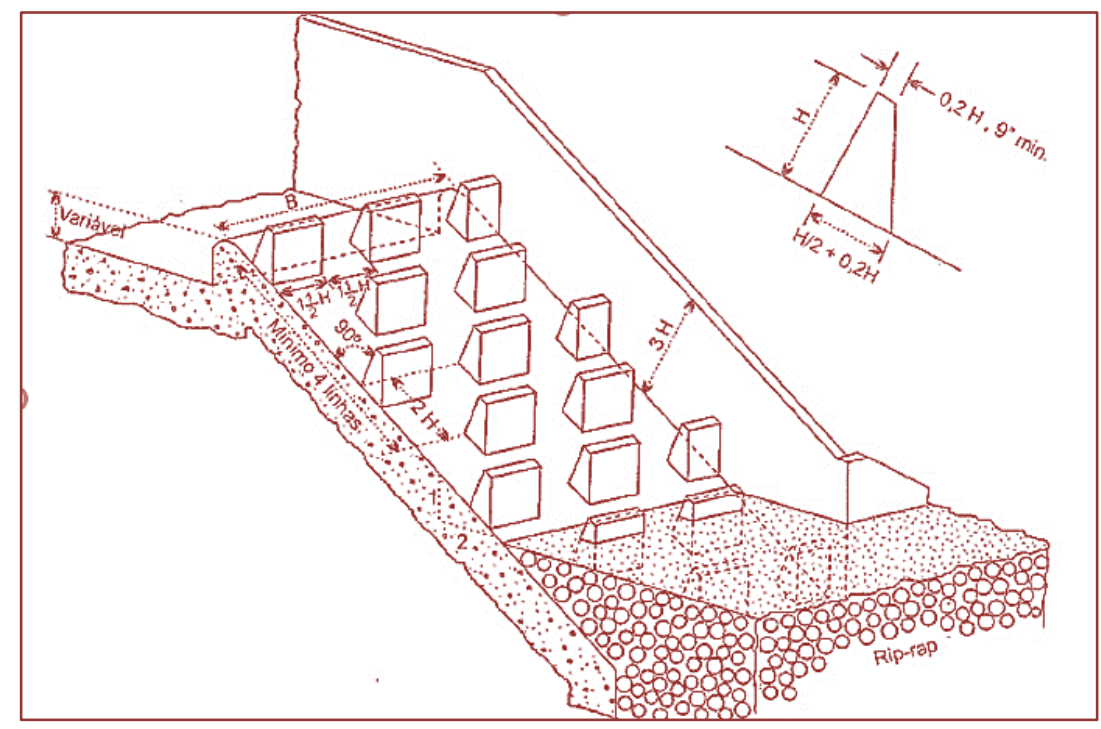

Fonte: Baptista (2010).

\section{- Degrau vertical}

O escoamento no degrau foi definido em função da vazão previamente estabelecida obtendo um número de queda (Dn) de 1, com base nestes dados obteve uma largura (L) de $3 \mathrm{~m}$. A partir destes dados e com o auxílio das equações 2 a 5, obteve as seguintes variáveis: Ld de 2,40 metros, Yp de 0,62metros, Y1 de 0,22 metros e Y2 de 0,93 metros. A Figura 04, representa a posição das variáveis no dimensionamento do degrau.

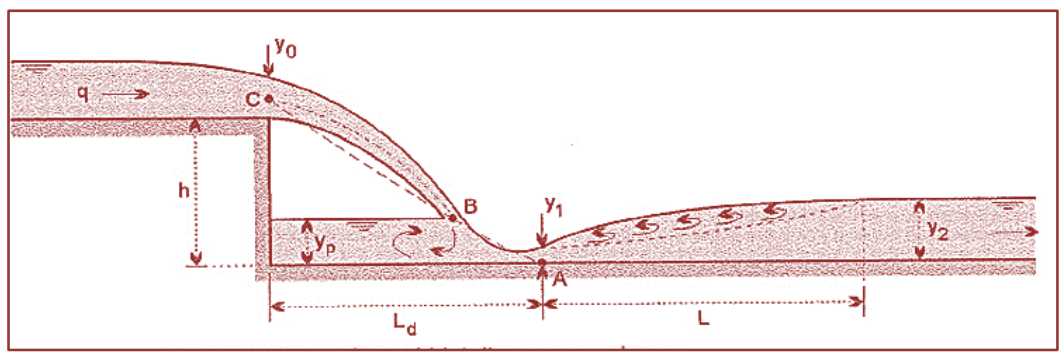

Figura 04- Esquema das condições hidráulicas em um degrau.

Fonte: Baptista (2010).

O dissipador de energia por degrau vertical por ter altura aproximada de 1,50 metros, necessitaria também de aterro para sua construção. Assim, tem grau baixo de viabilidade para execução. 


\section{- Escada hidráulica}

Gonçales, et al (2005), afirma que a dissipação da energia causada pelos degraus pode reduzir significativamente o tamanho e o custo da bacia de dissipação necessária na base do vertedouro, comparada com uma calha convencional de concreto (calha lisa).

Portanto, na escada hidráulica temos um regime especial de escoamento denominado skimming flow que é complexo e dependente de inúmeras pesquisas ainda em desenvolvimento.

Temos como informações iniciais:

A escada hidráulica tem ângulo de inclinação variando de $10^{\circ}$ a $55^{\circ}$. A altura do degrau é também chamada de espelho do degrau e varia de $0,2 \mathrm{~m}$ a $0,90 \mathrm{~m}$.

Com as informações do emissario fornecida e os dados coletados in loco, temos que a vazão estabelecido no pico (q) de $3,2 \mathrm{~m}^{3} / \mathrm{s}$, o diâmetro da tubulação (D) no final do emissário como sendo de $1,00 \mathrm{~m}$, a diferença de nível (H) de 3,60 m e o comprimento de declividade em projeção (Ld) =9,00 m.

Calculando a largura da escada hidráulica, como D de 1,00 metro, obtem-se, o valor de B de 2,00 metros. Logo teremos um canal de transição com a saída do tubo de diâmetro (D) de 1,00 m até a entrada da escada com largura (B) de 2,00 m.

A área molhada encontrada foi de $0,79 \mathrm{~m} 2$ e a velocidade obtida foi de $4,08 \mathrm{~m} / \mathrm{s}$. com esses dados encontrou-se o número de Froude de 1,30, segundo o autor esse número geralmente varia entre 1 e 2,5, ou seja, esta dentro do recomendado. Com o Número de Froude determinou-se o comprimento de transição de aproximadamente 2,00 metros e a altura do degrau (h) para as condições de escoamento analisadas entre 0,20 metros e 0,64 metros, adotando um valor intermediário de 0,30 metros e por consequência um número de 12 degraus com comprimento do degrau (b) de 0,75 metros e a profundidade crítica (dc) da água no início da escada hidráulica de 0,64 metros.

Verificação de que o regime de escoamento é skimming Flow, pois dc/h $>0,91-0,14 . h / b$

Altura da água + ar encontrado foi de 0,40, dando um ângulo em graus de 22,92ำ e número de Froude (F) de 4,984 .

Altura da parede da escada hidráulica (H1), foi de 0,75 metros.

Assim, temos todas as dimensões necessárias para a execução de um dissipador de energia em escada hidráulica pelo método de Gonçales, et al (2005).

A obra hidráulica de dissipador por escada é a mais comum e utilizada, sendo de maior acessibilidade por mão-de-obra e posicionamento no local analisado, devido a declividade observada e a facilidade de execução.

\section{CONCLUSÃO}

Tendo como base o referencial teórico, as visitas in loco e auxílio do Instituto Paranaense de Águas, o presente avaliou apartir dos dados fornecidos de vazão, a velocidade de escoamento e o dimensionamento de dissipadores de energia para um emissário do município de Campo Mourão, Paraná.

O emissário foi identificado e foi atestado que seria necessário a utilização de um dissipador de energia, por contar com uma erosão de grande porte no local escolhido. A erosão no local de escoamento do emissário tinha grandes proporções, se fazendo necessário um dissipador de energia. 0 local já contava com rochas para dissipação de energia parcial, sem a eficiência necessária.

Com o dimensionamento dos principais tipos de dissipador de energia, tem-se que o disipador com bloco de impacto seria necesario um aterramento para sua execução, tornando essa opção pouco satisfatória para o problema levantado, assim como o dissipador de energia por degrau vertical, por apresentar altura aproximada de 1,50 metros, necessitaria também de aterro para sua construção. Assim, tem grau baixo de viabilidade para execução.

O dissipador por rampa dentada pode ser uma boa alternativa, no entanto o dissipador por escada hidráulica é o mais indicado por ser muito utilizado na região, sendo de maior acessibilidade por mão-deobra e posicionamento no local analisado, devido a declividade observada e a facilidade de execução. 


\section{REFERÊNCIAS}

[1] Miguez, Marcelo Gomes; Veról, Aline Pires; Rezende, Osvaldo Moura (2016). Drenagem Urbana: do projeto tradicional à sustentabilidade. 1aㅡ Ed. Rio de Janeiro, Rio de Janeiro, Elsevier.

[2] Tucci, Carlos E. M.; Porto, Rubem Laina; Bastos, Mário T. (2015). Drenagem Urbana. 1a Ed, Porto Alegre, Rio Grande do Sul, ABRH - Associação Brasileira de Recursos Hídricos, 2015.

[3] Baptista, Márcio Benedito; Coelho, Márcia Maria Lara Pinto (2010). Fundamentos de Engenharia Hidráulica. 3 a Ed, Belo Horizonte, Minas Gerais, UFMG.

[4] COSTA, Alfredo Ribeiro; SIQUEIRA, Eduardo Queija; MENEZES FILHO, Frederico Carlos Martins. (2007). Águas Pluviais. Brasília, DF: Núcleo Regional Centro-Oeste de Capacitação e Extensão Tecnológica em Saneamento Ambiental. 2007.

[5] Gonzalez, C.A., Takahashi, M., and Chanson, H. (2005). Effects of Step Roughness in Skimming Flows: an Experimental Study. Research Report No. CE160, Dept. of Civil Engineering, The University of Queensland, Brisbane, Australia, July, 149 pages 


\section{Capítulo 15}

Telhados verdes : Caracterização das condições ótimas para o microclima da cidade de Recife-PE

\section{Teresinha Batista da Silva}

Marco Aurélio Calixto Ribeiro de Holanda

Willames de Albuquerque Soares

Resumo: Sabe-se que a cidade de Recife é corriqueiramente acometida a alagamentos, graças a predominância de áreas com solo impermeabilizado aliado aos deficientes sistemas convencionais de drenagem urbana. Neste contexto, o estudo de técnicas compensatórias como telhados verdes são essenciais para a redução do escoamento superficial da água oriunda da chuva. Visando minimizar os alagamentos que ocorrem na cidade de Recife, objetivou-se identificar qual a composição granulométrica do solo mais adequada para a montagem de telhados verdes, buscando maximizar sua eficiência quanto técnica compensatória. Para as simulações das diferentes composições dos telhados verdes extensivos, utilizou-se o Hydrus-1D. No dia 14/06/2019, com a precipitação mais intensa do mês $\left(147,2 \mathrm{~mm} \mathrm{dia}^{-1}\right)$, observou-se a partir das simulações um escoamento superficial de 139,81 $\mathrm{mm} \mathrm{dia}^{-1}$, no solo com maior percentual de finos (silte e argila, 70\%), enquanto no solo com maior percentual de areia (85\%), o escoamento superficial foi de $28,62 \mathrm{~mm} \mathrm{dia}^{-1}$. Deste modo, os solos com frações granulométricas mais grossas se mostraram bastante eficazes em realizar o proposto, viabilizando possíveis diminuições de alagamentos na localidade.

Palavras-Chave: composição do solo, Hydrus-1D, simulação 


\section{INTRODUÇÃO}

Alagamentos são eventos cada vez mais frequentes em diversas áreas do Brasil. Segundo o Instituto Brasileiro de Geografia e Estatística, IBGE, (IBGE, 2018), 93\% dos municípios com mais de 500 mil habitantes foram atingidos por alagamentos pelo menos uma vez. Na segunda metade do século 20, o Brasil foi cenário de uma acelerada transição urbana, descaracterizando sua identidade rural e agrícola para assumir um papel metropolitano.

Como esse crescimento urbano ocorreu de forma desorganizada, problemas decorrentes de eventos hidrológicos afetam tanto o meio social quanto ambiental. Segundo Silva et al. (2019), estas intervenções antrópicas sem planejamento, aliadas a características físico-naturais da cidade de Recife, como o fato de ser cortada por diversos rios e sua localização numa planície litorânea abaixo do nível do mar, comprovam a suscetibilidade da capital a alagamentos (Holanda e Soares, 2019).

Sendo assim, devido a drenagem do escoamento superficial na rede coletora de águas pluviais estar cada vez mais comprometido, surgem estudos e implantações que visam o uso de técnicas compensatórias para o retardo e redução do escoamento superficial da água oriunda da chuva (Fritzen e Binda, 2011). Dentre as diversas ações que buscam mitigar os impactos ambientais e sociais, o telhado verde é um método citado por diversos autores como uma alternativa sustentável e eficiente (Castro e Goldenfum, 2010; Clark et al., 2006; Santos et al. 2013; Tassi et al. 2014).

Historicamente, os primeiros telhados verdes, ou jardins suspensos, foram criados a cerca de 600 a.C. na região da Mesopotâmia, e tinham como objetivo manter o ciclo hidrológico e um bom desempenho térmico das habitações (Rangel et al., 2015). Essencialmente, o telhado verde extensivo é um sistema construtivo instalado sobre edificações e é composto por uma camada de vegetação, uma camada de substrato e outra de drenagem. No estado de Pernambuco, este sistema vem sendo estudado por autores como Santos et al. (2013), para atuar no controle do escoamento superficial, retendo água na camada de substrato, retardando o pico de escoamento e consequentemente, reduzindo o problema da drenagem urbana.

Com o objetivo de determinar o potencial de retenção hídrica do telhado verde se comparado ao telhado convencional, Santos et al. (2013) realizaram experimentos na cidade de Caruaru-PE, utilizando dois tipos de vegetação, as quais foram submetidas a precipitações de diferentes aportes. Estes autores evidenciaram a eficácia dos telhados verdes propostos quando comparados ao telhado de controle, os quais apresentaram uma retenção hídrica 14 vezes maior.

Sabe-se também que a camada de solo tem influência direta na capacidade de retenção de parte da chuva, para redução do escoamento superficial, possuindo funções essenciais para o funcionamento do sistema, tais como suporte para a fixação da vegetação e fornecimento de água e nutrientes necessários para a sua manutenção, além de ser importante para o armazenamento temporário da água durante os eventos chuvosos (Tassi et al., 2014). Logo, através de processos como interceptação, armazenamento de água e evapotranspiração, a camada de solo em telhados verdes tem papel fundamental sobre o controle do escoamento pluvial superficial (Yang et al., 2008).

Diante do exposto, objetiva-se identificar qual a composição granulométrica do solo que mais se adequa às condições hidrometeorológicas da cidade de Recife, visando maximizar a eficiência de telhados verdes na drenagem da região, utilizando o modelo computacional Hydrus-1D.

\section{METODOLOGIA}

As atividades desta pesquisa foram desenvolvidas para o bairro da Madalena, localizado na cidade do Recife, a qual é litorânea e apresenta um relevo característico de uma planície fluvial, cortada por diversos rios, que possui uma precipitação média anual de $2292,9 \mathrm{~mm}$, com um desvio padrão de $482,5 \mathrm{~mm}$ (Wanderley et al. 2018). o bairro da Madalena serve como um dos principais acessos para locais essenciais da cidade, além de abrigar pontos importantes como o campus Benfica da Universidade de Pernambuco, Museu da Abolição e o estádio Adelmar da Costa Carvalho. A região é cortada pelo rio Capibaribe e em seu território prevalecem áreas de solo impermeabilizado. Essas características aliadas ao cenário de ocupação e a falta de planejamento de toda cidade de Recife, tornam o bairro corriqueiramente suscetível a alagamentos (Holanda e Soares, 2019).

o Presente estudo foi abordado de forma quantitativa e analisou a influência do tipo de substrato no desempenho de telhados verdes em Recife. Foram realizadas simulações matemáticas unidimensionais de um telhado verde extensivo utilizando o software Hydrus-1D (Simunek et al. 2013). 
Logo, simulou-se no Hydrus-1D, um modelo de telhado verde com uma profundidade de $20 \mathrm{~cm}$, o qual é composto por uma camada de brita (drenagem) de $2 \mathrm{~cm}$, uma de solo com $12 \mathrm{~cm}$, e outra de solo vegetal (substrato) com $6 \mathrm{~cm}$, utilizando uma vegetação gramínea com $2 \mathrm{~cm}$ de altura e $10 \mathrm{~cm}$ de profundidade. As simulações foram feitas para o mês de junho de 2019, e utilizaram como parâmetros de entrada as temperaturas máxima e mínima, precipitação, insolação, velocidade do vento e umidade relativa, utilizouse os dados meteorológicos da estação do Curado, os quais foram disponibilizados pelo Instituto Nacional de Meteorologia (INMET).

O perfil de simulação o qual continha $20 \mathrm{~cm}$ de profundidade, foi subdividido em 10 porções iguais de 2 cm cada. A simulação foi realizada com um passo de tempo de 10-4, em um intervalo de 30 dias (mês de junho). Já nas condições de fronteira, foram adotadas condições atmosféricas com escoamento superficial para condição de fronteira superior, e drenagem livre para a condição de fronteira inferior.

Para determinar os parâmetros hidrodinâmicos do solo, o Hydrus-1D utiliza o complemento Rosetta (biblioteca dinamicamente vinculada), que implementa funções de pedotransferência (FTP) para estipular os parâmetros de retenção hídrica da equação de Van Genuchten (1980), Equações 1 e 2, e condutividade hidráulica saturada (Ks), a partir de informações das frações granulométricas e classe textural dos solos simulados.

$$
\begin{aligned}
& \theta(h)=\left\{\begin{array}{cc}
\theta_{r}+\frac{\theta_{s}-\theta_{r}}{\left(1+(\alpha h)^{n}\right)^{1-\frac{1}{n}}}, & h<0 \\
\theta_{s} & , \quad h \geq 0
\end{array}\right. \\
& K(\theta)=K_{s}\left(\frac{\theta-\theta_{s}}{\theta_{s}-\theta_{r}}\right)^{\frac{1}{2}}\left[1-\left(1-\left(\frac{\theta-\theta_{s}}{\theta_{s}-\theta_{r}}\right)^{\frac{1}{1-\frac{1}{n}}}\right)^{1-\frac{1}{n}}\right]^{2}
\end{aligned}
$$

Onde $\theta \mathrm{r}$ e $\theta$ s representam as umidades volumétricas residual e saturada, respectivamente, ? e ? são os parâmetros de forma ajustados, h o potencial matricial e Ks a condutividade hidráulica saturada. Foram realizadas cinco simulações variando a composição granulométrica da camada de solo, conforme exposto na Tabela 1.

\begin{tabular}{|c|c|c|c|c|}
\hline Simulação & Areia (\%) & Silte $(\%)$ & Argila (\%) & Classe Textural \\
\hline 1 & 20,00 & 20,00 & 60,00 & Muito Argiloso \\
\hline 2 & 30,00 & 30,00 & 40,00 & Franco Argiloso \\
\hline 3 & 33,33 & 33,33 & 33,33 & Franco Argiloso \\
\hline 4 & 60,00 & 10,00 & 30,00 & Franco Argiloso Arenoso \\
\hline 5 & 85,00 & 5,00 & 10,00 & Areia Franca \\
\hline
\end{tabular}

Tabela 1 - Percentuais das frações granulométricas dos testes realizados

Wanderley et al. (2018) agrupou os eventos pluviométricos diários da cidade do Recife e os classificou de acordo com a intensidade das precipitações, sendo precipitações fracas as que apresentaram valores abaixo de $15 \mathrm{~mm}$, moderadas entre 15 e $25 \mathrm{~mm}$, fortes entre 25 e $50 \mathrm{~mm}$ e extremamente fortes as precipitações que ultrapassam $50 \mathrm{~mm}$. Além disso, o escoamento superficial citado no decorrer do texto se refere a quantidade de água, oriunda da chuva, que escoou e foi drenada pelo telhado verde.

\section{RESULTADOS E DISCUSSÃO}

Os valores dos parâmetros hidrodinâmicos gerados pelo algoritmo Rosetta, a partir da composição granulométrica de cada solo simulado, estão presentes na Tabela 2. 
Tabela 2 - Parâmetros hidrodinâmicos dos solos

\begin{tabular}{|c|c|c|c|c|c|}
\hline Simulação & \multicolumn{1}{c}{$\theta_{r}$} & $\theta_{s}$ & \multicolumn{2}{c|}{$\alpha$} & \multicolumn{2}{c|}{$n$} & $K_{s}$ \\
\hline 1 & 0,10 & 0,48 & 0,02 & 1,21 & 17,73 \\
\hline 2 & 0,09 & 0,45 & 0,02 & 1,33 & 7,09 \\
\hline 3 & 0,08 & 0,43 & 0,01 & 1,39 & 6,39 \\
\hline 4 & 0,07 & 0,38 & 0,03 & 1,27 & 12,54 \\
\hline 5 & 0,05 & 0,37 & 0,03 & 1,85 & 118,27 \\
\hline
\end{tabular}

Os resultados das simulações foram organizados em gráficos, que comparam os dados de precipitação e escoamento superficial para analisar a eficiência de cada teste, Figura 1. Para o período analisado, as precipitações mais intensas estão compreendidas nos dias 13,14, 17 e 18 de junho de 2019, sendo dia 14 o de precipitação mais intensa, para o qual todos os solos testados apresentaram escoamento superficial.

A simulação 1, com elevado teor de argila (60\%), não apresentou uma retenção satisfatória, ou seja, nos dias em que a precipitação foi mais intensa, apresentou elevado escoamento superficial, Figura 1a. Tal fato, deve-se pelo preenchimento dos vazios do solo já que os grãos da argila apresentam um diâmetro reduzido e os poros são menores que o dos solos arenosos. Estes fatores caracterizam uma condutividade hidráulica saturada (Ks) reduzida e, consequentemente, um elevado escoamento superficial, bem como foi observado por Junqueira et al. (2018), onde os solos estudados apresentaram valores de Ks de até 94,7 cm h-1 e os menores coeficientes de escoamento.

Assim como ocorreu com na simulação 1, a simulação 2, para as precipitações de maior intensidade, observou-se uma grande dificuldade em reter o volume de água precipitado, porém o aumento no percentual do silte elevou ainda mais o escoamento superficial, o qual se tornou presente até mesmo nos dias com precipitações de intensidade moderada, Figura 1b. Em valores, o simulação 2 apresentou um aumento no escoamento superficial de 10,64 mm dia-1 quando comparado com o simulação 1 nos seis dias mais chuvosos do mês. Já a simulação 3 apresentou uma dificuldade ainda maior em reduzir os valores do escoamento superficial, proporcional ao aumento no percentual de partículas finas em sua composição, Figura 1c.

Figura 1 - Valores diários de precipitação, escoamento superficial e Transpiração para o mês de junho/2019 do modelo para: a) simulação 1, b) simulação 2 e c) simulação 3

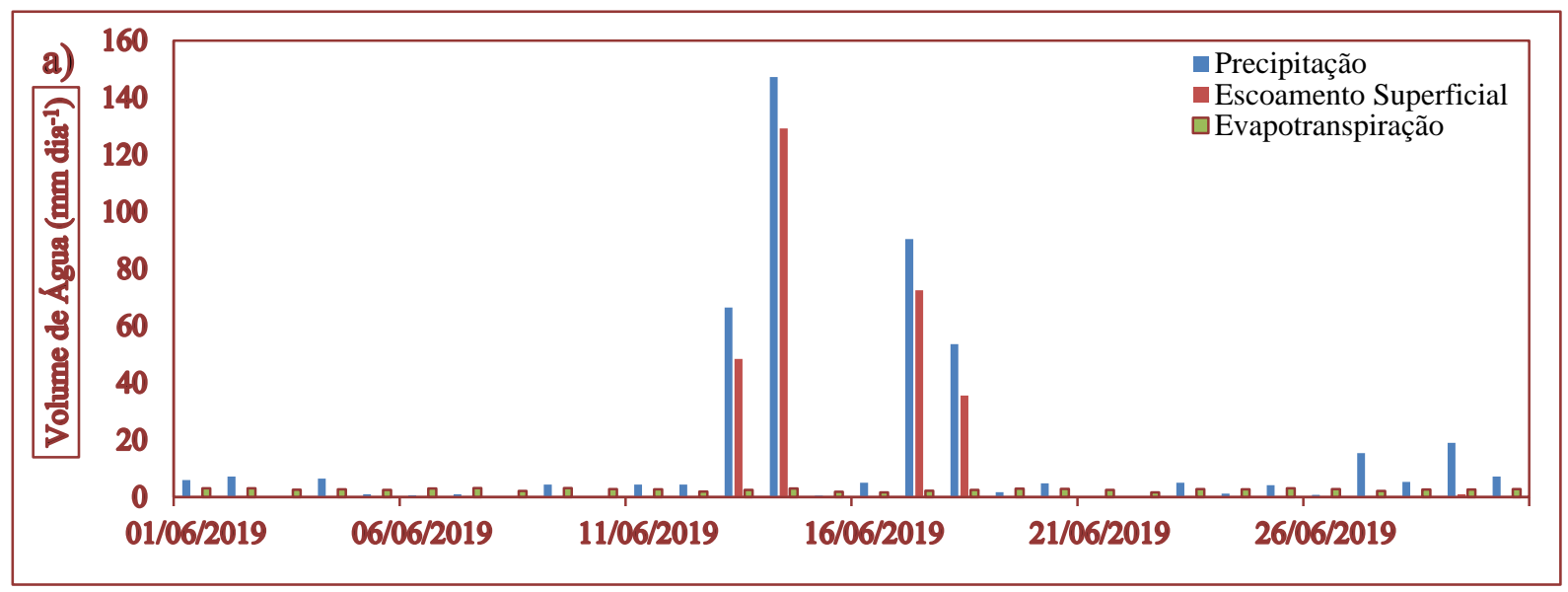



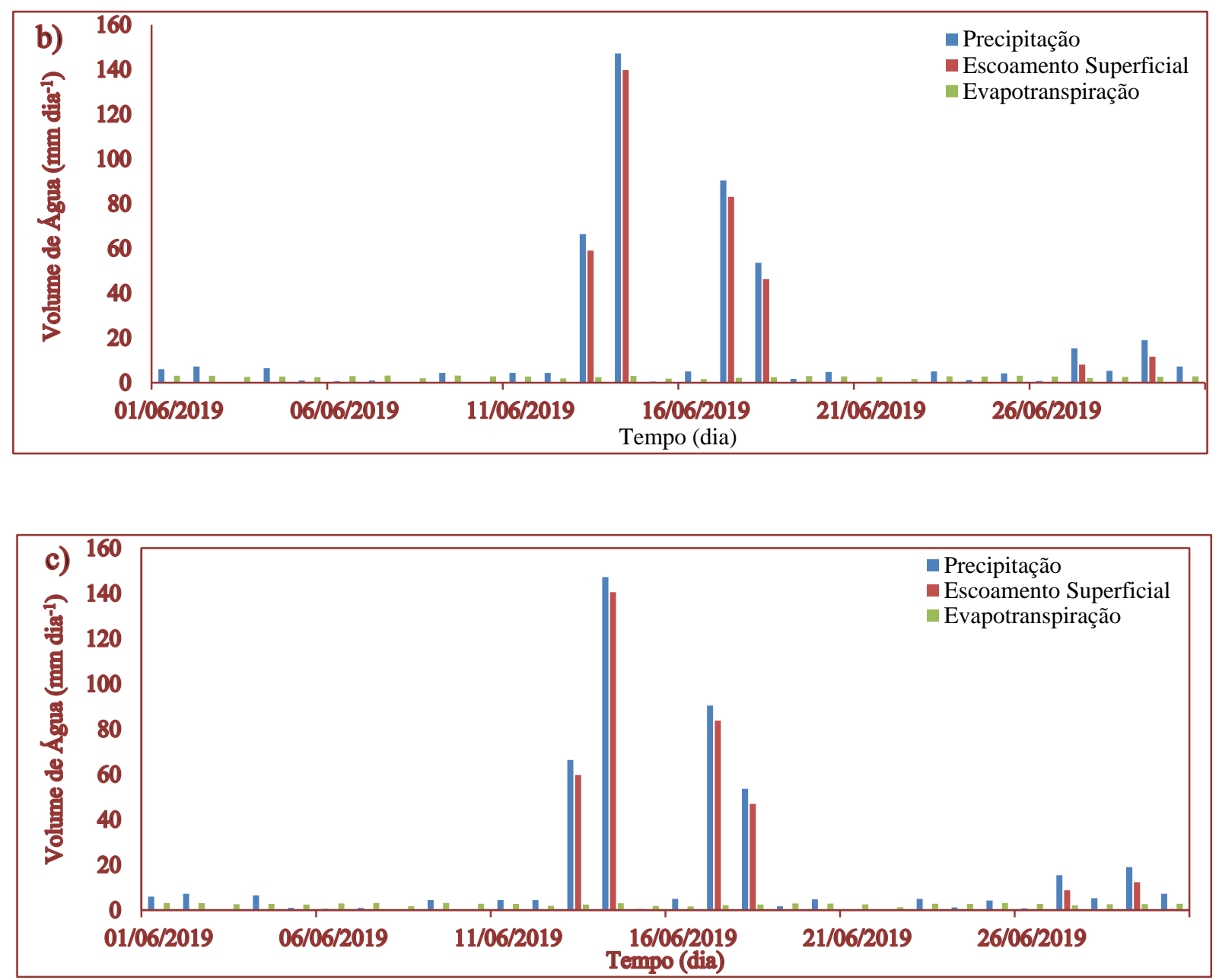

0 ensaio realizado com a simulação 4 deixou claro como o aumento no percentual de areia e a consequente redução nos percentuais de silte e argila refletem resultados positivos quanto a diminuição do volume escoado, Figura 2a. No dia de precipitação mais intensa (14/06/2019), a simulação 4 obteve uma redução no volume escoado de 6,15 mm dia-1 em relação a simulação 3, já com relação a simulação 2 essa redução foi de $5,45 \mathrm{~mm}$ dia-1.

Além disso, os ensaios mostraram que a simulação 5 apresentou um escoamento superficial consideravelmente inferior as demais simulações, tanto nos dias de alta precipitação como nos dias de precipitação moderada, onde o escoamento superficial da simulação 5 se tornou nulo, Figura 2 b. Ou seja, a areia, que constitui $85 \%$ da simulação 5, faz com que ela tenha apresentado uma maior condutividade hidráulica saturada quando comparado com a argila e ao silte, drenando mais facilmente a água armazenada em sua camada (Santos, 2011; Santos et al., 2013).

Tais resultados são condizentes com o que tem sido observado em outras pesquisas, entre as quais Reichardt (1990), diz que a presença de um grande percentual de areia no solo proporciona uma maior porosidade em seu perfil, fator que influi diretamente no tempo necessário para que o solo atinja o seu estado de saturação. Além destes pesquisadores, Dlapa et al. (2020) e Zhang et al. (2019) mencionam que solos compostos de frações granulométricas mais grossas são extremamente benéficos para as propriedades hidráulicas do solo já que aumentam a taxa de infiltração e reduzem o escoamento superficial, além de contribuir significativamente para o fluxo de água em condições saturadas. 
Figura 2 - Valores diários de precipitação, escoamento superficial e transpiração para o mês de junho/2019 do modelo para: a) simulação 4 e b) simulação 5
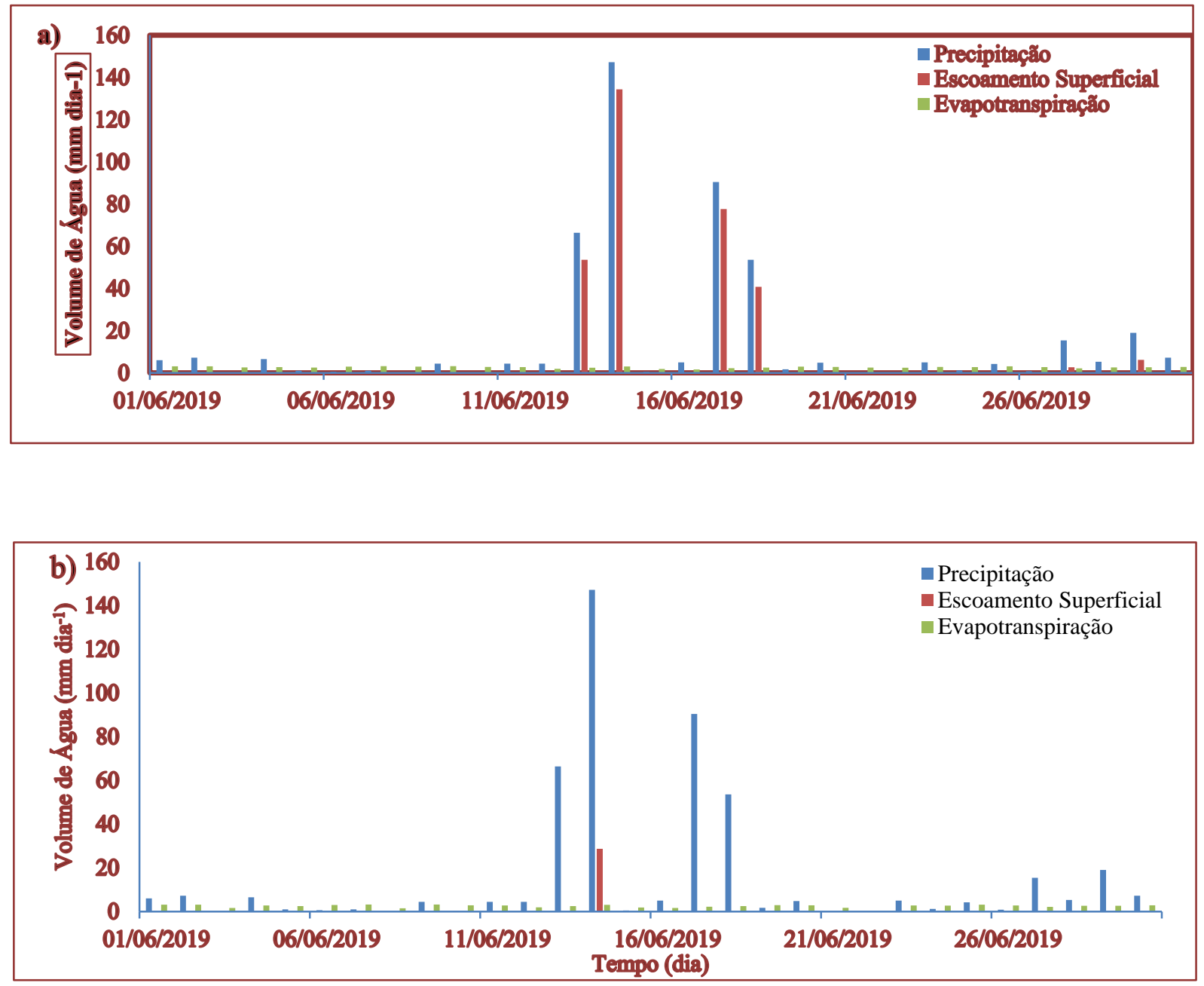

\section{CONCLUSÕES}

Os valores de escoamento superficial encontrados para os solos com altos percentuais de materiais finos (silte e argila) foram maiores que os valores encontrados para os solos arenosos, sendo o solo da simulação 3 o que apresentou os piores resultados, ou seja, os maiores valores de escoamento superficial, ratificando que os solos compostos de frações granulométricas mais grossas reduzem o escoamento superficial e auxiliam na redução dos alagamentos.

Dentre as simulações realizadas, o telhado verde composto por uma camada de solo contendo 85\% de areia, $5 \%$ de silte e $10 \%$ de argila apresentou o melhor desempenho no controle quantitativo do escoamento superficial para condições climáticas da localidade, viabilizando a redução das demandas dos sistemas convencionais de drenagem urbana, e possíveis diminuições de alagamentos.

\section{AGRADECIMENTOS}

0 primeiro autor deste trabalho agradece à FACEPE (Fundação de Amparo à Ciência e Tecnologia do Estado de Pernambuco) pelo financiamento da Bolsa de Iniciação Científica (BIC-1178-1.01/19) e à Escola Politécnica de Pernambuco. 


\section{REFERÊNCIAS}

[1] ALBRIEU, J. L. B.; REGINATO, J. C.; TARZIA, D. A. (2015). "Modeling water uptake by a root system growing in a fixed soil volume". Applied Mathematical Modelling 39 (12), pp. 3434-3447.

[2] CASTRO, A. S.; GOLDENFUM, J. A. (2010). "Uso de telhados verdes no controle quantitativo do escoamento superficial urbano". Atitude, Construindo Oportunidades: revista de divulgação científica da Faculdade Dom Bosco de Porto Alegre, Porto Alegre 4(7), pp. 75-81.

[3] CLARK, S. E; BAKER, K. H.; MIKULA, J. B.; BURKHARDT, C. S.; LALOR, M. M. (2006). Infiltration vs. Surfasse Water Discharge: guidance for stormwater managers. London: IWA, 288p.

[4] DLAPA, P.; HRINÍK, D.; HRABOVSKÝ, A.; ŠIMKOVIC, I.; ŽARNOVIČAN, H.; SEKUCIA, F.; KOLLÁR, J. (2020). “The Impact of Land-Use on the Hierarchical Pore Size Distribution and Water Retention Properties in Loamy Soils". Water 12(2), pp. 1-14.

[5] FERGUSON, I. M.; JEFFERSON, J. L.; MAXWELL, R. M.; KOLLET, S. J.; JEFFERSON, J. L. (2016). "Effects of root water uptake formulation on simulated water and energy budgets at local and basin scales". Environmental Earth Sciences 75(4), pp. 1-15.

[6] FRITZEN, M.; BINDA, A. L. (2011). “Alterações no ciclo hidrológico em áreas urbanas: cidade, hidrologia e impactos no ambiente”. Revista eletrônica Ateliê Geográfico 5(3), pp. 239-254.

[7] HOLANDA, M. A. C. R.; SOARES, W. A. (2019). "Analysis of the effect of impermeability of urban soils on the infiltration of rainwater in the city of Recife, PE”. Revista Ambiente e Água, 14(4), pp. 1-10.

[8] IBGE - Instituto Brasileiro de Geografia e Estatística. (2018). Perfil dos municípios brasileiros 2017: Pesquisa de informações básicas municipais - MUNIC. Rio de Janeiro, 106p.

[9] JUNQUEIRA, R.; MELLO, C. R.; OLIVEIRA, A. S.; ALVES, G. J.; AIRES, U. R. V. (2018). “Análise da Condutividade Hidráulica Saturada em uma Floresta de Cedro, Madrid, Espanha". Revista Agrogeoambiental 10(3), pp. 75-89.

[10] MACÊDO, K. G. (2018). “Simulação da extração de água do solo pela cultura do milho (Zea mays L.) utilizando modelo HYDRUS-1D”. Dissertação (Mestrado). Universidade Federal do Ceará, 2018, 68 p.

[11] RANGEL, C. L. C. A.; ARANHA, K. C.; SILVA, M. C. B. C. (2015). “Os telhados verdes nas políticas ambientais como medida indutora para a sustentabilidade". Revista Desenvolvimento. Meio Ambiente 35, pp. 397-409.

[12] REICHARDT, K. (1990). “A Água em Sistemas Agrícolas”. São Paulo: Editora Manole Ltda, 188 p.

[13] SILVA, F. A. A.; BARBOSA, B. G. S.; DUARTE, C. C. (2019). “Análise da interação entre eventos pluviométricos e ações antrópicas como agentes deflagradores de deslizamentos na Zona Norte do Recife". Revista de Geociências do Nordeste 5, pp. 01-11.

[14] SIMUNEK, J.; SEJNA, M.; SAITO, H.; SAKAI, M.; van GENUCHTEN, M. TH. (2013). "The HYDRUS-1D Software Package for Simulating the One-Dimensional Movement of Water, Heat, and Multiple Solutes in Variably-Saturated Media". Riverside, California.

[15] TASSI, R.; TASSINARI, L. C. S.; PICCILLI, D. G. A.; PERSCH, C. G. (2014). "Telhado verde: uma alternativa sustentável para a gestão das águas pluviais". Ambiente Construído 14(1), pp. 139-154.

[16] SANTOS, P. T. S. (2011). "Balanço hídrico em teto com cobertura vegetal no semiárido pernambucano". Dissertação (Mestrado). Programa de Pós-Graduação em Engenharia Civil, Universidade Federal de Pernambuco, 2011.

[17] SANTOS, P. T. S.; SANTOS, S. M.; MONTENEGRO, S. M. G. L.; COUTINHO, A. P.; MOURA, G. S. S.; ANTONINO, A. C. D. (2013). "Telhado verde: desempenho do sistema construtivo na redução do escoamento superficial". Ambiente Construído 13(1), pp. 161-174.

[18] WANDERLEY, L. S. A.; NÓBREGA, R. S.; MOREIRA, A. B.; ANJOS, R. S.; ALMEIDA, C. A. P (2018). "As chuvas na cidade do Recife: Uma climatologia de extremos". Revista Brasileira de Climatologia 22, 149-164.

[19] YANG, J.; YU, Q.; GONG, P. (2008). "Quantifying Air Pollution Removal by Green Roofs in Chicago". Atmospheric Environment 42(31), pp. 7266-7273.

[20] ZHANG, X.; ZHU, J.; WENDROTH, O.; MATOCHA, C.; EDWARDS. D. (2019). "Effect of macroporosity on pedotransfer function estimates at the field scale". Vadose Zone 18(1), pp. 1-15. 


\section{Capítulo 16}

Achados recentes sobre a qualidade da água do Rio Cocó em um trecho urbano da cidade de Fortaleza-CE

\section{Luís Gustavo Gomes Diógenes \\ Adriana Pereira do Nascimento \\ Rosa Márcia Araújo de Oliveira \\ Gilcenara de Oliveira \\ Fernando José Araújo da Silva}

Resumo - 0 Rio Cocó, atualmente, é o maior corpo hídrico presente no município de Fortaleza. Sua nascente se encontra na Serra de Aratanha, passando por diversas cidades e bairros dentro do município de Fortaleza, até seu deságue na Praia da Sabiaguaba. Por se tratar de um rio urbano, sofre vários impactos ao longo do seu percurso, é receptor de efluentes industriais, e domésticos. Este trabalho teve como objetivo analisar a qualidade da água do rio Cocó no período de julho a outubro de 2018. Utilizou-se as Resoluções CONAMA N ${ }^{\circ}$ 357/ 2005 e CONAMA N 274/ 2000 para realizar posterior comparação com os resultados achados. Os pontos 1 e 2 estão dentro do Parque Ecológico do Cocó e os pontos 3, 4, 5 e 6 estão situados no bairro Sabiaguaba, onde o último ponto se encontra na sua foz. A maioria dos resultados encontrados mostraram taxas preocupantes no que se diz respeito a poluição desse corpo hídrico. Alguns parâmetros apresentaram valores muito alterados nos pontos 1,2 e 6, e a análise microbiológica ultrapassou os limites estabelecidos pela legislação. Conclui-se que o trecho estudado apresenta qualidade sanitária precária como recurso hídrico urbano.

Palavras-Chave: Qualidade de água, Urbano, Rio Cocó. 


\section{INTRODUÇÃO}

Devido a problemática acerca do crescimento populacional e a necessidade da água pelos seres vivos, cresceu de forma desenfreada o uso deste recurso. A gestão da água em grandes quantidades está aliada à sua má gestão, trazendo problemas como a poluição. Essa problemática vem crescendo gradativamente, trazendo assim a preocupação acerca da qualidade da água dos corpos hídricos disponíveis em diversas regiões do nosso país. A qualidade da água é um fator de extrema importância quando se trata do seu uso, para que ele possa atender diversas necessidades, uma vez que é exercida por ela um papel em diversas áreas como na saúde, economia, lazer, dentre outros.

Segundo Pimenta (2009), as alterações na qualidade da água podem ser de origens naturais e antrópicas. As que se configuram por origens naturais passam por um processo de poluição mais demorado, sem a interferência do homem, sendo ela de forma lenta. Já as de fontes antrópicas são no geral oriundas de atividades industriais e humanas, comprometendo gravemente a qualidade das águas, em que diferentemente da poluição de origem natural, este tipo de contaminação se dá em grandes proporções e de forma acelerada.

Nesse ponto de vista, observa-se que tal problemática aflige o Rio Cocó, um corpo hídrico de uma extensão de 50 quilômetros, e de extrema importância para a sociedade fortalezense CEARÁ (2018). Atualmente ele apresenta quase em toda sua extensão áreas poluídas, isso se dá devido à grande parte a processos de urbanização, bem como ao crescimento populacional desordenado ao qual o rio está submetido. Tais ações são de característica antrópica, por meio de esgotos em sua maioria clandestinos, galerias pluviais ou até mesmo com o arraste de resíduos descartados erroneamente em sua proximidade.

Diante dos problemas em que o Rio Cocó se encontra, esse estudo teve como objetivo avaliar a qualidade dá água deste rio tão presente no cotidiano do cidadão fortalezense. As coletas foram realizadas no parque do Cocó e na sua foz, localizado no bairro da Sabiaguaba. Os resultados dessas análises foram confrontados com as Resoluções CONAMA 357/2005 e 274/2000.

\section{METODOLOGIA}

A pesquisa foi realizada no rio Cocó, que possui uma extensão de cerca de 50 km, segundo CEARÁ (2018). A área de estudo está situada dentro do Parque Ecológico do Cocó, Fortaleza - Ceará, como pode ser visualizado na figura 1. Foram realizadas coletas em 06 pontos distintos, sendo dois (02) dentro do Parque Ecológico do Cocó e quatro (04) situados na praia da Sabiaguaba. No período de julho a outubro de 2018 foram realizadas quatro coletas mensais. Todas as coletas foram efetuadas em maré de preamar, isso foi devido a baixar mar não possuir uma lâmina de água suficiente para a coleta de uma isobata de 1 metro como determina a legislação. Sempre que permitido, as amostras foram coletadas em uma profundidade de aproximadamente um metro da lâmina d'água; em alguns pontos, mesmo com a influência da maré alta, a lâmina não permitiu a coleta em altura mínima de 1 metro.

Figura 1: Localização dos pontos coletados.

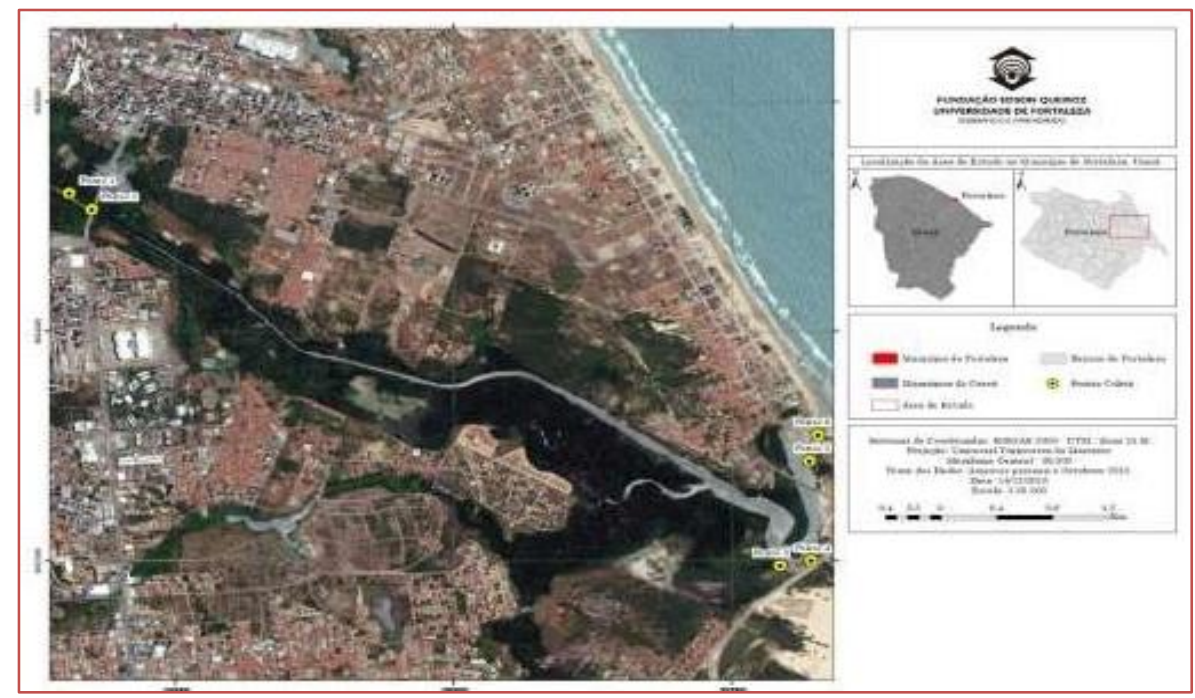

Fonte: Autor, 2018. 


\subsection{PARÂMETROS PARA ANÁLISE DE ÁGUA}

As variáveis analisadas foram definidas conforme sua relevância para caracterização da qualidade física, química e sanitária da água. Foram consideradas também a disponibilidade de material e a infra-estrutura laboratorial. 0 quadro 1, apresenta os parâmetros analisados e suas metodologias para análise e obtenção de dados.

Quadro 1: Variáveis analisadas e métodos.

\begin{tabular}{|c|c|c|}
\hline Parâmetros Potencial & Método analítico & Referência \\
\hline hidrogeniônico - pH & $\begin{array}{l}\text { Potenciométrico } \\
\text { Equipamento: pHmetro de marca HANNA®, modelo HI } 99121\end{array}$ & \multirow{3}{*}{$\begin{array}{l}\text { APHA et al. } \\
(2005)\end{array}$} \\
\hline Turbidez (NTU) & $\begin{array}{c}\text { Turbidimétrico } \\
\text { Equipamento: turbidimetro de bancada da marca ALFAKIT } \AA \text {, } \\
\text { modelo Plus II }\end{array}$ & \\
\hline $\begin{array}{l}\text { Condutividade elétrica - CE } \\
(\mathrm{mS} / \mathrm{cm})\end{array}$ & $\begin{array}{c}\text { Condutivimétrico } \\
\text { Equipamento: aparelho multiparamétrico de bancada da } \\
\text { marca AZ®, modelo } 86505\end{array}$ & \\
\hline $\begin{array}{l}\text { Oxigênio dissolvido } \\
\text { - OD (mg/L) }\end{array}$ & $\begin{array}{c}\text { Oxímetro portátil } \\
\text { Equipamento: Oxímetro portátil da marca Quimis@. }\end{array}$ & $\begin{array}{l}\text { APHA et al. } \\
(2005)\end{array}$ \\
\hline $\begin{array}{l}\text { Coliforme Totais e } \\
\text { Escherichia coli } \\
\text { - E.Coli (NPM) }\end{array}$ & $\begin{array}{c}\text { Substrato Cromogênico } \\
\text { Equipamentos: Cabine de fluxo laminar, Seladora modelo } \\
\text { QUANTI-TRAY@ SEALER de modelo 2X, } \\
\text { Estufa Incubadora modelo Q316M2, marca QUIMIS® e Luz } \\
\text { Ultravioleta }(365 \mathrm{~nm}) .\end{array}$ & $\begin{array}{l}\text { APHA et al. } \\
(2005)\end{array}$ \\
\hline Clorofila "a" ( $\mu \mathrm{g} / \mathrm{L})$ & $\begin{array}{l}\text { Lorenzen por Espectroscopia UV-VIS } \\
\text { Equipamentos: Centrífuga EXCELSA® modelo } 206 \text { BL da marca } \\
\text { FANEM e o Espectrofotômetro modelo 800XI } \\
\text { da marca FEMTO } \AA\end{array}$ & CETESB (2014) \\
\hline Cloreto (mg/L) & Argenométrico (Técnica de Mohr) & FUNASA (2013) \\
\hline $\begin{array}{l}\text { Nitrito e Nitrato - } \\
\text { NO2- e No3- } \\
\text { (mg/L) }\end{array}$ & $\begin{array}{l}\text { Diazotação por espectomotometro } \\
\text { Equipamento: esctrofotometro UV-VIS da marca FEMTOß e } \\
\text { modelo 800xi }\end{array}$ & $\begin{array}{l}\text { APHA et al. } \\
(1989)\end{array}$ \\
\hline $\begin{array}{l}\text { Ortofosfato } \\
\text { (mg/L) }\end{array}$ & $\begin{array}{c}\text { Murphy e Riley (ácido ascorbico) } \\
\text { Equipamento: esctrofotometro UV-VIS da marca FEMTOß e } \\
\text { modelo 800xi }\end{array}$ & $\begin{array}{l}\text { APHA et al. } \\
(2005)\end{array}$ \\
\hline
\end{tabular}

Fonte: Autor, 2018

\section{RESULTADOS}

As coletas foram realizadas nos horários em que a tábua de maré favorecesse a amostragem, tornando os valores dos parâmetros analisados mais próximos aos valores reais, uma vez que, quanto menor a tábua de maré mais concentrados serão esses parâmetros devido à baixa lâmina d'água. No período de coletas os valores de temperatura variaram entre $2,7^{\circ} \mathrm{C}$ a $30,1^{\circ} \mathrm{C}$, entretanto este parâmetro variou de acordo com horário de coleta, vale ressaltar que este parâmetro pode influenciar na qualidade de outros, como por exemplo: a proliferação de microrganismos e oxigênio dissolvido.

Analisando a figura 2 e comparando com a resolução vigente, pode-se observar que os pontos 1 e 2 são classificados como salobras; já os pontos 3, 4, 5 e 6 serão classificados como salinas, uma vez que em sua maioria, apresentou teores, aos longos meses, com as devidas características.

Para fins deste estudo as águas consideradas salobras foram classificadas como classe especial, uma vez que o local de coleta corresponde a uma área de preservação ambiental; as águas consideradas salinas, foram classificadas como de classe 1 , uma vez que a área é utilizada para recreação de frequentadores da região e em alguns pontos, foi observado, atividade pesqueira de pequeno porte. As linhas tracejadas são referentes ao limite de concentração salina presentes em uma água, que de acordo com a Resolução CONAMA 357/2005 é classificada como doce, salobra e salina.

Uma água de característica doce possui uma concentração de sal inferior a 0,5\%, já uma água considerada salobra pode apresentar um teor de $0,5 \%$ a $30 \%$ e a salgada, possui valores superiores a $30 \%$. 
Figura 2: Salinidade dos pontos em relação ao tempo coletado

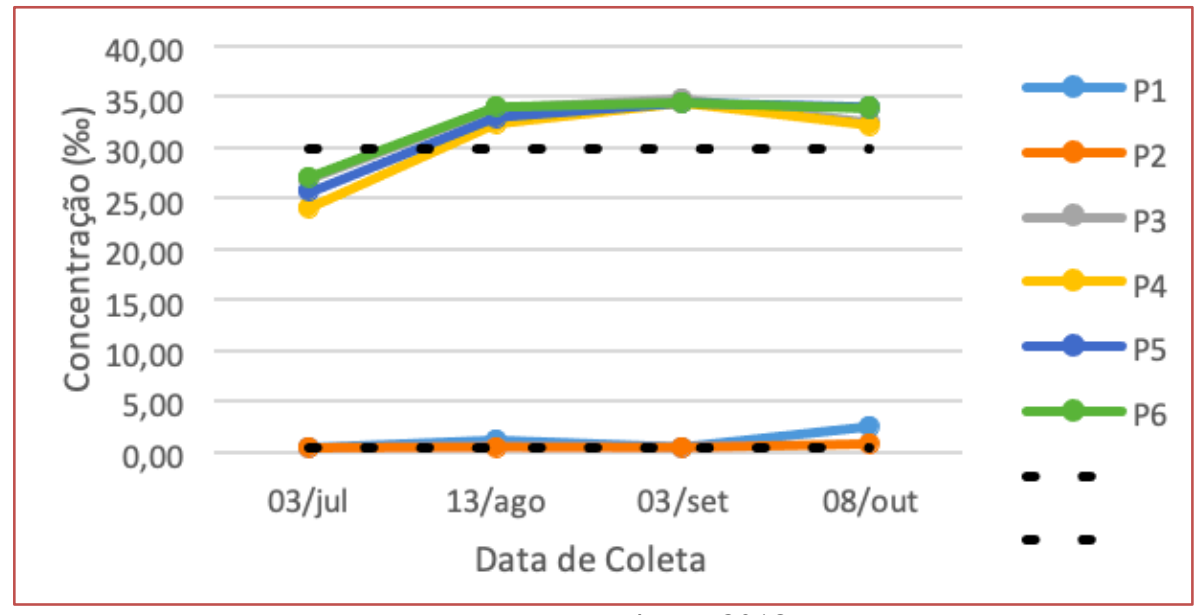

Fonte: Autor, 2018.

Em relação a turbidez figura 3, os pontos 1 e 2 apresentaram valores elevados, isto em comparação aos demais pontos, estes resultados podem esta relacionados a baixa lâmina d'água, no momento da coleta. Sendo uma área de mangue, observa-se a presença de vegetação típica dessa região, que pode influenciar os valores de turbidez devido aos materiais particulados como folhas, raízes. Já os pontos 3,4,5 e 6 no mês de julho apresentaram valores baixos, que podem estar relacionados ao espalhamento do material particulado na massa d'água, principalmente por estes pontos estarem localizados em áreas de maior revolvimento massas de água devido.

Figura 3: Resultados de Turbidez.

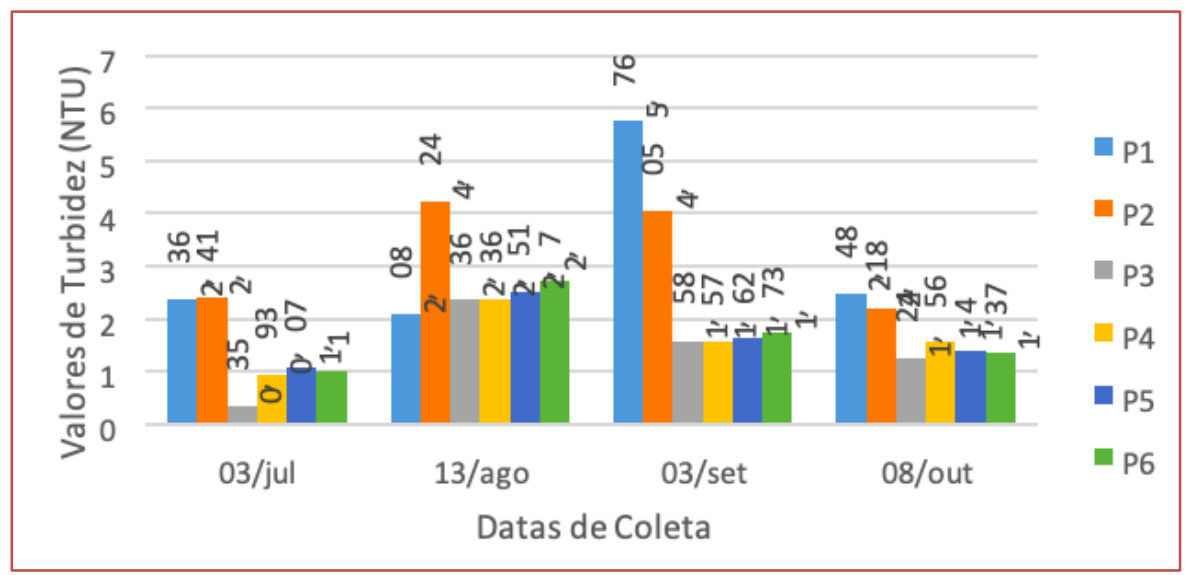

Fonte: Autor, 2018.

Os valores de pH, figura 4, variaram entre 7,26 a 9,05, de acordo com APHA (2005), águas naturais apresentam valores de pH que podem variar de 4 a 9, em alguns casos eles podem ser levemente básicos, devido a presença de bicarbonatos e carbonatos de metais alcalinos ou álcalis. De acordo com a legislação Conama $\mathrm{N}^{\circ} 357 / 2005$, o pH em águas salinas deverá estar entre 6,5 e 9,5; como observado, os valores do pH em todos os pontos do rio estão com valores aceitáveis. 
Figura 4: Resultados de $\mathrm{pH}$.

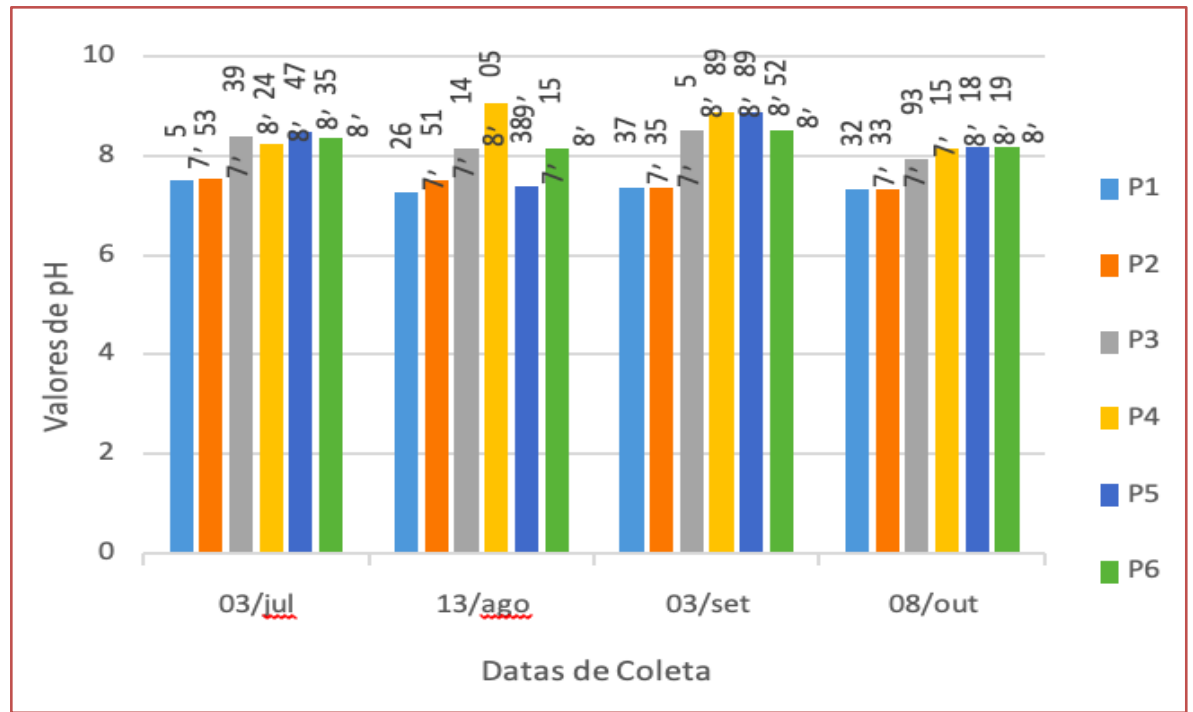

Font e: Autor, 2018.

A tabela 1, apresenta os índices de cloreto, que foram elevados nos pontos 3 a 6, estes locais são onde acontece o fenômeno da intrusão salina, entretanto, os índices se encontram em elevadas taxas, podendo ser devido a influências antrópicas. Para cloretos, a resolução CONAMA $N^{\circ}$ 357/2005 não possui parâmetros para as águas de classe salinas e salobras. Para os pontos 1 e 2 os valores de cloretos não foram tão significativos isto talvez pela não entrada de influencias antrópicas nessas regiões como também a não permanência da mesma nesse ambiente.

Tabela 1: Resultados de Cloretos.

\begin{tabular}{|c|c|c|c|c|c|c|}
\hline & P1 & P2 & P3 & P4 & P5 & P6 \\
\hline 03/jul & 4,99 & 2,99 & 470,85 & 385,88 & 393,88 & 385,88 \\
\hline 13/ago & 13,99 & 6,99 & 430,87 & 460,86 & 450,86 & 454,86 \\
\hline $03 /$ set & 7,99 & 5,99 & 481,85 & 440,86 & 441,86 & 450,86 \\
\hline 08/out & 10,99 & 4,99 & 440,86 & 432,86 & 445,86 & 455,85 \\
\hline
\end{tabular}

Fonte: Autor, 2018.

Em relação aos valores de oxigênio dissolvido figura 5, os pontos 1 e 2 apresentam valores que não ultrapassam $6 \mathrm{mg}$, porém o apresenta valor próximo a zero, no mês de setembro. Assim, para Silva (2013), este parâmetro é um dos principais a que diz respeito do controle do grau de poluição das águas, pois que indica as condições aeróbias em um corpo hídrico, que passa a receber material poluidor. De acordo com a legislação vigente, o OD dissolvido em água não poderá ser inferior a $6,0 \mathrm{mg} / \mathrm{L} 02$ em águas salinas, estando assim os pontos 3 a 6 dentro dos padrões 
Figura 5: Resultados de Oxigênio dissolvido.

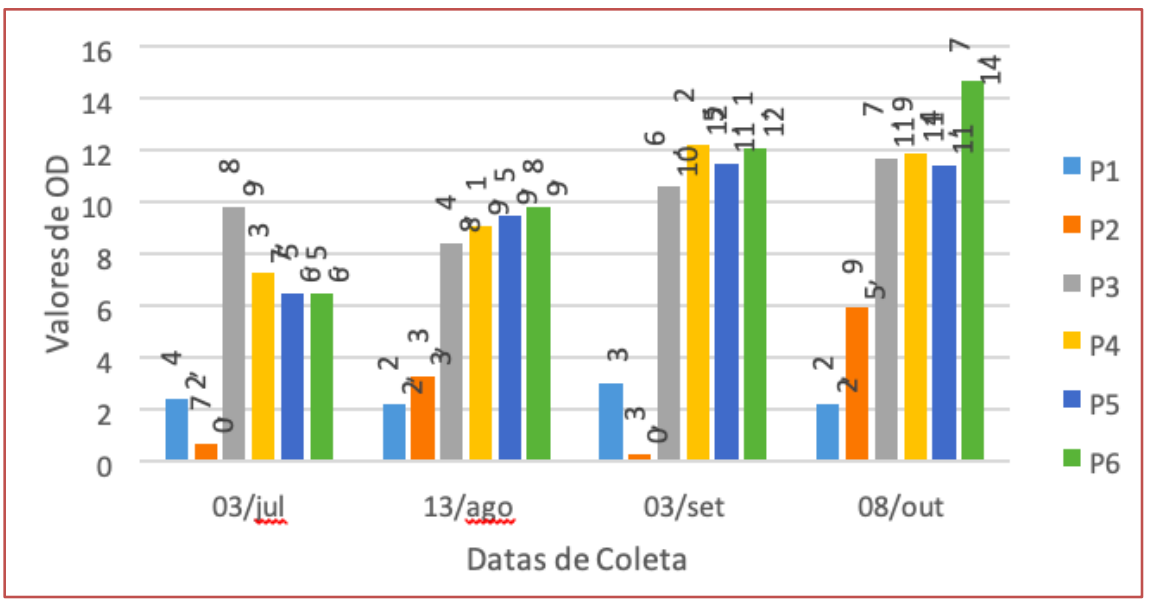

Fonte: Autor, 2018

Os valores de clorofila "a" oscilaram consideravelmente ao longo das análises, figura 6. Tal parâmetro está correlacionado a turbidez e pH, uma vez que a turbidez esteja alta, os níveis de clorofila "a" também podem estar altos, isso deve-se a falta de luz no ambiente, no caso do $\mathrm{pH}$ tendo assim a sua proliferação. Os níveis mais elevados foram nos pontos 1 e 2, tornando preocupante devido a produção de cianobactérias, que podem ser veiculadoras a diversas doenças e também a principal causadora do processo de eutrofização. Já os pontos de 3 a 6 apresentaram valores de clorofila mais baixos isto pode ser devido a correlação existente entre, quanto maiores os valores de $\mathrm{OD}$, menores os valores de Turb, menores os valores de ortofosfoto, os valores de Clorofila "a" diminuem consideravelmente. Para águas de classe salinas e salobras não é informado padrões pela Resolução CONAMA N ${ }^{\circ} 357$, assim impossibilitando a comparações dos níveis encontrados.

Figura 6: Resultados de Clorofila a.

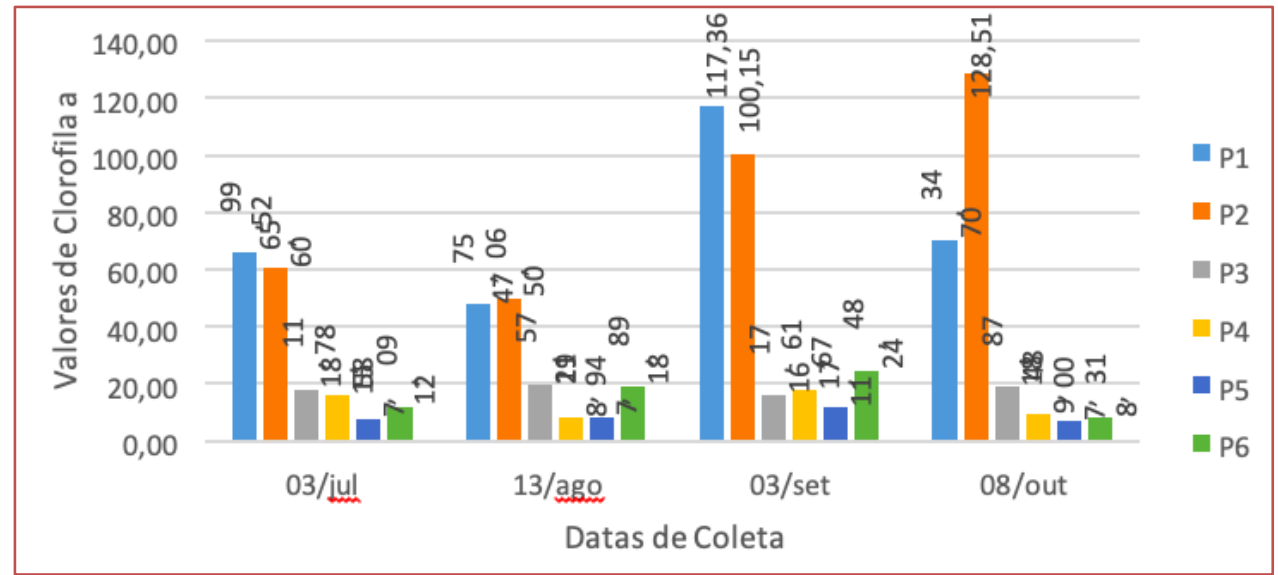

Fonte: Autor, 2018.

As tabelas 2 e 3 apresentam os níveis de Coliforme e E coli, que ultrapassaram os limites de leitura em alguns pontos. Em três dos quatro meses nos pontos 1 e 2, dentro do parque do cocó, os valores excederam o limite de leitura. No mês de julho e outubro o ponto 6, localizado na desembocadura do rio, também ultrapassou os limites possíveis de leitura de Coliforme e E coli. A presença deste microorganismo em água está diretamente ligada a níveis de contaminação fecal, sendo ela associada ao lançamento de efluentes líquidos as proximidades dos locais de coleta, influenciando no crescimento nos níveis do parâmetro. Vale ressaltar que neste ponto pode ser observado a presença de barracas de praia, uma grande quantidade de banhistas que podem influenciar no aumento deste parâmetro pela falta de condições sanitárias. 
Tabela 2: Resultado dos Coliformes.

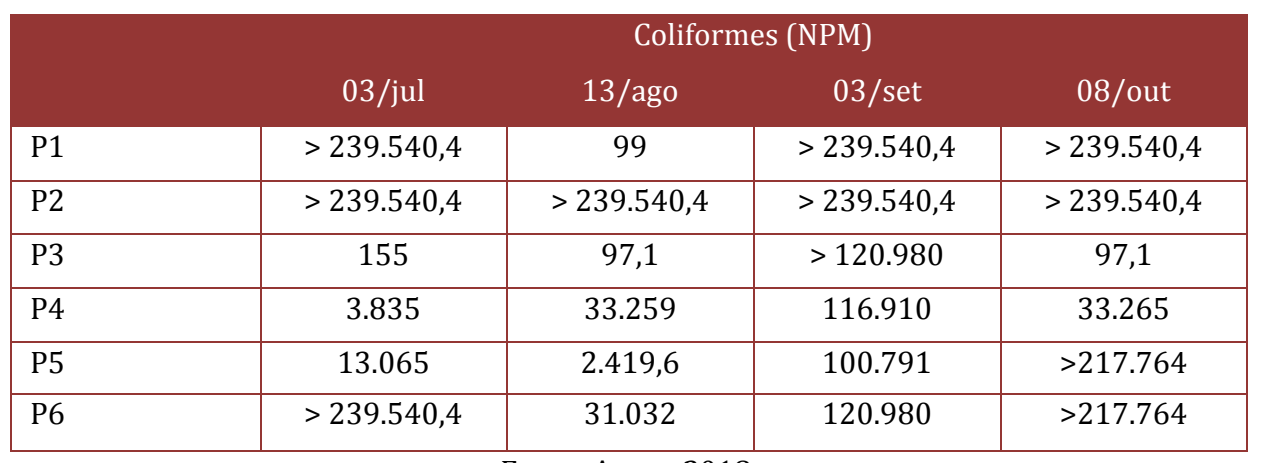

Fonte: Autor, 2018.

Tabela 3: Escherichia Coli.

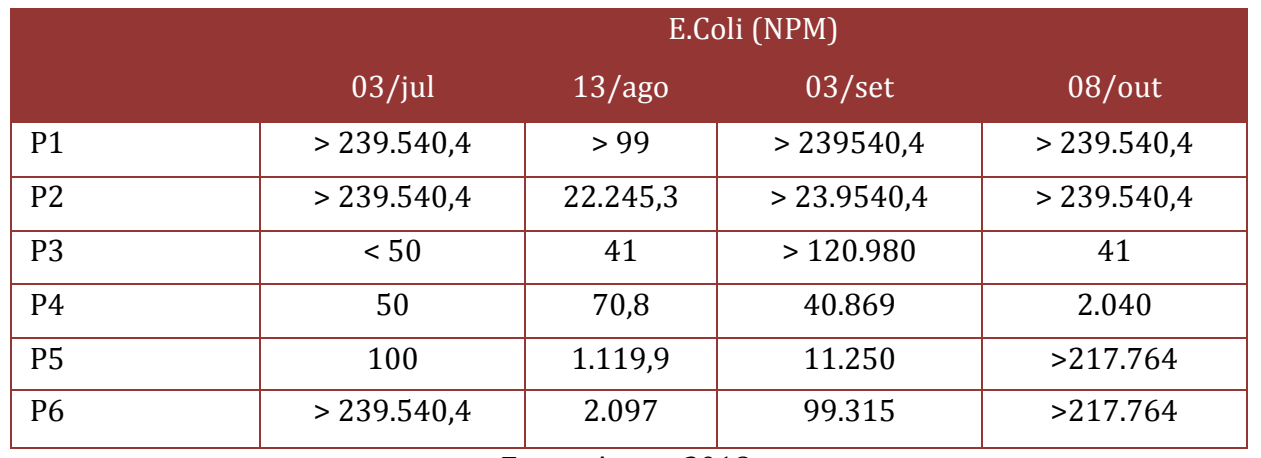

Fonte: Autor, 2018.

A tabela 4 apresenta os valores de nitrito, nitrato e ortofosfato encontrados. No mês de julho foi detectada a presença de nitrato em todos os pontos analisados, sua presença pode está relacionada a poluentes já presentes no local, devido à dispersão nitrogênio anterior as coletas, uma vez que, o nitrato se origina a partir do processo de nitrificação do nitrito. Nos pontos 1 e 2, em sua grande maioria, pode-se constatar a presença de nitrato e nitrito, esses nutrientes em água constata a presença de fontes poluidoras nas proximidades do rio, podendo ser efluentes clandestinos ou despejados.

0 ortofosfato, foi encontrado somente nos pontos 1 e 2, tal elemento é essencial para a vida aquática, entretanto, em excesso pode causar o enriquecimento de nutrientes, surgindo fitoplânctons que causam a baixa do oxigênio na água. Esses pontos durante o período da pesquisa grande quantidade de macrófitas na área de coleta, fortalecendo assim os dados que mostram os elevados valores ortofosfato em água.

Tabela 4: Resultados de Nitrito, Nitrato e Ortofosfato.

\begin{tabular}{|c|l|c|c|c|c|c|c|}
\multicolumn{2}{|c}{ Pontos } & P1 & P2 & P3 & P4 & P5 & P6 \\
\hline \multirow{3}{*}{$03 /$ jul } & Nitrito & 0,011 & 0,012 & NI & NI & NI & NI \\
& Nitrato & 0,019 & 0,018 & 0,001 & 0,007 & 0,028 & 0,006 \\
& Ortofosfato & 1,951 & 0,180 & NI & NI & NI & NI \\
\hline \multirow{3}{*}{ 13/ago } & Nitrito & 0,041 & NI & NI & NI & NI & NI \\
& Nitrato & NI & NI & NI & 0,055 & NI & NI \\
& Ortofosfato & 0,155 & 3,494 & NI & NI & NI & NI \\
\hline \multirow{3}{*}{$03 /$ set } & Nitrito & 0,077 & NI & NI & NI & NI & NI \\
& Nitrato & 0,977 & 1,908 & NI & NI & NI & NI \\
& Ortofosfato & 2,644 & 2,962 & NI & NI & NI & NI \\
\hline \multirow{3}{*}{$08 /$ out } & Nitrito & 0,220 & 0,111 & 0,096 & 0,102 & NI & NI \\
& Nitrato & 0,341 & 0,134 & 0,115 & 0,115 & NI & NI \\
& Ortofosfato & 3,525 & 4,643 & NI & NI & NI & NI \\
\hline
\end{tabular}

Fonte: Autor, 2018. 


\section{CONCLUSÃO}

Diante dos resultados obtidos os pontos 1 e 2 situados dentro do Parque Ecológico do Cocó são os com índices de maior preocupação, tendo em vista que o local é uma área de preservação ambiental, as análises indicam a presença de fontes poluidoras do ambiente aquático. Os pontos localizados no bairro da Sabiaguaba apontam uma menor poluição hídrica; uma vez que alguns parâmetros como clorofila, OD, nitrato, nitrito e ortofosfato se comportaram de acordo com as exigências das Resoluções CONAMA $357 / 2005$ e 274/2000, porém, os parâmetros cloreto, coliforme totais e E.Coli apresentaram valores não condizentes com o permitido pela legislação.

Os resultados mais alterados e que não condiziam com os valores da legislação em estudo foram nos pontos 1, 2 e 6. Nestes pontos o parâmetro microbiológico analisado, por diversas vezes, ultrapassou os limites permitidos pela legislação. Os resultados encontrados dentro do Parque Ecológico do Cocó ou na Sapiranga mostram o quanto é preocupante a forma como o rio Cocó tem sido utilizado. E se não houver conscientização para seu uso, o rio irá perecer em seus diversos compartimentos e a sociedade deixará de usufruir de um recurso natural tão importante.

\section{REFERÊNCIAS}

[1] APHA, AWWA, WEF, "Standard Methods for the Examination of Water and Wastewater". 21st ed. American Public Health Association, Washington, D.C, 2005.

[2] CEARÁ. Secretaria do Meio Ambiente (SEMA). Parque do Cocó será regulamentado após 40 anos. 2017. Disponível em: http://www.sema.ce.gov.br/index.php/sala-deimprensa/ Notícias /46151-parque-do-coco-seraregulamentado-após-40-anos. Acesso em: 20 jul. 2020.

[3] FUNDAÇÃO NACIONAL DE SAUDE. Manual de Utilização das Águas Pluviais. Disponível em: http://www.funasa.gov.br/site/wp-content/files_mf/manual_pratico_de_analise_de_agua_2.pdf. Acesso em: 12 nov. 2018.

[4] PIMENTA, S. M; PENA, A, P; GOMES, P. S. Aplicação de métodos físicos, químicos e biológicos na avaliação da qualidade das águas em áreas de aproveitamento hidroelétrico da bacia do rio São Tomás, município de Rio Verde Goiás. Soc. nat. (Online). 2009, vol.21, n.3, pp.393-412. ISSN 1982-4513. Disponível em: http://dx.doi.org/10.1590/S198245132009000300013. Acesso em: 31 maio 2018.

[5] RESOLUÇÃO CONAMA № 274, de 29 de novembro de 2000. Define os critérios de balneabilidade em águas brasileiras. Brasília, 2000. Disponível em: http://www.mma.gov.br/port/conama/legiabre.cfm?codlegi=272. Acesso em: 26 jul. 2020.

[6] RESOLUÇÃO CONAMA № 357, de 17 de março de 2005. Dispõe sobre a classificação dos corpos de água e diretrizes ambientais para o seu enquadramento, bem como estabelece as condições e padrões de lançamento de efluentes, e dá outras providências. Disponível em: http://www2.mma.gov.br/port/conama/legiabre.cfm?codlegi=459. Acesso em 20 de setembro de 2020.

[7] SÃO PAUlO (Estado). COMPANHIA AMBIENTAL DO ESTADO DE SÃO PAULO (CETESB). Relatório de qualidade das águas costeiras no estado de São Paulo 2016. São Paulo: CETESB, 2017a. 178 p. Disponível em: http://cetesb.sp.gov.br/aguas-interiores/wpcontent/ uploads/sites/12/2017/11/Cetesb_QualidadeAguasCosteiras_2016-22-05_Impresso.pdf. Acesso em: 20 jul 2020.

[8] SILVA, J. C. C. A poluição no rio Cocó, sub-bacia B-2, margem direita, e a expansão urbana de Fortaleza-CE. 2013. Disponível em: https://repositorio.unesp.br/handle/11449/104411 . Acesso em: 19 de set. de 2020. 


\section{Capítulo 17}

Avaliação do potencial do reuso de água cinza no município de Campo Grande-MS

\section{Ingrid Moreno Mamedes}

Silvia Gonzales Sorensen Tiradentes

\section{Paula Loureiro Paulo}

Resumo: A água cinza é considerada um recurso valioso com um alto potencial de reutilização e está rapidamente se tornando uma usual solução para escassez hídrica. No entanto, a adoção generalizada da reutilização de águas cinza depende de sua aceitabilidade pela população. Dessa forma, o objetivo deste trabalho foi levantar o potencial do reuso de água cinza no município de Campo Grande-MS. Para isso, foram levantadas as opiniões e hábitos dos habitantes em relação ao uso da água e ao reuso da água cinza com base em entrevistas realizadas nos domicílios. Observou-se que 95\% dos usuários utilizam água da rede pública e que o reaproveitamento da água cinza é um hábito comum entre a maioria dos entrevistados (69\%), os quais costumam reutilizá-la principalmente para limpeza de pisos e calçadas e para molhar o quintal. Entretanto, apesar de uma parcela do efluente produzido ser destinado ao reuso, apenas $51,7 \%$ do esgoto é coletado, o que torna o reuso da água cinza ainda mais interessante do ponto de vista ambiental. Logo frente a precariedade do sistema de coleta e tratamento de esgoto e ao elevado potencial do município em reutilizar a água cinza, essa prática deveria ser incentivada pelo poder público.

Palavras-Chave: Reuso de efluente doméstico; Escassez Hídrica. 


\section{INTRODUÇÃO}

Medidas para reduzir o uso de água por meio de maior conscientização, instalação de coleta de água da chuva e sistemas de tratamento de água cinza (AC) são vistos como soluções promissoras, especialmente em países em desenvolvimento que são mais vulneráveis à escassez de água (Neeri, 2007). A reutilização de AC está emergindo cada vez mais como parte integrante da gestão da demanda de água, proporcionando água não potável para o uso residencial e industrial (EA Relatório 2001).

Em geral, a água cinza é a água residual gerada a partir de atividades domésticas como banho, lavatórios, lavagem de louça, roupa e cozinha, desconsiderando as águas residuais do banheiro. As AC possuem menor potencial poluidor do que as águas negras, pois a ausência de urina e fezes implica em menores concentrações de nitrogênio (estudos mostram que raramente excedem $5 \mathrm{mg} / \mathrm{L}$ ), assim como patógenos e carga orgânica (Surendran e Wheatley 1998, Jefferson et al. 2004).

Sendo assim, a AC é considerada a maior fonte potencial de reutilização de água, representando cerca de $50-80 \%$ do total de água consumida e pode ser destinada a multiplos usos, como descarga de vaso sanitário, lavanderia, irrigação de jardins, arrefecimento, recarga de aquíferos, paisagismo, combate a incêndios, lavagem de carros e calçadas, entre outros (Christova-Boal et al. 1996; Eriksson et al. 2002; Jamrah et al. 2006).

Os aparelhos que contribuem com a parcela de água cinza podem ser separados dos contribuintes de água negra por meio da instalação de encanamento de dupla reticulação. A água cinza então é encaminhada para um sistema de tratamento para posterior reutilização, proporcionando a redução do volume de efluente enviado para estação de tratamento de esgoto ou fossa séptica e da necessidade da entrada de água potável na residência (Diaper e Sharma, 2007).

No entanto, a adoção generalizada da reutilização de águas cinzas depende de sua aceitabilidade pela população. Estudos anteriores avaliaram os custos de implementação da tecnologia de reutilização de águas cinzas, e consideraram sua aceitabilidade em princípio. Embora o custo seja claramente muito importante em termos de adoção / instalação da tecnologia, a percepção real da reutilização de águas cinzas é crucial para impulsionar a aceitabilidade de uso e obter sucesso a longo prazo da tecnologia. Vários autores estudaram a disposição da população para reutilizar água (por exemplo, Adapa, 2018; Fielding et al., 2019; Khan e Anderson, 2018), bem como as características que podem influenciar escolhas nesta área (Hartley, 2006; Hurlimann e Dolnicar, 2016; Smith et al., 2018). Dessa forma, objetivamos com essa pesquisa identificar o potencial de reuso da água cinza entre os moradores da cidade de Campo Grande-MS.

\section{MATERIAL E MÉTODOS}

Foi levantada a opinião e os hábitos dos moradores de Campo Grande- MS em relação a fonte de água utilizada, a prática de reuso da água cinza, tipos de reuso adotados e o destino dado ao esgoto sanitário, com base em uma pesquisa realizada em domićlios (survey). A pesquisa foi realizada por empresa terceirizada na zona urbana do município.

Utilizou-se a técnica de entrevistas domiciliares. Então, foi selecionada uma amostra quantitativa probabilística de 404 entrevistados, por meio do modelo estatístico de conglomerados (PPT Probabilidade proporcional ao tamanho) em dois estágios, que consiste na seleção dos setores censitários e seleção do quarteirão principal (onde o entrevistador iniciou as entrevistas) (Figura 1).

Figura 1- Município de Campo Grande dividido em setores censitários.

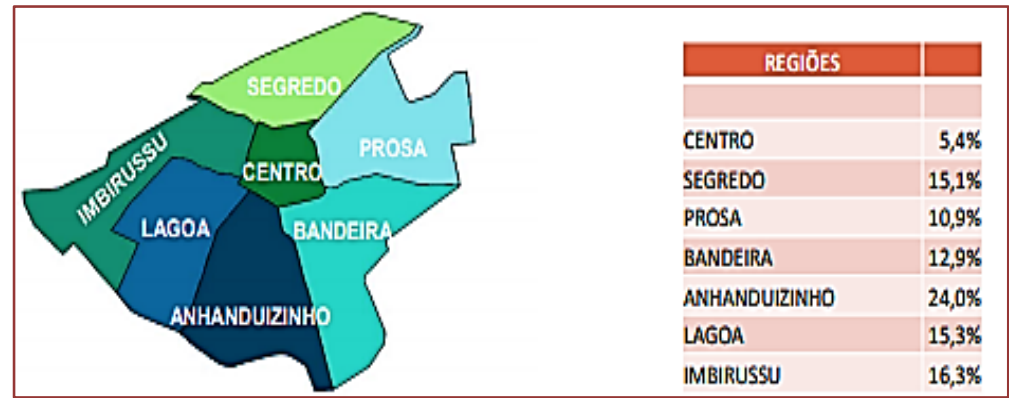




\section{RESULTADOS E DISCUSSÃO}

A quantidade de água cinza produzida está diretamente relacionada aos hábitos, quantidade de água doce disponível, custos, número de pessoas e a idade e sexo dos moradores (Murphy, 2006; Mungai, 2008). Desse modo, podemos observar que a maior parte desse público não concluiu o ensino médio, enquanto $13 \%$, aproximadamente tem nível superior, o que não difere muito do grau de instrução do chefe de família, considerando que cerca de $78 \%$ dos respondentes assumiram essa posição no lar. 0 número de moradores por domićlio é bem diversificado, porém, o mais comum é residir entre 2 a 4 pessoas, resultando em uma média de 3,14 pessoas por lar.

Quanto à distribuição por faixa etária e gênero, verificou-se que os três grupos que envolvem crianças e adolescentes estão presentes em uma parcela aproximada de lares (entre $22 \%$ e $29 \%$ ) e a proporção entre o sexo feminino e masculino também se mostrou equilibrada. Já a renda e classe econômica refletem as características da população em geral, pois são decorrentes de sorteio aleatório dos domicílios, confirmando-se a predominância de renda entre 1 e 5 salários mínimos e classe C. De acordo com Amaris et al (2020) a aceitabilidade para o reuso é menor para os entrevistados do sexo feminino e para os entrevistados com baixa escolaridade, porém não foram identificadas tais relações em nosso estudo.

Quanto ao consumo de água potável, notou-se que aproximadamente $95 \%$ dos domicílios utilizam água da rede pública (Figura 2), os quais consomem em média $11,61 \mathrm{~m}^{3}$ de água por mês. Sendo assim, ao compará-lo com o consumo médio de água por residência do município de São Paulo $\left(19,5 \mathrm{~m}^{3} / \mathrm{mês}\right)$ (Barreto, 2008), pode-se considerar o consumo médio de água um hábito populacional que influencia diretamente na geração de água cinza e possui considerável variação, levando-se em conta a disponibilidade de água, clima, no de habitantes por residência, entre outros.

Figura 2- Fonte de consumo de água das residências.

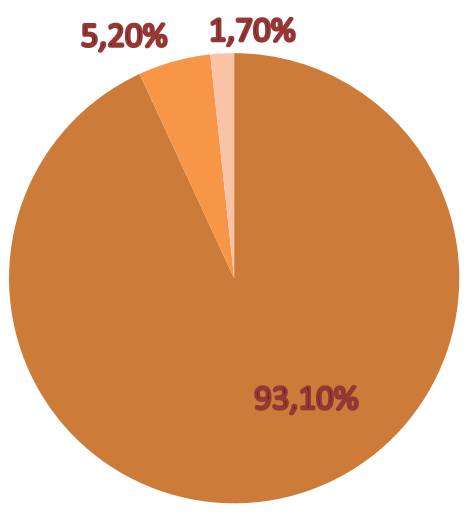

- Somente da rede pública

Somente de poço

Parte da rede pública e parte de poço

A recíproca também é verdade, o reuso da AC é um fator influenciador no consumo de água e observou-se que o reaproveitamento da água da lavagem de roupas é um hábito comum entre a maioria dos entrevistados (69\%), os quais costumam reutilizá-la, sem tratamento prévio, principalmente para limpeza de pisos e calçadas e para molhar o quintal reduzindo consideravelmente o consumo de água potável (Figura 3).

Na Alemanha, o reuso da AC é usado na recarga de água subterrânea, paisagismo e irrigação (Al-Jayyousi, 2003). No Chile há uma aceitação geral para o uso de água cinza tratada de alta qualidade para descarga de vasos sanitários, lavanderia, irrigação de jardins, lavagem das mãos e uso do chuveiro / banheira (seguindo uma ordem decrescente de prioridade) (Amaris et al., 2020). Em geral a água cinza é um recurso hídrico potencialmente reutilizável para irrigação de gramados e jardins domésticos (Al-Jayyousi, 2003), visto que o desvio de efluentes da lavanderia para jardins e gramados é tecnicamente possível sem tratamento (Jeppesen, 1996).

Para compreender a aceitabilidade dos indivíduos e suas escolhas para o reúso da água, existem duas fontes elementares de informação: experiências locais de sucesso e a percepção da população sobre o sistema (Chen et al., 2017; Woltersdorf et al., 2018; Lefebvre, 2018; Khan e Anderson, 2018), e estudos 
anteriores relacionados com a aceitabilidade da reutilização de água (Baumann, 1983; Fielding et al., 2019; Gu et al., 2015; Smith et al., 2018).

Figura 3- Formas de reuso praticadas pelos entrevistados.

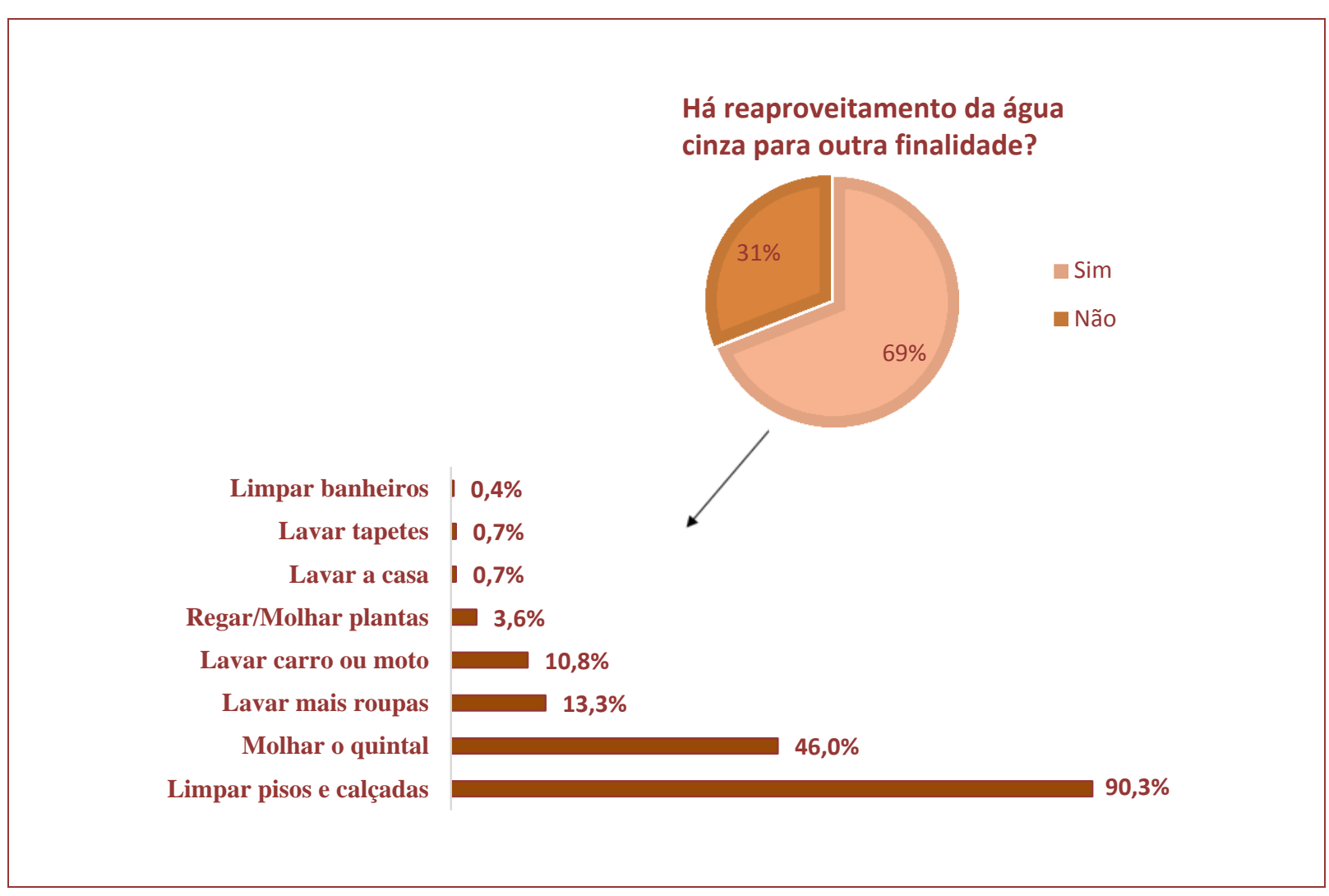

Entretanto, é importante considerar que apesar de parte dos entrevistados praticarem o reúso de uma parcela do efluente produzido (o que tende a reduzir a produção de efluente), apenas 51,7 \% do esgoto é coletado (Figura 4), enquanto nos demais lares são dispostos em fossas sépticas o que mostra a precariedade do sistema de coleta e tratamento de esgoto do município e torna o reuso da água cinza ainda mais interessante do ponto de vista ambiental, logo deveria ser incentivado pelo poder público.

Figura 4- Destino final do esgoto sanitário.

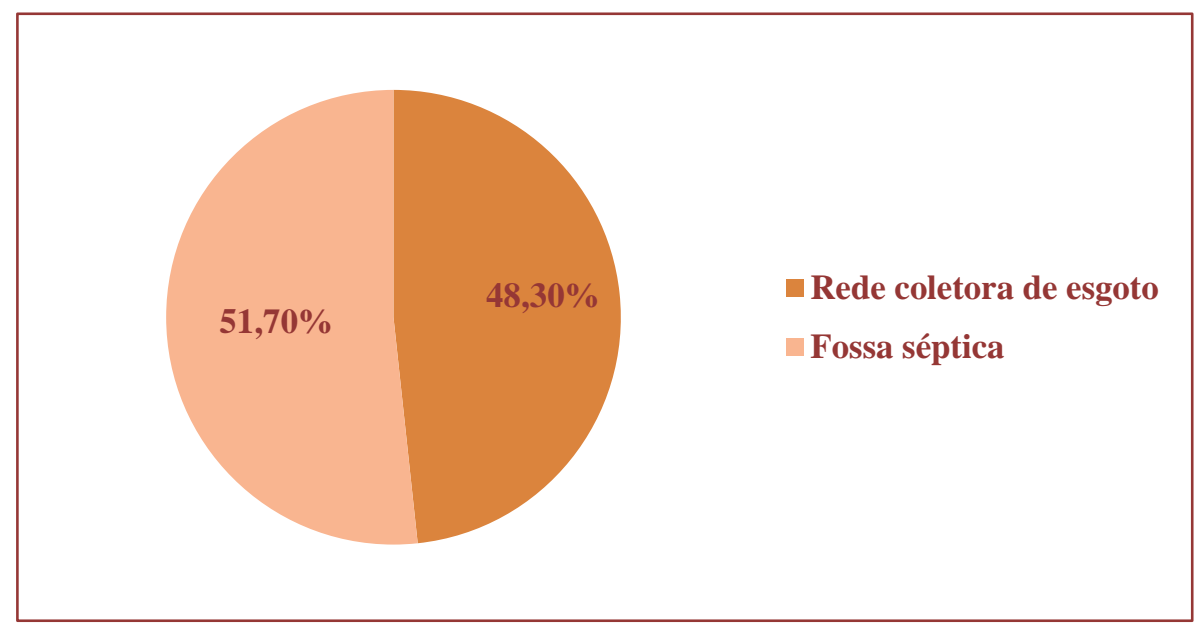


Queremos destacar que embora o primeiro seja muito importante em termos de adoção / instalação da tecnologia, o fator de repulsa é crucial em termos de impulsionar a aceitabilidade de uso e o sucesso de longo prazo da tecnologia, por isso é importante o conhecimento prévio da população em relação aos benefícios do reuso da água cinza e políticas de incentivo e educação ambiental.

\section{CONCLUSÃO}

O estudo concluiu que fatos como: o município ser abastecido em sua maior parte pela rede pública e possuir um sistema precário de coleta de esgoto, devem impulsionar e incentivar o reuso da água cinza com objetivo de reduzir o volume de efluente produzido e a quantidade de água potável fornecida a população. Além disso, Campo Grande possui boa aceitabilidade em relação ao reuso da água cinza, pois consderável parte dos entrevistados já iniciaram esta prática em seus lares. Dessa forma, as políticas ambientais atuais devem ter como objetivo o controle da poluição e a maximização da reciclagem e do reaproveitamento da água cinza.

\section{AGRADECIMENTO}

Os autores agradecem o apoio recebido do Conselho Nacional de Desenvolvimento Científico e Tecnológico - CNPq, da Coordenação de Aperfeiçoamento de Pessoal de Nível Superior - CAPES, da Fundação de Amparo à Pesquisa do Estado de Minas Gerais - FAPEMIG e do Instituto Nacional de Ciência e Tecnologia em Estações Sustentáveis de Tratamento de Esgoto - INCT ETEs Sustentáveis. O presente trabalho foi realizado com apoio da Fundação Universidade Federal de Mato Grosso do Sul - UFMS/MEC Brasil.

\section{REFERÊNCIAS}

[1] ADAPA, S. Factors influencing consumption and anti-consumption of recycled water: evidence from Australia. Journal of Cleaner Production. v. 201, p. 624-635, 2018.

[2] AL-JAYYOUSI, O.R. Greywater reuse: towards sustainable water management. Desalination. v.156, p.181-192, 2003

[3] AMARIS, G. et al. Understanding the preferences for different types of urban greywater uses and the impact of qualitative attributes. Water Research. v.184, 2020.

[4] BARRETO, D. Perfil do consumo residencial e usos finais da água. Amb Const. Porto Alegre, v. 8, n. 2, p. 23-40, abr. /jun. 2008.

[5] BAUMANN, D.D. Social acceptance of water reuse. Applied Geography. v.3, p.79-84, 1983.

[6] CHEN, Z., WU, Q., WU, G. \& HU, H.Y. Centralized water reuse system with multiple applications in urban areas: lessons from China's experience. Resources, Conservation and Recycling. v.117, p. 125-136, 2017.

[7] CHRISTOVA-BOAL D;; EVANS R.E.; MCFARLANE S. An investigation into gray water reuse for urban residential properties. Desalination. v. 106, p. 391-397, 1996.

[8] DIAPER, C., SHARMA, A. Innovative sewerage solutions for small rural towns. WatScien \& Tech, n.5, v.56, p. $97-103,2007$.

[9] EA Report. Water resources for the future-a strategy for England and Wales. Environment Agency, London, 2001.

[10] ERIKSSON E.; AUFFARTH K.; HENZE, M.; LEDIN, A. Characteristics of gray wastewater. Urban Water. v. 4, p. 85-104, 2002.

[11] FIELDING, K. S.; ROIKO, A.H. Providing information promotes greater public support for potable recycled water. Water Research. v. 61, p. 86-96, 2014.

[12] FIELDING, K. S.; ROIKO, A.H. Providing information promotes greater public support for potable recycled water. Water Research. v. 61, p.86-96, 2014.

[13] GU, Q.; CHEN, Y.; PODY, R.; CHENG, R.; ZHENG, X.; ZHANG, Z. Public perception and acceptability toward reclaimed water in Tianjin. Resources, Conservation and Recycling. v.104, p. 291-299, 2015.

[14] HARTLEY, T.W. Public perception and participation in water reuse. Desalination. v.187, p. 115-126, 2006. 
[15] HURLIMANN, A.; DOLNICAR, S. Public acceptance and perceptions of alternative water sources: a 710 comparative study in nine locations. International Journal of Water Resources Development. v. 32, p.650- 711, 2016.

[16] JAMRAH, A.; AL-OMARI, A.; AL-QASEM L.; ABDEL GHANI, N. Assessment availability and characteristics of gray water in Amman. Int Water Resour Assoc. v.31, p.210-220, 2006.

[17] JEFFERSON, B.et al. Grey water characterization and its impact on the selection and operation of technologies for urban reuse. Wat Scienand Techn. v.50, n.2, p.157-164, 2004.

[18] JEPPESEN, B. Domestic greywater re-use: Australia's challenge for the future. Desalination. v.106, p.311-315, 1996.

[19] KHAN, S.J.; ANDERSON, R. Potable reuse: experiences in Australia. Current Opinion in Environmental Science \& Health. v. 2, p. 55-60, 2018.

[20] KHAN, S.J.; ANDERSON, R. Potable reuse: experiences in Australia. Current Opinion in Environmental Science \& Health. v.2, p.55-60, 2018.

[21] LEFEBVRE, O. Beyond NEWater: an insight into Singapore's water reuse prospects. Current Opinion in Environmental Science \& Health. v.2, p.26-31, 2018.

[22] MUNGAI, G.G. Impacts of long-term greywater disposal on soil properties and reuse in urban agriculture in an informal settlement - a case study of Waruku, Nairobi. UNESCO-IHE Institute for Water Education, Eawag, 2008.

[23] MURPHY, K. O'H. A Scoping Study to Evaluate the Fitness-for-use of Greywater in Urban and Peri-Urban Agriculture. Pretoria: Water Research Commission Report No. 1479/1/06. 1-77005-471-5, 2006.

[24] NEERI, N. Guidance manual for water quality monitoring and assessment (First Edition). National Environmental Engineering Research Institute (Neeri), Nehru Marg, Nagpur. 2007.

[25] SMITH, H.M., BROUWER, S., JEFFREY, P. \& FRIJNS, J. Public responses to water reuse - understanding the evidence. Journal of Environmental Management. v.207, p. 43-50, 2018.

[26] SMITH, H.M.; BROUWER, S.; JEFFREY, P.; FRIJNS, J. Public responses to water reuse - 775 understanding the evidence. Journal of Environmental Management. v. 207, p.43-50, 2018.

[27] SURENDRAN, S.; WHEATLEY, A.D. Grey-water reclamation for non-potable reuse. Jof the Chart Inst of Water and Environ Manag. v.12, p. 406-413, 1998.

[28] WOLTERSDORF, L.; ZIMMERMANN, M.; DEFFNER, J.; GERLACH, M.; LIEHR, S. Benefits of an integrated 794 water and nutrient reuse system for urban areas in semi-arid developing countries. Resources, Conservation and Recycling. v. 128, p. 382-393, 2018. 


\section{Capítulo 18}

Contribuição da Política Nacional de Recursos Hídricos para governança da compensação ambiental interfederativa no Brasil

\section{Patrícia Helena Gambogi Boson}

Maria de Fátima Chagas Dias Coelho

Márcio Silva Pereira

Tácito Ribeiro de Matos

Resumo: Este artigo apresenta reflexões e aponta desafios e caminhos a trilhar para a implementação da compensação ambiental interfederativa no Brasil. A despeito da complexidade do tema, parece viável e oportuna a concepção e estruturação de instrumentos de fomento a processos de desenvolvimento endógenos, por meio do estímulo à melhoria da proteção e conservação ambiental, voltados para o fortalecimento municipal. Embora o mecanismo da compensação ambiental tenha sido incorporado ao Estatuto da Metrópole, ainda não se observa sua aplicação em um contexto de governança interfederativa das regiões metropolitanas e das aglomerações urbanas. É necessário concentrar esforços em campos específicos da problemática ambiental das cidades, sobretudo quando os problemas extrapolam os limites de uma única unidade federativa. Paralelamente, desafios terão que ser enfrentados na esfera jurídica. Para além do Direito Ambiental, a temática transita pelo entendimento da política e administração públicas e contém outros desafios no campo jurídico, especialmente de natureza do Direito Financeiro. Adicionalmente, há de se incorporar o aprendizado advindo da promulgação e da implementação da Política Nacional de Recursos Hídricos e de seus instrumentos, que pode contribuir para a construção de soluções para a questão da compensação ambiental interfederativa.

Palavra-Chave: Recursos hídricos e compensação interfederativa; \# recursos hídricos e governança interfederativa. 


\section{INTRODUÇÃO}

Desde a publicação do Relatório Brundtland que o desenvolvimento encontra cenário favorável à implantação de um novo modelo - na medida e que passamos a traduzir o termo "desenvolvimento" nos termos de Ignacy Sachs, como "crescimento econômico sustentado, socialmente inclusivo e em harmonia com o meio ambiente ${ }^{1 "}$ (também objeto de estudo de Amartya Sen em sua tese, "Desenvolvimento como Liberdade $^{2 "}$ ). A expectativa é desenvolver um novo modelo de crescimento econômico, que acolha os limites e a sustentabilidade dos recursos naturais e seja produto do desenvolvimento local-regional.

Nesse sentido, o presente artigo busca reflexões sobre os desafios para implementar a Compensação Ambiental Interfederativa em nosso país, explicitando a necessidade de convencer a sociedade do potencial da natureza no fornecimento dos serviços essenciais para sua sobrevivência.

Esse potencial deve ser visto como uma oportunidade de desenvolvimento local e regional.

Para que se atinja esse objetivo, é mandatória a integração da biodiversidade e dos serviços ecossistêmicos no planejamento territorial, na gestão do uso do solo e dos recursos hídricos, no desenvolvimento econômico local e nos projetos de infraestrutura.

\section{CONTEXTO}

Diante da crise política e econômica que vive o Brasil, a sociedade não pode mais esperar medidas de grande impacto e aplicáveis a todo o território nacional, por parte do governo central. Cabe buscar propostas locais e oferecer caminhos adaptados à realidade de cada região, permitindo a atuação e a valorização dos municípios. Nesse compasso, parece viável e oportuna a elaboração de novas regras que viabilizem instrumentos de desenvolvimento endógenos, economicamente sustentáveis, ambientalmente equilibrados e socialmente justos. Isso significa um novo modelo de desenvolvimento territorial integrado, que impõe a descentralização de poder e de decisão. A assunção de poder pela comunidade local empoderará as pessoas, mudando a ideia de que o cidadão é um ser passivo à espera das benesses concedidas pelo Estado. 0 indivíduo deixa de ser coadjuvante e passa a ator principal de sua história.

Dentre os instrumentos de empoderamento local, há de se destacar o poder das redes sociais e, consequentemente, dos inúmeros aplicativos que dão concretude ao avanço de uma democracia mais participativa. Cada vez menos os cidadãos querem delegar poderes e permitir interferências em suas decisões. A crise da representação dos dias atuais retrata a ideia de que a concentração de poder está ultrapassada. 0 acesso a tecnologias e às alternativas de comunicação fornece ao cidadão instrumentos de controle, cobrança e, porque não, de decisão final e direta. Interessante mencionar, apenas como exemplo, a iniciativa dos Observatórios Sociais - organização civil que tem como missão "despertar o espírito de Cidadania Fiscal na sociedade organizada, tornando-a proativa, através do seu próprio Observatório Social, exercendo a vigilância social na sua comunidade" e que já está presente em 134 cidades de 16 Estados brasileiros.

Também nesse contexto se insere o instrumento da compensação ambiental e a possibilidade de a sociedade interferir na aplicação de recursos públicos, inclusive aqueles decorrentes da referida compensação. A doutrina vem adotando, em muitos casos a ideia de que a compensação ambiental decorre do conceito do poluidor-pagador. Não obstante, em uma análise mais abrangente do conceito de sustentabilidade, pode-se inferir que a compensação também possa ter uma faceta de remuneração pelo uso de recursos naturais, bem públicos.

Se a compensação está relacionada ao uso, à exploração ou exaustão de um bem público, nada resta senão reconhecer que essa receita pública, ainda que gerida por um poder constituído, pertence à sociedade, 0 que mais legitima sua participação decisória na aplicação desses recursos.

\footnotetext{
${ }^{1}$ Sachs, Ignacy - A Terceira Margem: em busca do desenvolvimento - Tradução Rosa Freire d’Aguiar - Companhia da Letras

2 Sem, Amartya Kumar -Desenvolvimento como liberdade / Amartya Sem; tradução Laura Teixeira Motta; revisão técnica Ricardo Doniselli Mendes - São Paulo: Companhia das Letras, 2000
} 


\section{DESAFIOS E CAMINHOS A TRILHAR}

Desde a Constituição de 1988, apenas para ficarmos em tempos republicanos mais recentes, que o país tem demonstrado dificuldades de enfrentar o desafio de uma governança complexa, decorrente de nosso federalismo singular em três níveis. Em que pese alguns avanços regulatórios (somos bons nisso) como o Estatuto da Metrópole, nunca houve de fato uma ação efetiva para o fortalecimento municipal. Ao contrário, parece haver um desprezo ao municipalismo, representado pela concentração de riquezas no ente federal, o que dificulta um pacto federativo verdadeiro e efetivo no país.

Portanto, oferecer elementos e alternativas para a regulamentação de mecanismos de compensação ambiental interfederativa, em certa medida, implicará em apontar tendências e caminhos para promover a governança descentralizada, mas coordenada. Como fazer isso e, ao mesmo tempo, respeitar a autonomia municipal, em um ambiente federativo histórico e político que não favorece, certamente não é uma tarefa trivial.

Essa regulamentação decerto implicará, pela interdependência conceitual e jurídica dos temas, na edição de leis complementares que instituam as regiões metropolitanas ou de aglomeração urbana. Resgata-se, aqui, o art. 5o (incisos III e IV) da Lei 13.089/15, que instituiu o Estatuto da Metrópole, notadamente no que se refere à "conformação da estrutura de governança interfederativa, incluindo a organização administrativa e o sistema integrado de alocação de recursos e de prestação de contas, e os meios de controle social da organização, do planejamento e da execução de funções públicas de interesse comum". Essa mesma Lei estabelece princípios e diretrizes para a governança interfederativa das regiões metropolitanas e das aglomerações urbanas, dentre eles: o compartilhamento de responsabilidades para a promoção do desenvolvimento urbano integrado, a autonomia dos entes da Federação e a busca do desenvolvimento sustentável (art. $6^{\text {O }}$ incisos II, III e VII); e a execução compartilhada das funções públicas de interesse comum, mediante rateio de custos previamente pactuado no âmbito da estrutura de governança interfederativa e a participação de representantes da sociedade civil nos processos de planejamento e de tomada de decisão, no acompanhamento da prestação de serviços e na realização de obras afetas às funções públicas de interesse comum (art. $7^{\circ}$ incisos IV e V).

Muito embora o mecanismo da compensação ambiental tenha sido incorporado à Lei 13.089/2015, ainda não se vê sua efetiva aplicação em um contexto de governança interfederativa das regiões metropolitanas e das aglomerações urbanas. Não que o instrumento não esteja sendo implementado. Mas há dificuldade em aplicá-lo em um contexto de integração interfederativa. Daí decorre a necessidade de eleger e concentrar trabalhos em campos específicos que tratem a problemática ambiental das cidades, tanto mais quando tais problemas extrapolam os limites de uma única unidade federativa, seja por suas características naturais ou econômicas, tais como: áreas de conservação de fauna e flora; áreas de nascentes, recargas e de proteção dos corpos de água; tratamento de efluentes e "geração ou reuso" de água; tratamento de resíduos.

Há desafios que terão que ser enfretados no campo jurídico, com especial evolução do Direito Financeiro e Administrativo. Isso porque deveremos tratar de "mecanismos de compensação" interfederativos como alternativas que forneçam recursos financeiros em condições especiais a entes públicos e eventualmente de entes públicos para entes privados. Cite-se, por exemplo, a necessidade de adoção de mecanismos regulatórios e contratuais para amparar contrapartidas públicas e dar efetividade a instrumentos como: (i) convênios e consórcios; (ii) Fundos Financeiros públicos, (iii) Green Bonds emitidos por entes públicos, (iv) financiamento subsidiado e/ou garantido pelo Tesouro Nacional; (v) aumento de participação de entes públicos na repartição da arrecadação de tributos. Vale também mencionar instrumentos relacionados ou derivados do Direito Ambiental, como a viabilização das unidades provedoras de reserva legal (áreas com reservas ou unidades privadas de conservação que poderiam ser "alugadas" por quem não quer cumprir, em sua propriedade, a área de reserva legal).

Como se vê, os desafios para a implementação da compensação em escala interfederativa são consideráveis. Pode-se identificar um "norte" a guiar a elaboração de regras que condicionem e delimitem a obrigação compensatória, definindo seu objeto, atribuindo-lhe um caráter compulsório e criando um vínculo entre credor e devedor. Mas também há de se criar e/ou identificar e aplicar normas ligadas à ocupação territorial e associadas a incentivos à conservação de recursos naturais.

Por fim, outro desafio digno de nota é a definição de métricas para valoração dos serviços ambientais, especialmente no que tange à definição de um valor financeiro para bens que não são regidos por leis de mercado, sobretudo ante a dificuldade de percepção imediata sobre os benefícios decorrentes desses serviços, considerados bens intangíveis. 
Uma vez que se está a tratar de recursos naturais, deve-se reconhecer a relevância da água como elemento propulsor da articulação entre municípios, estejam eles inseridos em uma mesma bacia hidrográfica ou não, notadamente no que concerne aos serviços de saneamento. Acreditamos que, na Política Nacional de Recursos Hídricos e seus instrumentos, podemos encontrar amparo para estudar e apresentar soluções para a temática da compensação ambiental interfederativa.

Essa abordagem encontra respaldo na Lei 9.433/1997 (que institui a Política Nacional de Recursos Hídricos e cria o Sistema Nacional de Gerenciamento de Recursos Hídricos). A lei reconhece, de forma expressa, que a água é um recurso finito, dotado de valor econômico e prevê a descentralização no processo de gestão. As diretrizes para a implementação da Lei 9.433/1997 reforçam os conceitos de integração e articulação, tanto do ponto de vista dos processos socioambientais, quanto políticos e institucionais. Vale citar, dentre tais diretrizes, a integração da gestão de recursos hídricos com a gestão ambiental, a articulação do planejamento de recursos hídricos com os planejamentos regional, estadual e nacional e a articulação da gestão de recursos hídricos com o uso do solo.

Dentre os instrumentos de gestão instituídos pela Lei 9.433/1997, incluem-se a cobrança pelo uso de recursos hídricos e a compensação a municípios - instrumentos indicativos do valor econômico da água. Entretanto, após 20 anos da promulgação da Política Nacional de Recursos Hídricos, ainda há dificuldades relevantes de gestão, especialmente decorrentes das tentativas de concentração da gestão (em autarquias federais e estaduais), inadequação da figura jurídica da Agência de Água e entidades delegatárias, insegurança jurídica na gestão dos recurso financeiro públicos, o que limita os resultados alcançados.

O instrumento da compensação a municípios teve sua regulação vetada quando da edição da Lei 9.433/1997. O veto busca fundamento na falta de previsão constitucional, bem como na necessidade de alocar recursos da União para esta finalidade. Nada mais improcedente. Tanto mais quando se reconhece que os recursos hídricos são bens da sociedade, não da União, e que, portanto, pode o Congresso Nacional, como representante dessa sociedade, deliberar como se distribui os recursos derivados de seu uso. Portanto, identifica-se uma oportunidade de reexaminar esse tema e dar realidade a esse instrumento, por meio de normativo capaz de explicitar o conceito da compensação aos municípios, sem ferir ou superpor normas existentes e tendo como base o aprendizado acumulado com outros instrumentos econômicos de gestão ambiental e de recursos hídricos.

Para que isso seja possível, deve-se reconhecer a importância do engajamento das cidades e da sociedade na gestão integrada dos recursos naturais, uma vez que estes possuem a responsabilidade constitucional sobre o ordenamento territorial.

Por fim, atuar nessa seara, reforça a implementação da Agenda 2030, contribuindo com os esforços globais para a erradicação da pobreza, na busca da resiliência e do desenvolvimento sustentável.

\section{CONCLUSÕES}

Ainda não se observa a aplicação da compensação ambiental em um contexto de governança interfederativa, a despeito sua incorporação no Estatuto da Metrópole. Nesse sentido, os desafios e os caminhos para solucionar a implementação da compensação ambiental interfederativa no Brasil, debatidos no presente artigo, passam pela concepção e estruturação de instrumentos de fomento a processos de desenvolvimento endógenos, por meio do estímulo à melhoria da proteção e conservação ambiental, voltados para o fortalecimento municipal.

Para tanto, é imperativa a concentração de esforços em temas centrais que representem a problemática ambiental das cidades, sobretudo quando tais problemas extrapolam os limites de uma única unidade federativa. Além disso, apresentam-se os desafios na esfera jurídica, que perpassam o Direito Ambiental e se agregam à necessidade de entendimento da política e administração públicas, além do Direito Financeiro.

Adicionalmente, agregando uma visão diferenciada à abordagem do tema da compensação ambiental interfederativa, foi proposta a incorporação do aprendizado advindo da promulgação e da implementação da Política Nacional de Recursos Hídricos e de seus instrumentos, dada a relevância da água como elemento propulsor da articulação entre municípios, estejam eles inseridos em uma mesma bacia hidrográfica ou não. 


\section{REFERÊNCIAS}

[1] Da Costa, Fracisco José Lobato - Conceitos e Procedimentos Metodológicos para uma Efetiva Gestão Integrada dos Recursos Hídricos - Volume: 1, Edição: 1a, Editora: ABRH

[2] Gestão na Região Metropolitana de Belo Horizonte : http://www.rmbh.org.br/rmbh.php

[3] INTERACTBio - Ação Integrada pela Biodiversidade https://issuu.com/icleisams/docs/interactbio-brochura-br

[4] Makower, Joel - A economia verde: descubra as oportunidades e desafios de uma nova era dos negócios / Joel Makower; tradução Célio Knipel Moreira; revisão técnica Leonardo Abramowicz - Saõ Paulo: Editora Gente, 2009

[5] Milaré. Édis. Direito do Ambiente: a Gestão Ambiental em Foco. 6aㅗ ed. São Paulo: Revista dos Tribunais, 2009, p.829.

[6] Observatório Social do Brasil - http://osbrasil.org.br/tag/site/

[7] Sem, Amartya Kumar - Desenvolvimento como liberdade / Amartya Sem; tradução Laura Teixeira Motta; revisão técnica Ricardo Doniselli Mendes - São Paulo: Companhia das Letras, 2000

[8] Sachs, Ignacy - A Terceira Margem: em busca do desenvolvimento - Tradução Rosa Freire d'Aguiar - Companhia da Letras -2009

[9] Termo de Cooperação Técnica entre o ICLEI- Brasil, o município de Campinas, por intermédio da Secretaria Municipal do Verde, Meio Ambiente e Desenvolvimento Sustentável http://campinas.sp.gov.br/arquivos/meio-ambiente/rmc-coop-interact.pdf

[10] Um novo paradigma da sustentabilidade: Teoria e práxis da Gestão Integrada do Território / Inguelore Scheunemann e Luiz Oosterbeeck (orgs) - Rio de Janeiro: IBIO. 2012 


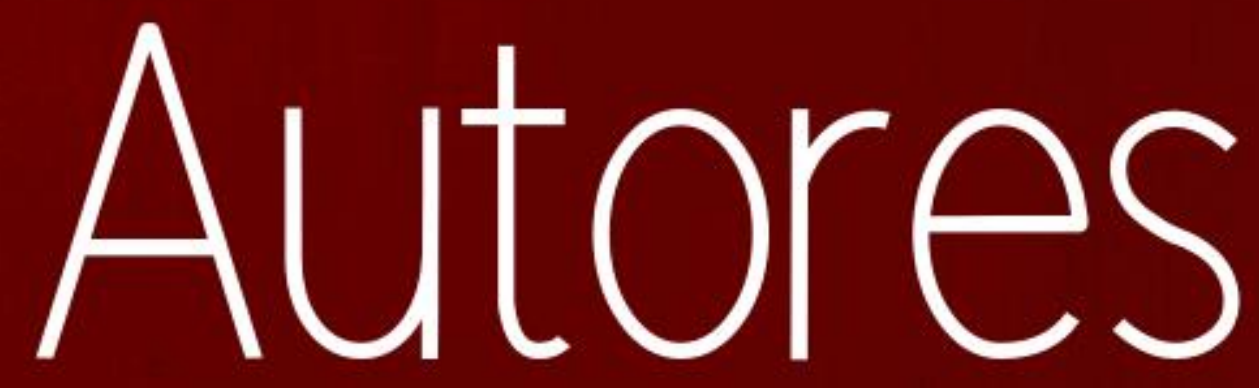




\section{JOSÉ HENRIQUE PORTO SILVEIRA (ORGANIZADOR)}

Bacharel e licenciado em Psicologia pela UFMG, Especialização em Percepção e Planejamento Urbano. Mestre em Gestão e Auditoria Ambiental, especialização em educação ambiental. Consultor em percepção e educação ambiental. Sócio diretor da Alternativa Educação e Manejo Ambiental.

\section{ABELARDO ANTÔNIO DE ASSUNÇÃO MONTENEGRO}

Possui graduação em Engenharia Civil pela Universidade Federal de Pernambuco (1985), mestrado em Hidráulica e Saneamento pela Universidade de São Paulo, São Carlos (1989) e doutorado em Water Resources - University of Newcastle Upon Tyne (1997). Tem pós-doutorado em modelagem hidrológica pelo Centre for Ecology and Hydrology de Wallingford, Inglaterra (2008). É professor titular da Universidade Federal Rural de Pernambuco, e membro permanente do Programa de PósGraduação em Engenharia Agrícola da UFRPE. Atua principalmente nos seguintes temas: semiárido, manejo de bacias hidrográficas, hidrologia experimental e numérica, hidráulica, dinâmica de umidade do solo, serviços ambientais, saneamento e reúso de águas de qualidade inferior na agricultura, dessalinizadores e aproveitamento integrado de concentrados, conservação de água e solo, geoestatística, qualidade de água, salinidade, recarga em aluviões e agricultura familiar.

\section{ADRIANA PEREIRA DO NASCIMENTO}

Licenciatura em química pela Universidade Federal do Ceará - UFC. Especialista em Gestão Ambiental Urbana pelo Centro Federal de Educação Tecnológica do Ceará -CEFET. Mestre em Ciências Marinhas Tropicais pela Universidade Federal do Ceará - UFC. Experiência na área de Química, com ênfase em Química Analítica, Química Ambiental atuando principalmente nas seguintes áreas: poluição urbana, qualidade de água e sedimento. Professor Auxiliar, Centro de Ciências Tecnológicas, Universidade de Fortaleza - UNIFOR.

\section{ADRIANO AUGUSTO DE MIRANDA}

Engenheiro Civil, professor na PUCPR e mestre em Recursos Hídricos e Ambiental.

\section{ALAN CAVALCANTI DA CUNHA}

Graduado em Engenharia Química, mestre em Engenharia Hidráulica e Saneamento e doutor em Engenharia Civil - Hidráulica e Saneamento. Atualmente é Professor Associado III do Curso de Engenharia Civil da Universidade Federal do Amapá, professor permanente dos Programas de PósGraduação em Biodiversidade Tropical (PPGBio - UNIFAP/IEPA/EMBRAPA-AP/CI) e Programa de Pós-Graduação em Ciências Ambientais (PPGCA). Atua nas áreas de Ciências Ambientais: Água e Energia, Modelagem de Sistemas Ambientais, Hidráulica e Saneamento, Fenômenos de Transporte, Clima e Recursos Hídricos, Limnologia, Estatística Aplicada à Ecologia.

\section{ALBERTO LUIZ FRANCATO}

Engenheiro Civil pela EESC/USP, Mestre e Doutor em Engenharia Civil na área de Recursos Hídricos pela FEC/UNICAMP, Livre Docente na área de Planejamento Energético e Sistemas Elétricos pela FEC-UNICAMP. É Professor da FEC/UNICAMP, atua no Programa de Pós-Graduação, pesquisador a 25 anos na área de Recursos Hídricos e Energéticos. Atualmente é diretor da FEC/UNICAMP.

\section{ALINE MARIA SOARES DAS CHAGAS}

Estudante de graduação em Engenharia Agrícola e Ambiental na Universidade Federal Rural de Pernambuco, monitora na disciplina de hidráulica aplicada e iniciação cientifica na área de hidrologia aplicada; recursos hídricos, hidrologia; análises temporais; e geoprocessamento no Laboratório de Água e solo - UFRPE. 


\section{ANA JÚLIA LOGRADO DA CONCEIÇÃO}

Acadêmica de Engenharia Agronômica pela Universidade Estadual da Região Tocantina do Maranhão - UEMASUL. Pesquisadora do grupo de pesquisa Agrociências da UEMASUL. Técnica em Agronegócio pelo SENAR - Campus Imperatriz/MA.

\section{ANTONNIO CELSO DANTAS ANTONINO}

Engenheiro Civil pela Universidade Federal de Pernambuco - UFPE, mestre em Tecnologias Energéticas e Nucleares pela UFPE e doutor em Física do Solo pela Universidade Joseph Fourier Grenoble I (França). Atualmente é professor titular da UFPE. Pós-doutorado no LTHE-INPG (França). Professor visitante (estagio sênior de pesquisa) no Departamento de Ciências dos Recursos Terrestres da Universidade de Guelph, Canadá no período de 4/11/2009 a 28/01/2010. Professor visitante (estagio sênior de pesquisa) no Departamento de Engenharia Civil e Ambiental da Pratt School of Engineering da Universidade de Duke, Carolina do Norte, EUA no período de 01/02 a 31/05/2012. Programa Ciências sem Fronteiras.Experiência na área de Física do Solo e de Recursos Hídricos.

\section{ARIELA ROCHA CAVALCANTI}

Engenheira Civil graduada pela Universidade Católica de Pernambuco (UNICAP). Durante a graduação tive a oportunidade de desenvolver projetos de pesquisa mediante a participação nos programas de iniciação científica e tecnológica, monitoria na disciplina de Mecânica dos Solos, além dos estágios em empresas privadas. Atualmente sou aluna do Mestrado Acadêmico em Engenharia Civil da Escola Politécnica da Universidade de Pernambuco (POLI/UPE). Durante o mestrado participei de projetos de extensão acadêmica e estágio docência na disciplina de Cálculo III.

\section{CAMILLA BARRÊTTO RIQUE DE BARROS}

Mestranda em Engenharia Civil na Universidade de Pernambuco - UPE. Especialização em inspeção, manutenção e recuperação estrutural pela Universidade de Pernambuco - UPE. Graduação em engenharia Civil na Universidade Católica de Pernambuco, UNICAP, Brasil. Interesse na área de Engenharia Civil, com ênfase em linhas de pesquisa de Materiais da Construção Civil (estudo e elaboração de materiais buscando o desenvolvimento auto sustentável no ambiente construtivo) e drenagem urbana (uso de técnicas compensatórias de drenagem urbana). Participante do Grupo de Pesquisa Construção Civil e Análise Estrutural/UNICAP-PE. Bolsista de iniciação cientifica/UNICAP 2015 a 2017.

\section{CAROLINA OLIVEIRA SOUZA}

Possui graduação em Engenharia Ambiental e Sanitária pela Universidade Federal de Sergipe (2017), mestrado em Engenharia e Ciências Ambientais pela Universidade Federal de Sergipe (2020). Obteve experiência em Engenharia Ambiental e Sanitária, tendo atuado em projeto de aproveitamento e suprimento de recursos energéticos.

\section{CRISTIANE MATOS DA SILVA}

Possui graduação em Agronomia pela Universidade Federal Rural do Rio de Janeiro (2005), Especialização em Ciências Biológicas pela Universidade Estadual do Maranhão (UEMA/CESI), (2011), Mestra em Engenharia de Barragem e Gestão Ambiental (NDAE/UFPA), (2019), Doutoranda em Ciência e Tecnologia Ambiental (UNIVALI) Tem experiência na área de Engenharia Agrícola e Agronomia, com ênfase em Hidráulica, Irrigação, Drenagem, Paisagismo, Parques, Jardins e gestão ambiental. Atualmente exerce o cargo de Professora Assistente, no Centro de Ciências Agrárias - Campus Imperatriz, no curso de Engenharia Florestal sendo responsável pela área de HIDRÁULICA E HIDROLOGIA FLORESTAL. 


\section{DANIELE SUZANE DA SILVA PINTO TELES}

Possui graduação em Geologia Bacharelado e Mestrado em Engenharia e Ciências Ambientais pela Universidade Federal de Sergipe e graduação em Engenharia Ambiental pela Universidade Tiradentes. Atualmente atua como consultora técnica, com ênfase na área de gestão de resíduos sólidos.

\section{DERICK MARTINS BORGES DE MOURA}

Doutorando em Geografia pela UFG/Goiânia

\section{DIANI FERNANDA DA SILVA LESS}

Graduada em Engenharia Ambiental, Mestre emEngenharia Química e Doutora em Biodiversidade e Biotecnologia. Atualmente é Professora Adjunta do Instituto de Ciências e Tecnologia das AÁguas (ICTA) da Universidade Federal do Oeste do Pará (UFOPA). Atua nas áreas de Hidrodinâmica e Biogeoquímica de Sistemas Fluviais e Saneamento.

\section{DIOGO BOTELHO CORREA DE OLIVEIRA}

Possui Mestrado em Engenharia Civil (UPE) e graduação em Engenharia Civil (UPE). Pós Graduado em Engenharia de Segurança do Trabalho (UCAM) e em Engenharia Sanitária e Ambiental (Unyleya). Foi Cadete da Academia Militar das Agulhas Negras. Atuou em obras MCMV na área de infraestrutura (drenagem, abastecimento, esgotamento, subestações, pavimentação, terraplenagem) e em programas de implantação e operação de SES. É Gerente Operacional no Grupo Alves da Cunha, responsável pela manutenção e CV de redes de esgoto na RMR. Possui experiência nas áreas de infraestrutura e saneamento. Desenvolveu pesquisas e trabalhos acadêmicos nos seguintes temas: Saneamento Ambiental, tratamento de efluentes, modelagem, matemática aplicada, infiltração de água no solo, drenagem urbana e condutividades térmica e hidráulica do solo.

\section{EBENÉZER DE FRANÇA SANTOS}

Doutor em Tecnologias Energéticas e Nucleares pela Universidade Federal de Pernambuco (UFPE), Mestre em Tecnologia Ambiental pelo Instituto de Tecnologia de Pernambuco, Higienista Ocupacional pela Faculdade de Ciências Médicas de Minas Gerais, certificado pela Associação Brasileira de Higienistas Ocupacionais (HOC 0084), Ergonomista pela UFPE, membro da Associação Brasileira de Ergonomia, Engenheiro de Segurança do Trabalho pela Escola Politécnica da Universidade de Pernambuco (POLI/UPE), Tecnólogo em Sistema de Gestão Ambiental pelo Instituto Federal de Educação, Ciência e Tecnologia de Pernambuco (IFPE) e Engenheiro Civil pela POLI/UPE. Professor do Ensino Básico, Técnico e Tecnológico do IFPE/Campus Recife.

\section{FERNANDO JOSÉ ARAÚJO DA SILVA}

Engenheiro Civil pela Universidade de Fortaleza. Mestre em Engenharia pela Universidade Federal da Paraíba. Doutor em Engenharia Civil pela Universidade Federal do Ceará. Experiência na área de Engenharia Sanitária e Ambiental, com ênfase em Tecnologias de Tratamento de Águas Residuárias, Planejamento e Controle da Qualidade da Ambiental. Prof. Adjunto, Engenharia Civil, UFC/Fortaleza

\section{GABRIEL RODRIGUES BARRETO}

Graduando em Engenharia Civil pela PUCPR.

\section{GEOVANA ALIEVI}

Aluna do Curso de Graduação em Engenharia Ambiental, IF Goiano - Campus Rio Verde 


\section{GILCENARA DE OLIVEIRA}

Engenharia Química pela Universidade de Caxias do Sul, mestrado em Engenharia de Alimentos pela Universidade Estadual de Campinas e doutorado em Biotecnologia pelo RENORBIO. Atualmente é professor auxiliar da Universidade de Fortaleza - UNIFOR. Desenvolve pesquisa na área de biotecnologia e atividades na área de meio ambiente, energia e alimentos, atuando principalmente nos seguintes temas: processos, purificação, poluição urbana, qualidade da água, produção de energia a partir de resíduos agroindustriais, projetos sustentáveis.

\section{GUILHERME DOS SANTOS TELES}

Possui graduação em Geologia Bacharelado pela Universidade Federal de Sergipe, Mestrado e Doutorado em Geologia pela Universidade de Brasília. Atualmente é professor adjunto do curso de Engenharia de Minas da Universidade Federal de Campina Grande.

\section{HELOÍSA THAÍS RODRIGUES DE SOUZA}

Pós Doutora, Doutora e Mestre em Desenvolvimento e Meio Ambiente - PRODEMA pela Universidade Federal de Sergipe - UFS. Engenheira Florestal pela Universidade Federal de Sergipe UFS, Bolsista do DAAD - Serviço Alemão de Intercâmbio Acadêmico (2009/2011), pesquisadora desde o ano de 2005 do GEOPLAN - Grupo de Pesquisa em Geoecologia e Planejamento Territorial (UFS/CNPq) pela Universidade Federal de Sergipe.

\section{HELTON ROGERIO MAZZER}

Doutorado em Agronomia (Irrigacao e Drenagem) pela Universidade Estadual Paulista Júlio de Mesquita Filho, Brasil(2006) Pesquisador da Universidade Estadual de Maringá , Brasil

\section{HEVRLI DA SILVA CARNEIRO PILATTI}

Mestranda em Engenharia Aplicada e Sustentabilidade, IFGoiano - Campus Rio Verde

\section{INGRID MORENO MAMEDES}

Graduada em Engenharia Sanitária e Ambiental pela Universidade Federal de Mato Grosso, Especialista em Perícia e Auditoria Ambiental pela UNINTER, Mestre em Tecnologias Ambientais pela Universidade Federal de Mato Grosso do Sul e Doutoranda em Tecnologias Ambientais pela Universidade Federal de Mato Grosso do Sul.

\section{JOÃO PEDRO GOMES DOS SANTOS}

Graduando em Engenharia Ambiental na Universidade Federal de São Carlos campus Lagoa do Sino.

\section{JOEDLA RODRIGUES DE LIMA}

Professora Titular da Unidade Acadêmica de Engenharia Florestal, Universidade Federal de Campina Grande. Graduada em Engenharia Agrícola pela Universidade Federal da Paraíba (1991); mestrado em Engenharia Agrícola pela Universidade Federal da Paraíba (1995); doutorado em Planejamento de Sistemas Energéticos pela Universidade Estadual de Campinas (2004) e PósDoutorado em Geografia e Meio Ambiente na Universidade Federal do Paraná (2014). Desenvolvo pesquisas e atividades de extensão com foco na agricultura familiar no contexto do realidade semiárido e também em "sociedade, recursos naturais e sustentabilidade". 


\section{JORGE LUIS RODRIGUES PANTOJA FILHO}

Graduou-se em Engenharia Sanitária e Ambiental pela Universidade Federal do Pará (UFPA) (2005). Obteve os títulos de Mestre (2008) e Doutor (2011) em Engenharia (Hidráulica e Saneamento) pela Escola de Engenharia de São Carlos da Universidade de São Paulo (USP). Durante o doutorado realizou breve intercâmbio, financiado pelo Banco Santander, no Massachusetts Institute of Technology (MIT), na Northeastern University e na Brown University. Realizou o Pós-Doutoramento no Instituto Tecnológico de Aeronáutica (ITA) na Divisão de Engenharia Civil (DEC-ITA). Cursando o Micromaster em Statistics and Data Science pelo Massachusetts Institute of Technology (MIT). . Atua como professor substituto na Universidade Federal de São Carlos (UFSCar) desde Abril/2018 até o corrente mês.

\section{JÚNIOR HIROYUKI ISHIHARA}

Possui graduação em Engenharia Sanitária pela Universidade Federal do Pará (2008), mestrado em Engenharia Civil na área de Recursos Hídricos e Saneamento Ambiental pelo PPGEC/UFPA (2010), Doutorado em Ciências na área de Desenvolvimento Socioambiental pelo NAEA/UFPA (2015). Possui experiência na área de Engenharia Sanitária, com ênfase em Saneamento Ambiental, sustentabilidade dos materiais e Recursos Hídricos. Atualmente é professor efetivo da Universidade Federal do Pará no Campus de Tucuruí, Diretor Adjunto do Núcleo de Desenvolvimento Amazônico em Engenharia - NDAE. Coordenador do Programa de Pós-Graduação em Engenharia de Infraestrutura e Desenvolvimento Energético - PPGINDE e docente permanente do Programa de Pós Graduação em Engenharia de Barragens e Gestão Ambiental - PEBGA.

\section{LAYSSA DE MOURA OLIVEIRA}

Graduando em Engenharia Ambiental na Universidade Federal de São Carlos campus Lagoa do Sino.

\section{LETÍCIA BORSATO ROSSI}

Graduando em Engenharia Ambiental na Universidade Federal de São Carlos campus Lagoa do Sino.

\section{LETÍCIA SORIANO}

Engenheira Civil graduada pela Pontifícia Universidade Católica de Campinas (2018). Premiada com Honra ao mérito pelo Instituto de Engenharia (2019) e nomeada para o prêmio de Melhores Alunos de 2018 do CREA-SP (2019). Atualmente é mestranda da área de Recursos Hídricos, Energéticos e Ambientais da instituição de Universidade Estadual de Campinas tendo enfoque no uso de artifícios de inteligência artificial e otimização na obtenção da eficiência energética e hídrica.

\section{LUÍS GUSTAVO GOMES DIÓGENES}

Engenheiro Ambiental e Sanitarista pela Universidade de Fortaleza - UNIFOR, pós-graduando em planejamento e gestão ambiental na cadeia produtiva pela Universidade de Fortaleza - UNIFOR. Especialista em processos de análises físico-químicas e microbiológicos em águas e efluentes. Experiência em obras da construção civil no quesito ambiental, elaboração de licitações na área de esgotamento sanitário, bem como experiência em estações de tratamento de água e efluentes, e na elaboração de Planos de resíduos sólidos.

\section{MANUELLA VIRGÍNIA SALGUEIRO GONDIM}

Bacharel em Ciências Biológicas pela Universidade Federal de Pernambuco (2006), Mestre em Tecnologias Energéticas Nucleares pela Universidade Federal de Pernambuco (2009), com ênfase em Física do solo. Doutora em engenharia civil em ênfase em Tecnologia Ambiental e Recursos Hídricos em regime de cotutela com a Universidade de Grenoble, França. Atualmente está bolsista 
de de PNPD (Programa Nacional de Pós-Doutorado) com início em 2017 e térmico previsto para 2022.

\section{MARCIO SILVA PEREIRA}

Advogado, é sócio da área Ambiental do BMA. Foi coordenador da área jurídica ambiental corporativa da Vale S.A.. Foi docente de Direito Ambiental e de Tutela Processual do Ambiente. Possui pós-graduação em Gestão Ambiental pela Universidade de São Paulo - USP (1999) e graduação em Direito, com especialização em Interesses Difusos pela Pontifícia Universidade Católica de São Paulo - PUC-SP (1997)Reconhecido como expert em Direito Ambiental pelo Chambers Latin America, Latin Lawyer 250, The Legal 500, Expert Guides e Análise Advocacia 500. É membro da Comissão de Meio Ambiente da OAB-RJ; e da União Brasileira de Advogados Ambientalistas - UBAA.

\section{MARCO AURÉLIO CALIXTO RIBEIRO DE HOLANDA}

Mestrando em Engenharia Civil na Escola Politécnica de Pernambuco - UPE. Formado em Engenharia Elétrica de Telecomunicações pela Universidade de Pernambuco - UPE. Bolsista de iniciação científica da Universidade de Pernambuco de 2014 a 2017. Tem experiência na área de Engenharia Elétrica de Telecomunicações, atuando principalmente nos seguintes temas: transformada de Wavelet e modulação digital, e na área de Engenharia Civil, com ênfase em solos, transferência e calor e drenagem urbana. Participou do intercâmbio na Faculdade de Engenharia da Universidade do Porto - FEUP, através do programa Santander Universidades em 2017.

\section{MARIA ANTONIA BALBINO PEREIRA}

Aluna do Curso de Graduação em Engenharia Ambiental, IF Goiano - Campus Rio Verde

\section{MARIA DE FÁTIMA CHAGAS DIAS COELHO -}

Graduação em engenharia civil, pela Universidade Federal de Minas Gerais, pós-graduação em engenharia de barragens pela Universidade Federal de Ouro Preto (1989). Experiência em políticas públicas de recursos hídricos e de meio ambiente, planejamento e gestão de recursos hídricos, hidrologia e sustentabilidade ambiental, áreas nas quais atua atualmente como consultora. Ocupou cargos e funções em instituições públicas e privadas, relacionados às temáticas dos recursos hídricos e do meio ambiente. Membro do Conselho de Administração da GASMIG (de 2015 a 04/2018), Diretora Geral do Instituto Mineiro de Gestão das Águas (de 2015 a 10/2017), ExSecretária Adjunta de Meio Ambiente e Desenvolvimento Sustentável de Minas Gerais (2002), Diretora da Secretaria Nacional de Recursos Hídricos e Gerente Executiva na Agência Nacional de Águas. Atuação por três anos como Gerente Geral Corporativa de Tecnologias Ambientais da Vale S.A., nos seguintes temas: resíduos, áreas contaminadas, recursos hídricos, emissões atmosféricas, mudanças climáticas, ruído, vibração, barragens e pilhas; relatório de sustentabilidade e os trabalhos de participação da Companhia no ISE/Bovespa. Vasta experiência como consultora e habilidade na coordenação de equipes multidisciplinares. Ministrou aulas, proferiu palestras e possui diversos trabalhos publicados, além da atuação como ex-Pesquisadora na área de recursos hídricos do CETEC

\section{MARIA JULIA DEGLI ESPOSTI BERGAMASCO}

Mestranda no Programa de Pós- Graduação em Engenharia Hidráulica e Saneamento (SHS - USP). Graduada em Engenharia Ambiental (2020) pela Universidade Federal de São Carlos - UFSCar Campus Lagoa do Sino, Buri. Formação nível técnico em Edificações, pelo COTIL-UNICAMP, 2014. Formação nível médio pelo Claretiano Colégio - Rio Claro, 2014. Diretora Financeira (2016) e Diretora Geral (2018) do Centro Acadêmico de Engenharia Ambiental. Gerente Jurídica da LS Consultoria Jr. (2017). Co-autora da publicação em forma de livro intitulada "Hidráulica de Canais: Guia Prático para profissionais de Engenharia", a qual se encontra em fase de produção para publicação em um futuro próximo. 


\section{NIVALDA DA COSTA NUNES}

Doutoranda em Física Ambiental, UFMT - Campus Cuiabá

\section{PATRICIA HELENA GAMBOGI BOSON}

Engenheira civil, pelo IPUC/MG com especialização em administração pela Fundação Dom Cabral. Larga experiência em planejamento e gestão ambiental e de recursos hídricos e na formulação de políticas públicas e institucionais na área de ciência e tecnologia, meio ambiente e hidrologia. Ocupou vários cargos de direção nas esferas públicos e privadas, incluindo Secretaria Adjunta de Ciência e Tecnologia do Estado de Minas Gerais e Secretaria Executiva do Conselho de Empresários para o Meio Ambiente, da Federação da Indústria do Estado de Minas Gerais (2000 a 2018) e do Conselho de Infraestrutura na mesma Federação (2014 a 2018), e ainda, assessoria especial do Conselho de Assuntos Metropolitanos e Municipais também da FIEMG (2014 a 2018). Membro do Conselho Nacional de Recursos Hídricos e do Conselho Nacional de Meio Ambiente no período de 2000 a 2018. Autora de livros e vários artigos técnicos. Exerce ainda as funções de consultora na área de gestão ambiental e de recursos hídricos, como diretora da empresa Conciliare Consultoria Socioambiental. Foi uma das idealizadoras e atua como consultora do Programa Ambiental do Transporte da Confederação Nacional de Transporte - CNT, Despoluir. Idealizadora e sócio proprietária do Ecoguia Sustentável, a primeira plataforma digital brasileira para gestão de fornecedores facilitando as compras corporativas sustentáveis

\section{PAULA CRISTINA DE SOUZA}

Possui graduação em Engenharia Civil pela Universidade Estadual de Maringá(1999), mestrado em Engenharia Agrícola pela Universidade Estadual do Oeste do Paraná(2006) e doutorado em Engenharia Química pela Universidade Estadual de Maringá(2016). Atualmente é professor da Universidade Tecnológica Federal do Paraná. Tem experiência na área de Engenharia Civil. Atuando principalmente nos seguintes temas: recursos hídricos; eletrocoagulação, coagulação/floculação, integração de processos, efluente têxtil.

\section{PAULA LOUREIRO PAULO}

Graduada em Engenharia Química pela Universidade Estadual de Maringá, Doutora em Ciências Ambientais pela Wageningen University And Research Centrum, WUR, Holanda e Professora associada da Universidade Federal de Mato Grosso do Sul, Campo Grande-MS.

\section{PAULO HENRIQUE RODRIGUES}

Engenheiro Civil formado pela Universidade Tecnológica Federal do Paraná. Mestrando em Eng. Química pela universidade Estadual de Maringá. Eng. Civil na prefeitura Municipal de Campina da Lagoa-Pr. Projetista na Construtora e Imobiliária Pronenge. Coordenador dos Cursos de Engenharia Civil, Produção, Elétrica e Mecânica do Centro Universitário Integrado

\section{ROSA MÁRCIA ARAÚJO DE OLIVEIRA}

Engenheira ambiental pela Universidade de Fortaleza - UNIFOR. Tem experiência na área de Engenharia Ambiental e Sanitária, com ênfase em Qualidade da água.

\section{ROSIVÂNIA JERÔNIMO DE LUCENA}

Graduada em Engenharia Florestal (2012), Mestre em Ciências Florestais (2019) pela Universidade Federal de Campina Grande. Tem experiência na área de agricultura familiar e melhoramento florestal , atuando principalmente nos seguintes temas: agroecologia, semiárido. 


\section{SILVIA G. SORENSEN TIRADENTES}

Graduada em Engenharia Química pela Universidade Federal de São Carlos e Mestre em Tecnologias Ambientais pela Universidade Federal do Mato Grosso do Sul, Campo Grande-MS.

\section{SOANNE HEMYLLE DE JESUS SANTOS}

Possui graduação em Tecnologia em Saneamento Ambiental pelo Instituto Federal de Sergipe, atualmente é mestranda do programa de pós-graduação em Engenharia e Ciências Ambientais da Universidade Federal de Sergipe. Pesquisadora nas áreas de análise e monitoramento de águas e efluentes, gestão sustentável, tecnologias ambientais, logística reversa, resíduos sólidos e educação ambiental.

\section{TÁCITO RIBEIRO DE MATOS}

Graduado em Direito pela Faculdade de Ciências Jurídicas da UFRJ. Atividade acadêmica como professor convidado para a cátedra de Planejamento Fiscal na Faculdade de Contabilidade da UFRJ - 4 anos e 6 meses. Professor convidado para cursos de pós-graduação no IBMEC, FGV, Universidade Cândido Mandes, Instituto Brasileiro de Petróleo e Escola Superior de Advocacia. Há mais de 25 anos, desenvolvendo atividades de assessoria e contencioso relacionados ao Direito empresarial, atendendo clientes locais e internacionais, com especial foco no Direito Tributário e Administrativo. Participamos de diversos projetos de infraestrutura (saneamento e recursos hídricos, energia elétrica e renováveis, portos e aeroportos, rodovias e mobilidade urbana, petróleo, gás natural e biogás, transporte urbano e interurbano de cargas e passageiros, telecomunicações e TI). Trabalhou na empresa de auditoria PricewaterhouseCoopers (7 anos), no startup da Intelig Telecomunicações (3 anos) e em outros três renomados escritórios brasileiros: Machado Meyer Advogados, Schmidt Valois Advogados, Kfuri Advogados e LO Baptista Advogados.

\section{TERESINHA BATISTA DA SILVA}

Cursando o $7^{\circ}$ período do curso de Engenharia Civil pela Universidade de Pernambuco. Foi monitora das disciplinas de Cálculo I e Cálculo II pela UPE-POLI, onde administrava aulas resolvendo exercícios e esclarecendo dúvidas. Bolsista de iniciação científica PIBIC-FACEPE no ano de 2020, atuando em pesquisa na área de Engenharia Civil com ênfase em recursos hídricos.

\section{THAYNÁ ALICE BRITO ALMEIDA}

Engenheira Agrícola e ambiental pela Universidade Federal Rural de Pernambuco (2018), mestre em Engenharia agrícola (2020) e, atualmente, doutoranda em Engenharia Agrícola pelo programa de Pós graduação de Engenharia Agrícola da UFRPE (PGEA/UFRPE). Foi bolsista do Projeto Especial Jovens Talentos da Ciência CAPES/CNPq, atuando em projetos de pesquisa e extensão na Região semiárida de Pernambuco. É pesquisadora do Laboratório de Água e Solo da UFRPE. Possui experiências nas áreas de recursos hídricos, hidrologia; qualidade da água; análises temporais; geoprocessamento; manejo e conservação de água e solo; salinidade e análises físico-químicas da água e solo.

\section{VALMIR FELIX DE LIMA}

Doutor em Engenharia Química pela Universidade Federal de Pernambuco (UFPE) 2015, Mestre em Engenharia Química (UFPE) 2010. Possui graduação em Química Industrial pela Universidade Federal de Pernambuco (1978), graduação em Engenharia Mecânica pela Universidade de Pernambuco (1982), Especialização em Engenharia de Segurança do Trabalho pela UPE (2002). Exerce, desde 1978, funções técnicas/administrativas em vários ramos de atividades produtiva e com larga experiência em manutenção e produção, desde fabrica de alimentos a plataforma de Petróleo e gás e vendas técnicas, de produtos químicos, em diversos ramos de atividades fabris. 


\section{VICTOR AUGUSTO MENEGON}

Possui graduação em Engenharia Civil pela Universidade Tecnológica Federal do Paraná (2018). Experiência como professor de inglês da Escola Evolução. Experiência na área de Engenharia Civil, com ênfase em pavimentação e gestão de obras. Pós-graduado em Gestão e Educação Ambiental.

\section{VICTOR DE BARROS DEANTONI}

Engenheiro Civil graduado pela Universidade Estadual de Campinas (2012). Mestrado e Doutorado na área de Recursos Hídricos e Energéticos pela Universidade Estadual de Campinas (2013 e 2018). Atualmente é professor dos cursos de Engenharia Civil e Arquitetura na PUC Campinas e Diretor da Faculdade de Engenharia Civil da PUC Campinas.

\section{VINICIUS MOURA COSTA}

Graduando em Engenharia Ambiental na Universidade Federal de São Carlos campus Lagoa do Sino. Possuo pesquisas também na área de geotecnologias.

\section{WELLMO DOS SANTOS ALVES}

Professor e pesquisador no Programa de Pós-Graduação em Geografia da UFJ

\section{WILLAMES DE ALBUQUERQUE SOARES}

Concluiu o doutorado em Tecnologias Energéticas Nucleares pela UFPE, na área de Física dos Solos. É formado em Licenciatura plena em Matemática pela UFRPE. Atualmente é professor adjunto da Universidade de Pernambuco, em atividade na Escola Politécnica de Pernambuco POLI. Publicou diversos artigos em periódicos especializados e em anais de eventos. Recebeu 7 prêmios e/ou homenagens. Atua na área de Matemática Aplicada e computacional, com ênfase no meio ambiente. Em seu currículo Lattes os termos mais freqüentes na contextualização da produção científica, tecnológica e artístico-cultural são: Caracterização térmica e Hidrodinâmica de solos, fluxo de calor no solo, evapotranspiração e método inverso. 


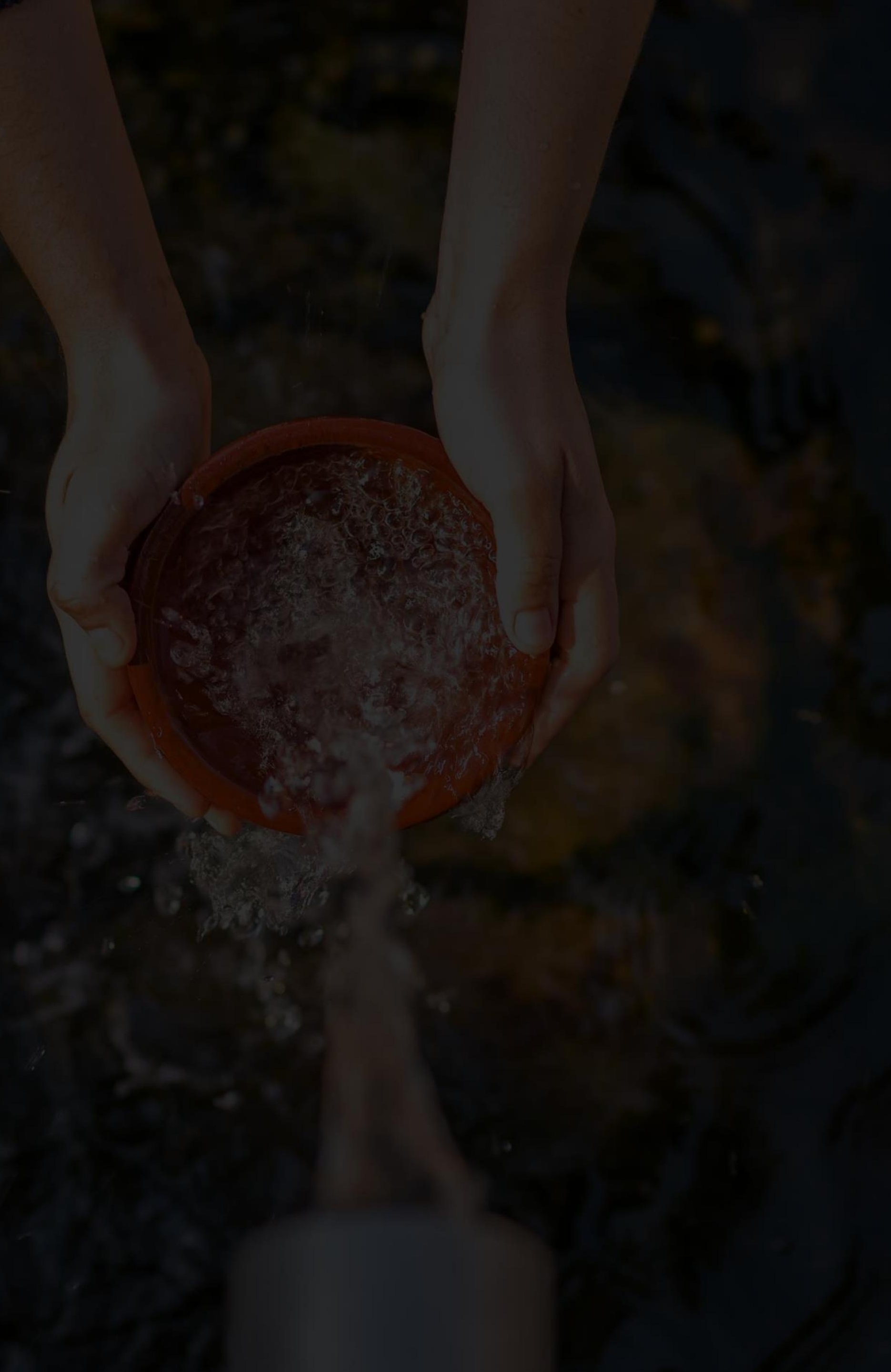

